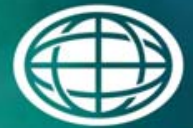

Savannah River

National Laboratory ${ }^{m}$

OPERATED BY SAVANNAH RIVER NUCLEAR SOLUTIONS

\title{
DEVELOPMENT OF AN ANTIFOAM TRACKING SYSTEM AS AN OPTION TO SUPPORT THE MELTER OFF-GAS FLAMMABILITY CONTROL STRATEGY AT THE DWPF
}

T. B. Edwards

D. P. Lambert

August 2014

SRNL-STI-2014-00323 
SRNL-STI-2014-00323

Revision 0

\section{DISCLAIMER}

This work was prepared under an agreement with and funded by the U.S. Government. Neither the U.S. Government or its employees, nor any of its contractors, subcontractors or their employees, makes any express or implied:

1. warranty or assumes any legal liability for the accuracy, completeness, or for the use or results of such use of any information, product, or process disclosed; or

2. representation that such use or results of such use would not infringe privately owned rights; or

3. endorsement or recommendation of any specifically identified commercial product, process, or service.

Any views and opinions of authors expressed in this work do not necessarily state or reflect those of the United States Government, or its contractors, or subcontractors.

Printed in the United States of America

Prepared for

U.S. Department of Energy 
Keywords: carbon, oxalate, formate, nitrate, TOC, uncertainty, random, bias

Retention: permanent

\section{DEVELOPMENT OF AN ANTIFOAM TRACKING SYSTEM AS AN OPTION TO SUPPORT THE MELTER OFF-GAS FLAMMABILITY CONTROL STRATEGY AT THE DWPF}

August 2014 


\section{REVIEWS AND APPROVALS}

\section{AUTHORS:}

T. B. Edwards, Applied Computational Engineering and Statistics, SRNL

Date

D. P. Lambert, Process Technology Programs, SRNL

Date

\section{TECHNICAL REVIEW:}

Document Review per E7, 2.60

E. P. Shine, Applied Computational Engineering and Statistics, SRNL

Date

\section{APPROVALS:}

D. H. McGuire, Manager

Date

Process Technology Programs, SRNL

S. L. Marra, Manager

Date

Environmental \& Chemical Process Technology Research Programs, SRNL

E. J. Freed, Manager

Date

DWPF/Saltstone Facility Engineering, SRR 
SRNL-STI-2014-00323

Revision 0

\section{Executive Summary}

The Savannah River National Laboratory (SRNL) has been working with the Savannah River Remediation (SRR) Defense Waste Processing Facility (DWPF) in the development and implementation of an additional strategy for confidently satisfying the flammability controls for DWPF's melter operation. An initial strategy for implementing the operational constraints associated with flammability control in DWPF was based upon an analytically determined carbon concentration from antifoam. Due to the conservative error structure associated with the analytical approach, its implementation has significantly reduced the operating window for processing and has led to recurrent Slurry Mix Evaporator (SME) and Melter Feed Tank (MFT) remediation.

To address the adverse operating impact of the current implementation strategy, SRR issued a Technical Task Request (TTR) to SRNL requesting the development and documentation of an alternate strategy for evaluating the carbon contribution from antifoam. The proposed strategy presented in this report was developed under the guidance of a Task Technical and Quality Assurance Plan (TTQAP) and involves calculating the carbon concentration from antifoam based upon the actual mass of antifoam added to the process assuming $100 \%$ retention.

The mass of antifoam in the Additive Mix Feed Tank (AMFT), in the Sludge Receipt and Adjustment Tank (SRAT), and in the SME is tracked by mass balance as part of this strategy. As these quantities are monitored, the random and bias uncertainties affecting their values are also maintained and accounted for. This report documents:

1) the development of an alternate implementation strategy and associated equations describing the carbon concentration from antifoam in each SME batch derived from the actual amount of antifoam introduced into the AMFT, SRAT, and SME during the processing of the batch.

2) the equations and error structure for incorporating the proposed strategy into melter off-gas flammability assessments.

Sample calculations of the system are also included in this report. Please note that the system developed and documented in this report is intended as an alternative to the current, analytically-driven system being utilized by DWPF; the proposed system is not intended to eliminate the current system.

Also note that the system developed in this report to track antifoam mass in the AMFT, SRAT, and SME will be applicable beyond just Sludge Batch 8 . While the model used to determine acceptability of the SME product with respect to melter off-gas flammability controls must be reassessed for each change in sludge batch, the antifoam mass tracking methodology is independent of sludge batch composition and as such will be transferable to future sludge batches. 


\section{TABLE OF CONTENTS}

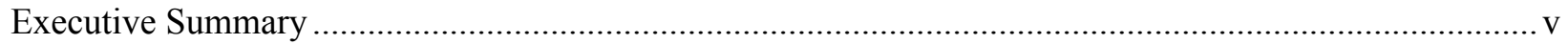

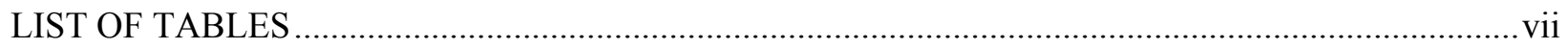

LIST OF EXHIBITS .................................................................................................................. vii

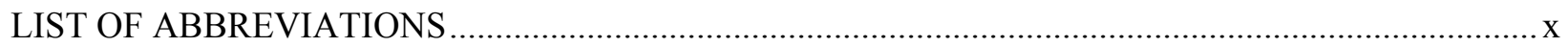

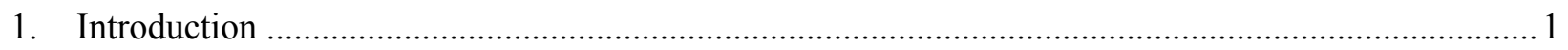

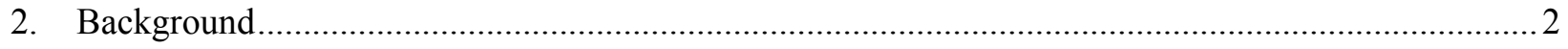

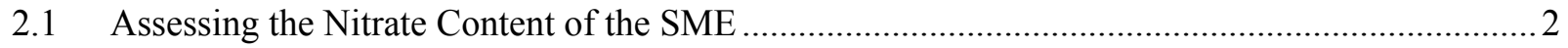

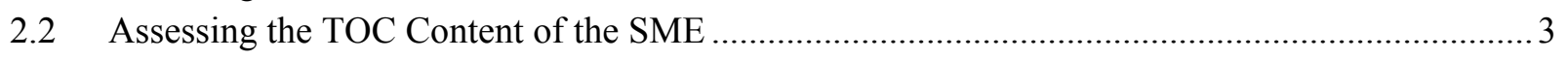

2.3 Assessing the Carbon Content of the SME Attributable to Antifoam ......................................... 5

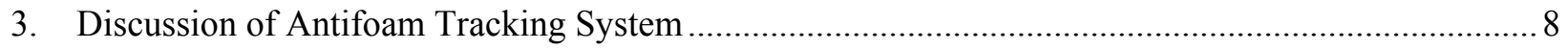

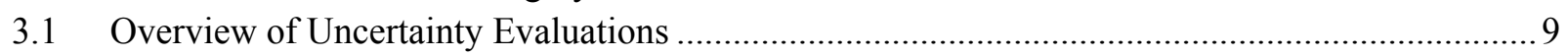

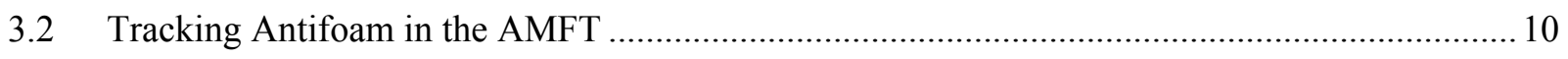

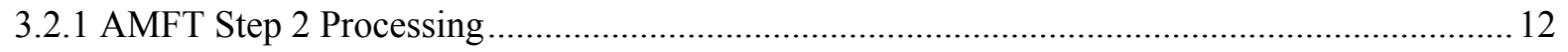

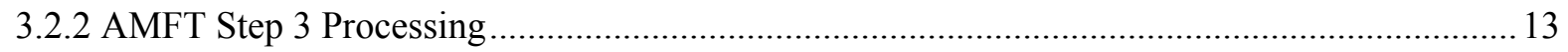

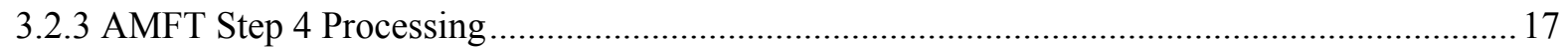

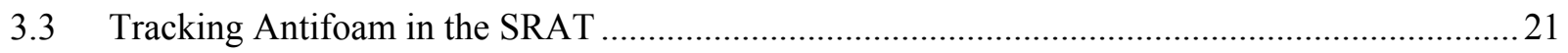

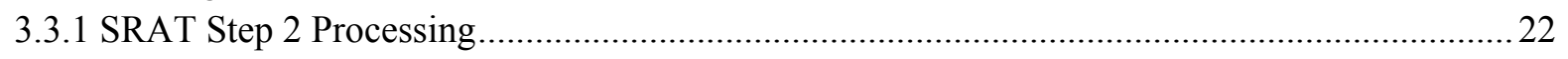

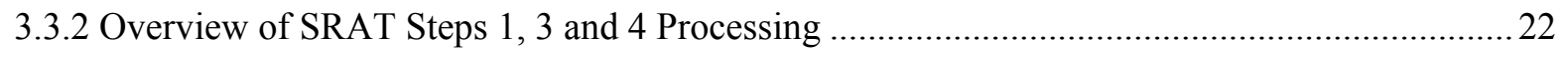

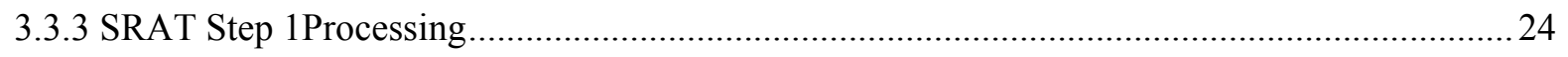

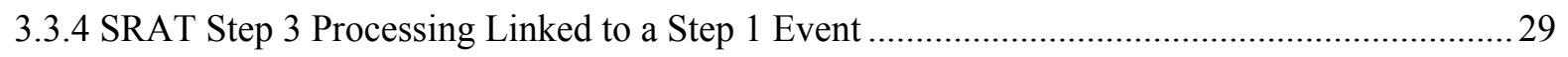

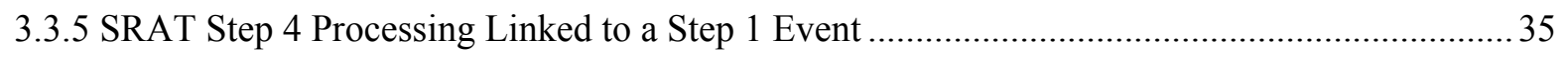

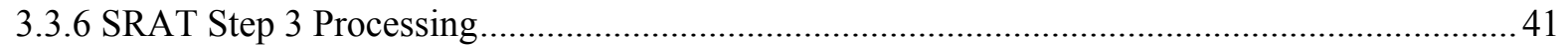

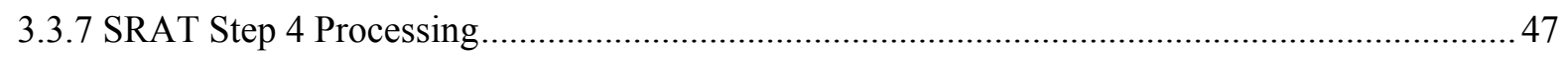

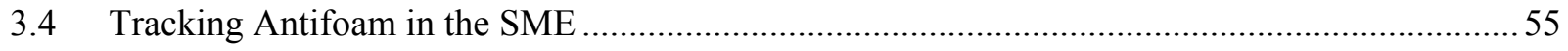

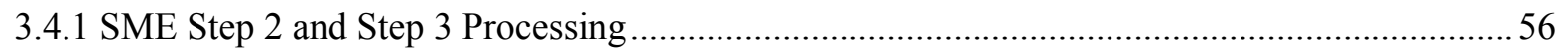

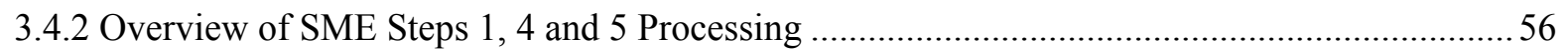

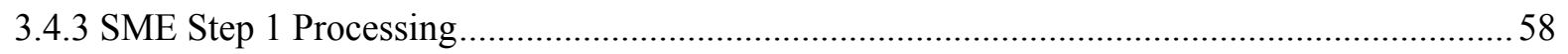

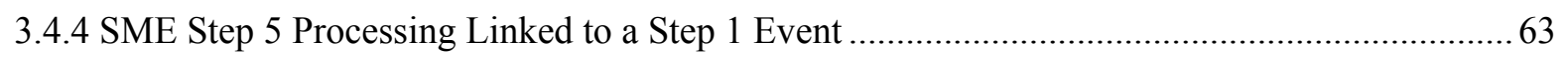

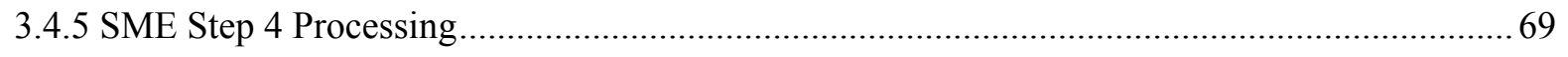

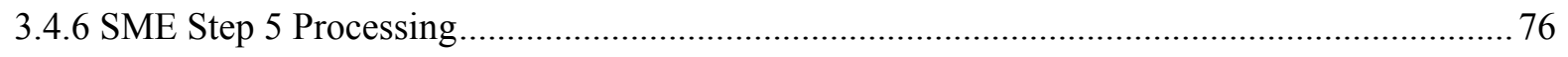

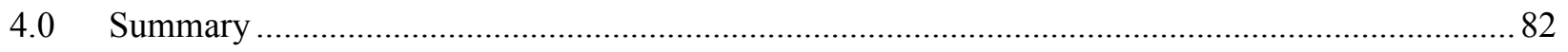

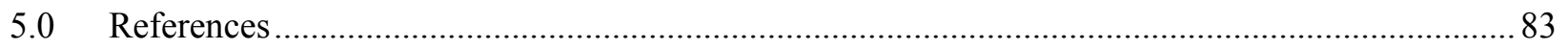




\section{LIST OF TABLES}

Table 1 Coefficients for the Linear Equations Relating TOC Content to $\mathrm{NO}_{3}$ Content

Table 2 Coefficients for the Equations Relating Maximum Carbon Content from Antifoam Additions to

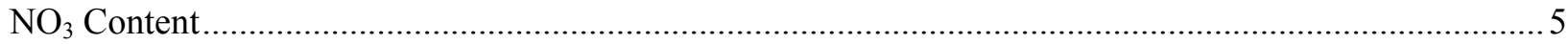

Table 3 Terms and Estimated Random Uncertainties Supporting Equation 16...................................... 14

Table 4 Terms and Estimated Bias Uncertainties Supporting Equation 17 ............................................ 16

Table 5 Terms and Estimated Random Uncertainties Supporting Equation 19................................... 17

Table 6 Terms and Estimated Bias Uncertainties Supporting Equation 20 ............................................ 20

Table 7 Terms and Estimated Random Uncertainties Supporting Equation 22 …................................25

Table 8 Terms and Estimated Bias Uncertainties Supporting Equation 23 ......................................... 27

Table 9 Terms and Estimated Random Uncertainties Supporting Equation 25 ..................................... 31

Table 10 Terms and Estimated Bias Uncertainties Supporting Equation 26 ...........................................34

Table 11 Terms and Estimated Random Uncertainties Supporting Equation 28 ….............................. 37

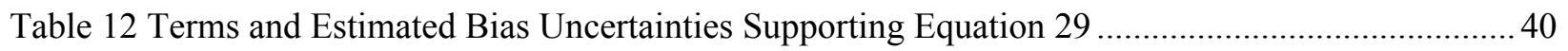

Table 13 Terms and Estimated Random Uncertainties Supporting Equation 31 ................................... 43

Table 14 Terms and Estimated Bias Uncertainties Supporting Equation 32 ......................................... 45

Table 15 Terms and Estimated Random Uncertainties Supporting Equation 34 .................................... 51

Table 16 Terms and Estimated Bias Uncertainties Supporting Equation 35 ......................................... 52

Table 17 Terms and Estimated Random Uncertainties Supporting Equation 37....................................59

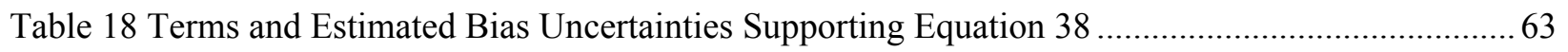

Table 19 Terms and Estimated Random Uncertainties Supporting Equation 40 .....................................6 66

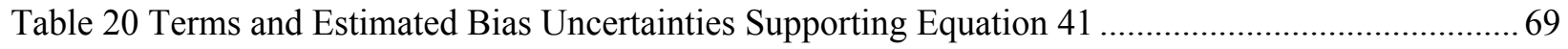

Table 21 Terms and Estimated Random Uncertainties Supporting Equation 43 .................................. 72

Table 22 Terms and Estimated Bias Uncertainties Supporting Equation 44 ......................................... 74

Table 23 Terms and Estimated Random Uncertainties Supporting Equation 50................................... 78

Table 24 Terms and Estimated Bias Uncertainties Supporting Equation 51 ........................................ 81 


\section{LIST OF EXHIBITS}

Exhibit 1 Process Flow for Tracking Antifoam Mass in the AMFT....................................................... 11

Exhibit 2 AMFT Calculations Supporting the Antifoam Tracking System........................................... 12

Exhibit 3 Equations for Calculating the Standard Deviation of the Random Uncertainty of the $\mathrm{M}_{\mathrm{AF}}$

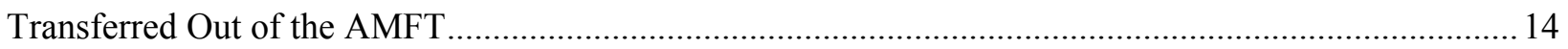

Exhibit 4 Equations for Calculating the Bias of the $\mathrm{M}_{\mathrm{AF}}$ Transferred Out of the AMFT ........................ 16

Exhibit 5 Equations for Calculating the Random Uncertainty for the $\mathrm{M}_{\mathrm{AF}}$ Remaining After the Transfer

Out of the AMFT

Exhibit 6 Equations for Calculating the Bias for the $\mathrm{M}_{\mathrm{AF}}$ Remaining After the Transfer Out of the AMFT

Exhibit 7 Process Flow for Tracking Antifoam Mass in the Sludge Receipt and Adjustment Tank (SRAT)

Exhibit 8 SRAT Calculations Supporting the Antifoam Tracking System (part 1 of 2) ..........................23

Exhibit 9 SRAT Calculations Supporting the Antifoam Tracking System (part 2 of 2) .........................2 24

Exhibit 10 Equations for Re-Base-Lining the $\mathrm{M}_{\mathrm{AF}}$ of the SRAT with Random Uncertainty ....................26

Exhibit 11 Equations for Re-Base-Lining the $\mathrm{M}_{\mathrm{AF}}$ of the SRAT with Bias Uncertainty..........................28

Exhibit 12 Equations for Analytical $\mathrm{M}_{\mathrm{AF}_{-} \text {out }}$ from the SRAT with Random Uncertainty (part 1 of 2)....... 30

Exhibit 13 Equations for Analytical $\mathrm{M}_{\mathrm{AF}_{-} \text {out }}$ from the SRAT with Random Uncertainty (part 2 of 2)....... 31

Exhibit 14 Equations for Analytical $\mathrm{M}_{\mathrm{AF}_{-} \text {out }}$ from the SRAT with Bias Uncertainty (part 1 of 2) ............. 33

Exhibit 15 Equations for Analytical $\mathrm{M}_{\mathrm{AF}_{-} \text {out }}$ from the SRAT with Bias Uncertainty (part 2 of 2) ............. 34

Exhibit 16 Equations for Analytical $\mathrm{M}_{\mathrm{AF}_{-} \text {new }}$ for the SRAT Heel with Random Uncertainty (part 1 of 2) 36

Exhibit 17 Equations for Analytical $\mathrm{M}_{\mathrm{AF}_{-} \text {new }}$ for the SRAT Heel with Random Uncertainty (part 2 of 2) 37

Exhibit 18 Equations for Analytical $\mathrm{M}_{\mathrm{AF}_{-} \text {new }}$ for the SRAT Heel with Bias Uncertainty (part 1 of 2)....... 39

Exhibit 19 Equations for Analytical $\mathrm{M}_{\mathrm{AF}_{-} \text {new }}$ for the SRAT Heel with Bias Uncertainty (part 2 of 2)....... 40

Exhibit 20 Equations for Calculating the Random Uncertainty for the $\mathrm{M}_{\mathrm{AF}}$ Transferred Out of the SRAT

(part 1/2)

Exhibit 21 Equations for Calculating the Random Uncertainty for the $\mathrm{M}_{\mathrm{AF}}$ Transferred Out of the SRAT

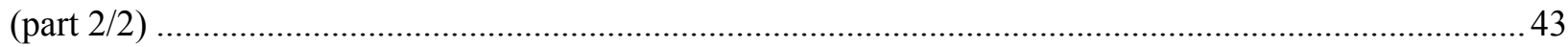

Exhibit 22 Equations for $\mathrm{M}_{\mathrm{AF} \_ \text {out }}$ from the SRAT with Bias Uncertainty (part 1 of 2) .............................. 46

Exhibit 23 Equations for $\mathrm{M}_{\mathrm{AF} \_ \text {out }}$ from the SRAT with Bias Uncertainty (part 2 of 2) ............................ 47

Exhibit 24 Equations for Calculating the Random Uncertainty for the $\mathrm{M}_{\mathrm{AF}}$ Heel in the SRAT (part 1/2). 49

Exhibit 25 Equations for Calculating the Random Uncertainty for the $\mathrm{M}_{\mathrm{AF}}$ Heel in the SRAT (part 2/2). 50

Exhibit 26 Equations for $\mathrm{M}_{\mathrm{AF}_{-} \text {new }}$ for the SRAT Heel with Bias Uncertainty (part 1 of 2)...................... 53

Exhibit 27 Equations for $\mathrm{M}_{\mathrm{AF} \text { new }}$ for the SRAT Heel with Bias Uncertainty (part 2 of 2)....................... 54

Exhibit 28 Process Flow for Tracking Antifoam Mass in the Slurry Mix Evaporator (SME) Tank .........56

Exhibit 29 SME Calculations Supporting the Antifoam Tracking System (part 1 of 2) .........................57

Exhibit 30 SME Calculations Supporting the Antifoam Tracking System (part 2 of 2) ..........................58

Exhibit 31 Equations for Re-Base-Lining the $\mathrm{M}_{\mathrm{AF}}$ of the SME with Random Uncertainty ...................... 60

Exhibit 32 Equations for Re-Base-Lining the $\mathrm{M}_{\mathrm{AF}}$ of the SME with Bias Uncertainty ............................62

Exhibit 33 Equations for Analytical $\mathrm{M}_{\mathrm{AF}_{-} \text {new }}$ for SME Heel with Random Uncertainty (part 1 of 2) ........ 65

Exhibit 34 Equations for Analytical $\mathrm{M}_{\mathrm{AF}_{-} \text {new }}$ for SME Heel with Random Uncertainty (part 2 of 2) ........ 66

Exhibit 35 Equations for Analytical $\mathrm{M}_{\mathrm{AF}_{-} \text {new }}$ for SME Heel with Bias Uncertainty (part 1 of 2)............. 68

Exhibit 36 Equations for Analytical $\mathrm{M}_{\mathrm{AF}_{-} \text {new }}$ for SME Heel with Bias Uncertainty (part 2 of 2)..............69 
Exhibit 37 Equations for $\mathrm{C}_{\mathrm{AF}}$ for SME Product with Random Uncertainty ........................................... 71

Exhibit 38 Equations for $\mathrm{C}_{\mathrm{AF}}$ for SME Product with Bias Uncertainty .............................................. 73

Exhibit 39 Equations for $\mathrm{M}_{\mathrm{AF}_{-} \text {new }}$ for SME Heel with Random Uncertainty (part 1 of 2) ....................... 77

Exhibit 40 Equations for $\mathrm{M}_{\mathrm{AF} \text { new }}$ for SME Heel with Random Uncertainty (part 2 of 2) ....................... 78

Exhibit 41 Equations for $\mathrm{M}_{\mathrm{AF} \_ \text {new }}$ for SME Heel with Bias Uncertainty (part 1 of 2) ............................. 80

Exhibit 42 Equations for $\mathrm{M}_{\mathrm{AF}_{-} \text {new }}$ for SME Heel with Bias Uncertainty (part 2 of 2) ............................. 81 


\section{LIST OF ABBREVIATIONS}

$\begin{array}{ll}\text { AF } & \text { antifoam } \\ \text { AMFT } & \text { Additive Mix Feed Tank } \\ \text { DCS } & \text { Distributed Control System } \\ \text { DWPF } & \text { Defense Waste Processing Facility } \\ \text { JMP } & \text { Pronounced "jump”, commercial statistical software from SAS Institute, Inc. } \\ \text { IC } & \text { Ion Chromatography } \\ \text { inwc } & \text { inches of water column } \\ \text { LFL } & \text { Lower Flammability Limit } \\ \text { MAF } & \text { Antifoam mass in kg } \\ \text { MFT } & \text { Melter Feed Tank } \\ \text { SB8 } & \text { Sludge Batch 8 } \\ \text { SME } & \text { Slurry Mix Evaporator } \\ \text { SRAT } & \text { Sludge Receipt } \\ \text { SRNL } & \text { Savannah River National Laboratory } \\ \text { SRR } & \text { Savannah River Remediation, LLC } \\ \text { TOC } & \text { Total Organic Carbon } \\ \text { TTQAP } & \text { Task Technical and Quality Assurance Plan } \\ \text { TTR } & \text { Technical Task Request }\end{array}$


SRNL-STI-2014-00323

Revision 0

\section{Introduction}

The Savannah River National Laboratory (SRNL) has been working with the Savannah River Remediation (SRR) Defense Waste Processing Facility (DWPF) in the development and implementation of an additional strategy for confidently satisfying the flammability controls for DWPF's melter operation during the processing of Sludge Batch 8 (SB8). The flammability controls for SB8 were developed by Choi [1], who established a framework of operational constraints that include limitations on the carbon concentration from antifoam. The constraints developed by Choi maintain the contributors to melter flammability to less than $60 \%$ of the lower flammability limit (LFL) [1]. An initial strategy for implementing these operational constraints in DWPF was documented by Edwards [2] in the form of a decision support system based upon an analytically determined carbon concentration from antifoam. Since the implementation of the decision support system into its operation, the DWPF has identified issues related to the impact of the system on melter feed composition. Due to the conservative error structure associated with the analytical approach underlying the decision support system, implementation of this control has significantly reduced the operating window for processing and has led to recurrent Slurry Mix Evaporator (SME) and Melter Feed Tank (MFT) remediation.

To address the adverse operating impact of the current implementation strategy, SRR issued a Technical Task Request (TTR) to SRNL requesting the development and documentation of an alternate strategy for evaluating the carbon contribution from antifoam [3]. The proposed strategy involves calculating the carbon concentration from antifoam based upon the actual amount of antifoam added to the process assuming $100 \%$ retention. The purpose of this report is to document the following:

1) The development of an alternate implementation strategy and associated equations describing the carbon concentration from antifoam in each SME batch derived from the actual amount of antifoam introduced during the processing of the batch.

2) The error structure for incorporation of the proposed strategy into melter off-gas flammability assessments.

This work was conducted under the guidance of the Task Technical and Quality Assurance Plan (TTQAP) provided in reference [4]. Section 2 provides a background discussion of the melter flammability controls and the implementation strategy currently being utilized by DWPF. Section 3 provides the proposed strategy for tracking the antifoam additions to a SME process batch: Tracking these additions is done on a mass basis with the mass of antifoam being monitored in the Additive Mix Feed Tank (AMFT), in the Sludge Receipt and Adjustment Tank (SRAT) and in the SME. Also in Section 3 are the equations utilized to facilitate this tracking of antifoam along with the associated uncertainties. A summary of this work is provided in Section 4. 


\section{Background}

As stated in the Introduction, SRNL supported SRR in the development of a melter off-gas flammability control strategy for SB8 [1]. The strategy relies on a SME batch satisfying three categories of constraints. The contents of the SME batch must have

(1) a nitrate concentration within the interval from 10,000 to $70,000 \mathrm{mg} / \mathrm{kg}$,

(2) a total organic carbon (TOC) concentration below a value tied (via a functional relationship) to the nitrate content of the SME and one of three different amounts of antifoam (728, 894, and 1,017 gallons (gal)) that were used by Choi [1] to frame possible preparations of the SME batch, and

(3) a carbon concentration contributed from antifoam that is below the amount that is allowed by the same amount of antifoam $(728,894$, and 1,017 gal) utilized to meet the TOC constraint in (2).

Regardless of the strategy for implementing these constraints into the DWPF operation, uncertainties affecting the strategy must be addressed to ensure a reliable decision for SME acceptability. The current decision support system is driven by analytical measurements of the SME contents: TOC measurements and measurements by Ion Chromatography (IC) of select anions: nitrate, oxalate, and formate. The uncertainties of these measurements were integrated into the decision support system developed by Edwards [2]. In the following sub-sections, the strategy from [2] for utilizing analytical measurements from the SME samples to meet each of these constraints is summarized.

It is probably worth mentioning again: the decision support system developed and documented in this report is intended as an alternative to the current system being utilized by DWPF; the proposed system is not intended to eliminate the current system. Also note that the system developed in this report to track antifoam mass in the AMFT, SRAT, and SME will be applicable beyond just SB8.

\subsection{Assessing the Nitrate Content of the SME}

Equation 1 and Equation 2 provide the constraints associated with ensuring that the nitrate $\left(\mathrm{NO}_{3}\right)$ content is within the interval of 10,000 to 70,000 $\mathrm{mg} / \mathrm{kg}$. (See Edwards [2] for the development of these equations.)

Equation 1

$$
\left(\overline{\mathrm{NO}_{3}} \cdot 0.9924\right)-10000-3.182 \cdot \sqrt{\left(\mathrm{se}_{\overline{\mathrm{NO}_{3}}}\right)^{2}+\left(\mathrm{s}_{\delta_{\mathrm{NO}_{3}}}\right)^{2}}>0
$$

and

\section{Equation 2}

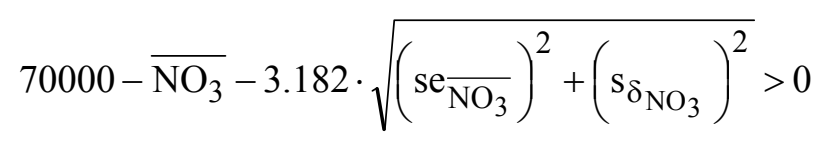


SRNL-STI-2014-00323

Revision 0

where $\overline{\mathrm{NO}_{3}}$ represents the average of the $\mathrm{NO}_{3}$ concentration measurements for the 4 samples of the given SME batch. This average has a 1-sigma random uncertainty of $\mathrm{se}_{\overline{\mathrm{NO}_{3}}}$,

0.9924 is the adjustment for a potentially high bias in the nitrate measurements, and

$\delta_{\mathrm{NO}_{3}}$ represents the batch-to-batch source of variation affecting the nitrate measurements for a SME batch. For the evaluations of Equation 1 and Equation 2, the value of $\delta_{\mathrm{NO}_{3}}$ is taken as zero. Its 1-sigma relative random uncertainty is the batch-to-batch variation and is represented by $\mathrm{s}_{\mathrm{N}_{\mathrm{NO}_{3}}}$, and based upon the discussion provided by Edwards [2], its value is given by $2.73 \%$ of the $\overline{\mathrm{NO}_{3}}$ value.

It should be noted that during the processing of SB8, the constraints imposed by these equations must be met for the current strategy and for the proposed strategy discussed in this report.

\subsection{Assessing the TOC Content of the SME}

During the processing of SB8, the restrictions on the TOC content of the SME will have to be met regardless of whether the current or the proposed antifoam strategy is utilized. The linearized relationship between $\mathrm{TOC}$ and $\mathrm{NO}_{3}$ developed by Edwards [2] is provided in Equation 3.

\section{Equation 3}

$$
\mathrm{TOC}_{\mathrm{i}}=\mathrm{f}_{\mathrm{i}}+\mathrm{g}_{\mathrm{i}} \cdot\left(\mathrm{NO}_{3}\right)
$$

where the $\mathrm{TOC}_{\mathrm{i}}$ term on the left-hand side of the equation represents the maximum TOC allowed to maintain the system below the $60 \%$ LFL based upon a linearized relationship between $\mathrm{TOC}$ and $\mathrm{NO}_{3}$, while the $\mathrm{NO}_{3}$ term on the right-hand side represents the nitrate content of the melter feed in $\mathrm{mg} / \mathrm{kg}$. The values of the $f_{i}$ and $g_{i}$ coefficients are given in Table 1 for $i=1,2$, and 3 , and each value of the $i$ index corresponds to one of the three additions of antifoam (in gallons) for which Choi developed an associated TOC versus $\mathrm{NO}_{3}$ relationship.

Table 1 Coefficients for the Linear Equations

Relating TOC Content to $\mathrm{NO}_{3}$ Content

\begin{tabular}{|c|c|c|c|}
\hline $\mathrm{i}$ & $\begin{array}{c}\text { Antifoam } \\
\text { Addition (gal) }\end{array}$ & $\mathrm{f}_{\mathrm{i}}$ & $\mathrm{g}_{\mathrm{i}}$ \\
\hline 1 & 728 & 8140 & 0.37 \\
\hline 2 & 894 & 6550 & 0.37 \\
\hline 3 & 1,017 & 5300 & 0.37 \\
\hline
\end{tabular}

In the discussion provided in [2], no statistically significant bias was indicated for the TOC measurements; while for the nitrate measurements, there was a statistically significant high bias. Thus, to be conservative, an adjustment is made to the nitrate value in Equation 3 for this bias. The direct 
SRNL-STI-2014-00323

Revision 0

utilization of the family of equations given by Equation 3 for melter flammability control yields this acceptability equation for a given SME batch during the processing of SB8:

\section{Equation 4}

$$
\mathrm{D}_{\mathrm{i}}=\mathrm{f}_{\mathrm{i}}+\mathrm{g}_{\mathrm{i}} \cdot 0.9924 \cdot \overline{\mathrm{NO}_{3}}-\overline{\mathrm{TOC}}-\text { other }_{\mathrm{C}}>0
$$

where $D_{i} \quad$ is the measurand, it represents the difference in $\mathrm{mg} / \mathrm{kg}$ between the carbon allowed by Equation 3 and the carbon content of the SME, and its value must be positive,

$f_{i} \& g_{i}$ are the coefficients from Table 1 corresponding to the appropriate bound on the gallons of antifoam utilized in the preparation of the SME batch (indexed by i) as determined following the approach discussed in Section 2.3 below,

0.9924 is the adjustment for a potential high bias in the nitrate measurements, and

$\overline{\mathrm{NO}_{3}}$ represents the average of the $\mathrm{NO}_{3}$ concentration measurements in $\mathrm{mg} / \mathrm{kg}$ for the samples of the given SME batch,

$\overline{\text { TOC }}$ represents the average of the TOC concentration measurements in $\mathrm{mg} / \mathrm{kg}$ for the samples of the given SME batch, and

${ }^{\text {other }} \mathrm{C}_{\mathrm{C}}$ represents carbon that is present in the SME in a form that is not measured by the TOC analytical protocol. Note, however, that such carbon was included in the determination of the TOC relationship to nitrate given by Equation 3. Its value is associated with the amount of coal in the SME and is bounded by $240 \mathrm{mg} / \mathrm{kg}$ [2].

The form of Equation 4 is such that the value of $D_{i}$ must be positive for acceptability. That is, the amount of TOC allowed by Equation 3 must be greater than the TOC content of the given SME for the given level of antifoam addition (indexed by i), and this must be true with high confidence after accounting for the uncertainties in the measurements used to make this determination.

The values of $\delta_{\mathrm{NO}_{3}}$ and $\delta_{\mathrm{TOC}}$ are zero in the determination of the value of $\mathrm{D}_{\mathrm{i}}$, but including these terms in the equation for $D_{i}$ allows for their contributions to the variance of $D_{i}$ to be included in the variance propagation for Equation 4.

Using the estimates of the batch-to-batch variations discussed above, the variance of Equation 4 may be expressed as:

\section{Equation 5}

$$
\begin{aligned}
\operatorname{var}\left(D_{1}\right) & =\operatorname{var}\left(D_{2}\right)=\operatorname{var}\left(D_{3}\right) \approx 0.1369 \cdot\left(s e_{\overline{\mathrm{NO}_{3}}}\right)^{2}+0.1369 \cdot\left(s_{\delta_{\mathrm{NO}_{3}}}\right)^{2}+\left(s e_{\overline{\mathrm{TOC}}}\right)^{2}+\left(s_{\delta_{\mathrm{IOC}}}\right)^{2} \\
& =0.1369 \cdot\left(s e_{\overline{\mathrm{NO}_{3}}}\right)^{2}+0.1369 \cdot\left(0.0273 \cdot \overline{\mathrm{NO}_{3}}\right)^{2}+\left(s e_{\overline{\mathrm{TOC}}}\right)^{2}+(0.0272 \cdot \overline{\mathrm{TOC}})^{2} \\
& =0.1369 \cdot\left(s e_{\overline{\mathrm{NO}_{3}}}\right)^{2}+0.00010203 \cdot\left(\overline{\mathrm{NO}_{3}}\right)^{2}+\left(s e_{\overline{\mathrm{TOC}}}\right)^{2}+0.00073984 \cdot(\overline{\mathrm{TOC}})^{2}
\end{aligned}
$$


SRNL-STI-2014-00323

Revision 0

Integrating these estimates of the variance for $D_{i}$ into the expression of the constraint leads to

\section{Equation 6}

$$
\mathrm{D}_{\mathrm{i}}-\mathrm{t}_{(0.05,3)} \cdot\left(\text { Est. } \operatorname{var}\left(\mathrm{D}_{\mathrm{i}}\right)\right)^{0.5}=\mathrm{D}_{\mathrm{i}}-2.353 \cdot\left(\text { Est. } \operatorname{var}\left(\mathrm{D}_{\mathrm{i}}\right)\right)^{0.5}>0
$$

where $D_{i}$ is determined using Equation 4 (for the associated level of antifoam additions),

$t_{(0.05,3)}$ is the upper 5\%-tail of the Student's t distribution with 3 degrees of freedom (i.e., 2.353), and

Est. $\operatorname{var}\left(\mathrm{D}_{\mathrm{i}}\right)$ represents the estimate of the variance of $\mathrm{D}_{\mathrm{i}}$, which may be computed using Equation 5 regardless of the antifoam addition being considered.

\subsection{Assessing the Carbon Content of the SME Attributable to Antifoam}

As described above, the relationship between the maximum allowable TOC content and the $\mathrm{NO}_{3}$ content of a SME batch was associated with the total amount of antifoam used to prepare the SME batch. Three levels for this total antifoam amount in gallons were established by Choi [1]: 728, 894, and 1,017 gal. As part of his study, Choi developed a relationship between the maximum amount of carbon that would be generated from each of these bounding amounts of antifoam and the $\mathrm{NO}_{3}$ content of the SME. These relationships are given by:

\section{Equation 7}

$$
\left(\text { Antifoam }_{\mathrm{Ci}}\right)^{2}=\mathrm{h}_{\mathrm{i}}+\mathrm{j}_{\mathrm{i}} \cdot\left(\mathrm{NO}_{3}\right) \Rightarrow \text { Antifoam }_{\mathrm{C}}=\sqrt{\mathrm{h}_{\mathrm{i}}+\mathrm{j}_{\mathrm{i}} \cdot\left(\mathrm{NO}_{3}\right)}
$$

where Antifoam ${ }_{\mathrm{Ci}}$ represents the maximum amount of carbon in $\mathrm{mg} / \mathrm{kg}$ that would be generated from antifoam additions for three cases indexed by i: 1 corresponds to 728 gal, 2 to 894 gal, and finally, 3 to 1,017 gal of antifoam, and $\mathrm{NO}_{3}$ represents the nitrate content of the SME in $\mathrm{mg} / \mathrm{kg}$. The $\mathrm{h}_{\mathrm{i}}$ and $\mathrm{j}_{\mathrm{i}}$ values, which are provided in Table 2, are from the models developed by Choi [1].

Table 2 Coefficients for the Equations Relating Maximum

Carbon Content from Antifoam Additions to $\mathrm{NO}_{3}$ Content

\begin{tabular}{|c|c|c|c|}
\hline $\mathrm{i}$ & $\begin{array}{c}\text { Antifoam } \\
\text { Addition (gal) }\end{array}$ & $\mathrm{h}_{\mathrm{i}}$ & $\mathrm{j}_{\mathrm{i}}$ \\
\hline 1 & 728 & 5117745.1 & -35.869438 \\
\hline 2 & 894 & 7884790.5 & -55.545316 \\
\hline 3 & 1,017 & 10373798 & -73.602487 \\
\hline
\end{tabular}

Thus, DWPF's melter flammability control strategy requires that SRR confidently estimate an upper bound on the amount of carbon attributable to the antifoam added during the processing of each SME batch, and then use this result to confidently establish one of the three antifoam levels developed by Choi (i.e., for additions of no more than 728, 894, or 1,017 gal) as the upper bound on the gallons of antifoam added during the processing of the SME batch. The importance of this outcome is that it establishes the 
SRNL-STI-2014-00323

Revision 0

appropriate TOC to $\mathrm{NO}_{3}$ relationship that must be used in satisfying Equation 6 as discussed in Section 2.2 .

Thus, there is a need to estimate the amount of antifoam that was added during DWPF's preparation of a given SME batch. From the previous section, there is a relationship between the nitrate content of the SME and the limit on the carbon generated by antifoam additions to that SME for three different levels of antifoam addition: 728, 894, and 1,017 gal. Thus, one may estimate the amount of antifoam added during the preparation of a SME batch by estimating an upper bound on the carbon content due to antifoam additions for the prepared SME. During the processing of SB8, this constraint must be met by the proposed as well as by the current implementation strategy at the DWPF.

For the current strategy as documented by Edwards [2], the estimation is conducted by backing out contributions to the measured TOC concentration in the SME from the oxalate and the formate concentrations that are measured in the SME. The resulting adjusted TOC value provides a basis for estimating the amount of carbon in the SME attributable to antifoam. When this estimate is bounded at $95 \%$ confidence by accounting for its uncertainty, the resulting bounded amount of carbon attributable to antifoam must be below the carbon allowed by the level of antifoam (i.e., one of the three values:728, 894 , or 1,017 gal) that is selected to be appropriate for the given SME batch. For the current strategy, the restriction imposed on the contents of the SME by Equation 7 may be expressed as:

\section{Equation 8}

$$
\mathrm{M}_{\mathrm{Ci}}=\sqrt{\mathrm{h}_{\mathrm{i}}+\mathrm{j}_{\mathrm{i}} \cdot \overline{\mathrm{NO}_{3}}}-\overline{\mathrm{TOC}}+\mathrm{f}_{\mathrm{C}} \cdot \overline{\text { formate }} \cdot 0.9697+\mathrm{o}_{\mathrm{C}} \cdot \overline{\text { oxalate }} \cdot 0.9459>0
$$

where

$\mathrm{M}_{\mathrm{Ci}}$ is the measurand; it represents the difference between the allowable concentration in $\mathrm{mg} / \mathrm{kg}$ of carbon from antifoam at a level indexed by i (where $\mathrm{i}=1$ represents 728 gal, 2 represents $894 \mathrm{gal}$, and 3 represents 1,017 gal) and the estimated amount of carbon attributable to antifoam; and the difference must be positive,

$i$ is used as an index for the level of antifoam addition in gallons, $i=1$ (728 gal), 2 (894 gal), and $3(1,017 \mathrm{gal})$.

$\mathrm{h}_{\mathrm{i}} \& \mathrm{j}_{\mathrm{i}}$ are the coefficients corresponding to the $\mathrm{i}^{\text {th }}$ level of antifoam (see Table 2),

$\overline{\mathrm{NO}_{3}}$ represents (as above) the average of the $\mathrm{NO}_{3}$ concentration measurements in $\mathrm{mg} / \mathrm{kg}$ for the samples of the given SME batch,

$\overline{\mathrm{TOC}}$ is (as above) the average of the TOC measurements in $\mathrm{mg} / \mathrm{kg}$ for the samples from the given SME batch, 
SRNL-STI-2014-00323

Revision 0

$\overline{\text { formate }}$ is the average of the formate measurements in $\mathrm{mg} / \mathrm{kg}$ for the samples from the SME batch $^{f}$,

$\overline{\text { oxalate }}$ is the average of the oxalate measurements in $\mathrm{mg} / \mathrm{kg}$ for the samples from the SME batch $^{f}$,

0.9697 is included in the measurement equation to adjust (with a better than $95 \%$ confidence) for the potential bias in the formate measurement,

$\mathrm{f}_{\mathrm{C}}$ is the conversion factor needed to determine the carbon contributed by the formate content of the $\mathrm{SME}$ in $\mathrm{mg} / \mathrm{kg}$ (i.e., $\mathrm{f}_{\mathrm{C}}=0.266807 \mathrm{mg}$ carbon/(kg SME slurry),

$\mathrm{o}_{\mathrm{C}}$ is the conversion factor needed to determine the carbon contributed by the oxalate content of the SME in $\mathrm{mg} / \mathrm{kg}$ (i.e., $\mathrm{o}_{\mathrm{C}}=0.27292 \mathrm{mg}$ carbon/(kg SME slurry), and

0.9459 is included in the measurement equation to adjust (with a better than $95 \%$ confidence) for the potential bias in the oxalate measurement,

The expanded uncertainty of the estimated difference, $\mathrm{M}_{\mathrm{Ci}}$, at $95 \%$ confidence is determined by multiplying the square root of the estimated variance of $\mathrm{M}_{\mathrm{Ci}}$ by an appropriate Student's $\mathrm{t}$ statistic. In this case a one-sided confidence statement is needed; so, an upper 5\%-tail of the Student's t distribution will be used. Again, utilizing a conservative 3 degrees of freedom for the estimated variance, the $t$ value is 2.353. Thus, at $95 \%$ confidence the expanded uncertainty of the difference is 2.353 times the square root of the estimated variance of $\mathrm{M}_{\mathrm{Ci}}$. Thus, for the antifoam content of the SME to be acceptable (at $95 \%$ confidence), the following constraint must be met:

\section{Equation 9}

$$
\mathrm{M}_{\mathrm{Ci}}-2.353 \cdot\left(\operatorname{Var}\left(\mathrm{M}_{\mathrm{Ci}}\right)\right)^{0.5}>0
$$

where, for each level of antifoam indexed by $\mathrm{i}, \mathrm{M}_{\mathrm{Ci}}$ is determined from Equation 8 above, and $\operatorname{Var}\left(\mathrm{M}_{\mathrm{Ci}}\right)$ is the estimate of the variance of $\mathrm{M}_{\mathrm{Ci}}$ determined using Equation 10 below (see Edwards [2] for details). The smallest of the three levels of antifoam that meets the constraint imposed by Equation 9 is used to select the appropriate TOC constraint that must also be met (as described in Section 2.2) for an acceptable SME decision during the processing of SB8.

Equation 10

$$
\begin{aligned}
\operatorname{var}\left(M_{C i}\right) \approx & 0.25 \cdot\left[j_{i} \cdot\left(h_{i}+j_{i} \cdot \overline{N O_{3}}\right)^{-0.5}\right]^{2} \cdot\left(s e_{\overline{N O_{3}}}\right)^{2}+0.000186323 \cdot\left[j_{i} \cdot\left(h_{i}+j_{i} \cdot \overline{N O_{3}}\right)^{-0.5}\right]^{2} \cdot\left(\overline{N O_{3}}\right)^{2} \\
& +\left(s e_{\overline{T O C}}\right)^{2}+0.00073984 \cdot(\overline{\mathrm{TOC}})^{2}+0.0711876 \cdot\left(\mathrm{se}_{\overline{\text { formate }}}\right)^{2}+0.000043431 \cdot(\overline{\text { formate }})^{2} \\
& +0.0744853 \cdot\left(\mathrm{se}_{\overline{\text { oxalate }}}\right)^{2}+0.000189956 \cdot(\overline{\text { oxalate }})^{2}
\end{aligned}
$$

\footnotetext{
${ }^{f}$ Note the multiplications by 0.9697 and 0.9459 . This makes the adjustments for the potential biases in the measured formate and oxalate content, respectively, of the SME.
} 
Note that Equation 8 may be restated in a more generic form that will support the estimation of the carbon concentration from antifoam, $\mathrm{AF}_{\mathrm{C}}$, for either the SRAT, the SME, or the MFT (based upon analytical measurements of TOC, oxalate, and formate samples from the tank in question). This estimation method holds regardless of the sludge batch being processed, and thus, it would be applicable for future sludge batches beyond SB8. The form of the resulting equation is given by:

\section{Equation 11}

$$
A F_{C}=\overline{T O C}-f_{C} \cdot \overline{\text { formate }} \cdot 0.9697-o_{C} \cdot \overline{\text { oxalate }} \cdot 0.9459
$$

with an estimated random error variance, based upon the measurement uncertainty information in [2], given by

\section{Equation 12}

$$
\begin{aligned}
& \operatorname{var}\left(A F_{C}\right) \approx\left(s e_{\overline{T O C}}\right)^{2}+0.00073984 \cdot(\overline{T O C})^{2}+0.0711876 \cdot\left(s e_{\overline{\text { formate }}}\right)^{2}+0.000043431 \cdot(\overline{\text { formate }})^{2} \\
&+0.0744853 \cdot\left(s e_{\overline{\text { oxalate }}}\right)^{2}+0.000189956 \cdot(\overline{\text { oxalate }})^{2}
\end{aligned}
$$

Since potential biases in the measurements have been addressed in this approach, there is no additional bias associated with this estimate of $\mathrm{AF}_{\mathrm{C}}$. That is, the $\mathrm{AF}_{\mathrm{C}}$ value determined by Equation 11 is unbiased.

\section{Discussion of Antifoam Tracking System}

During the processing of SB8, the proposed strategy would have to meet the restrictions imposed by Equation 1 through Equation 6 and these rely on analytical measurements of both TOC and $\mathrm{NO}_{3}$. However, the benefit of the proposed strategy derives from an improvement in the approach of demonstrating that antifoam carbon is bounded by one of the limits imposed by Equation 7 and the set of parameters given in Table 2. Specifically, the proposed strategy relies on tracking the antifoam additions affecting the processing of each SME batch to estimate the carbon concentration from antifoam instead of relying of deriving this estimate from analytical measurements of SME Product samples. Another benefit of this alternate approach is that it will be transferable to future sludge batches. That is, this is a generic approach to estimating the carbon concentration from antifoam in the SME Product and is not specific to SB8.

Such additions occur to the Additive Mix Feed Tank (AMFT), to the SRAT, and to the SME. The role of the AMFT is to be the source of antifoam that is added to the SRAT and to the SME. In addition, the role of the SRAT is to be the source of feed to the SME tank, where this feed would also contain antifoam from additions that were made to the SRAT during routine processing. The SME tank is the hold point in the DWPF process flow at which acceptability decisions regarding the contents of the SME are made. These acceptability decisions are two-fold: (1) Product Composition Control System (PCCS) acceptability, whose criteria are defined by [5] and are not the subject of this report and (2) antifoam carbon acceptability with criteria as defined above from Choi [1].

A tracking system for antifoam mass $\left(\mathrm{M}_{\mathrm{AF}}\right)$ is the proposed, alternative strategy for meeting the second set of acceptability criteria. So, for each of the three tanks listed above (i.e., the AMFT, SRAT, and SME) 
the goal is to maintain, continuously, the status of the antifoam mass in the tank along with an estimate of the uncertainty of that mass. Two types of uncertainties are to be tracked: (1) random uncertainty and (2) systematic or bias uncertainty. The metric for each source of random uncertainty is an estimated standard deviation for that source while a bound on the bias uncertainty from each contributor to this type of uncertainty is to be estimated at a $95 \%$ confidence level. Each type of uncertainty (i.e., random and bias) is to be estimated and maintained separately for each tank (i.e., AMFT, SRAT, and SME) as part of the antifoam tracking system.

With the antifoam status of each tank known, there are several events that have to be processed by the tracking system. These include: an antifoam addition to the AMFT, a transfer of antifoam from the AMFT to the SRAT, a transfer of antifoam from the AMFT to the SME, a transfer of SRAT product from the SRAT to the SME, and, finally, an acceptability decision for a SME Product batch relative to its antifoam content. As each of these events is processed, the impact of the event on the antifoam mass and on its uncertainty (both bias and random) for each of the tanks must be determined.

In addition, the strategy must be able to address any event that leads to the status of the antifoam mass and/or its uncertainty being unavailable or coming into question for any of these tanks. This will require a re-base-lining of the status of the impacted tank utilizing an analytically (e.g., analyses of samples of the tank contents for the SRAT or for the SME, see Equation 11 and Equation 12 above) driven assessment. More on this as each tank is discussed.

A process flow diagram for each tank and each of the events identified above has been prepared during the development of the antifoam tracking system. The software package GUM Workbench Version 2.41.410 [6] was used to support the evaluation of the uncertainties associated with the antifoam tracking system. Specifically, equations utilized to represent the events of the process flow diagram were developed in GUM Workbench and the software was used to generate the partial derivatives required for the determination of uncertainties associated with those equations. This is more fully discussed in the sections that follow.

\subsection{Overview of Uncertainty Evaluations}

Discussions in [7] were used as the basis of the approach for estimating the uncertainty for the antifoam mass presented in this report. Recall that there are two types of uncertainties being tracked: (1) random and (2) systematic or bias. The metric for each source of random uncertainty is an estimated standard deviation for that source while a bound on each bias uncertainty is to be estimated at a $95 \%$ confidence for each contributing source.

The random uncertainty variance of the antifoam mass, $\mathrm{M}_{\mathrm{AF}}$, is estimated by appealing to a Taylor Series expansion of the equation providing the value of $\mathrm{M}_{\mathrm{AF}}$ determined at that processing step. For example, if $M_{A F}=f\left(x_{1}, x_{2}, x_{3}\right)$ for some function, $f$, of three variables $x_{1}, x_{2}$, and $x_{3}$, then the estimated random variance of $\mathrm{M}_{\mathrm{AF}}$ is given by:

\section{Equation 13}

$$
\operatorname{Variance}\left(M_{A F}\right) \approx\left(\frac{\partial f}{\partial x_{1}}\right)^{2} \times \operatorname{variance}\left(x_{1}\right)+\left(\frac{\partial f}{\partial x_{2}}\right)^{2} \times \operatorname{variance}\left(x_{2}\right)+\left(\frac{\partial f}{\partial x_{3}}\right)^{2} \times \operatorname{variance}\left(x_{3}\right)
$$


where $\left(\frac{\partial f}{\partial x}\right)$ represents the partial derivative of the function $\mathrm{f}$ relative to the variable $\mathrm{x}$. and there is no correlation among the random uncertainties from the variables $\mathrm{x}_{1}, \mathrm{x}_{2}$, and $\mathrm{x}_{3} *$.

A bound (at $95 \%$ confidence) on the bias of the antifoam mass, $\mathrm{M}_{\mathrm{AF}}$, is estimated also by appealing to a Taylor Series expansion of the equation providing the value of $\mathrm{M}_{\mathrm{AF}}$ determined at that processing step. For example, if $\mathrm{M}_{\mathrm{AF}}=\mathrm{f}\left(\mathrm{x}_{1}, \mathrm{x}_{2}, \mathrm{x}_{3}\right)$ for some function, $\mathrm{f}$, of three variables $\mathrm{x}_{1}, \mathrm{x}_{2}$, and $\mathrm{x}_{3}$ and $\mathrm{b}_{1}, \mathrm{~b}_{2}$, and $\mathrm{b}_{3}$, respectively, are bounds (all positive) on the estimated bias for these terms, then the estimated variance of $\mathrm{M}_{\mathrm{AF}}$ is given by:

\section{Equation 14}

$$
\begin{gathered}
\left\{\operatorname{bias}\left(M_{A F}\right)\right\}^{2} \approx\left(\frac{\partial f}{\partial x_{1}}\right)^{2} \times\left(b_{1}\right)^{2}+\left(\frac{\partial f}{\partial x_{2}}\right)^{2} \times\left(b_{2}\right)^{2}+\left(\frac{\partial f}{\partial x_{3}}\right)^{2} \times\left(b_{3}\right)^{2} \\
+2 \times\left|\rho_{12}\right| \times\left|\frac{\partial f}{\partial x_{1}}\right| \times\left|\frac{\partial f}{\partial x_{2}}\right| \times b_{1} \times b_{2}+2 \times\left|\rho_{13}\right| \times\left|\frac{\partial f}{\partial x_{1}}\right| \times\left|\frac{\partial f}{\partial x_{3}}\right| \times b_{1} \times b_{3} \\
+2 \times\left|\rho_{23}\right| \times\left|\frac{\partial f}{\partial x_{2}}\right| \times\left|\frac{\partial f}{\partial x_{3}}\right| \times b_{2} \times b_{3}
\end{gathered}
$$

where $\left(\frac{\partial f}{\partial x}\right)$ represents the partial derivative of the function f relative to the variable $\mathrm{x}$. and $\rho_{\mathrm{ij}}$ represents a potential correlation between the biases for variables $\mathrm{x}_{\mathrm{i}}$ and $\mathrm{x}_{\mathrm{j}}$. The expression for this equation is provided in a manner to demonstrate how to include the impact of potential correlations among biases. Where there appears to be some likelihood of a correlation between a pair of biases, the absolute values of the partials and a value for the correlation of 1 (i.e., $\rho_{\mathrm{ij}}=1$ ) will be included in the Taylor Series expansion. This approach will ensure that potential correlations that could lead to increased uncertainty are accounted for in a conservative manner. More will be said regarding potential correlations for biases as necessary in the discussions that follow.

\subsection{Tracking Antifoam in the AMFT}

The AMFT is the tank where antifoam is prepared for introduction into the DWPF process. Additions of antifoam to the AMFT and transfers of antifoam from the AMFT to the SRAT or to the SME are routine actions during DWPF operations. To support the tracking of antifoam for a SME batch, the $\mathrm{M}_{\mathrm{AF}}$ value and its uncertainty associated with the AMFT contents are to be maintained at all times. If these values are not known, the contents of the AFMT must be re-base-lined. This requires that the AMFT be emptied and rinsed and its contents reinitialized with a bounded mass of antifoam. This operation will re-establish the value of $\mathrm{M}_{\mathrm{AF}}$, and since it is bounding the random and bias uncertainties are set to zero. More of this aspect of the AF tracking system will be discussed below.

With $\mathrm{M}_{\mathrm{AF}}$ status of the AMFT known, the antifoam tracking system must be capable of handling (1) events involving transfers from the AMFT to either the SRAT or the SME. Handling these events entails

\footnotetext{
* For the situations evaluated in this report, there are no correlations among random uncertainties. This is not the case for the bias uncertainties, as seen in the discussions that follow.
} 
updating the status of the $\mathrm{M}_{\mathrm{AF}}$ value and its uncertainty in the AMFT as well as updating the status of the $\mathrm{M}_{\mathrm{AF}}$ and its uncertainty in the receiving tank, and (2) events involving the addition of antifoam to the AMFT.

Exhibit 1 provides a flow diagram for processing an event involving the AMFT. For such an event, there is an initial assessment of the current status of the $\mathrm{M}_{\mathrm{AF}}$ value and its uncertainty in the AMFT. That is represented by the first decision step in the process flow diagram. If the status is unknown, then the "No" branch is taken out of this decision block and the value of the $\mathrm{M}_{\mathrm{AF}}$ and its uncertainty must be re-baselined as indicated in Step 1 of the diagram. If the status is known, the "Yes" branch is taken out of this decision block. With the $\mathrm{M}_{\mathrm{AF}}$ value and its uncertainty known, the next decision block is evaluated to determine the event that needs to be addressed by the tracking system. There are two events captured in this flow diagram: a) if the AMFT level is low, then an antifoam addition is to be made to the AMFT and the impact of this addition on the $\mathrm{M}_{\mathrm{AF}}$ value must be determined (indicated as Step 2 in Exhibit 1) or b) if a transfer of antifoam is to be made from the AMFT, then the impact of the change in the level of the contents of the AMFT (determined by information from the bubbler instrumentation in the tank) as the transfer is made must be utilized to provide information on the mass of antifoam for the receiving tank involved in the transfer (indicated as Step 3 in Exhibit 1) and to update the $\mathrm{M}_{\mathrm{AF}}$ status of the AMFT after the transfer (indicated as Step 4 in Exhibit 1).

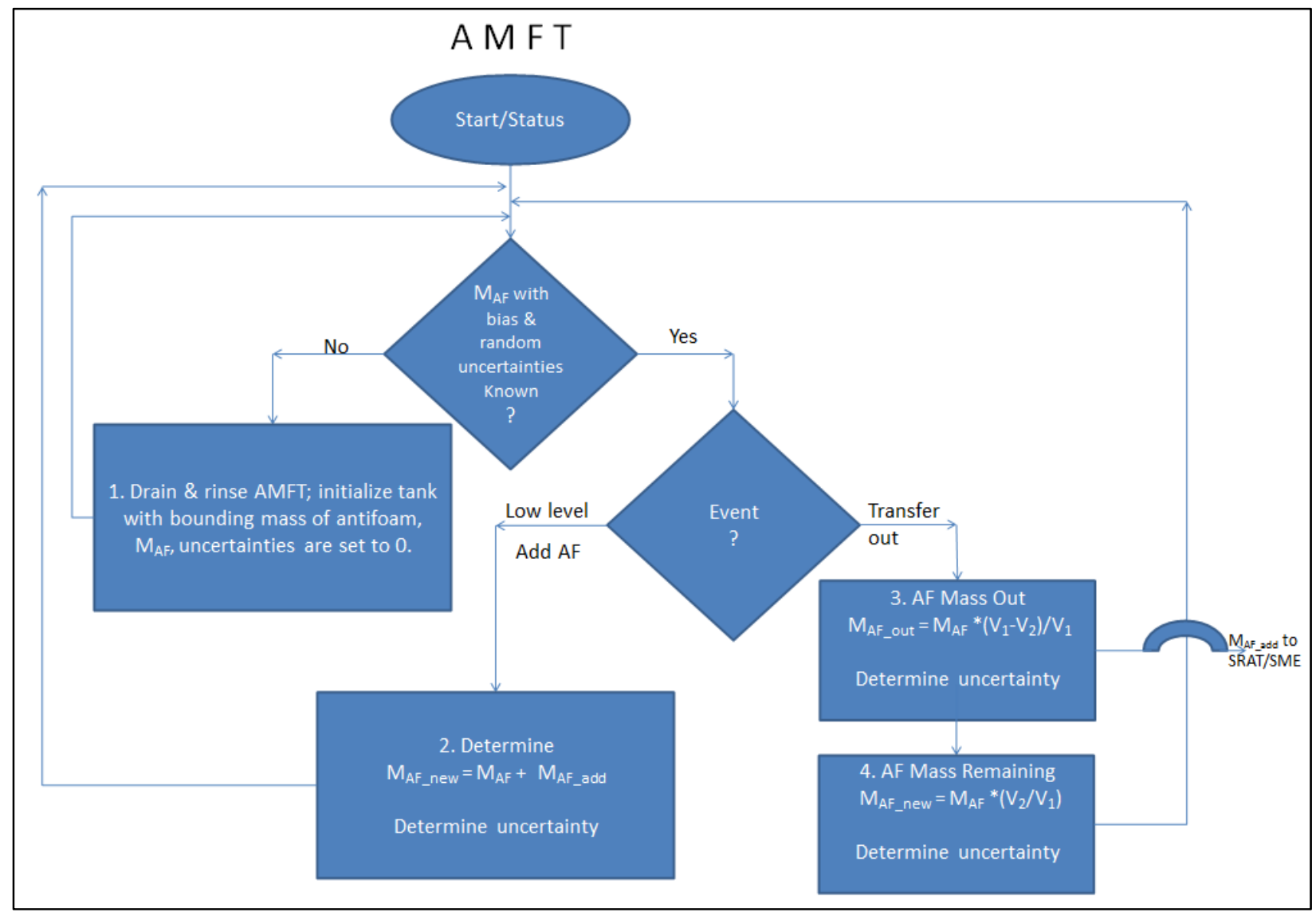

Exhibit 1 Process Flow for Tracking Antifoam Mass in the AMFT 
Exhibit 2 provides an overview of the AMFT calculations supporting the antifoam tracking system. Step 1 is executed if the $\mathrm{M}_{\mathrm{AF}}$ value or its uncertainty is unknown for the AMFT; this results in the reestablishment of a $\mathrm{M}_{\mathrm{AF}}$ value along with its one-sigma random uncertainty and the bounding bias. The rebase-lining of the value for $\mathrm{M}_{\mathrm{AF}}$ will utilize a bounding value for this mass, $18.91 \mathrm{~kg}$, and the uncertainties (bias and random) are set to zero. See Appendix A for the development of this bounding mass for Step 1.

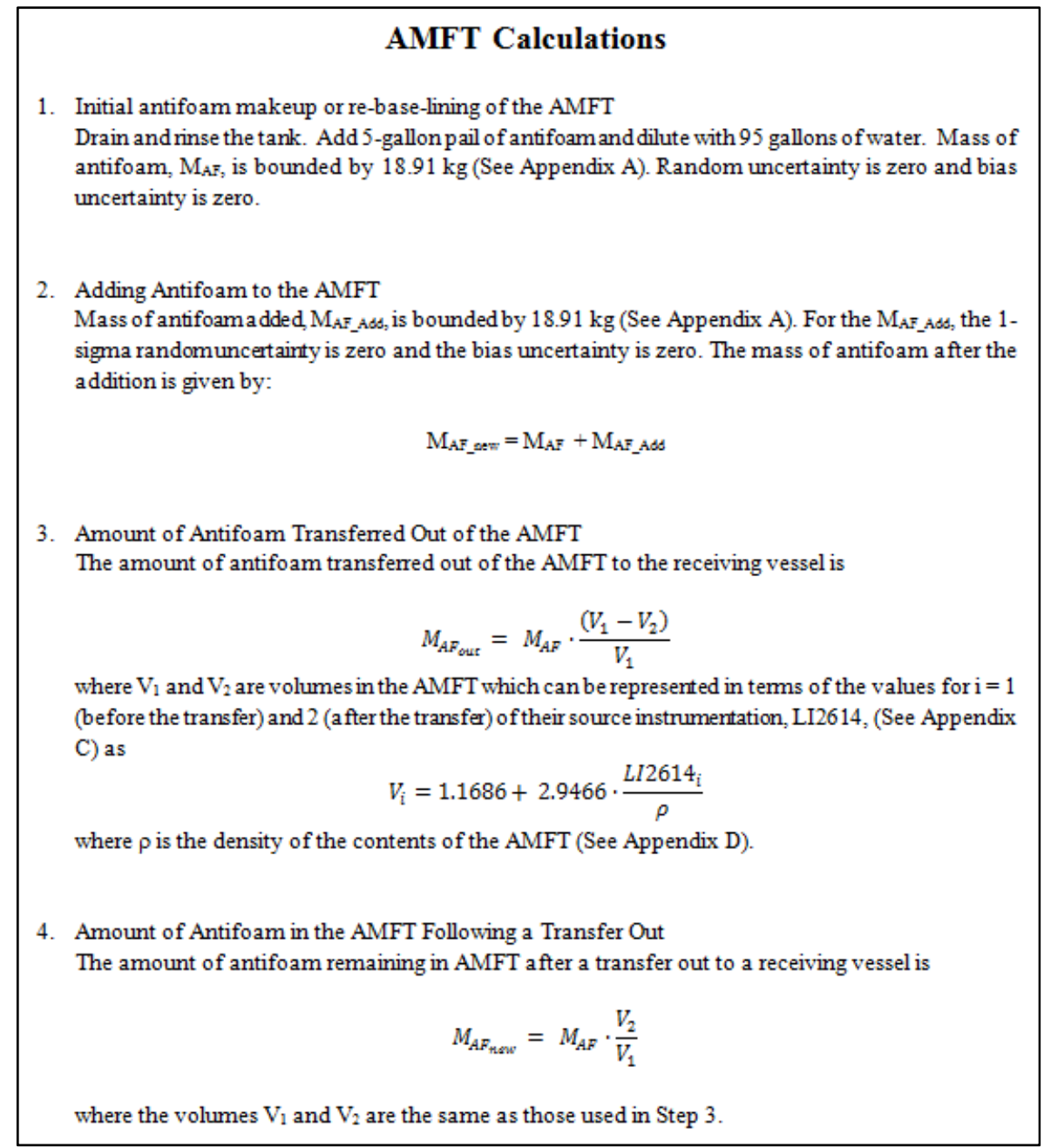

Exhibit 2 AMFT Calculations Supporting the Antifoam Tracking System

\subsubsection{AMFT Step 2 Processing}

For Step 2, the one-sigma random uncertainty for the new value of $\mathrm{M}_{\mathrm{AF}}$ (i.e., $\mathrm{M}_{\mathrm{AF} \mathrm{F}_{\mathrm{N}} \text { in }}$ in the Step 2 equation) is the square root of the sum of the variances of the random errors of the two terms on the right-

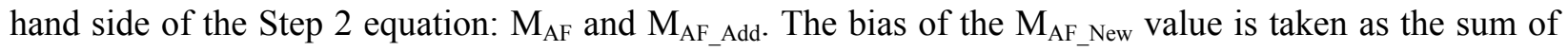
the biases of the two terms on the right-side of the Step 2 equation. This way of combining the biases (i.e., directly summing) is more conservative than combining them in quadrature (i.e., root sum of squares). Note that the random and bias uncertainties of the addition are zero, since a bounded value for 
SRNL-STI-2014-00323

Revision 0

the mass of the addition is utilized. A sample calculation for this step is provided in Exhibit B1 in Appendix B.

\subsubsection{AMFT Step 3 Processing}

So, consider the impact of a Step 3 event with the AMFT $\mathrm{M}_{\mathrm{AF}}$ information known. The equation for the $\mathrm{M}_{\mathrm{AF} \_ \text {out }}$ is given by:

\section{Equation 15}

$$
M_{A F_{\text {out }}}=\frac{M_{A F} \cdot\left(V_{1}-V_{2}\right)}{V_{1}}
$$

where the volumes $V_{1}$ and $V_{2}$ in gallons are intermediary values which are determined from the level instrument LI2614 and the specific gravity, $\rho$, as described in Exhibit 2 with the two volumes each having an additional random variability that is to be incorporated into the random uncertainty and biases that are to be incorporated in the bias uncertainty of $\mathrm{M}_{\mathrm{AF}_{-} \text {out }}$.

Following the Taylor's Series expansion approach described above, the estimated variance of $\mathrm{M}_{\mathrm{AF} \_ \text {out }}$ for Step 3 of Exhibit 1 may be written in terms of the fundamental measurements with $\delta_{1}$ and $\delta_{2}$ representing the random uncertainties for $\mathrm{V}_{1}$ and $\mathrm{V}_{2}$, respectively, as:

Equation 16

$$
\begin{gathered}
\operatorname{Variance}\left(M_{A F_{\text {out }}}\right) \approx\left(\frac{\partial M_{A F_{\text {out }}}}{\partial M_{A F}}\right)^{2} \times \operatorname{variance}\left(M_{A F}\right)+\left(\frac{\partial M_{A F_{\text {out }}}}{\partial L I 2614_{1}}\right)^{2} \times \operatorname{variance}\left(L_{\left.I 2614_{1}\right)}\right) \\
+\left(\frac{\partial M_{A F_{\text {out }}}}{\partial \rho}\right)^{2} \times \operatorname{variance}(\rho)+\left(\frac{\partial M_{A F_{\text {out }}}}{\partial L I 2614_{2}}\right)^{2} \times \operatorname{variance}(\text { LI2614 } 2) \\
+\left(\frac{\partial M_{A F_{\text {out }}}}{\partial \delta_{1}}\right)^{2} \times \operatorname{variance}\left(\delta_{1}\right)+\left(\frac{\partial M_{A F_{\text {out }}}}{\partial \delta_{2}}\right)^{2} \times \operatorname{variance}\left(\delta_{2}\right)
\end{gathered}
$$

where the numerical subscripts 1 and 2 represent the before and after, respectively, transfer values for the level instrument LI2614.

Exhibit 3 provides equations developed using GUM Workbench that support the evaluation of $\mathrm{M}_{\mathrm{AF}_{-} \text {out }}$ determined in Step 3. The model equation and associated intermediary values supporting the determination of $\mathrm{M}_{\mathrm{AF}_{-} \text {out }}$ for Step 3 are given in the upper portion of Exhibit 3 and the complete set of partial derivatives needed to support the estimation of the variance of the $\mathrm{M}_{\mathrm{AF}_{-} \text {out }}$ value are given in the lower portion of this exhibit. 
SRNL-STI-2014-00323

Revision 0

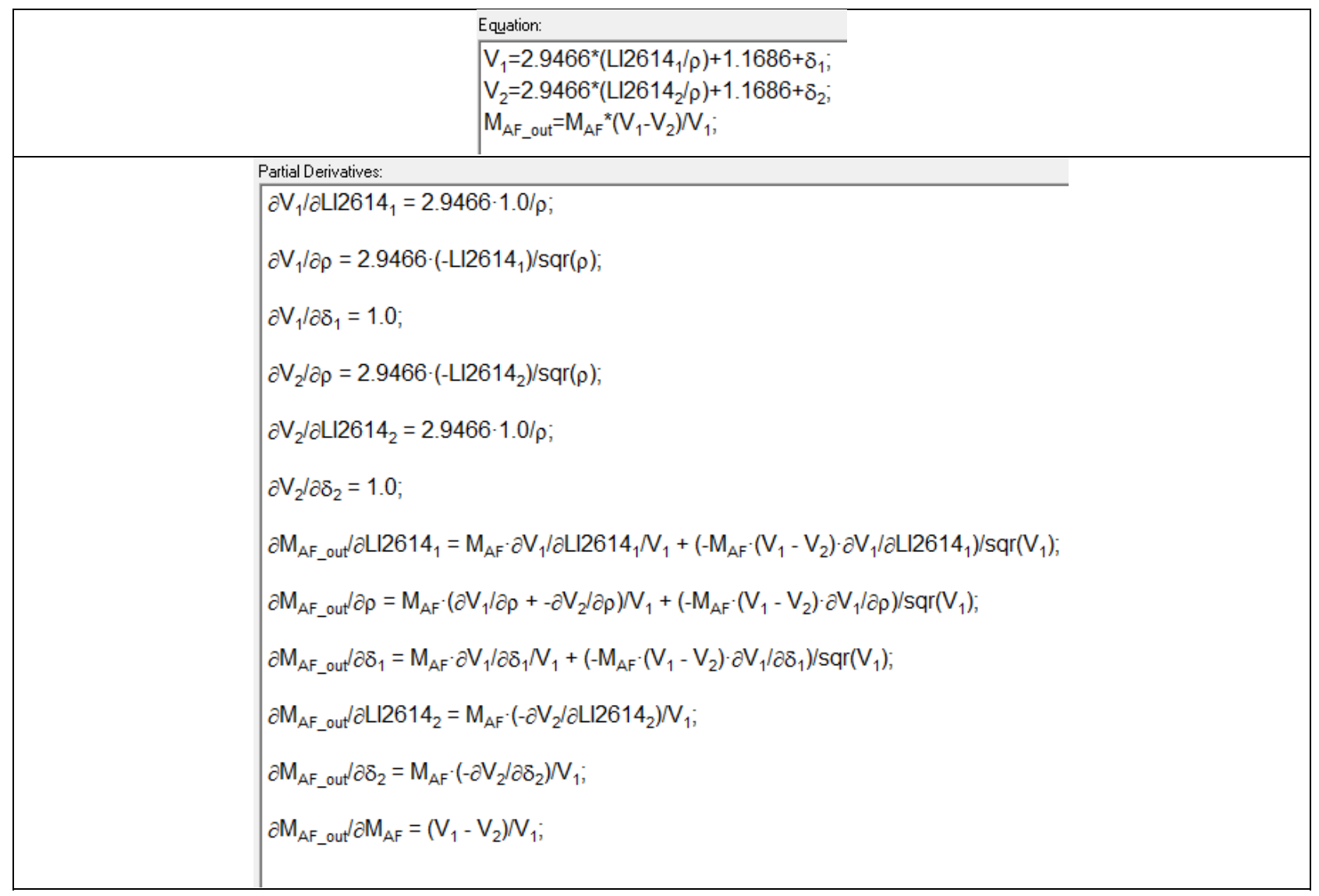

Exhibit 3 Equations for Calculating the Standard Deviation of the Random Uncertainty of the $\mathbf{M}_{\mathrm{AF}}$ Transferred Out of the AMFT

To complete the information necessary to compute the estimate of the random variance of the $\mathrm{M}_{\mathrm{AF}_{-} \text {out}}$, estimates of the variances of the terms of Equation 16 are needed. These values are provided in Table 3.

Table 3 Terms and Estimated Random Uncertainties Supporting Equation 16

\begin{tabular}{|c|c|c|}
\hline Term/Instrument & Description & 1-Sigma Random Uncertainty \\
\hline $\mathrm{M}_{\mathrm{AF}}$ & mass of antifoam $(\mathrm{kg})$ & from the AMFT status \\
\hline \multirow[t]{3}{*}{ LI2614 with subscripts 1 and 2} & level bubbler values (inwc) & $\pm 1 \%$ of 41 inwe span [10]; \\
\hline & $\begin{array}{c}\text { Distribution Control System (DCS) } \\
\text { deviation limit (inwc) }\end{array}$ & \pm 0.025 inwc $[10]$ \\
\hline & & $\begin{array}{l}\text { Using a uniform distribution, 1-sigma } \\
\text { random uncertainty (inwc) is } \\
{\left[(0.41 / \sqrt{ } 3)^{2}+(0.025 / \sqrt{ } 3)^{2}\right]^{0.5}=0.2372}\end{array}$ \\
\hline$\rho$ (this value is set to 1 ) & Specific Gravity of AMFT Material & $0.0036^{*}$ \\
\hline (1) & $\begin{array}{c}\text { Calibration uncertainty } \\
\text { (see Appendix C for details) }\end{array}$ & 0.637 gallon \\
\hline$\delta_{2}$ & $\begin{array}{c}\text { Calibration uncertainty } \\
\text { (see Appendix C for details) }\end{array}$ & 0.637 gallon \\
\hline
\end{tabular}

\footnotetext{
* See Appendix D for a discussion of the uncertainties associated with the density assessments of the AMFT.
} 
SRNL-STI-2014-00323

Revision 0

With the information from Exhibit 1, Exhibit 2, and Equation 14 as background, the estimated bias error for $\mathrm{M}_{\mathrm{AF} \_ \text {out }}$, determined in Step 3, using the Taylor's Series approach, may be written as:

\section{Equation 17}

$$
\begin{aligned}
& \left\{\operatorname{bias}\left(M_{A F_{\text {out }}}\right)\right\}^{2} \approx\left(\frac{\partial M_{A F_{\text {out }}}}{\partial M_{A F}}\right)^{2} \times\left\{\operatorname{bias}\left(M_{A F}\right)\right\}^{2}+\left(\frac{\partial M_{A F_{\text {out }}}}{\partial L I 2614_{1}}\right)^{2} \times\{\operatorname{bias}(\text { LI2614 } 1)\}^{2} \\
& +\left(\frac{\partial M_{A F_{\text {out }}}}{\partial \rho}\right)^{2} \times\{\operatorname{bias}(\rho)\}^{2}+\left(\frac{\partial M_{A F_{\text {out }}}}{\partial L I 2614_{2}}\right)^{2} \times\left\{\operatorname{bias}\left(L I 2614_{2}\right)\right\}^{2} \\
& +\left(\frac{\partial M_{A F_{\text {out }}}}{\partial b_{1}}\right)^{2} \times\left\{\operatorname{bias}\left(b_{1}\right)\right\}^{2}+\left(\frac{\partial M_{A F_{\text {out }}}}{\partial b_{2}}\right)^{2} \times\left\{\operatorname{bias}\left(b_{2}\right)\right\}^{2}
\end{aligned}
$$

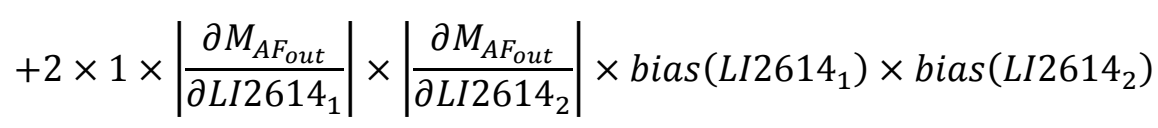

$$
\begin{aligned}
& +2 \times 1 \times\left|\frac{\partial M_{A F_{\text {out }}}}{\partial b_{1}}\right| \times\left|\frac{\partial M_{A F_{\text {out }}}}{\partial b_{2}}\right| \times \operatorname{bias}\left(b_{1}\right) \times \operatorname{bias}\left(b_{2}\right)
\end{aligned}
$$

Note that in evaluating Equation 17, the bias for the $\mathrm{M}_{\mathrm{AF}}$ term, i.e., bias $\left(\mathrm{M}_{\mathrm{AF}}\right)$ term, is provided by the status information for the AMFT prior to the transfer out and that two potential correlations among the biases are introduced into the equation, both represented in a bounding manner. So the approach may be stated as: the $b_{1}$ and $b_{2}$ terms are the estimated bias in the $V_{1}$ and $V_{2}$ volumes, respectively, and there is a potential correlation in these biases. Also, there is a potential correlation in the biases for the two LI2614 measurements. Basically, a perfect correlation is assumed and the sign of the correlation (i.e., representing the correlation as positive or negative) is taken as the worst of the two possibilities. GUM Workbench was used to develop the model equation and associated intermediary values supporting the determination of the bias of $\mathrm{M}_{\mathrm{AF}_{-} \text {out }}$ for Step 3 (see the upper portion of Exhibit 4) and to document the complete set of partial derivatives needed to support the estimation of the bias of the $\mathrm{M}_{\mathrm{AF} \text { _out }}$ value (see the lower portion of Exhibit 4). To complete the information necessary to compute the estimate of the bias of the $\mathrm{M}_{\mathrm{AF} \_ \text {out }}$, estimates of the bias terms of Equation 17 are needed. Table 4 provides the details of the bias information needed to complete the estimation of the bias for the $\mathrm{M}_{\mathrm{AF} \_ \text {out }}$ value. A sample calculation for this step including the random and bias uncertainties is provided in Exhibit B2 in Appendix B. 
SRNL-STI-2014-00323

Revision 0

\begin{tabular}{|c|c|}
\hline & $\begin{array}{l}\text { Equation: } \\
\begin{array}{l}\mathrm{V}_{1}=2.9466^{*}\left(\mathrm{LI} 2614_{1} / \rho\right)+1.1686+\mathrm{b}_{1} \\
\mathrm{~V}_{2}=2.9466^{*}\left(\mathrm{LI}_{2} 614_{2} / \rho\right)+1.1686+\mathrm{b}_{2} \\
\mathrm{M}_{\mathrm{AF}_{-} \text {out }}=\mathrm{M}_{\mathrm{AF}^{*}}{ }^{*}\left(\mathrm{~V}_{1}-\mathrm{V}_{2}\right) / \mathrm{V}_{1}\end{array}\end{array}$ \\
\hline & $\begin{array}{l}1.0 / \rho \\
\left.14_{1}\right) / \operatorname{sqr}(\rho) ; \\
\left.14_{2}\right) / \mathrm{sqr}(\rho) ; \\
1.0 / \rho \\
/ \partial \rho+\partial \mathrm{V}_{1} / \partial \mathrm{LI} 2614_{1} / \mathrm{V}_{1}+\left(-\mathrm{M}_{\mathrm{AF}} \cdot\left(\mathrm{V}_{1}-\mathrm{V}_{2}\right) \cdot \partial \mathrm{V}_{1} / \partial \mathrm{LI} 2614_{1}\right) / \mathrm{sqr}\left(\mathrm{V}_{1}\right) ; \\
/ \partial \mathrm{b}_{1} / \mathrm{V}_{1}+\left(-\mathrm{M}_{\mathrm{AF}} \cdot\left(\mathrm{V}_{1}-\mathrm{V}_{2}\right) \cdot \partial \mathrm{V}_{1} / \partial \mathrm{b}_{1}\right) / \mathrm{sqr}\left(\mathrm{V}_{1}\right) ; \\
{ }_{\mathrm{AF}} \cdot\left(-\partial \mathrm{V}_{2} / \partial \mathrm{LI} 2614_{2}\right) / \mathrm{V}_{1} ; \\
\left.\mathrm{V}_{2} / \partial \mathrm{b}_{2}\right) / \mathrm{V}_{1} ; \\
\left.{ }_{2}\right) / \mathrm{V}_{1} ;\end{array}$ \\
\hline
\end{tabular}

Exhibit 4 Equations for Calculating the Bias of the $\mathrm{M}_{\mathrm{AF}}$ Transferred Out of the AMFT

Table 4 Terms and Estimated Bias Uncertainties Supporting Equation 17

\begin{tabular}{|c|c|c|}
\hline Term/Instrument & Description & Bias Error at 95\% Confidence \\
\hline $\mathrm{M}_{\mathrm{AF}}$ & mass of antifoam (kg) & bias from the AMFT status information \\
\hline LI2614 with subscripts 1 and 2 & level bubbler values (inwc) & $1 \%$ of 41 inwc span $=0.41$ inwc [10] \\
\hline$\rho$ (this value is set to 1) & specific gravity of AMFT material & $0.0108^{*}$ \\
\hline $\mathrm{b}_{1}$ & $\begin{array}{c}\text { calibration uncertainty } \\
\text { (see Appendix C for details) }\end{array}$ & 0.232 gallon \\
\hline $\mathrm{b}_{2}$ & $\begin{array}{c}\text { calibration uncertainty } \\
\text { (see Appendix C for details) }\end{array}$ & 0.232 gallon \\
\hline
\end{tabular}

\footnotetext{
* See Appendix D for a discussion of the uncertainties associated with the density assessments of the AMFT.
} 
SRNL-STI-2014-00323

Revision 0

\subsubsection{AMFT Step 4 Processing}

Consider the determination of the $\mathrm{M}_{\mathrm{AF}}$ information after a transfer from the AMFT (Step 4 of Exhibit 1 and Exhibit 2). The $\mathrm{M}_{\mathrm{AF}_{-} \text {new }}$ value is given by:

Equation 18

$$
M_{A F_{n e w}}=\frac{M_{A F} \cdot V_{2}}{V_{1}}
$$

Using the approach described above, the estimated random uncertainty variance of $\mathrm{M}_{\mathrm{AF} \_ \text {new }}$ determined for that step may be written as:

\section{Equation 19}

$$
\begin{gathered}
\operatorname{Variance}\left(M_{A F_{\text {new }}}\right) \approx\left(\frac{\partial M_{A F_{\text {new }}}}{\partial M_{A F}}\right)^{2} \times \operatorname{variance}\left(M_{A F}\right)+\left(\frac{\partial M_{A F_{\text {new }}}}{\partial L I 2614_{1}}\right)^{2} \times \operatorname{variance}\left(L I 2614_{1}\right) \\
+\left(\frac{\partial M_{A F_{\text {new }}}}{\partial \rho}\right)^{2} \times \operatorname{variance}(\rho)+\left(\frac{\partial M_{A F_{\text {new }}}}{\partial L I 2614_{2}}\right)^{2} \times \operatorname{variance}(\text { LI2614 } 2) \\
+\left(\frac{\partial M_{A F_{\text {new }}}}{\partial \delta_{1}}\right)^{2} \times \operatorname{variance}\left(\delta_{1}\right)+\left(\frac{\partial M_{A F_{n e w}}}{\partial \delta_{2}}\right)^{2} \times \operatorname{variance}\left(\delta_{2}\right)
\end{gathered}
$$

GUM Workbench was used to develop equations supporting the evaluation of Step 4 and the resulting equations are provided in Exhibit 5. Also, in this exhibit is the set of partial derivatives needed to support the estimation of the variance of the $\mathrm{M}_{\mathrm{AF}_{\mathrm{B}} \text { new }}$ value. To complete the information necessary to compute the

\begin{tabular}{|c|c|c|}
\hline Term/Instrument & Description & 1-Sigma Random Uncertainty \\
\hline $\mathrm{M}_{\mathrm{AF}}$ & mass of antifoam $(\mathrm{kg})$ & from the AMFT status \\
\hline \multirow[t]{3}{*}{ LI2614 with subscripts 1 and 2} & level bubbler values (inwc) & $\pm 1 \%$ of 41 inwe span [10]; \\
\hline & DCS deviation limit (inwc) & \pm 0.025 inwc $[10]$ \\
\hline & & $\begin{array}{l}\text { Using a uniform distribution, 1-sigma } \\
\text { random uncertainty (inwc) is } \\
{\left[(0.41 / \sqrt{ } 3)^{2}+(0.025 / \sqrt{ } 3)^{2}\right]^{0.5}=0.2372}\end{array}$ \\
\hline$\rho$ (this value is set to 1$)$ & specific gravity of AMFT material & $0.0036^{*}$ \\
\hline$\delta_{1}$ & $\begin{array}{c}\text { calibration uncertainty } \\
\text { (see Appendix C for details) }\end{array}$ & 0.637 gallon \\
\hline$\delta_{2}$ & $\begin{array}{c}\text { calibration uncertainty } \\
\text { (see Appendix C for details) }\end{array}$ & 0.637 gallon \\
\hline
\end{tabular}
estimate of the variance of the $\mathrm{M}_{\mathrm{AF} \_ \text {new }}$, estimates of the variance terms of Equation 19 are needed. These values are provided in Table 5.

Table 5 Terms and Estimated Random Uncertainties Supporting Equation 19

\footnotetext{
* See Appendix D for a discussion of the uncertainties associated with the density assessments of the AMFT.
} 
SRNL-STI-2014-00323

Revision 0

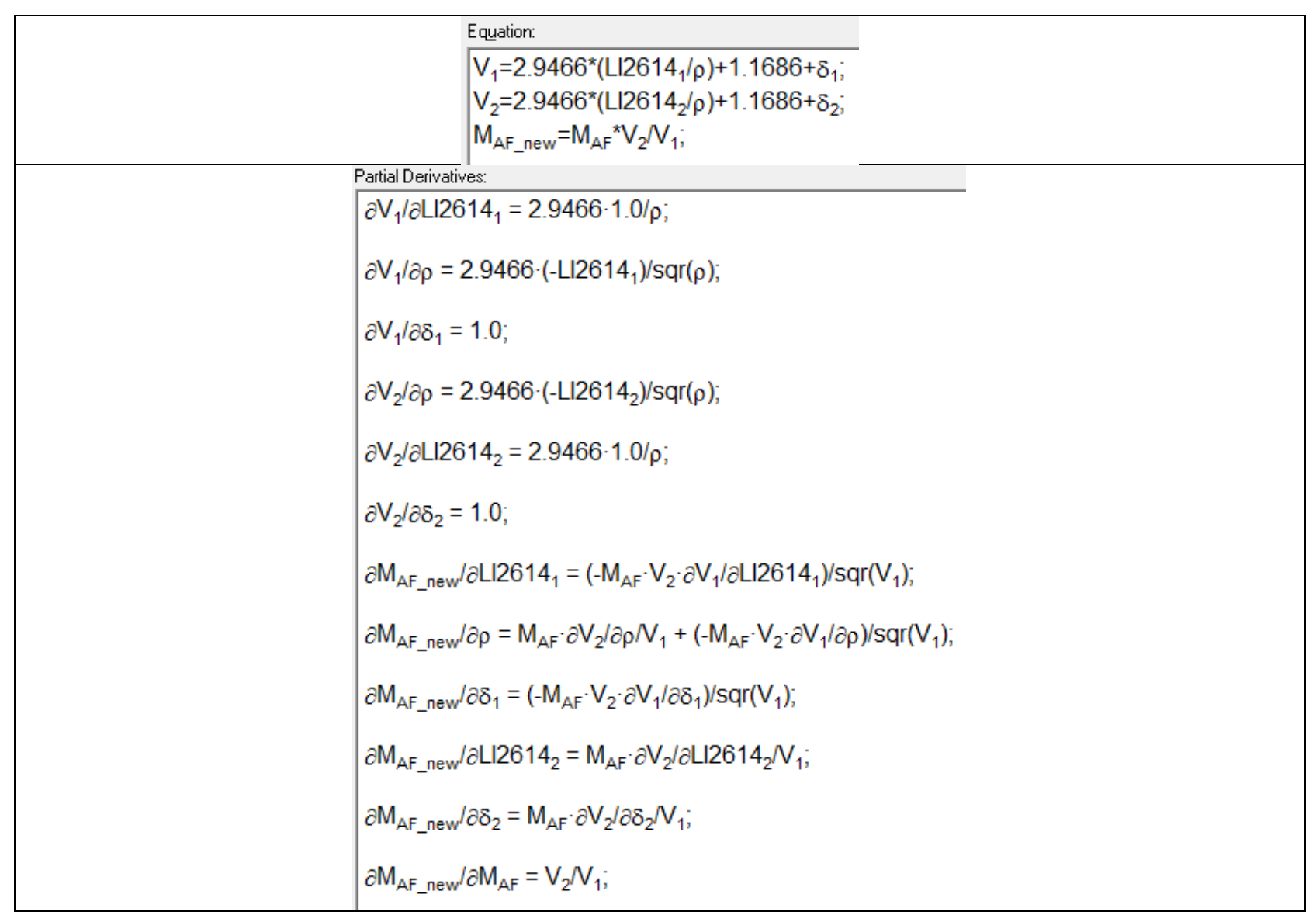

Exhibit 5 Equations for Calculating the Random Uncertainty for the $\mathbf{M}_{\mathrm{AF}}$ Remaining After the Transfer Out of the AMFT 
SRNL-STI-2014-00323

Revision 0

The estimated bias error for $\mathrm{M}_{\mathrm{AF} \_ \text {new }}$, determined in Step 4, may be written as:

Equation 20

$$
\begin{aligned}
& \left\{\operatorname{bias}\left(M_{A F_{n e w}}\right)\right\}^{2} \approx\left(\frac{\partial M_{A F_{n e w}}}{\partial M_{A F}}\right)^{2} \times\left\{\operatorname{bias}\left(M_{A F}\right)\right\}^{2}+\left(\frac{\partial M_{A F_{n e w}}}{\partial L I 2614_{1}}\right)^{2} \times\{\operatorname{bias}(\text { LI2614 } 1)\}^{2} \\
& +\left(\frac{\partial M_{A F_{n e w}}}{\partial \rho}\right)^{2} \times\{\operatorname{bias}(\rho)\}^{2}+\left(\frac{\partial M_{A F_{n e w}}}{\partial L I 2614_{2}}\right)^{2} \times\left\{\operatorname{bias}\left(L I 2614_{2}\right)\right\}^{2} \\
& +\left(\frac{\partial M_{A F_{\text {new }}}}{\partial b_{1}}\right)^{2} \times\left\{\operatorname{bias}\left(b_{1}\right)\right\}^{2}+\left(\frac{\partial M_{A F_{n e w}}}{\partial b_{2}}\right)^{2} \times\left\{\operatorname{bias}\left(b_{2}\right)\right\}^{2} \\
& +2 \times 1 \times\left|\frac{\partial M_{A F_{n e w}}}{\partial L I 2614_{1}}\right| \times\left|\frac{\partial M_{A F_{n e w}}}{\partial L I 2614_{2}}\right| \times \operatorname{bias}\left(L I 2614_{1}\right) \times \operatorname{bias}\left(L I 2614_{2}\right) \\
& +2 \times 1 \times\left|\frac{\partial M_{A F_{\text {new }}}}{\partial b_{1}}\right| \times\left|\frac{\partial M_{A F_{\text {new }}}}{\partial b_{2}}\right| \times \operatorname{bias}\left(b_{1}\right) \times \operatorname{bias}\left(b_{2}\right)
\end{aligned}
$$

Note that in evaluating Equation 20, the bias for the $\mathrm{M}_{\mathrm{AF}}$ term, i.e., bias $\left(\mathrm{M}_{\mathrm{AF}}\right)$ term, is provided by the status information for the AMFT prior to the transfer out and that two potential correlations among the biases are introduced into the equation, both represented in a bounding manner. So the approach may be stated as: the $b_{1}$ and $b_{2}$ terms are the estimated biases in the $V_{1}$ and $V_{2}$ volumes, respectively, and there is a potential correlation in these biases. Also, there is a potential correlation in the biases for the two LI2614 measurements. Basically, a perfect correlation is assumed and the sign of the correlation (i.e., representing the correlation as positive or negative) is taken as the worst of the two possibilities. GUM Workbench was used to develop the model equation and associated intermediary values supporting the determination of the bias of $\mathrm{M}_{\mathrm{AF}_{-} \text {new }}$ for Step 4 (see the upper portion of Exhibit 6) and to document the complete set of partial derivatives needed to support the estimation of the bias of the $\mathrm{M}_{\mathrm{AF}-\mathrm{new}}$ value (see the lower portion of Exhibit 6). To complete the information necessary to compute the estimate of the bias

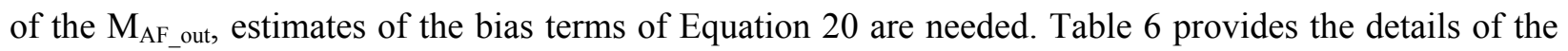
bias information needed to complete the estimation of the bias for the $\mathrm{M}_{\mathrm{AF}_{-} \text {new }}$ value. A sample calculation for this step including the random and bias uncertainties is provided in Exhibit B3 in Appendix B. 
SRNL-STI-2014-00323

Revision 0

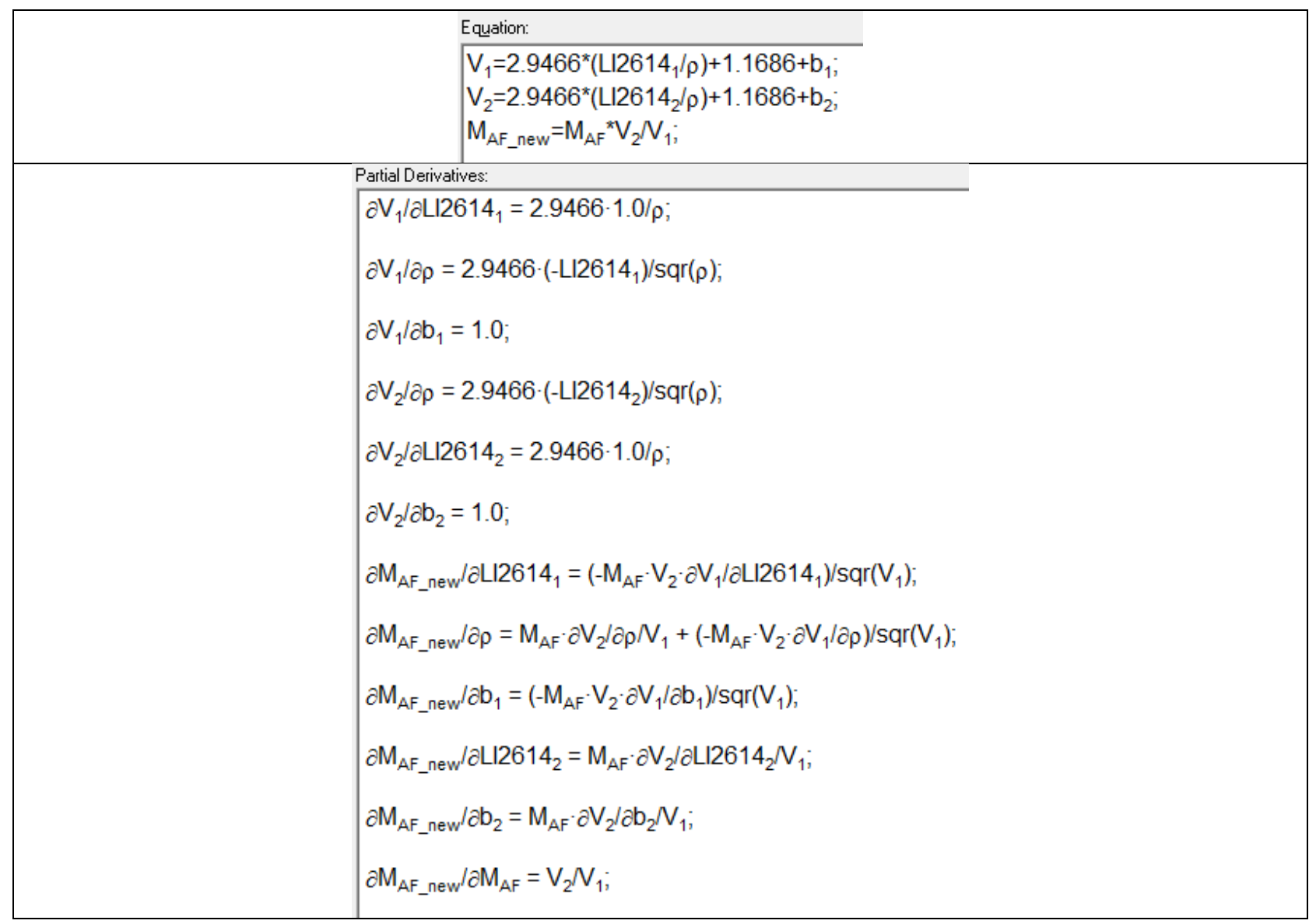

Exhibit 6 Equations for Calculating the Bias for the $\mathbf{M}_{\mathrm{AF}}$ Remaining After the Transfer Out of the AMFT

Table 6 Terms and Estimated Bias Uncertainties Supporting Equation 20

\begin{tabular}{|c|c|c|}
\hline Term/Instrument & Description & Bias Error at 95\% Confidence \\
\hline$M_{\mathrm{AF}}$ & $\begin{array}{c}\text { antifoam carbon concentration } \\
(\mathrm{mg} / \mathrm{kg})\end{array}$ & $\begin{array}{c}\text { Bias from the AMFT status } \\
\text { information }\end{array}$ \\
\hline LI2614 with subscripts 1 and 2 & Level Bubbler (inwc) & $1 \%$ of 41 inwc span $=0.41$ inwc [10] \\
\hline$\rho$ (this value is set to 1) & Specific Gravity of AMFT Material & $0.0108^{*}$ \\
\hline $\mathrm{b}_{1}$ & $\begin{array}{c}\text { Calibration uncertainty } \\
\text { (see Appendix C for details) }\end{array}$ & 0.232 gallon \\
\hline $\mathrm{b}_{2}$ & $\begin{array}{c}\text { Calibration uncertainty } \\
\text { (see Appendix C for details) }\end{array}$ & 0.232 gallon \\
\hline
\end{tabular}

\footnotetext{
* See Appendix D for a discussion of the uncertainties associated with the density assessments of the AMFT.
} 
SRNL-STI-2014-00323

Revision 0

\subsection{Tracking Antifoam in the SRAT}

The SRAT is a sludge preparation tank where antifoam is added by transfers from the AMFT. To support the tracking of antifoam for a SME batch, the $\mathrm{M}_{\mathrm{AF}}$ value and its uncertainty (i.e., a one-sigma random uncertainty and a bias uncertainty at $95 \%$ confidence) associated with the SRAT contents are to be maintained at all times. If these values are not known, the contents of the SRAT are to be sampled and analyzed to re-baseline the antifoam mass and its uncertainty in this tank. With the values for the $\mathrm{M}_{\mathrm{AF}}$ and its uncertainty known, the antifoam tracking system must be capable up handling two types of events: (1) an event involving a transfer from the AMFT into the SRAT and (2) an event involving the transfer of SRAT product to the SME. Handling these events entails updating the status of the $\mathrm{M}_{\mathrm{AF}}$ value and its uncertainty in the SRAT for event types (1) and (2) as well as updating the status of the $\mathrm{M}_{\mathrm{AF}}$ and its uncertainty in the SME tank to complete the impact of a type (2) event (addressed in the next section).

Exhibit 7 provides a flow diagram at the SRAT level for processing an event involving the SRAT. For any SRAT-related event, there is an initial assessment of the current status of the $\mathrm{M}_{\mathrm{AF}}$ value and its uncertainty in the SRAT as represented by the first decision step in the event flow diagram. If the $\mathrm{M}_{\mathrm{AF}}$ status is unknown, then the "No" branch is taken out of this decision block and the value of the $\mathrm{M}_{\mathrm{AF}}$ and its uncertainty must be re-base-lined as indicated in Step 1 of the diagram. If the status is known, the "Yes" branch is taken out of this decision block. With the $\mathrm{M}_{\mathrm{AF}}$ value and its uncertainty known for the SRAT, the next decision block is evaluated to determine the type of event that needs to be addressed by the tracking system. Once again there are two types of events captured in this flow diagram: a) if there is a transfer from the AMFT to the SRAT, then an antifoam addition is to be made to the SRAT and the impact of this addition on the $\mathrm{M}_{\mathrm{AF}}$ value and its uncertainty must be determined (indicated as Step 2 in Exhibit 7) or b) if a transfer of SRAT product is to be made to the SME, then the impact of the change in the level of the contents of the SRAT (determined by information from the bubbler instrumentation in the tank) as the transfer is made must be utilized to provide information on the mass of antifoam for the receiving tank (i.e., the SME) involved in the transfer (indicated as Step 3 in Exhibit 7) and to update the $\mathrm{M}_{\mathrm{AF}}$ status of the SRAT after the transfer (indicated as Step 4 in Exhibit 7). 


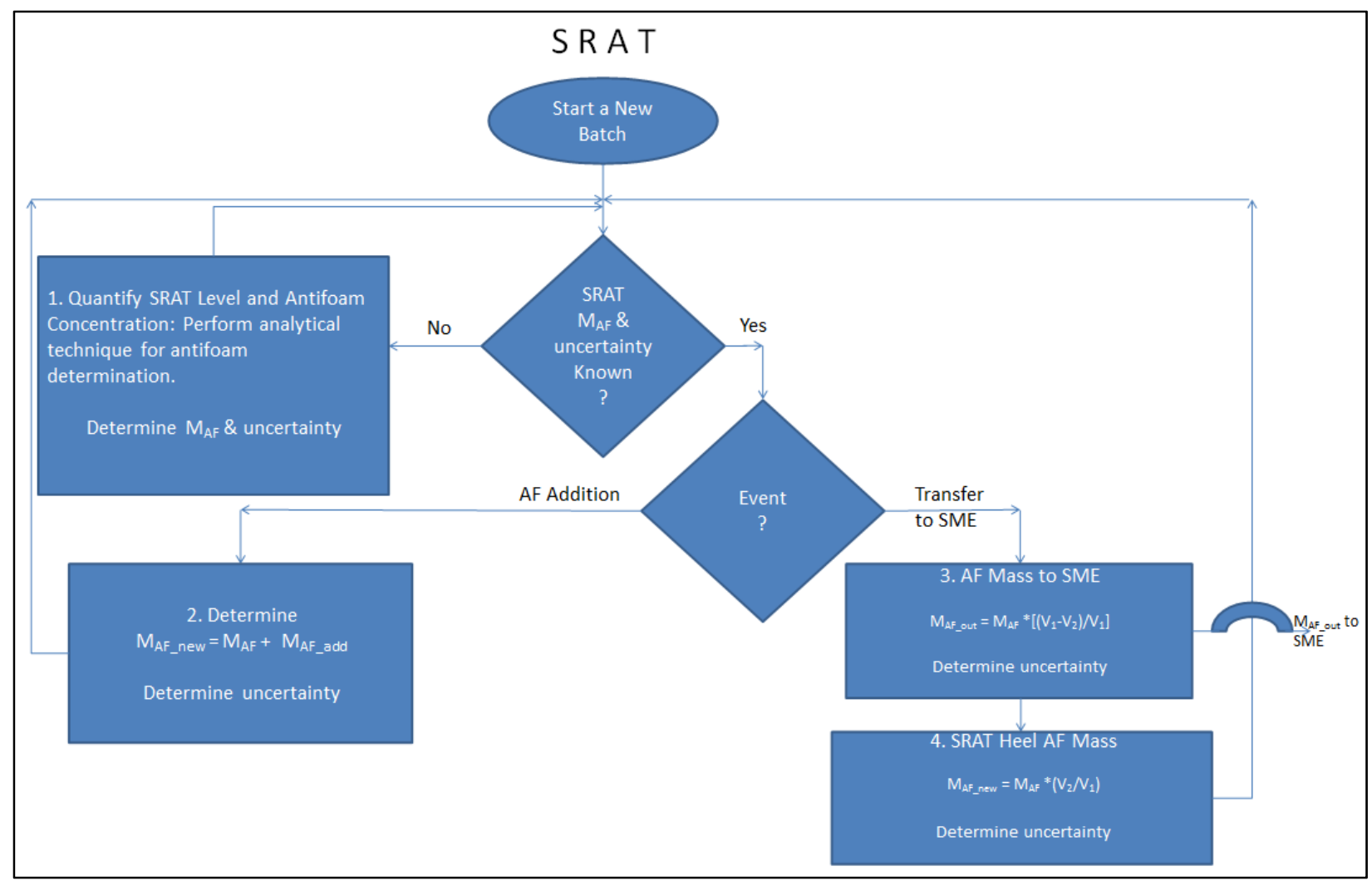

Exhibit 7 Process Flow for Tracking Antifoam Mass in the Sludge Receipt and Adjustment Tank (SRAT)

Exhibit 8 and Exhibit 9 provide an overview of the SRAT calculations supporting the antifoam tracking system. The calculations for Step 1 are executed if the $\mathrm{M}_{\mathrm{AF}}$ value or its uncertainty is unknown for the SRAT; and these calculations re-establish the $\mathrm{M}_{\mathrm{AF}}$ value along with its uncertainty.

\subsubsection{SRAT Step 2 Processing}

For Step 2, the uncertainty is to be updated as follows: the one-sigma random uncertainty for the new value of $\mathrm{M}_{\mathrm{AF}}$ (i.e., $\mathrm{M}_{\mathrm{AF} \_ \text {New }}$ in the Step 2 equation) is the square root of the sum of the random variances of the two terms on the right-hand side of the Step 2 equation $\left(\mathrm{M}_{\mathrm{AF}}\right.$ and $\left.\mathrm{M}_{\mathrm{AF}_{-} \mathrm{Add}}\right)$, and the bias for the $\mathrm{M}_{\mathrm{AF}_{-} \text {New }}$ value is simply the sum of the biases of the two terms on the right-hand side of the Step 2 equation. A sample calculation for this step including the random and bias uncertainties is provided in Exhibit B4 in Appendix B.

\subsubsection{Overview of SRAT Steps 1, 3 and 4 Processing}

Step 3 provides the determination of the $\mathrm{M}_{\mathrm{AF} \text { out }}$ value associated with the transfer from the SRAT to the SME. The role of the bubbler instruments is also indicated as part of the Step 3 calculations. Step 4 provides the mass of the antifoam remaining in the SRAT (i.e., the SRAT heel) after the transfer out has been completed. The calculations supporting each of steps 1, 3 and 4 of the tracking system for the SRAT are covered in turn in the following discussion. 


\section{SRAT Calculations}

1. Re-base-lining of the SRAT

The SRAT vessel will be re-base-lined using the analytical method for antifoam concentration determination that is currently used. The mass of antifoam at the time of the SRAT sample can be determined by

$$
M_{A F}=C_{A F} \cdot V_{1} \cdot \rho
$$

where the determination of volume, $V_{1}$, from the source instrumentation, LI3025 and DI3026, is described below and $\rho$ is calculated from these instruments by

$$
\rho=\frac{\left(L 13025_{1}-D I 3026_{1}\right)}{S e p}
$$

and Sep stands for the separation between the two instruments. The Sep value is 47 inches.

The volume in the SRAT can be represented in terms of the value at event, $\mathrm{i}=1$ (before a transfer) or $\mathrm{i}=2$ (after a transfer), of its source instrumentation LI3025 as:

$$
\begin{aligned}
\text { For } x_{i 2}<\left(\frac{L 13025_{i}}{\rho}\right. & + \text { Heel })<x_{i 1}, \\
& \frac{\frac{L I 3025_{i}}{\rho}+\text { Heel }-x_{i 2}}{\left(x_{i 1}-x_{i 2}\right)} \times\left(y_{i 1}-y_{i 2}\right)+y_{i 2}
\end{aligned}
$$

where the Heel is 6.77 inches and there are five sets of x's and y's corresponding to 5 segments within the SRAT. These values are (see reference [5]):

\begin{tabular}{|c|c|c|c|c|}
\hline Segment & $\mathrm{x}_{i 1}$ & $\mathrm{x}_{\mathrm{i} 2}$ & $\mathrm{y}_{\mathrm{i} 1}$ & $\mathrm{y}_{\mathrm{i} 2}$ \\
\hline 1 (lowest) & 17.416 & 0 & 1000 & 0 \\
\hline 2 & 78.513 & 17.416 & 5175 & 1000 \\
\hline 3 & 138.28 & 78.513 & 9400 & 5175 \\
\hline 4 & 158.89 & 138.28 & 10850 & 9400 \\
\hline 5 (highest) & 175.91 & 158.89 & 12000 & 10850 \\
\hline
\end{tabular}

Exhibit 8 SRAT Calculations Supporting the Antifoam Tracking System (part 1 of 2) 
2. Antifoam Mass in the SRAT after an Addition from the AMFT

The mass of antifoam in the SRAT after the AMFT addition (the amount from the AMFT is as determined in AMFT Step 3) is given by:

$$
\mathrm{M}_{\mathrm{AF} F_{-} \mathrm{new}}=\mathrm{M}_{\mathrm{AF}}+\mathrm{M}_{\mathrm{AF} F_{-} \mathrm{Add}}
$$

3. Amount of Antifoam Transferred Out of the SRAT to the SME

The amount of antifoam transferred out of the SRAT to the SME is

$$
M_{A F_{\text {out }}}=M_{A F} \cdot \frac{\left(V_{1}-V_{2}\right)}{V_{1}}
$$

where $V_{1}$ and $V_{2}$ are volumes in the SRAT which can be represented in terms of the values for $i=1$ (before the transfer) and 2 (after the transfer) of their source instrumentation, LI3025. These values are determined as described in Step 1 above. Note that the density value, $\rho$, that is used in the determination of $V_{1}$ is also used in the determination of $V_{2}$.

4. Amount of Antifoam in the SRAT Heel Following a Transfer Out to the SME

The amount of antifoam remaining in SRAT after a transfer out to a receiving vessel is

$$
M_{A F_{n e w}}=M_{A F} \cdot \frac{V_{2}}{V_{1}}
$$

where the $V_{1}$ and $V_{2}$ are the same volumes from Step 3 above.

Exhibit 9 SRAT Calculations Supporting the Antifoam Tracking System (part 2 of 2)

\subsubsection{SRAT Step 1Processing}

The equation for Step 1 of Exhibit 8 provides a guide for re-base lining the $\mathrm{M}_{\mathrm{AF}_{-} \text {new }}(\mathrm{kg})$ value for the SRAT. Writing the equation out with more detail to include the appropriate unit conversions yields:

\section{Equation 21}

$$
M_{A F_{\text {new }}}=\frac{3.7854 \cdot C_{A F} \cdot V_{1} \cdot \rho}{0.4723 \cdot 1000000}
$$

In this equation, $\mathrm{C}_{\mathrm{AF}}$ represents the carbon concentration $(\mathrm{mg} / \mathrm{kg})$ from $\mathrm{AF}$ determined from the analytical measurements of the SRAT contents (see Equation 11) with the volume (gal), $\mathrm{V}_{1}$, and density (assuming units of $\mathrm{kg} / \mathrm{L}), \rho$, determined as indicated in the Step 1 description of Exhibit 8 by measurements from instruments LI3025 and DI3026 along with values for the separation (Sep) between the bubblers and the heel (Heel) for LI3025. The value of 3.7854 is a conversion factor with units of L/gal. The value of 0.4723 is a conservative (i.e., bounding on the low side) conversion factor with units of $\mathrm{kg}$ of carbon per 
$\mathrm{kg}$ of antifoam ${ }^{f}$. The 1000000 value is a conversion factor with units of $\mathrm{mg} / \mathrm{kg}$. Note that $\rho$ and $\mathrm{V}_{1}$ are intermediary values with the $\mathrm{V}_{1}$ value having an additional variability described below. Using the Taylor's Series expansion approach described above, the estimated random variance of $\mathrm{M}_{\mathrm{AF} \text { nnw }}$ for Step 1 of Exhibit 8 may be expressed in the fundamental measurements as given by:

\section{Equation 22}

$$
\begin{gathered}
\operatorname{Variance}\left(M_{A F_{n e w}}\right) \approx\left(\frac{\partial M_{A F_{n e w}}}{\partial C_{A F}}\right)^{2} \times \operatorname{variance}\left(C_{A F}\right)+\left(\frac{\partial M_{A F_{\text {new }}}}{\partial L I 3025_{1}}\right)^{2} \times \operatorname{variance}\left(L I 3025_{1}\right) \\
+\left(\frac{\partial M_{A F_{n e w}}}{\partial D I 3026_{1}}\right)^{2} \times \operatorname{variance}\left(D I 3026_{1}\right)+\left(\frac{\partial M_{A F_{n e w}}}{\partial \delta_{1}}\right)^{2} \times \operatorname{variance}\left(\delta_{1}\right)
\end{gathered}
$$

where all of the estimated variances are for the random uncertainties of the indicated measurements. Specifically, the variance for $\mathrm{C}_{\mathrm{AF}}$ is estimated from the analyses of the SRAT samples as given by Equation 12 and the variance $\left(\delta_{1}\right)$ term represents the variance of the random uncertainty associated with the computed volume, $\mathrm{V}_{1}$. (see the upper portion of Exhibit 10 for the introduction of the $\delta_{1}$ term into the model equation for $\mathrm{M}_{\mathrm{AF} \_ \text {new }}$ ). GUM Workbench was used to develop the model equation and associated intermediary values supporting the determination of $\mathrm{M}_{\mathrm{AF}_{-} \text {new }}$ for Step 1 (see the upper portion of Exhibit 10) and to document the complete set of partial derivatives needed to support the estimation of the variance of the $\mathrm{M}_{\mathrm{AF}{ }_{-} \text {new }}$ value (see the lower portion of Exhibit 10). For example, $\mathrm{x}_{1}, \mathrm{x}_{2}, \mathrm{y}_{1}$, and $\mathrm{y}_{2}$ are appropriately selected values (based upon the value of the LI3025 instrument as indicated by LI3025 $)$ for determining volume as indicated in Exhibit 8.To complete the information necessary to compute the estimate of the variance of the $\mathrm{M}_{\mathrm{AF} \text { new }}$, estimates of the variance terms of Equation 22 are needed. These values along with a description of the terms of Equation 22 are provided in Table 7.

\begin{tabular}{|c|c|c|}
\hline Term/Instrument & Description & 1-Sigma Random Uncertainty \\
\hline $\mathrm{C}_{\mathrm{AF}}($ see Equation 11$)$ & $\begin{array}{l}\text { antifoam carbon concentration } \\
(\mathrm{mg} / \mathrm{kg})\end{array}$ & Analytical uncertainty (see Equation 12) \\
\hline \multirow[t]{3}{*}{ LI3025 with subscript 1} & level bubbler value (inwc) & $\pm 1 \%$ of 231.6 inwc span [11] \\
\hline & DCS deviation limit & \pm 0.1 inwc $[11]$ \\
\hline & & $\begin{array}{l}\text { Using a uniform distribution, 1-sigma random } \\
\text { uncertainty (inwc) is } \\
{\left[(2.316 / \sqrt{3})^{2}+(0.1 / \sqrt{3})^{2}\right]^{0.5}=1.3384 \text { inwc }}\end{array}$ \\
\hline \multirow[t]{3}{*}{ DI3026 with subscript 1} & density bubbler value (inwc) & $\pm 1 \%$ of 161.0 inwe span $[12]$ \\
\hline & DCS deviation limit & \pm 0.05 inwc [12] \\
\hline & & $\begin{array}{l}\text { Using a uniform distribution, 1-sigma random } \\
\text { uncertainty (inwc) is } \\
{\left[(1.61 / \sqrt{ } 3)^{2}+(0.05 / \sqrt{3})^{2}\right]^{0.5}=0.9300 \text { inwc }}\end{array}$ \\
\hline$\delta_{1}$ & $\begin{array}{l}\text { tank calibration uncertainty } \\
\text { (see WSRC-TR-92-250 [8]") }\end{array}$ & 1 -sigma random $=9$ gallons \\
\hline
\end{tabular}

Table 7 Terms and Estimated Random Uncertainties Supporting Equation 22

\footnotetext{
${ }^{f}$ See SRNL E-Notebook O7787-00055-09, Antifoam 747 Basic Data and Acceptance Testing, July 29, 2014.

* The random uncertainty of the tank calibration was estimated in this report for the SRAT and the SME as the total error of the Holledge gauge, 0.25 inch, times the slope of the calibration curve. For the SRAT, the largest slope is 70.696 gal/inch, leading to an estimate of the total (2-sigma) random uncertainty of $70.696 \times 0.25=17.7$ gal, or a 1-sigma random uncertainty of 9 gal.
} 
SRNL-STI-2014-00323

Revision 0

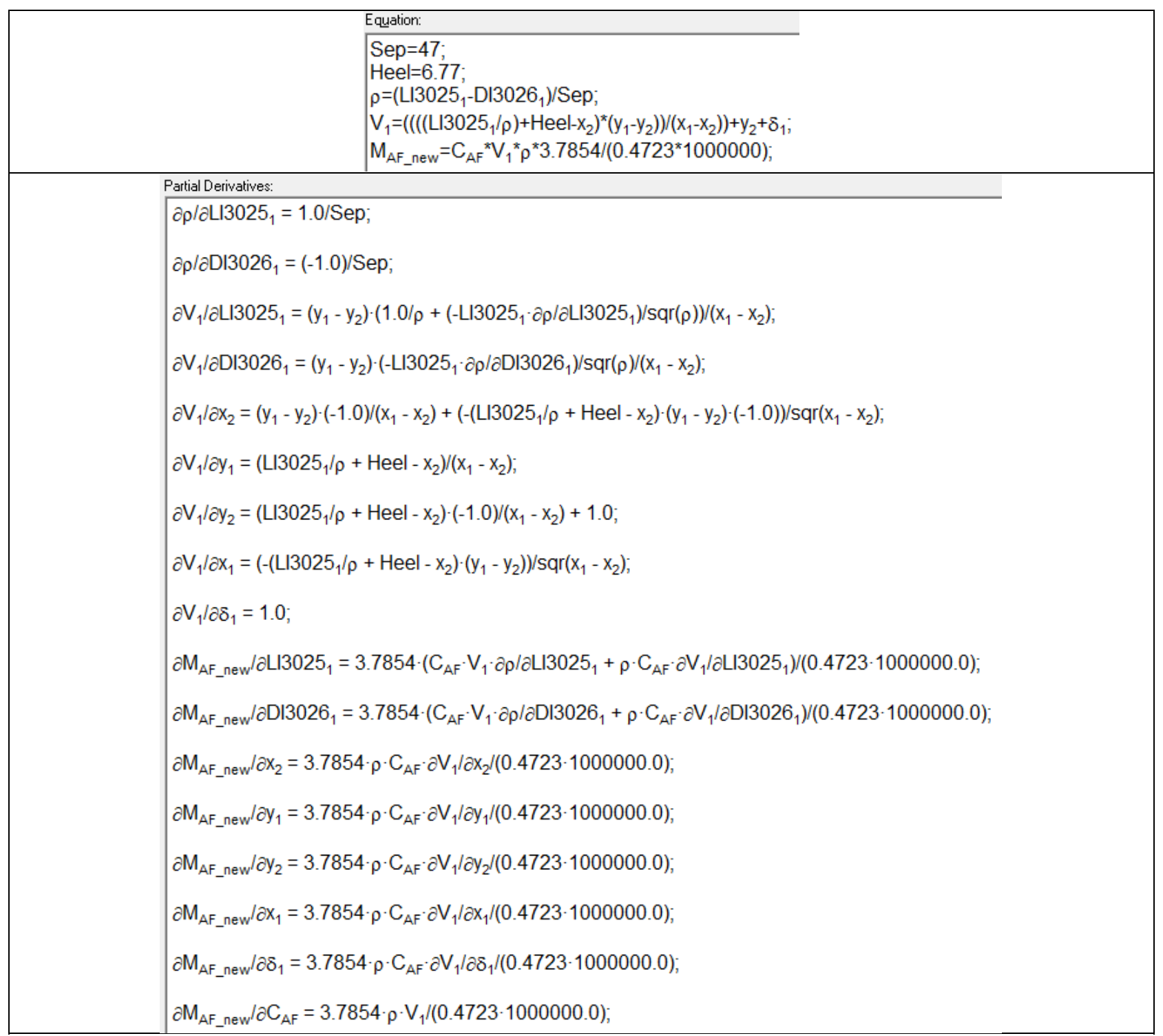

Exhibit 10 Equations for Re-Base-Lining the $\mathbf{M}_{\mathrm{AF}}$ of the SRAT with Random Uncertainty*

\footnotetext{
* In this and in future exhibits that provide the partial derivations associated with a set of GUM Workbench model equations, note that the GUM Workbench software generates the partial derivative for every term that is included in the set of model equations. No effort was made to strip out from the exhibit the partial derivatives for those terms that are considered constants (i.e., terms for which no uncertainties need to be addressed). In this exhibit, the x's and y's are considered constants with no uncertainty.
} 
To complete the updating of the $\mathrm{M}_{\mathrm{AF}}$ status required for Step 1, the bias for $\mathrm{M}_{\mathrm{AF} \text { new }}$ determined by Equation 21 must be estimated. A bound (at 95\% confidence) on the bias of the antifoam mass, $\mathrm{M}_{\mathrm{AF}_{-} \text {new, }}$ is estimated, as above, by appealing to a Taylor Series expansion of the Equation 21 in the fundamental measurements. Once again, note that $\rho$ and $V_{1}$ are intermediary values and the Taylor's Series expansion may be expressed in the fundamental measurements as given by:

\section{Equation 23}

$$
\begin{aligned}
& \left\{\operatorname{bias}\left(M_{A F_{\text {new }}}\right)\right\}^{2} \approx\left(\frac{\partial M_{A F_{\text {new }}}}{\partial C_{A F}}\right)^{2} \times\left\{\operatorname{bias}\left(C_{A F}\right)\right\}^{2}+\left(\frac{\partial M_{A F_{\text {new }}}}{\partial L I 3025_{1}}\right)^{2} \times\{\text { bias }(\text { LI3025 } 12)\}^{2} \\
& +\left(\frac{\partial M_{A F_{n e w}}}{\partial D I 3026_{1}}\right)^{2} \times\left\{\operatorname{bias}\left(D I 3026_{1}\right)\right\}^{2}+\left(\frac{\partial M_{A F_{n e w}}}{\partial S e p}\right)^{2} \times\{\text { bias }(\text { Sep })\}^{2} \\
& +\left(\frac{\partial M_{A F_{\text {new }}}}{\partial H_{\text {eel }}}\right)^{2} \times\{\text { bias }(\text { Heel })\}^{2}+\left(\frac{\partial M_{A F_{\text {new }}}}{\partial \delta_{1}}\right)^{2} \times\left\{b_{1}\right\}^{2}
\end{aligned}
$$

Note that in evaluating Equation 23 , the bias for the $\mathrm{C}_{\mathrm{AF}}$ term, i.e., bias $\left(\mathrm{C}_{\mathrm{AF}}\right)$ term is estimated to be zero and that there are no correlations among the bias terms in this equation. That is, the analytical estimate of the concentration of carbon from AF is unbiased. Also, the $b_{1}$ term is the estimated bias in the volume, $V_{1}$, of Equation 21. GUM Workbench was used to develop the model equation and associated intermediary values supporting the determination of $\mathrm{M}_{\mathrm{AF}_{-} \text {new }}$ for Step 1 (see the upper portion of Exhibit 11) and to document the complete set of partial derivatives needed to support the estimation of the bias of the $\mathrm{M}_{\mathrm{AF}_{-} \text {new }}$ value (see the lower portion of Exhibit 11). Once again, $\mathrm{x}_{1}, \mathrm{x}_{2}, \mathrm{y}_{1}$, and $\mathrm{y}_{2}$ are appropriately selected values (based upon the value of the LI3025 instrument as indicated by LI3025 $)$ for determining volume as indicated in Exhibit 8.To complete the information necessary to compute the estimate of the bias of the $\mathrm{M}_{\mathrm{AF} \text { new }}$, estimates of the bias terms of Equation 23 are needed. Table 8 provides the details of the bias information needed to complete the estimation of the bias for the $\mathrm{M}_{\mathrm{AF} \text { nnw }}$ value. A sample calculation for this step including the random and bias uncertainties is provided in Exhibit B5 in Appendix B.

Table 8 Terms and Estimated Bias Uncertainties Supporting Equation 23

\begin{tabular}{|c|c|c|}
\hline Term/Instrument & Description & Bias Uncertainty at 95\% Confidence \\
\hline $\mathrm{C}_{\mathrm{AF}}$ (see Equation 11) & antifoam carbon concentration (mg/kg) & 0 \\
\hline LI3025 with subscript 1 & level bubbler value (inwc) & $\pm 1 \%$ of 231.6 inwc span [11] \\
\hline & & Bias $=2.316$ inwc \\
\hline DI3026 with subscript 1 & density bubbler value (inwc) & Bias $=1.61$ inwc \\
\hline & & 12 gallons \\
\hline $\mathrm{b}_{1}$ & tank calibration uncertainty \\
\hline Sep & Separation between bubblers (47 inches) & 0.0625 inch [13] \\
\hline Heel & Tank heel below LI3025 (6.77 inches) & 0.0625 inch [13] \\
\hline
\end{tabular}

\footnotetext{
* The bias in the calibration for the SRAT is taken as the largest value from Table 3d. Rounding up this value is 12 gallons.
} 
SRNL-STI-2014-00323

Revision 0

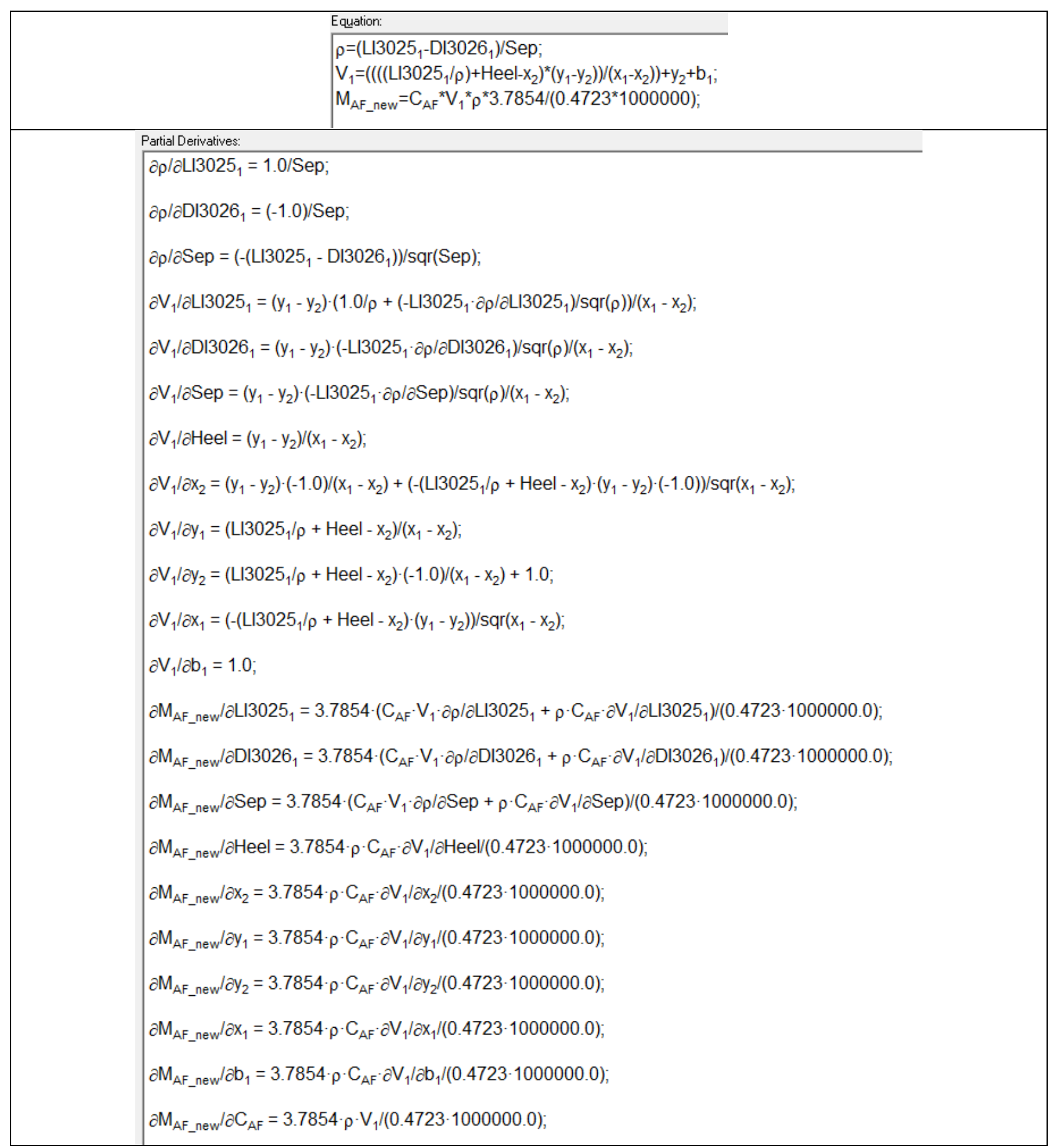

Exhibit 11 Equations for Re-Base-Lining the $\mathrm{M}_{\mathrm{AF}}$ of the SRAT with Bias Uncertainty 
SRNL-STI-2014-00323

Revision 0

\subsubsection{SRAT Step 3 Processing Linked to a Step 1 Event}

Next consider the Step 3 event immediately following a Step 1 re-base lining of the $\mathrm{M}_{\mathrm{AF}}$ information in the SRAT. The equation for the $\mathrm{M}_{\mathrm{AF}_{-} \text {out }}$ is given by:

Equation 24

$$
M_{A F_{\text {out }}}=\frac{3.7854 \cdot C_{A F} \cdot \rho \cdot\left(V_{1}-V_{2}\right)}{0.4723 \cdot 1000000}
$$

Where the density, $\rho$, and the volumes $\mathrm{V}_{1}$ and $\mathrm{V}_{2}$ are intermediary values which are determined from LI3025 and DI3016 as described in Exhibit 8 and Exhibit 9 with the two volumes each having an additional random variability that is to be incorporated to the random uncertainty of $\mathrm{M}_{\mathrm{AF}_{-} \text {out }}$.

Following the Taylor's Series expansion approach described above, the estimated variance of $\mathrm{M}_{\mathrm{AF}_{\mathrm{F}} \text { out }}$ for Step 3 of Exhibit 9 may be written in terms of the fundamental measurements with $\delta_{1}$ and $\delta_{2}$ representing the random errors for $V_{1}$ and $V_{2}$, respectively, as:

Equation 25

$$
\begin{aligned}
\operatorname{Variance}( & \left.M_{A F_{\text {out }}}\right) \approx\left(\frac{\partial M_{A F_{\text {out }}}}{\partial C_{A F}}\right)^{2} \times \operatorname{variance}\left(C_{A F}\right)+\left(\frac{\partial M_{A F_{\text {out }}}}{\partial L I 3025_{1}}\right)^{2} \times \operatorname{variance}\left(L I 3025_{1}\right) \\
& +\left(\frac{\partial M_{A F_{\text {out }}}}{\partial D I 3026_{1}}\right)^{2} \times \operatorname{variance}\left(D I 3026_{1}\right)+\left(\frac{\partial M_{A F_{\text {out }}}}{\partial \delta_{1}}\right)^{2} \times \operatorname{variance}\left(\delta_{1}\right) \\
& +\left(\frac{\partial M_{A F_{\text {out }}}}{\partial L I 3025_{2}}\right)^{2} \times \operatorname{variance}\left(L_{I I 3025_{2}}\right)+\left(\frac{\partial M_{A F_{\text {out }}}}{\partial \delta_{2}}\right)^{2} \times \operatorname{variance}\left(\delta_{2}\right)
\end{aligned}
$$

GUM Workbench was used to develop the model equation and associated intermediary values supporting the determination of $\mathrm{M}_{\mathrm{AF} \text { _out }}$ for Step 3 (see the upper portion of Exhibit 12) and to document the complete set of partial derivatives needed to support the estimation of the variance of the $\mathrm{M}_{\mathrm{AF}_{-} \text {out }}$ value (see the lower portion of Exhibit 12 and Exhibit 13). For example, the $\mathrm{x}_{11}, \mathrm{x}_{12}, \mathrm{y}_{11}$, and $\mathrm{y}_{12}$ values; and the $\mathrm{x}_{21}, \mathrm{x}_{22}$, $\mathrm{y}_{21}$, and $\mathrm{y}_{22}$ values are appropriately selected values (based upon the values of the LI3025 instrument as indicated by LI3025 and LI3025, respectively) for determining volume as indicated in Exhibit 8. To complete the information necessary to compute the estimate of the variance of the $\mathrm{M}_{\mathrm{AF}}$ out, estimates of the variance terms of Equation 25 are needed. These values are provided in Table 9. 
SRNL-STI-2014-00323

Revision 0

Equation:

$\rho=\left(\mathrm{LI} 3025_{1}-\mathrm{Dl} 3026_{1}\right) / \mathrm{Sep}$;

$V_{1}=\left(\left(L / 3025_{1} / \rho+\text { Heel- } \mathrm{x}_{12}\right)^{*}\left(\mathrm{y}_{11}-\mathrm{y}_{12}\right) /\left(\mathrm{x}_{11}-\mathrm{x}_{12}\right)\right)+\mathrm{y}_{12}+\delta_{1}$

$\mathrm{V}_{2}=\left(\left(\mathrm{LI} 3025_{2} / \rho\right)+\mathrm{Heel}-\mathrm{x}_{22}\right)^{*}\left(\mathrm{y}_{21}-\mathrm{y}_{22}\right) /\left(\mathrm{x}_{21}-\mathrm{X}_{22}\right)+\mathrm{y}_{22}+\delta_{2}$

$\mathrm{M}_{\text {AF_out }}=3.7854^{*} \mathrm{C}_{\mathrm{AF}}{ }^{*}\left(\mathrm{~V}_{1}-\mathrm{V}_{2}\right)^{*} \mathrm{\rho} /\left(0.4723^{*} 1000000\right)$;

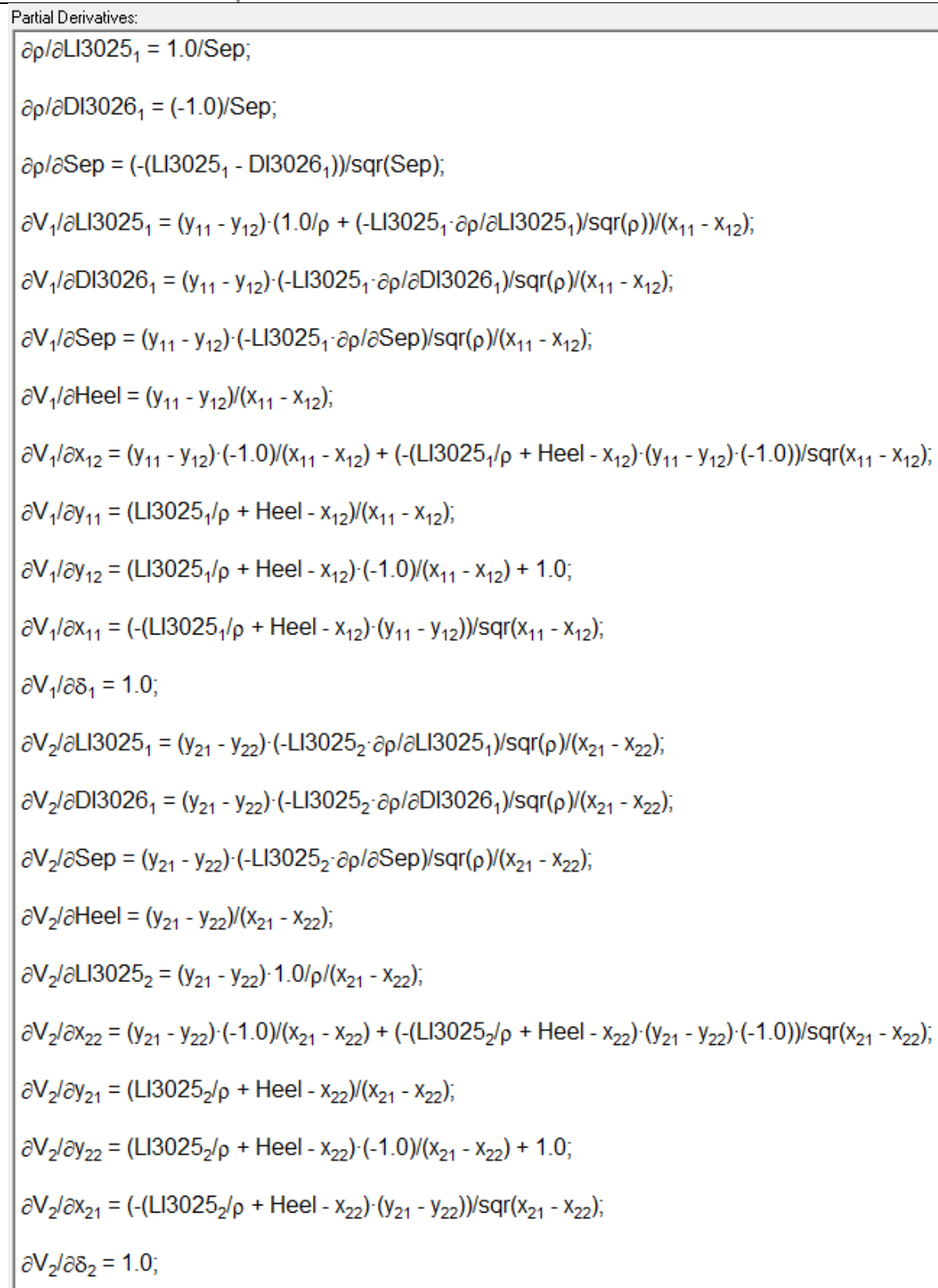

Exhibit 12 Equations for Analytical $\mathrm{M}_{\mathrm{AF}_{-} \text {out }}$ from the SRAT with Random Uncertainty (part 1 of 2) 
SRNL-STI-2014-00323

Revision 0

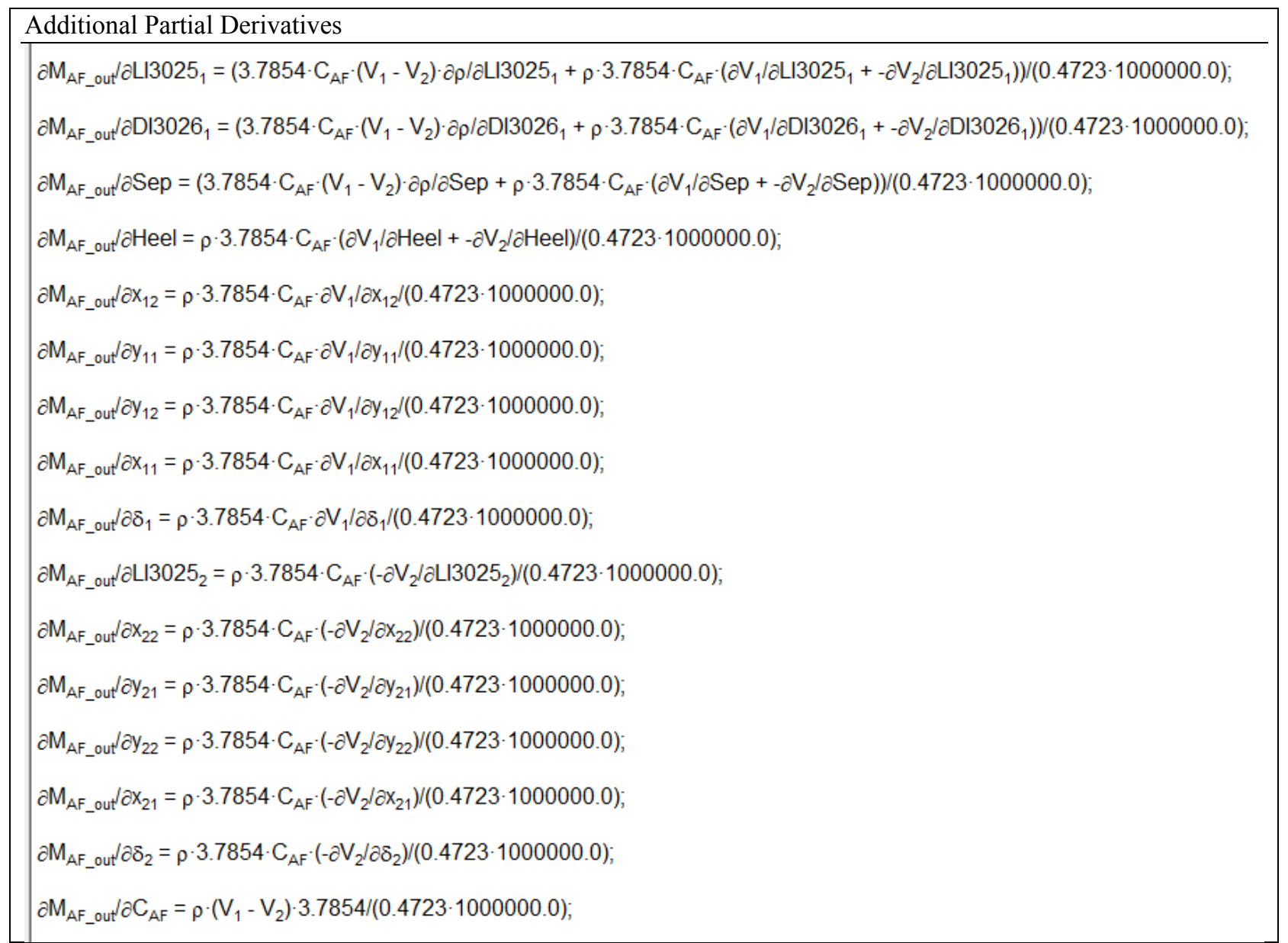

Exhibit 13 Equations for Analytical $\mathrm{M}_{\mathrm{AF}_{\text {_out }}}$ from the SRAT with Random Uncertainty (part 2 of 2)

Table 9 Terms and Estimated Random Uncertainties Supporting Equation 25

\begin{tabular}{|c|c|c|}
\hline Term/Instrument & Description & 1-Sigma Random Uncertainty \\
\hline $\mathrm{C}_{\mathrm{AF}}$ (see Equation 11) & $\begin{array}{l}\text { antifoam carbon concentration } \\
(\mathrm{mg} / \mathrm{kg})\end{array}$ & Analytical uncertainty (see Equation 12) \\
\hline \multirow[t]{3}{*}{ LI3025 with subscript 1} & level bubbler value (inwc) & $\pm 1 \%$ of 231.6 inwe span [11] \\
\hline & DCS Deviation Limit & \pm 0.1 inwc [11] \\
\hline & & $\begin{array}{l}\text { Using a uniform distribution, 1-sigma random is } \\
{\left[(2.316 / \sqrt{3})^{2}+(0.1 / \sqrt{3})^{2}\right]^{0.5}=1.3384 \text { inwc }}\end{array}$ \\
\hline \multirow[t]{3}{*}{ DI3026 with subscript 1} & density bubbler value (inwc) & $\pm 1 \%$ of 161.0 inwc span [12] \\
\hline & DCS deviation limit & \pm 0.05 inwc [12] \\
\hline & & $\begin{array}{l}\text { Using a uniform distribution, 1-sigma random is } \\
{\left[(1.61 / \sqrt{ } 3)^{2}+(0.05 / \sqrt{3})^{2}\right]^{0.5}=0.9300 \text { inwc }}\end{array}$ \\
\hline$\delta_{1}$ & $\begin{array}{l}\text { tank calibration uncertainty } \\
\text { (see footnote for Table 7) }\end{array}$ & 1-sigma random $=9$ gallons \\
\hline$\delta_{2}$ & $\begin{array}{l}\text { tank calibration uncertainty } \\
\text { (see footnote for Table 7) }\end{array}$ & 1-sigma random $=9$ gallons \\
\hline
\end{tabular}


To complete the evaluation of the $\mathrm{M}_{\mathrm{AF}_{-} \text {out }}$ required for Step 3, the bias for $\mathrm{M}_{\mathrm{AF}_{-} \text {out }}$ determined by Equation 24 must be estimated. A bound (at 95\% confidence) on the bias of the antifoam mass transferred out of the SRAT, $\mathrm{M}_{\mathrm{AF}_{-} \text {out }}$ is estimated, as above, by appealing to a Taylor Series expansion of the Equation 24 in the fundamental measurements. Once again, note that $\rho, V_{1}$, and $V_{2}$ are intermediary values. Also, the $V_{1}$ and $V_{2}$ values each have a potential bias that is to be included in the evaluation. The Taylor's Series expansion may be expressed in the fundamental measurements and the potential biases $\left(b_{1}\right.$ for $V_{1}$ and $b_{2}$ for $\mathrm{V}_{2}$ ) of the calculated volumes as given by:

\section{Equation 26}

$$
\begin{aligned}
& \left\{\operatorname{bias}\left(M_{A F_{\text {out }}}\right)\right\}^{2} \approx\left(\frac{\partial M_{A F_{\text {out }}}}{\partial C_{A F}}\right)^{2} \times\left\{\operatorname{bias}\left(C_{A F}\right)\right\}^{2}+\left(\frac{\partial M_{A F_{\text {out }}}}{\partial L I 3025_{1}}\right)^{2} \times\left\{\operatorname{bias}(\text { LI3025 } 12\}^{2}\right. \\
& +\left(\frac{\partial M_{A F_{\text {out }}}}{\partial D I 3026_{1}}\right)^{2} \times\left\{\operatorname{bias}\left(D I 3026_{1}\right)\right\}^{2}+\left(\frac{\partial M_{A F_{o u t}}}{\partial \text { Sep }}\right)^{2} \times\{\text { bias }(\text { Sep })\}^{2} \\
& +\left(\frac{\partial M_{A F_{\text {out }}}}{\partial \text { Heel }}\right)^{2} \times\{\text { bias }(\text { Heel })\}^{2}+\left(\frac{\partial M_{A F_{\text {out }}}}{\partial{\text { LI I } 255_{2}}}\right)^{2} \times\{\text { bias }(\text { LI3025 } 2)\}^{2} \\
& +\left(\frac{\partial M_{A F_{\text {out }}}}{\partial b_{1}}\right)^{2} \times\left\{\operatorname{bias}\left(b_{1}\right)\right\}^{2}+\left(\frac{\partial M_{A F_{\text {out }}}}{\partial b_{2}}\right)^{2} \times\left\{\operatorname{bias}\left(b_{2}\right)\right\}^{2} \\
& +2 \times 1 \times\left|\frac{\partial M_{A F_{o u t}}}{\partial L I 3025_{1}}\right| \times\left|\frac{\partial M_{A F_{\text {out }}}}{\partial L I 3025_{2}}\right| \times \operatorname{bias}\left(L I 3025_{1}\right) \times \operatorname{bias}\left(L I 3025_{2}\right) \\
& +2 \times 1 \times\left|\frac{\partial M_{A F_{\text {out }}}}{\partial b_{1}}\right| \times\left|\frac{\partial M_{A F_{\text {out }}}}{\partial b_{2}}\right| \times \operatorname{bias}\left(b_{1}\right) \times \operatorname{bias}\left(b_{2}\right)
\end{aligned}
$$

Note that in evaluating Equation 26, the bias for the $\mathrm{C}_{\mathrm{AF}}$ term, i.e., bias $\left(\mathrm{C}_{\mathrm{AF}}\right)$ term is estimated to be zero and that two potential correlations among the biases are introduced in a bounding manner. So the approach may be stated as: The analytical estimate of the concentration of carbon from AF is unbiased and the $b_{1}$ and $b_{2}$ terms are the estimated biases in the volumes $V_{1}$ and $V_{2}$, respectively, of Equation 24 . GUM Workbench was used to develop the model equation and associated intermediary values supporting the determination of the bias of $\mathrm{M}_{\mathrm{AF} \text { out }}$ for Step 3 (see the upper portion of Exhibit 14) and to document the complete set of partial derivatives needed to support the estimation of the bias of the $\mathrm{M}_{\mathrm{AF}_{-} \text {out }}$ value (see the lower portion of Exhibit 14 and Exhibit 15). Once again, the $\mathrm{x}_{11}, \mathrm{x}_{12}, \mathrm{y}_{11}$, and $\mathrm{y}_{12}$ values and the $\mathrm{x}_{21}, \mathrm{x}_{22}, \mathrm{y}_{21}$, and $\mathrm{y}_{22}$ values are appropriately selected values (based upon the value of the LI3025 instrument as indicated by LI3025 1 and LI3025 ) for determining volumes as indicated in Exhibit 8.To complete the information necessary to compute the estimate of the bias of the $\mathrm{M}_{\mathrm{AF} \text { _out }}$, estimates of the bias terms of Equation 26 are needed. Table 10 provides the details of the bias information needed to complete the estimation of the bias for the $\mathrm{M}_{\mathrm{AF}_{-} \text {out }}$ value. A sample calculation for this step including the random and bias uncertainties is provided in Exhibit B6 in Appendix B. 
SRNL-STI-2014-00323

Revision 0

Equation:
\begin{tabular}{|l}
$\rho=\left(\right.$ LI $3025_{1}-$ DI $\left.3026_{1}\right) /$ Sep; \\
$V_{1}=\left(\left(\text { LI3025 } / \rho+\text { Heel- } x_{12}\right)^{*}\left(y_{11}-y_{12}\right) /\left(x_{11}-x_{12}\right)\right)+y_{12}+b_{1}$ \\
$V_{2}=\left(\left(L I 3025_{2} / \rho\right)+\text { Heel- }-x_{22}\right)^{*}\left(y_{21}-y_{22}\right) /\left(x_{21}-x_{22}\right)+y_{22}+b_{2} ;$ \\
$M_{\text {AF_out }}=3.7854^{*} C_{\text {AF }}^{*}\left(V_{1}-V_{2}\right)^{*} \rho /\left(0.4723^{*} 1000000\right) ;$
\end{tabular}

Partial Derivatives:

$\partial \rho / \partial \mathrm{LI}_{3025_{1}}=1.0 / \mathrm{Sep} ;$

$\partial \rho / \partial \mathrm{DI} 3026_{1}=(-1.0) / \mathrm{Sep} ;$

$\partial \rho / \partial \operatorname{Sep}=\left(-\left(\mathrm{LI} 3025_{1}-\mathrm{DI} 3026_{1}\right)\right) /$ sqr(Sep)

$\partial \mathrm{V}_{1} / \partial \mathrm{LI} 3025_{1}=\left(\mathrm{y}_{11}-\mathrm{y}_{12}\right) \cdot\left(1.0 / \rho+\left(-\mathrm{LI} 3025_{1} \cdot \partial \rho / \partial \mathrm{LI} 3025_{1}\right) / \mathrm{sqr}(\rho)\right) /\left(\mathrm{x}_{11}-\mathrm{x}_{12}\right) ;$

$\partial \mathrm{V}_{1} / \partial \mathrm{DI} 3026_{1}=\left(\mathrm{y}_{11}-\mathrm{y}_{12}\right) \cdot\left(-\mathrm{LI} 3025_{1} \cdot \partial \rho / \partial \mathrm{DI} 3026_{1}\right) / \operatorname{sqr}(\rho) /\left(\mathrm{x}_{11}-\mathrm{x}_{12}\right) ;$

$\partial \mathrm{V}_{1} / \partial \operatorname{Sep}=\left(\mathrm{y}_{11}-\mathrm{y}_{12}\right) \cdot\left(-\mathrm{LI} 3025_{1} \cdot \partial \rho / \partial \operatorname{Sep}\right) / \operatorname{sqr}(\rho) /\left(\mathrm{x}_{11}-\mathrm{x}_{12}\right)$

$\partial \mathrm{V}_{1} / \partial$ Heel $=\left(\mathrm{y}_{11}-\mathrm{y}_{12}\right) /\left(\mathrm{x}_{11}-\mathrm{x}_{12}\right)$;

$\partial \mathrm{V}_{1} / \partial \mathrm{x}_{12}=\left(\mathrm{y}_{11}-\mathrm{y}_{12}\right) \cdot(-1.0) /\left(\mathrm{x}_{11}-\mathrm{x}_{12}\right)+\left(-\left(\mathrm{LI} 3025_{1} / \rho+\right.\right.$ Heel $\left.\left.-\mathrm{x}_{12}\right) \cdot\left(\mathrm{y}_{11}-\mathrm{y}_{12}\right) \cdot(-1.0)\right) / \mathrm{sqr}\left(\mathrm{x}_{11}-\mathrm{x}_{12}\right)$

$\partial \mathrm{V}_{1} / \partial \mathrm{y}_{11}=\left(\mathrm{LI} 3025_{1} / \rho+\right.$ Heel $\left.-\mathrm{x}_{12}\right) /\left(\mathrm{x}_{11}-\mathrm{X}_{12}\right)$

$\partial \mathrm{V}_{1} / \partial \mathrm{y}_{12}=\left(\mathrm{LI} 3025_{1} / \rho+\right.$ Heel $\left.-\mathrm{x}_{12}\right) \cdot(-1.0) /\left(\mathrm{x}_{11}-\mathrm{x}_{12}\right)+1.0$

$\partial \mathrm{V}_{1} / \partial \mathrm{x}_{11}=\left(-\left(\mathrm{LI} 3025_{1} / \rho+\right.\right.$ Heel $\left.\left.-\mathrm{x}_{12}\right) \cdot\left(\mathrm{y}_{11}-\mathrm{y}_{12}\right)\right) / \operatorname{sqr}\left(\mathrm{x}_{11}-\mathrm{x}_{12}\right)$

$\partial \mathrm{V}_{1} / \partial \mathrm{b}_{1}=1.0$

$\partial \mathrm{V}_{2} / \partial \mathrm{LI} 3025_{1}=\left(\mathrm{y}_{21}-\mathrm{y}_{22}\right) \cdot\left(-\mathrm{LI} 3025_{2} \cdot \partial \rho / \partial \mathrm{LI} 3025_{1}\right) / \operatorname{sqr}(\rho) /\left(\mathrm{x}_{21}-\mathrm{x}_{22}\right) ;$

$\partial \mathrm{V}_{2} / \partial \mathrm{DI} 3026_{1}=\left(\mathrm{y}_{21}-\mathrm{y}_{22}\right) \cdot\left(-\mathrm{LI} 3025_{2} \cdot \partial \rho / \partial \mathrm{DI} 3026_{1}\right) / \operatorname{sqr}(\rho) /\left(\mathrm{x}_{21}-\mathrm{x}_{22}\right) ;$

$\partial \mathrm{V}_{2} / \partial \operatorname{Sep}=\left(\mathrm{y}_{21}-\mathrm{y}_{22}\right) \cdot(-$ LI3025 $2 \cdot \partial \rho / \partial \operatorname{Sep}) / \operatorname{sqr}(\rho) /\left(\mathrm{x}_{21}-\mathrm{x}_{22}\right) ;$

$\partial \mathrm{V}_{2} / \partial$ Heel $=\left(\mathrm{y}_{21}-\mathrm{y}_{22}\right) /\left(\mathrm{x}_{21}-\mathrm{x}_{22}\right)$;

$\partial \mathrm{V}_{2} / \partial \mathrm{LI} 3025_{2}=\left(\mathrm{y}_{21}-\mathrm{y}_{22}\right) \cdot 1.0 / \rho /\left(\mathrm{x}_{21}-\mathrm{x}_{22}\right) ;$

$\partial \mathrm{V}_{2} / \partial \mathrm{x}_{22}=\left(\mathrm{y}_{21}-\mathrm{y}_{22}\right) \cdot(-1.0) /\left(\mathrm{x}_{21}-\mathrm{X}_{22}\right)+\left(-\left(\mathrm{LI} 3025_{2} / \rho+\right.\right.$ Heel $\left.\left.-\mathrm{x}_{22}\right) \cdot\left(\mathrm{y}_{21}-\mathrm{y}_{22}\right) \cdot(-1.0)\right) / \mathrm{sqr}\left(\mathrm{x}_{21}-\mathrm{X}_{22}\right) ;$

$\partial \mathrm{V}_{2} / \partial \mathrm{y}_{21}=\left(\mathrm{LI} 3025_{2} / \rho+\right.$ Heel $\left.-\mathrm{x}_{22}\right) /\left(\mathrm{x}_{21}-\mathrm{x}_{22}\right)$

$\partial \mathrm{V}_{2} / \partial \mathrm{y}_{22}=\left(\mathrm{LI} 3025_{2} / \rho+\right.$ Heel $\left.-\mathrm{X}_{22}\right) \cdot(-1.0) /\left(\mathrm{x}_{21}-\mathrm{X}_{22}\right)+1.0$;

$\partial \mathrm{V}_{2} / \partial \mathrm{x}_{21}=\left(-\left(\mathrm{LI} 3025_{2} / \rho+\right.\right.$ Heel $\left.\left.-\mathrm{x}_{22}\right) \cdot\left(\mathrm{y}_{21}-\mathrm{y}_{22}\right)\right) / \operatorname{sqr}\left(\mathrm{x}_{21}-\mathrm{x}_{22}\right) ;$

$\partial \mathrm{V}_{2} / \partial \mathrm{b}_{2}=1.0$;

Exhibit 14 Equations for Analytical $\mathrm{M}_{\mathrm{AF} \_ \text {out }}$ from the SRAT with Bias Uncertainty (part 1 of 2) 


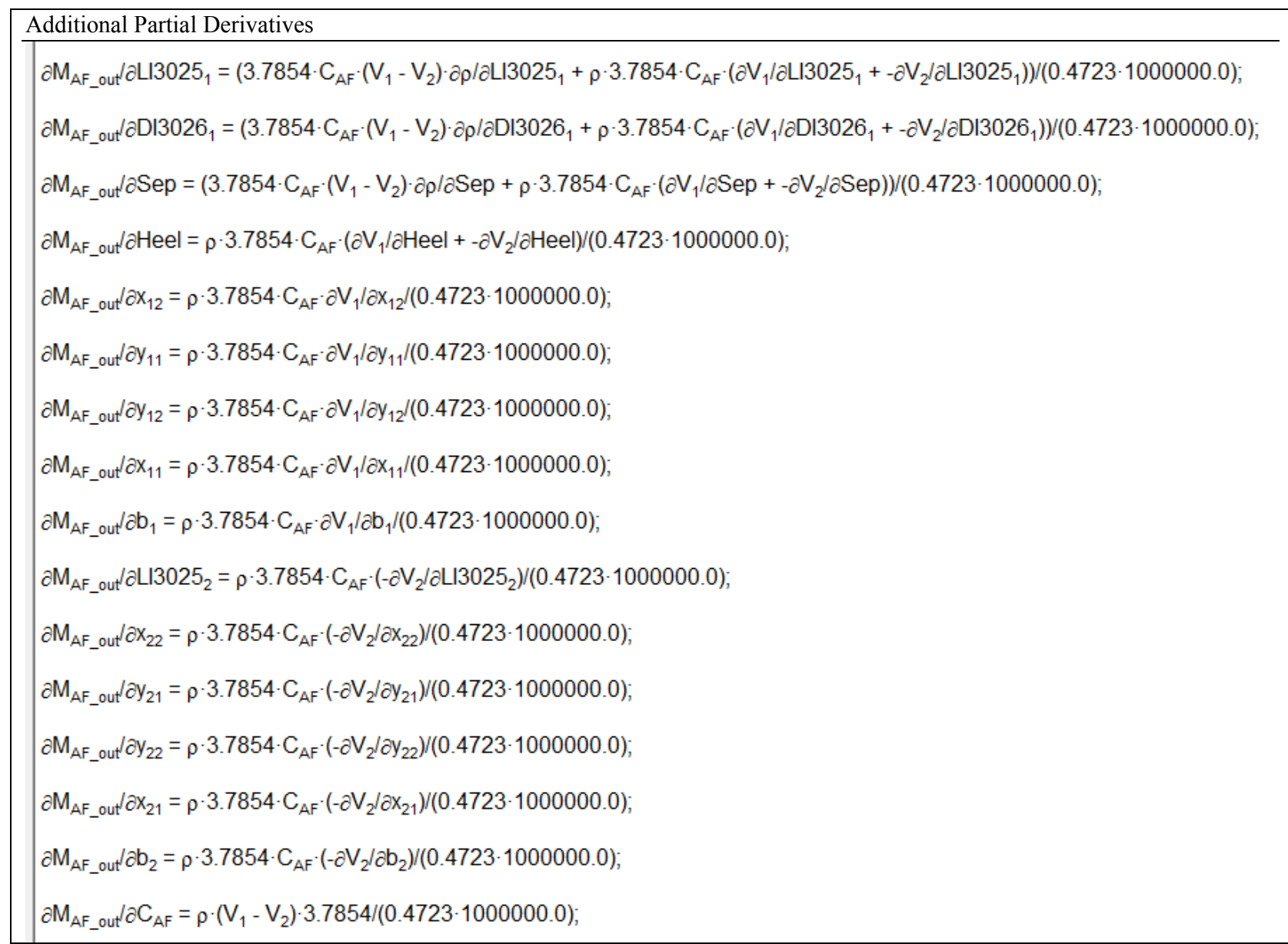

Exhibit 15 Equations for Analytical $\mathrm{M}_{\mathrm{AF}_{-} \text {out }}$ from the SRAT with Bias Uncertainty (part 2 of 2)

Table 10 Terms and Estimated Bias Uncertainties Supporting Equation 26

\begin{tabular}{|c|c|c|}
\hline Term/Instrument & Description & Bias Uncertainty at $95 \%$ Confidence \\
\hline $\mathrm{C}_{\mathrm{AF}}$ (see Equation 11) & antifoam carbon concentration $(\mathrm{mg} / \mathrm{kg})$ & 0 \\
\hline \multirow[t]{2}{*}{$\begin{array}{c}\text { LI3025 } \\
\text { with subscripts } 1 \text { and } 2 \\
\end{array}$} & level bubbler values (inwc) & $\pm 1 \%$ of 231.6 inwc span [11] \\
\hline & & Bias $=2.316$ inwc \\
\hline \multirow[t]{2}{*}{ DI3026 with subscript 1} & density bubbler value (inwc) & $\pm 1 \%$ of 161.0 inwc span [12] \\
\hline & & Bias $=1.61$ inwc \\
\hline $\mathrm{b}_{1}$ & $\begin{array}{l}\text { tank calibration uncertainty } \\
\text { (see footnote for Table } 8 \text { ) }\end{array}$ & 12 gallons \\
\hline$b_{2}$ & $\begin{array}{l}\text { tank calibration uncertainty } \\
\text { (see footnote for Table } 8 \text { ) }\end{array}$ & 12 gallons \\
\hline Sep & $\begin{array}{l}\text { separation between bubblers } \\
\text { (47 inch) }\end{array}$ & 0.0625 inch [13] \\
\hline Heel & $\begin{array}{c}\text { tank heel below LI3025 } \\
\text { (6.77 inch) }\end{array}$ & 0.0625 inch [13] \\
\hline
\end{tabular}


SRNL-STI-2014-00323

Revision 0

\subsubsection{SRAT Step 4 Processing Linked to a Step 1 Event}

Next consider the Step 4 event immediately following a Step 1 re-base lining of the $\mathrm{M}_{\mathrm{AF}}$ information in the SRAT. The equation for the $\mathrm{M}_{\mathrm{AF}_{-} \text {new }}$ for step 4 is given by:

Equation 27

$$
M_{A F_{\text {new }}}=\frac{3.7854 \cdot C_{A F} \cdot \rho \cdot V_{2}}{0.4723 \cdot 1000000}
$$

where the density, $\rho$, and the volume $\mathrm{V}_{2}$ are intermediary values which are determined from LI3025 and DI3016 as described in Exhibit 8 and Exhibit 9 with the volume having an additional random variability that is to be incorporated to the random uncertainty of $\mathrm{M}_{\mathrm{AF} \text { nnw }}$.

Following the Taylor's Series expansion approach described above, the estimated variance of $\mathrm{M}_{\mathrm{AF}_{-} \text {new }}$ for Step 4 of Exhibit 9 may be written in terms of the fundamental measurements with $\delta_{2}$ representing the random error for $\mathrm{V}_{2}$ as:

Equation 28

$$
\begin{gathered}
\operatorname{Variance}\left(M_{A F_{n e w}}\right) \approx\left(\frac{\partial M_{A F_{n e w}}}{\partial C_{A F}}\right)^{2} \times \operatorname{variance}\left(C_{A F}\right)+\left(\frac{\partial M_{A F_{n e w}}}{\partial L I 3025_{1}}\right)^{2} \times \operatorname{variance}\left(L I 3025_{1}\right) \\
+\left(\frac{\partial M_{A F_{n e w}}}{\partial D I 3026_{1}}\right)^{2} \times \operatorname{variance}\left(D I 3026_{1}\right)++\left(\frac{\partial M_{A F_{n e w}}}{\partial L I 3025_{2}}\right)^{2} \times \operatorname{variance}\left(L I 3025_{2}\right) \\
+\left(\frac{\partial M_{A F_{n e w}}}{\partial \delta_{2}}\right)^{2} \times \operatorname{variance}\left(\delta_{2}\right)
\end{gathered}
$$

GUM Workbench was used to develop the model equation and associated intermediary values supporting the determination of $\mathrm{M}_{\mathrm{AF}_{-} \text {new }}$ for Step 4 (see the upper portion of Exhibit 16) and to document the complete set of partial derivatives needed to support the estimation of the variance of the $\mathrm{M}_{\mathrm{AF}_{-} \text {new }}$ value (see the lower portion of Exhibit 16 and Exhibit 17). For example, the $\mathrm{x}_{21}, \mathrm{x}_{22}, \mathrm{y}_{21}$, and $\mathrm{y}_{22}$ values are appropriately selected values (based upon the values of the LI3025 instrument as indicated by LI3025 ) for determining volume as indicated in Exhibit 8.To complete the information necessary to compute the estimate of the variance of the $\mathrm{M}_{\mathrm{AF}_{-} \text {new }}$, estimates of the variance terms of Equation 28 are needed. These values are provided in Table 11. 
SRNL-STI-2014-00323

Revision 0

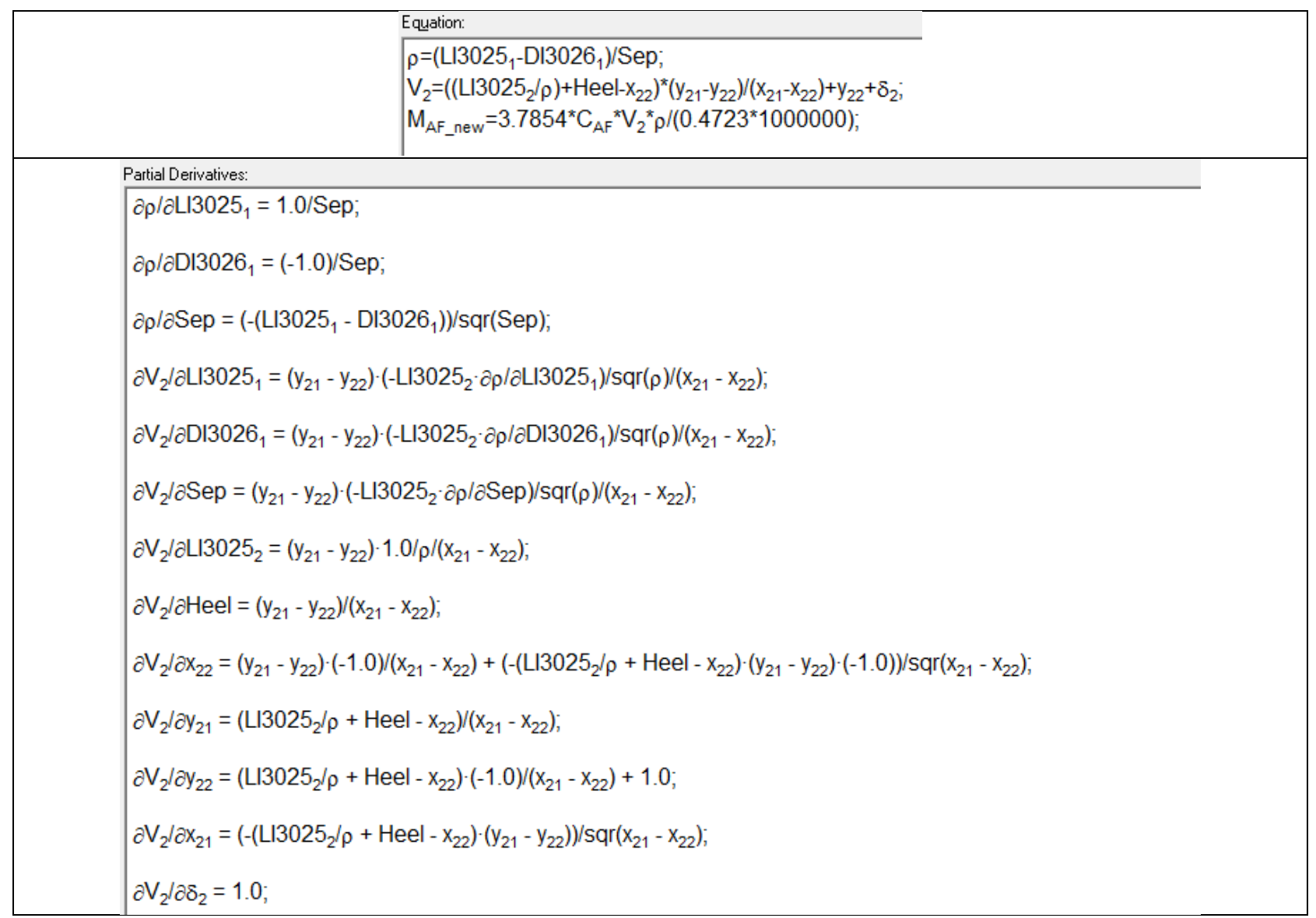

Exhibit 16 Equations for Analytical $\mathrm{M}_{\mathrm{AF} \_ \text {new }}$ for the SRAT Heel with Random Uncertainty (part 1 of 2) 
SRNL-STI-2014-00323

Revision 0

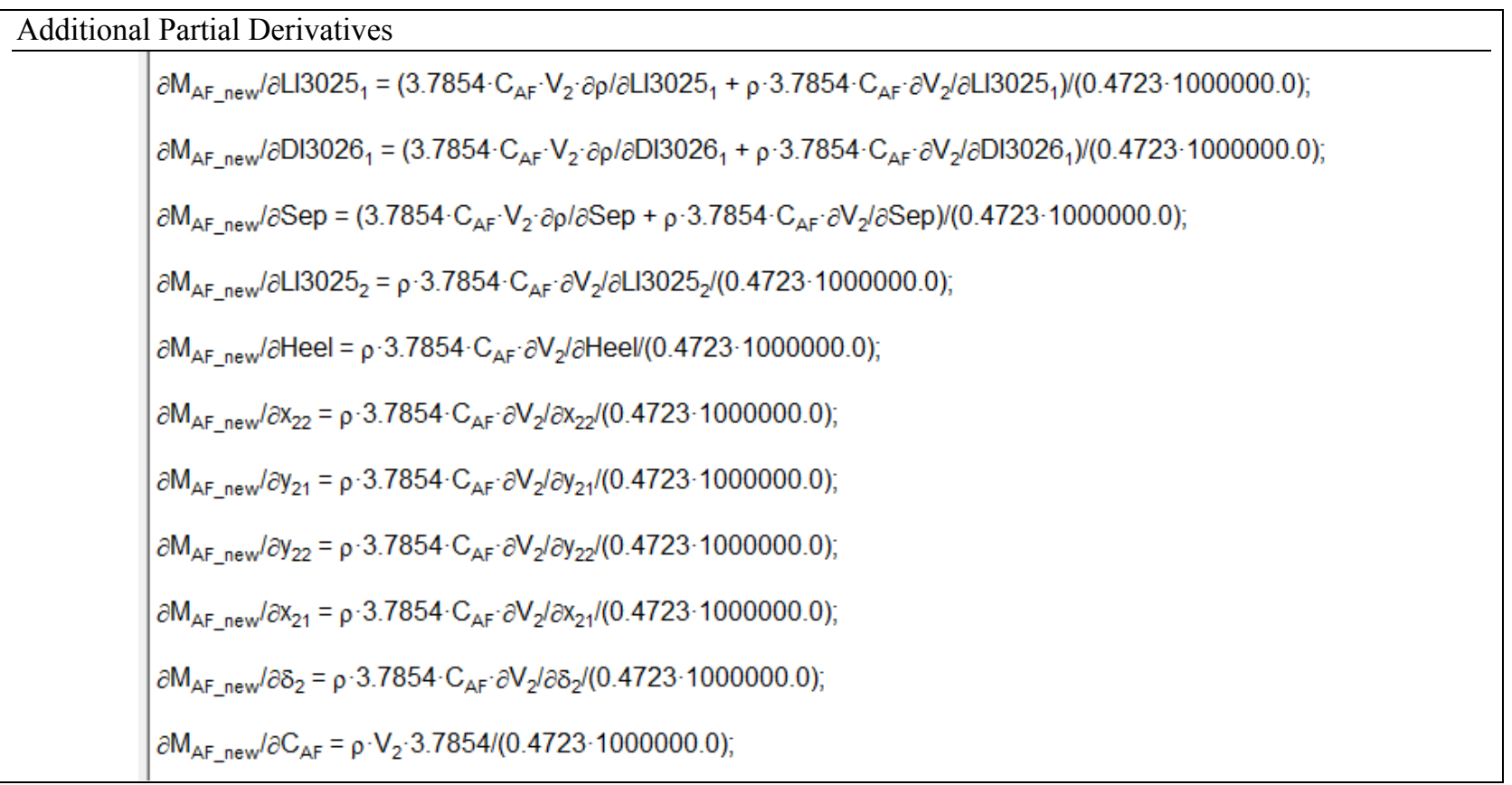

Exhibit 17 Equations for Analytical $\mathrm{M}_{\mathrm{AF} \_ \text {new }}$ for the SRAT Heel with Random Uncertainty (part 2 of 2)

Table 11 Terms and Estimated Random Uncertainties Supporting Equation 28

\begin{tabular}{|c|c|c|}
\hline Term/Instrument & Description & 1-Sigma Random Uncertainty \\
\hline $\mathrm{C}_{\mathrm{AF}}$ (see Equation 11) & $\begin{array}{c}\text { antifoam carbon concentration } \\
(\mathrm{mg} / \mathrm{kg})\end{array}$ & Analytical uncertainty (see Equation 12) \\
\hline $\begin{array}{c}\text { LI3025 } \\
\text { with subscripts 1 and 2 }\end{array}$ & level bubbler values (inwc) & $\pm 1 \%$ of 231.6 inwc span $[11]$ \\
\hline & DCS deviation limit & \pm 0.1 inwc [11] \\
\hline & density bubbler value (inwc) & $\begin{array}{c}\text { Using a uniform distribution, } 1 \text {-sigma random is } \\
{\left[(2.316 / \sqrt{3})^{2}+(0.1 / \sqrt{3})^{2}\right]^{0.5}=1.3384 \text { inwc }}\end{array}$ \\
\hline DI3026 with subscript 1 & DCS deviation limit & $\pm 1 \%$ of 161.0 inwc span $[12]$ \\
\hline & & $\begin{array}{c}\text { Using a uniform distribution, } 1 \text {-sigma random is } \\
{\left[(1.61 / \sqrt{3})^{2}+(0.05 / \sqrt{3})^{2}\right]^{0.5}=0.9300 \text { inwc }}\end{array}$ \\
\hline$\delta_{2}$ & $\begin{array}{c}\text { tank calibration uncertainty } \\
\text { (see footnote for Table } 7)\end{array}$ & $1-\operatorname{sigma}$ random $=9$ gallons \\
\hline
\end{tabular}

To complete the evaluation of the $\mathrm{M}_{\mathrm{AF} \text { new }}$ required for Step 4, the bias for $\mathrm{M}_{\mathrm{AF}_{-} \text {new }}$ determined by Equation 27 must be estimated. A bound (at 95\% confidence) on the bias of the antifoam mass remaining in the heel of the SRAT, $\mathrm{M}_{\mathrm{AF}_{-} \text {new }}$, is estimated, as above, by appealing to a Taylor Series expansion of the Equation 27 in the fundamental measurements. Once again, note that $\rho$ and $V_{2}$ are intermediary values. Also, note that the $V_{2}$ value has a potential bias that is to be included in the evaluation. The Taylor's Series expansion may be expressed in the fundamental measurements and the potential bias of the calculated volume as given by: 
SRNL-STI-2014-00323

Revision 0

Equation 29

$$
\begin{aligned}
& \left\{\operatorname{bias}\left(M_{A F_{n e w}}\right)\right\}^{2} \approx\left(\frac{\partial M_{A F_{n e w}}}{\partial C_{A F}}\right)^{2} \times\left\{\operatorname{bias}\left(C_{A F}\right)\right\}^{2}+\left(\frac{\partial M_{A F_{n e w}}}{\partial L I 3025_{1}}\right)^{2} \times\left\{\operatorname{bias}\left(L I 3025_{1}\right)\right\}^{2} \\
& +\left(\frac{\partial M_{A F_{n e w}}}{\partial D I 3026_{1}}\right)^{2} \times\left\{\operatorname{bias}\left(D I 3026_{1}\right)\right\}^{2}+\left(\frac{\partial M_{A F_{n e w}}}{\partial S e p}\right)^{2} \times\{\operatorname{bias}(\operatorname{Sep})\}^{2} \\
& +\left(\frac{\partial M_{A F_{\text {new }}}}{\partial H_{\text {eel }}}\right)^{2} \times\{\text { bias }(\text { Heel })\}^{2}+\left(\frac{\partial M_{A F_{\text {new }}}}{\partial L I 3025_{2}}\right)^{2} \times\left\{\text { bias }\left(L I 3025_{2}\right)\right\}^{2} \\
& +\left(\frac{\partial M_{A F_{n e w}}}{\partial b_{2}}\right)^{2} \times\left\{\operatorname{bias}\left(b_{2}\right)\right\}^{2} \\
& +2 \times 1 \times\left|\frac{\partial M_{A F_{n e w}}}{\partial L I 3025_{1}}\right| \times\left|\frac{\partial M_{A F_{n e w}}}{\partial L I 3025_{2}}\right| \times \operatorname{bias}\left(L I 3025_{1}\right) \times \operatorname{bias}\left(L I 3025_{2}\right)
\end{aligned}
$$

Note that in evaluating Equation 29, the bias for the $\mathrm{C}_{\mathrm{AF}}$ term, i.e., bias $\left(\mathrm{C}_{\mathrm{AF}}\right)$ term is estimated to be zero and that a potential correlation among the biases for LI3025 values is introduced in a bounding manner. So the approach may be stated as: The analytical estimate of the concentration of carbon from AF is unbiased and the $b_{2}$ term is the estimated bias in the volume $V_{2}$ of Equation 27. GUM Workbench was used to develop the model equation and associated intermediary values supporting the determination of the bias of $\mathrm{M}_{\mathrm{AF} \text { new }}$ for Step 4 (see the upper portion of Exhibit 18) and to document the complete set of partial derivatives needed to support the estimation of the bias of the $\mathrm{M}_{\mathrm{AF}_{-} \text {new }}$ value (see the lower portion of Exhibit 18 and Exhibit 19). Once again, $\mathrm{x}_{21}, \mathrm{x}_{22}, \mathrm{y}_{121}$, and $\mathrm{y}_{22}$ are appropriately selected values (based upon the value of the LI3025 instrument as indicated by LI30252) for determining volume as indicated in Exhibit 8.To complete the information necessary to compute the estimate of the bias of the $\mathrm{M}_{\mathrm{AF}_{-} \text {new }}$, estimates of the bias terms of Equation 29 are needed. Table 12 provides the details of the bias information needed to complete the estimation of the bias for the $\mathrm{M}_{\mathrm{AF} \text { new }}$ value. A sample calculation for this step including the random and bias uncertainties is provided in Exhibit B7 in Appendix B. 
SRNL-STI-2014-00323

Revision 0

Equation:

$\rho=\left(\mathrm{LI} 3025_{1}-\mathrm{Dl} 3026_{1}\right) / \mathrm{Sep}$;

$\mathrm{V}_{2}=\left(\left(\mathrm{LI} 3025_{2} / \rho\right)+\text { Heel- } \mathrm{x}_{22}\right)^{*}\left(\mathrm{y}_{21}-\mathrm{y}_{22}\right) /\left(\mathrm{x}_{21}-\mathrm{x}_{22}\right)+\mathrm{y}_{22}+\mathrm{b}_{2}$;

$\mathrm{M}_{\mathrm{AF}_{\mathrm{B}} \text { new }}=3.7854^{*} \mathrm{C}_{\mathrm{AF}}{ }^{*} \mathrm{~V}_{2}{ }^{*} \rho /\left(0.4723^{*} 1000000\right)$;

Partial Derivatives:

$\partial \rho / \partial \mathrm{LI} 3025_{1}=1.0 /$ Sep;

$\partial \rho / \partial \mathrm{DI} 3026_{1}=(-1.0) / \mathrm{Sep} ;$

$\partial \rho / \partial \operatorname{Sep}=\left(-\left(\mathrm{LI}_{3025_{1}}-\mathrm{DI} 3026_{1}\right)\right) / \mathrm{sqr}(\mathrm{Sep}) ;$

$\partial \mathrm{V}_{2} / \partial \mathrm{LI} 3025_{1}=\left(\mathrm{y}_{21}-\mathrm{y}_{22}\right) \cdot\left(-\mathrm{LI} 3025_{2} \cdot \partial \rho / \partial \mathrm{LI} 3025_{1}\right) / \operatorname{sqr}(\rho) /\left(\mathrm{x}_{21}-\mathrm{x}_{22}\right) ;$

$\partial \mathrm{V}_{2} / \partial \mathrm{DI} 3026_{1}=\left(\mathrm{y}_{21}-\mathrm{y}_{22}\right) \cdot\left(-\mathrm{LI} 3025_{2} \cdot \partial \rho / \partial \mathrm{DI} 3026_{1}\right) / \mathrm{sqr}(\rho) /\left(\mathrm{x}_{21}-\mathrm{x}_{22}\right)$;

$\partial \mathrm{V}_{2} / \partial \operatorname{Sep}=\left(\mathrm{y}_{21}-\mathrm{y}_{22}\right) \cdot\left(-\mathrm{LI} 3025_{2} \cdot \partial \rho / \partial \operatorname{Sep}\right) / \operatorname{sqr}(\rho) /\left(\mathrm{x}_{21}-\mathrm{x}_{22}\right) ;$

$\partial \mathrm{V}_{2} / \partial \mathrm{LI} 3025_{2}=\left(\mathrm{y}_{21}-\mathrm{y}_{22}\right) \cdot 1.0 / \rho /\left(\mathrm{x}_{21}-\mathrm{x}_{22}\right) ;$

$\partial \mathrm{V}_{2} / \partial \mathrm{Heel}=\left(\mathrm{y}_{21}-\mathrm{y}_{22}\right) /\left(\mathrm{x}_{21}-\mathrm{x}_{22}\right)$

$\partial \mathrm{V}_{2} / \partial \mathrm{x}_{22}=\left(\mathrm{y}_{21}-\mathrm{y}_{22}\right) \cdot(-1.0) /\left(\mathrm{x}_{21}-\mathrm{x}_{22}\right)+\left(-\left(\mathrm{LI} 3025_{2} / \mathrm{\rho}+\right.\right.$ Heel $\left.\left.-\mathrm{x}_{22}\right) \cdot\left(\mathrm{y}_{21}-\mathrm{y}_{22}\right) \cdot(-1.0)\right) / \operatorname{sqr}\left(\mathrm{x}_{21}-\mathrm{x}_{22}\right)$;

$\partial \mathrm{V}_{2} / \partial \mathrm{y}_{21}=\left(\mathrm{LI} 3025_{2} / \rho+\right.$ Heel $\left.-\mathrm{X}_{22}\right) /\left(\mathrm{x}_{21}-\mathrm{X}_{22}\right) ;$

$\partial \mathrm{V}_{2} / \partial \mathrm{y}_{22}=\left(\mathrm{LI} 3025_{2} / \rho+\right.$ Heel $\left.-\mathrm{x}_{22}\right) \cdot(-1.0) /\left(\mathrm{x}_{21}-\mathrm{X}_{22}\right)+1.0$

$\partial \mathrm{V}_{2} / \partial \mathrm{x}_{21}=\left(-\left(\mathrm{LI} 3025_{2} / \rho+\right.\right.$ Heel $\left.\left.-\mathrm{x}_{22}\right) \cdot\left(\mathrm{y}_{21}-\mathrm{y}_{22}\right)\right) / \operatorname{sqr}\left(\mathrm{x}_{21}-\mathrm{x}_{22}\right) ;$

$\partial \mathrm{V}_{2} / \partial \mathrm{b}_{2}=1.0$

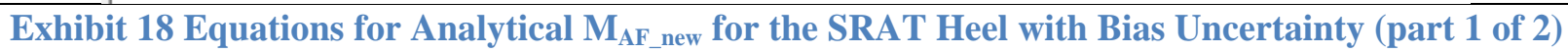




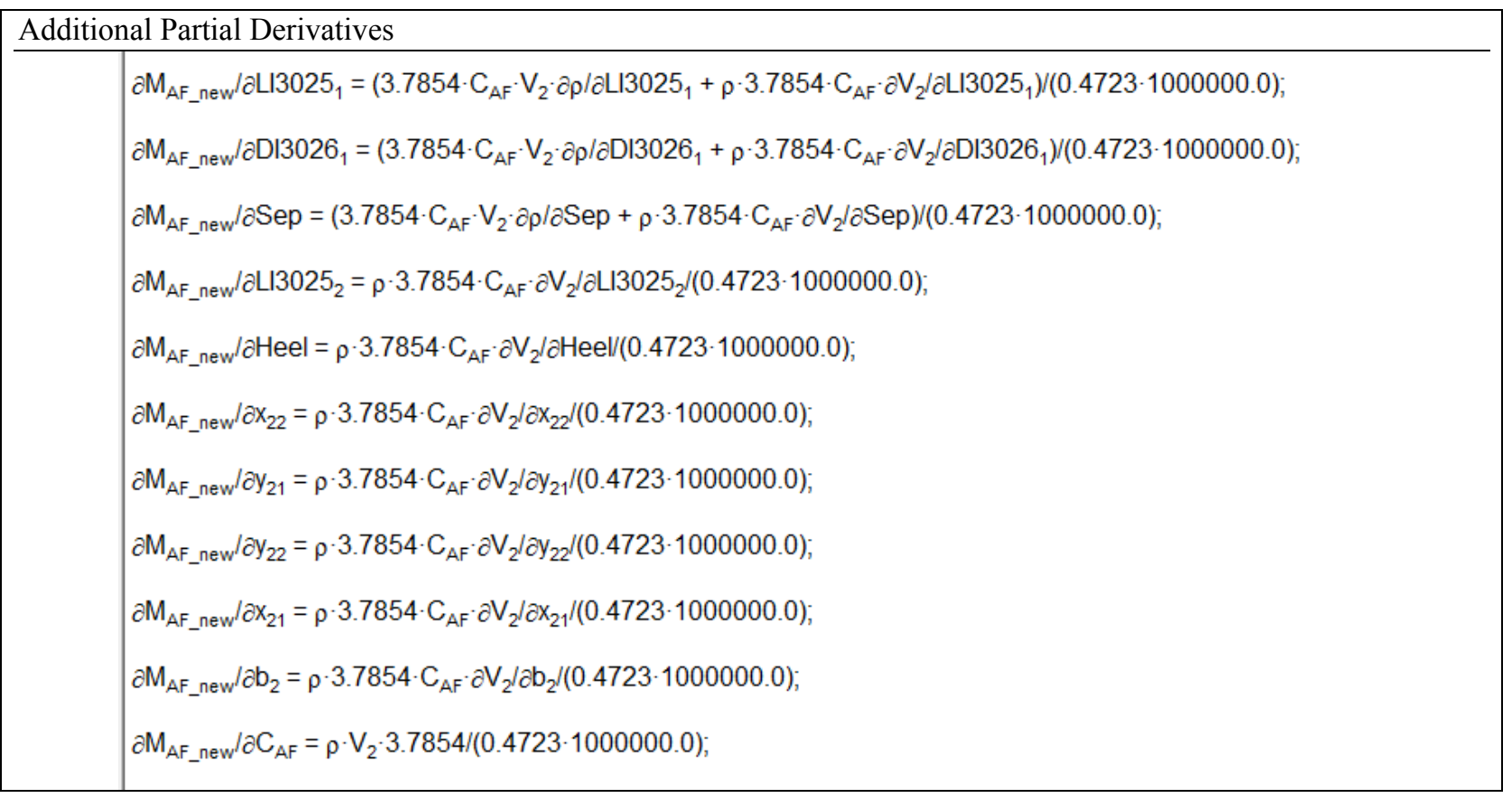

Exhibit 19 Equations for Analytical $\mathrm{M}_{\mathrm{AF} \_ \text {new }}$ for the SRAT Heel with Bias Uncertainty (part 2 of 2)

Table 12 Terms and Estimated Bias Uncertainties Supporting Equation 29

\begin{tabular}{|c|c|c|}
\hline Term/Instrument & Description & Bias Uncertainty at 95\% Confidence \\
\hline $\mathrm{C}_{\mathrm{AF}}$ (see Equation 11) & $\begin{array}{c}\text { antifoam carbon concentration } \\
(\mathrm{mg} / \mathrm{kg})\end{array}$ & 0 \\
\hline $\begin{array}{c}\text { LI3025 } \\
\text { with subscripts 1 and 2 }\end{array}$ & level bubbler values (inwc) & Bias $=2.316$ inwc \\
\hline & density bubbler value (inwc) 231.6 inwc span $[11]$ \\
\hline DI3026 with subscript 1 & $\begin{array}{c}\text { tank calibration uncertainty } \\
\text { (see footnote for Table } 8)\end{array}$ & Bias $=1.61$ inwc \\
\hline & $\begin{array}{c}\text { separation between bubblers } \\
(47 \text { inches })\end{array}$ & 0.0625 inch $[13]$ \\
\hline $\mathrm{b}_{2}$ & $\begin{array}{c}\text { tank heel below LI3025 } \\
(6.77 \text { inches })\end{array}$ & 0.0625 inch $[13]$ \\
\hline Sep & Heel &
\end{tabular}


SRNL-STI-2014-00323

Revision 0

\subsubsection{SRAT Step 3 Processing}

Next consider the Step 3 event with the SRAT $\mathrm{M}_{\mathrm{AF}}$ information available. The equation for the $\mathrm{M}_{\mathrm{AF} \_ \text {out }}$ is given by:

Equation 30

$$
M_{A F_{\text {out }}}=\frac{M_{A F} \cdot\left(V_{1}-V_{2}\right)}{V_{1}}
$$

where the volumes $\mathrm{V}_{1}$ and $\mathrm{V}_{2}$ are intermediary values which are determined from LI3025 and DI3016 as described in Exhibit 8 and Exhibit 9 with the two volumes each having an additional random variability that is to be incorporated into the random uncertainty of $\mathrm{M}_{\mathrm{AF}_{-} \text {out }}$.

Following the Taylor's Series expansion approach described above, the estimated variance of $\mathrm{M}_{\mathrm{AF} \_ \text {out }}$ for Step 3 of Exhibit 9 may be written in terms of the fundamental measurements with $\delta_{1}$ and $\delta_{2}$ representing the random errors for $V_{1}$ and $V_{2}$, respectively, as:

\section{Equation 31}

$$
\begin{aligned}
\operatorname{Variance}\left(M_{A F_{\text {out }}}\right) \approx\left(\frac{\partial M_{A F_{\text {out }}}}{\partial M_{A F}}\right)^{2} \times \operatorname{variance}\left(M_{A F}\right)+\left(\frac{\partial M_{A F_{\text {out }}}}{\partial L I 3025_{1}}\right)^{2} \times \operatorname{variance}\left(L I 3025_{1}\right) \\
+\left(\frac{\partial M_{A F_{\text {out }}}}{\partial D I 3026_{1}}\right)^{2} \times \operatorname{variance}\left(D I 3026_{1}\right)+\left(\frac{\partial M_{A F_{\text {out }}}}{\partial \delta_{1}}\right)^{2} \times \operatorname{variance}\left(\delta_{1}\right) \\
+\left(\frac{\partial M_{A F_{\text {out }}}}{\partial L I 3025_{2}}\right)^{2} \times \operatorname{variance}\left(L I 3025_{2}\right)+\left(\frac{\partial M_{A F_{\text {out }}}}{\partial \delta_{2}}\right)^{2} \times \operatorname{variance}\left(\delta_{2}\right)
\end{aligned}
$$

GUM Workbench was used to develop the model equation and associated intermediary values supporting the determination of $\mathrm{M}_{\mathrm{AF}_{-} \text {out }}$ for Step 3 (see the upper portion of Exhibit 20) and to document the complete set of partial derivatives needed to support the estimation of the variance of the $\mathrm{M}_{\mathrm{AF}_{-} \text {out }}$ value (see the lower portion of Exhibit 20 and Exhibit 21). For example, the $\mathrm{x}_{11}, \mathrm{x}_{12}, \mathrm{y}_{11}$, and $\mathrm{y}_{12}$ values; and the $\mathrm{x}_{21}, \mathrm{x}_{22}$, $\mathrm{y}_{21}$, and $\mathrm{y}_{22}$ values are appropriately selected values (based upon the values of the LI3025 instrument as indicated by LI3025 and LI3025 2 , respectively) for determining volume as indicated in Exhibit 8. To complete the information necessary to compute the estimate of the variance of the $\mathrm{M}_{\mathrm{AF} \text { out }}$, estimates of the variance terms of Equation 31 are needed. These values along with a description of the terms of Equation 31 are provided in Table 13. 
SRNL-STI-2014-00323

Revision 0

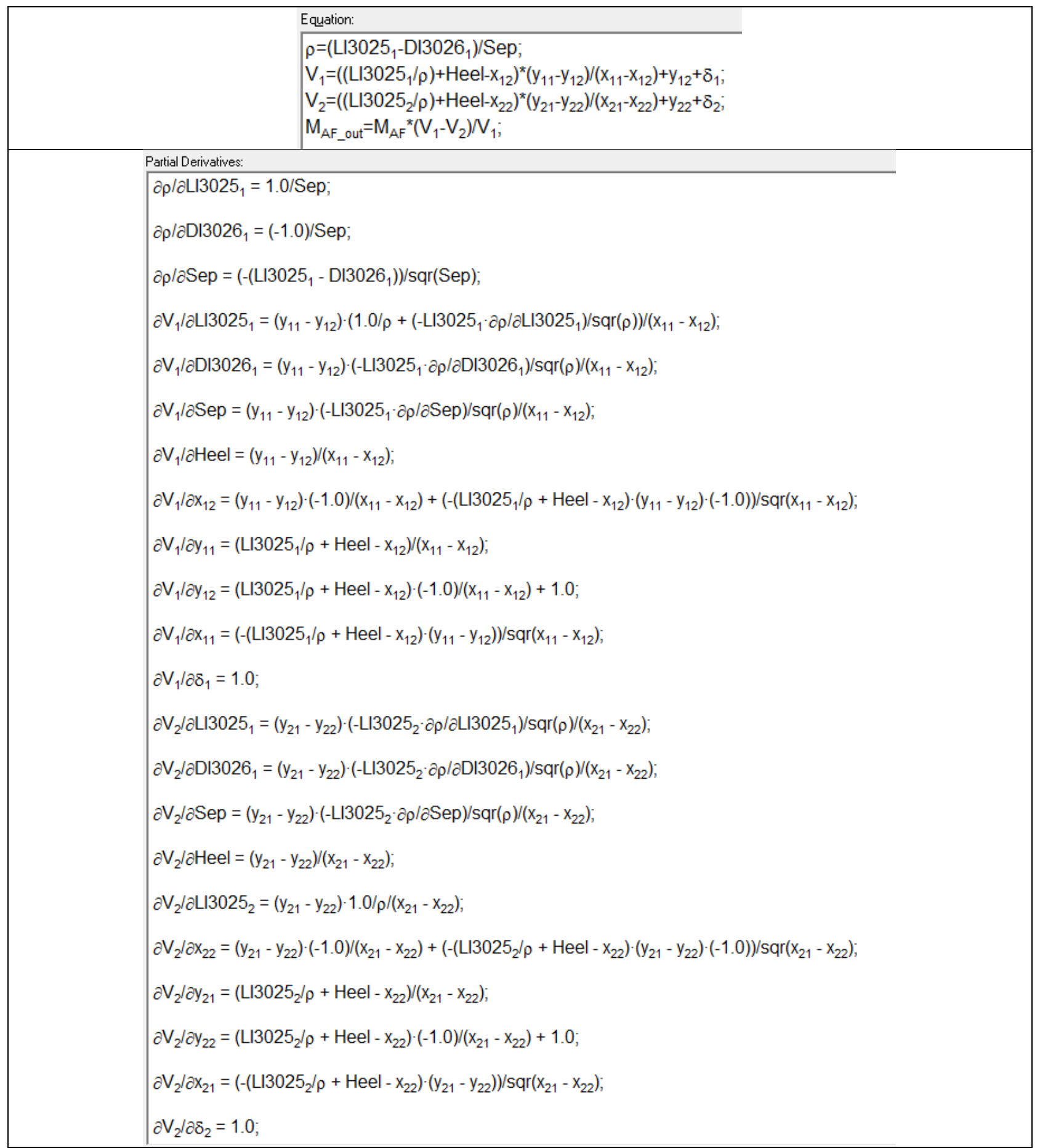

Exhibit 20 Equations for Calculating the Random Uncertainty for the $\mathbf{M}_{\mathrm{AF}}$ Transferred Out of the SRAT (part 1 of 2) 


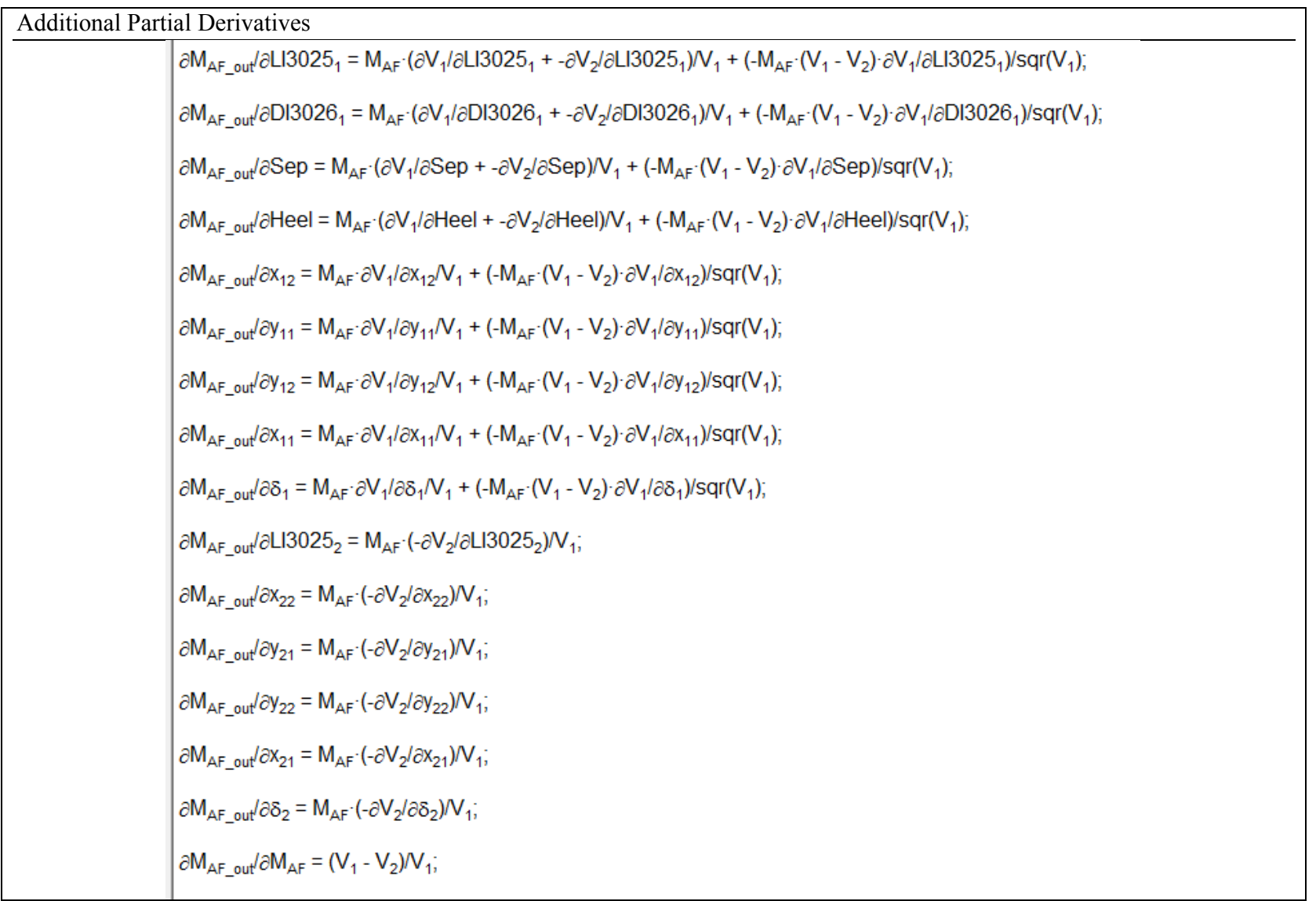

Exhibit 21 Equations for Calculating the Random Uncertainty for the $\mathbf{M}_{\mathrm{AF}}$ Transferred Out of the SRAT (part 2 of 2)

Table 13 Terms and Estimated Random Uncertainties Supporting Equation 31

\begin{tabular}{|c|c|c|}
\hline Term/Instrument & Description & 1-Sigma Random Uncertainty \\
\hline $\mathrm{M}_{\mathrm{AF}}$ & $\begin{array}{l}\text { current AF mass prior to transfer } \\
(\mathrm{kg})\end{array}$ & based upon SRAT status information \\
\hline \multirow[t]{3}{*}{ LI3025 with subscript 1} & level bubbler value (inwc) & $\pm 1 \%$ of 231.6 inwe span [11] \\
\hline & DCS deviation Limit & \pm 0.1 inwc $[11]$ \\
\hline & & $\begin{array}{l}\text { Using a uniform distribution, 1-sigma random is } \\
{\left[(2.316 / \sqrt{ } 3)^{2}+(0.1 / \sqrt{3})^{2}\right]^{0.5}=1.3384 \text { inwc }}\end{array}$ \\
\hline \multirow[t]{3}{*}{ DI3026 with subscript 1} & density bubbler value (inwc) & $\pm 1 \%$ of 161.0 inwc span [12] \\
\hline & DCS deviation limit & \pm 0.05 inwc [12] \\
\hline & & $\begin{array}{l}\text { Using a uniform distribution, 1-sigma random is } \\
{\left[(1.61 / \sqrt{ } 3)^{2}+(0.05 / \sqrt{3})^{2}\right]^{0.5}=0.9300 \text { inwc }}\end{array}$ \\
\hline$\delta_{1}$ & $\begin{array}{l}\text { tank calibration uncertainty } \\
\text { (see footnote for Table } 7 \text { ) }\end{array}$ & 1-sigma random $=9$ gallons \\
\hline$\delta_{2}$ & $\begin{array}{l}\text { tank calibration uncertainty } \\
\text { (see footnote for Table 7) }\end{array}$ & 1-sigma random $=9$ gallons \\
\hline
\end{tabular}

To complete the evaluation of the $\mathrm{M}_{\mathrm{AF} \mathrm{F}_{-} \text {out }}$ required for Step 3, the bias for $\mathrm{M}_{\mathrm{AF} \text {-out }}$ determined by Equation 30 must be estimated. A bound (at $95 \%$ confidence) on the bias of the antifoam mass transferred out of the SRAT, $\mathrm{M}_{\mathrm{AF}_{-} \text {out }}$, is estimated, as above, by appealing to a Taylor Series expansion of the Equation 30 in the fundamental measurements. Once again, note that $\rho, V_{1}$, and $V_{2}$ are intermediary values. Also, the 
SRNL-STI-2014-00323

Revision 0

$V_{1}$ and $V_{2}$ values each have a potential bias that is to be included in the evaluation. The Taylor's Series expansion may be expressed in the fundamental measurements and the potential biases of the calculated volumes as given by:

Equation 32

$$
\begin{aligned}
& \left\{\operatorname{bias}\left(M_{A F_{\text {out }}}\right)\right\}^{2} \approx\left(\frac{\partial M_{A F_{\text {out }}}}{\partial M_{A F}}\right)^{2} \times\left\{\operatorname{bias}\left(M_{A F}\right)\right\}^{2}+\left(\frac{\partial M_{A F_{\text {out }}}}{\partial L I 3025_{1}}\right)^{2} \times\{\operatorname{bias}(\text { LI3025 } 1)\}^{2} \\
& +\left(\frac{\partial M_{A F_{\text {out }}}}{\partial D I 3026_{1}}\right)^{2} \times\left\{\operatorname{bias}\left(D I 3026_{1}\right)\right\}^{2}+\left(\frac{\partial M_{A F_{\text {out }}}}{\partial \operatorname{Sep}}\right)^{2} \times\{\text { bias }(\text { Sep })\}^{2} \\
& +\left(\frac{\partial M_{A F_{\text {out }}}}{\partial \text { Heel }^{2}}\right)^{2} \times\{\text { bias }(\text { Heel })\}^{2}+\left(\frac{\partial M_{A F_{\text {out }}}}{\partial L I 3025_{2}}\right)^{2} \times\{\text { bias }(\text { LI3025 } 2)\}^{2} \\
& +\left(\frac{\partial M_{A F_{\text {out }}}}{\partial b_{1}}\right)^{2} \times\left\{\operatorname{bias}\left(b_{1}\right)\right\}^{2}+\left(\frac{\partial M_{A F_{\text {out }}}}{\partial b_{2}}\right)^{2} \times\left\{\operatorname{bias}\left(b_{2}\right)\right\}^{2} \\
& +2 \times 1 \times\left|\frac{\partial M_{A F_{\text {out }}}}{\partial L I 3025_{1}}\right| \times\left|\frac{\partial M_{A F_{\text {out }}}}{\partial L I 3025_{2}}\right| \times \operatorname{bias}\left(L I 3025_{1}\right) \times \operatorname{bias}\left(L I 3025_{2}\right) \\
& +2 \times 1 \times\left|\frac{\partial M_{A F_{\text {out }}}}{\partial b_{1}}\right| \times\left|\frac{\partial M_{A F_{\text {out }}}}{\partial b_{2}}\right| \times \operatorname{bias}\left(b_{1}\right) \times \operatorname{bias}\left(b_{2}\right)
\end{aligned}
$$

Note that in evaluating Equation 32, two potential correlations among the biases are introduced in a bounding manner. So the approach of may be stated as: the $b_{1}$ and $b_{2}$ terms are the estimated biases in the volumes $\mathrm{V}_{1}$ and $\mathrm{V}_{2}$, respectively, which may be correlated. In addition, the biases of the two LI3025 values (LI3025 and LI3025 ) may also be correlated. GUM Workbench was used to develop the model equation and associated intermediary values supporting the determination of the bias of $\mathrm{M}_{\mathrm{AF} \_ \text {out }}$ for Step 3 (see the upper portion of Exhibit 22) and to document the complete set of partial derivatives needed to support the estimation of the bias of the $\mathrm{M}_{\mathrm{AF}_{-} \text {out }}$ value (see the lower portion of Exhibit 22 and Exhibit 23). Once again, the $x_{11}, x_{12}, y_{11}$, and $y_{12}$ values and the $x_{21}, x_{22}, y_{21}$, and $y_{22}$ values are appropriately selected values (based upon the values of the LI3025 instrument as indicated by LI3025 and LI3025, respectively) for determining volumes as indicated in Exhibit 8. To complete the information necessary to compute the estimate of the bias of the $\mathrm{M}_{\mathrm{AF}_{-} \text {out, }}$, estimates of the bias terms of Equation 32 are needed. These values along with a description of the terms are provided in Table 14. A sample calculation for this step including the random and bias uncertainties is provided in Exhibit B8 in Appendix B. 
SRNL-STI-2014-00323

Revision 0

Table 14 Terms and Estimated Bias Uncertainties Supporting Equation 32

\begin{tabular}{|c|c|c|}
\hline Term/Instrument & Description & Bias Uncertainty at 95\% Confidence \\
\hline $\mathrm{M}_{\mathrm{AF}}$ & $\begin{array}{c}\text { Current AF mass prior to transfer } \\
(\mathrm{kg})\end{array}$ & Based upon SRAT Status information \\
\hline $\begin{array}{c}\text { LI3025 } \\
\text { with subscripts 1 and 2 }\end{array}$ & level bubbler values (inwc) & Bias $=2.316$ inwc \\
\hline DI3026 with subscript 1 & density bubbler value (inwc) & Bias $=1.61$ inwc \\
\hline & $\begin{array}{c}\text { tank calibration uncertainty } \\
\text { (see footnote for Table } 8)\end{array}$ & 12 gallons \\
\hline $\mathrm{b}_{1}$ & $\begin{array}{c}\text { tank calibration uncertainty } \\
(\text { see footnote for Table } 8)\end{array}$ & 12 gallons \\
\hline $\mathrm{b}_{2}$ & $\begin{array}{c}\text { Separation between bubblers } \\
(47 \text { inches) }\end{array}$ & 0.0625 inch [13] \\
\hline Sep & $\begin{array}{c}\text { Tank heel below LI3025 } \\
(6.77 \text { inches })\end{array}$ & 0.0625 inch [13] \\
\hline Heel & $\quad$
\end{tabular}


SRNL-STI-2014-00323

Revision 0

Equation:

$\rho=\left(\mathrm{LI} 3025_{1}-\mathrm{Dl} 3026_{1}\right) / \mathrm{Sep}$;

$\mathrm{V}_{1}=\left(\left(\mathrm{L} / 3025_{1} / \rho\right)+\text { Heel- } \mathrm{x}_{12}\right)^{*}\left(\mathrm{y}_{11}-\mathrm{y}_{12}\right) /\left(\mathrm{x}_{11}-\mathrm{x}_{12}\right)+\mathrm{y}_{12}+\mathrm{b}_{1}$;

$\mathrm{V}_{2}=\left(\left(\mathrm{LI} 3025_{2} / \rho\right)+\text { Heel- } \mathrm{x}_{22}\right)^{*}\left(\mathrm{y}_{21}-\mathrm{y}_{22}\right) /\left(\mathrm{x}_{21}-\mathrm{X}_{22}\right)+\mathrm{y}_{22}+\mathrm{b}_{2}$;

$\mathrm{M}_{\mathrm{AF} \_ \text {out }}=\mathrm{M}_{\mathrm{AF}}{ }^{*}\left(\mathrm{~V}_{1}-\mathrm{V}_{2}\right) \mathrm{N}_{1}$;

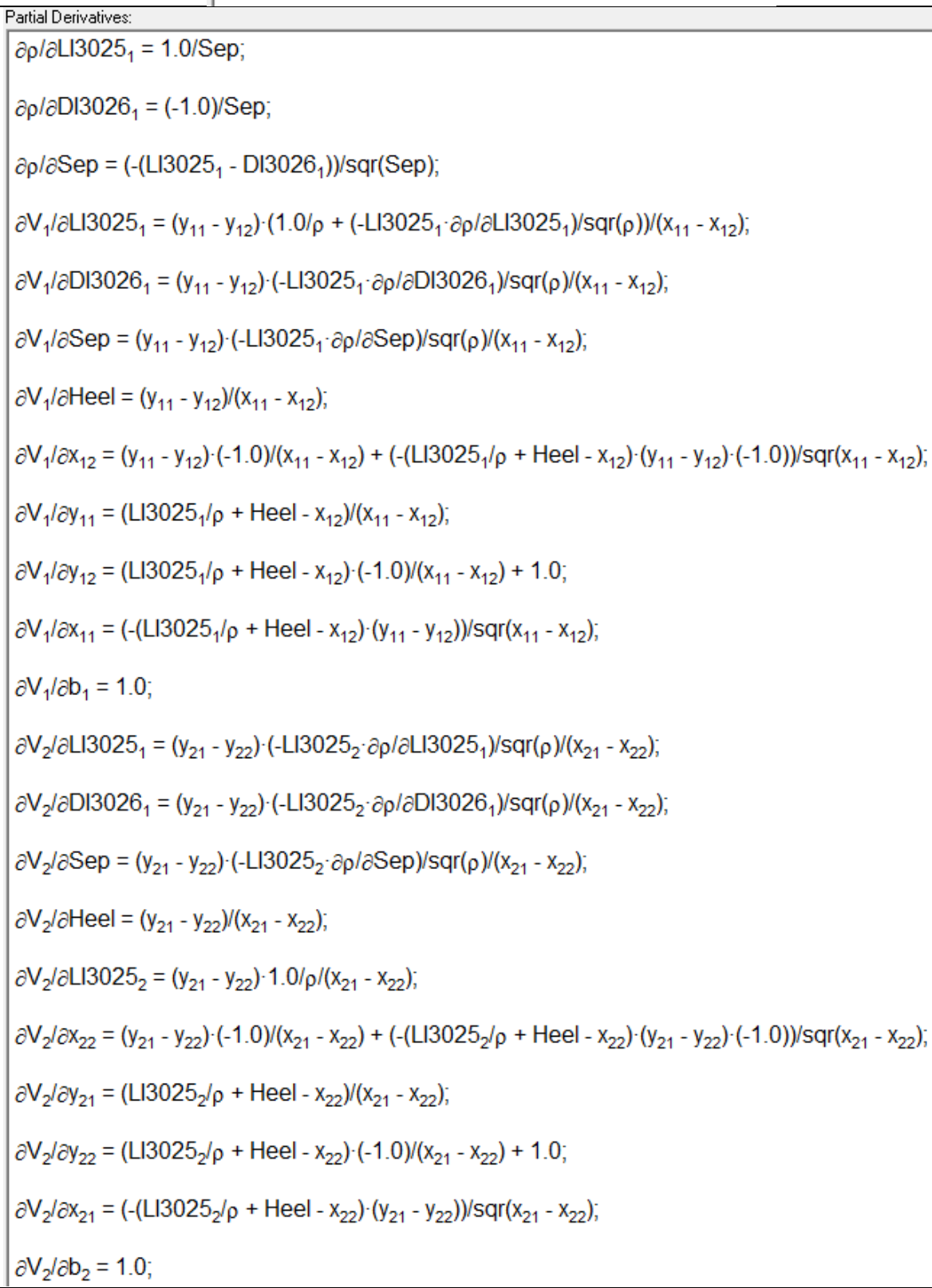

Exhibit 22 Equations for $\mathrm{M}_{\mathrm{AF}_{\text {_out }}}$ from the SRAT with Bias Uncertainty (part 1 of 2) 
SRNL-STI-2014-00323

Revision 0

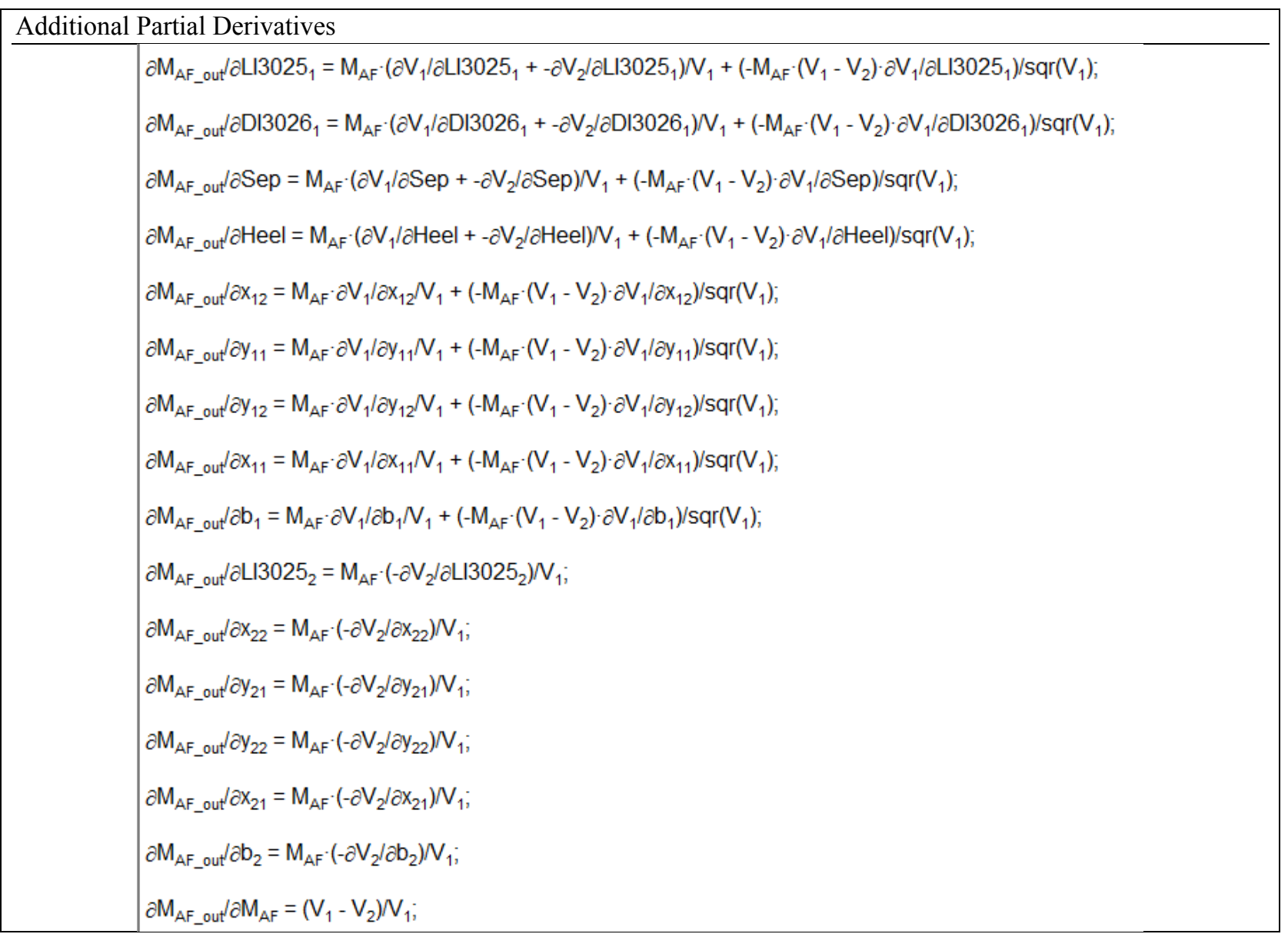

Exhibit 23 Equations for $\mathrm{M}_{\mathrm{AF} \_ \text {out }}$ from the SRAT with Bias Uncertainty (part 2 of 2)

\subsubsection{SRAT Step 4 Processing}

Next consider the Step 4 event with the SRAT $\mathrm{M}_{\mathrm{AF}}$ information available. The equation for the $\mathrm{M}_{\mathrm{AF}-\mathrm{new}}$ is given by:

Equation 33

$$
M_{A F_{\text {new }}}=\frac{M_{A F} \cdot V_{2}}{V_{1}}
$$

where the volumes $\mathrm{V}_{1}$ and $\mathrm{V}_{2}$ are intermediary values which are determined from LI3025 and DI3016 as described in Exhibit 8 and Exhibit 9 with the two volumes each having an additional random variability that is to be incorporated to the random uncertainty of $\mathrm{M}_{\mathrm{AF}_{-} \text {new. }}$.

Following the Taylor's Series expansion approach described above, the estimated variance of $\mathrm{M}_{\mathrm{AF}_{-} \text {new }}$ for Step 4 of Exhibit 9 may be written in terms of the fundamental measurements with $\delta_{1}$ and $\delta_{2}$ representing the random errors for $\mathrm{V}_{1}$ and $\mathrm{V}_{2}$, respectively, as: 
SRNL-STI-2014-00323

Revision 0

\section{Equation 34}

$$
\begin{gathered}
\operatorname{Variance}\left(M_{A F_{\text {new }}}\right) \approx\left(\frac{\partial M_{A F_{\text {new }}}}{\partial M_{A F}}\right)^{2} \times \operatorname{variance}\left(M_{A F}\right)+\left(\frac{\partial M_{A F_{\text {new }}}}{\partial L I 3025_{1}}\right)^{2} \times \operatorname{variance}\left(L I 3025_{1}\right) \\
+\left(\frac{\partial M_{A F_{\text {new }}}}{\partial D I 3026_{1}}\right)^{2} \times \operatorname{variance}\left(D I 3026_{1}\right)+\left(\frac{\partial M_{A F_{n e w}}}{\partial \delta_{1}}\right)^{2} \times \operatorname{variance}\left(\delta_{1}\right) \\
+\left(\frac{\partial M_{A F_{n e w}}}{\partial L I 3025_{2}}\right)^{2} \times \operatorname{variance}\left(L I 3025_{2}\right)+\left(\frac{\partial M_{A F_{\text {new }}}}{\partial \delta_{2}}\right)^{2} \times \operatorname{variance}\left(\delta_{2}\right)
\end{gathered}
$$

GUM Workbench was used to develop the model equation and associated intermediary values supporting the determination of $\mathrm{M}_{\mathrm{AF}_{-} \text {new }}$ for Step 4 (see the upper portion of Exhibit 24) and to document the complete set of partial derivatives needed to support the estimation of the variance of the $\mathrm{M}_{\mathrm{AF}_{-} \text {out }}$ value (see the lower portion of Exhibit 24 and Exhibit 25). For example, the $\mathrm{x}_{11}, \mathrm{x}_{12}, \mathrm{y}_{11}$, and $\mathrm{y}_{12}$ values; and the $\mathrm{x}_{21}, \mathrm{x}_{22}, \mathrm{y}_{21}$, and $\mathrm{y}_{22}$ values are appropriately selected values (based upon the values of the LI3025 instrument as indicated by LI3025 and LI30252, respectively) for determining volume as indicated in Exhibit 8. To complete the information necessary to compute the estimate of the variance of the $\mathrm{M}_{\mathrm{AF}_{-} \text {out}}$, estimates of the variance terms of Equation 34 are needed. These values along with a description of the terms of Equation 34 are provided in Table 15. 


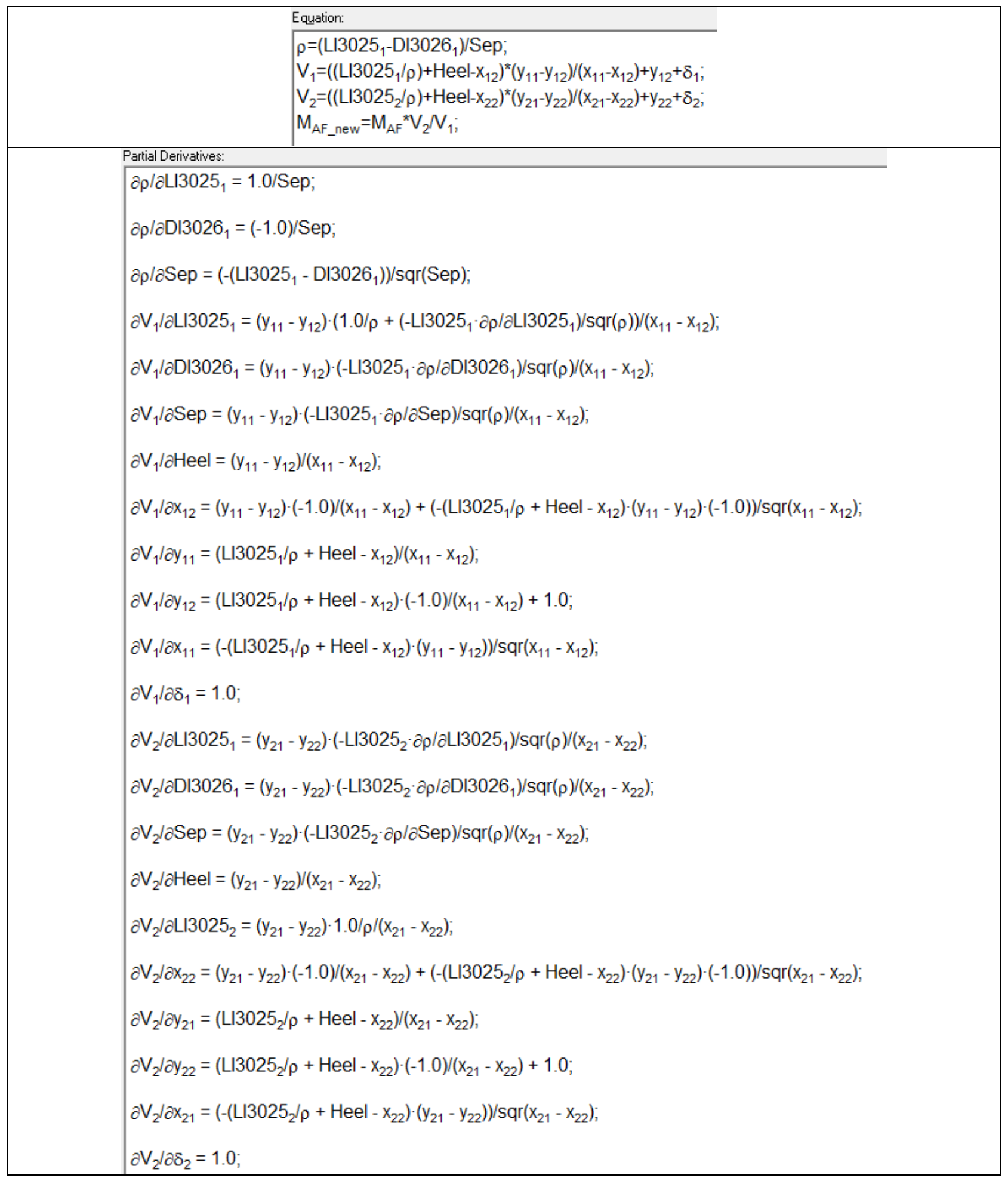

Exhibit 24 Equations for Calculating the Random Uncertainty for the $\mathbf{M}_{\mathrm{AF}}$ Heel in the SRAT (part 1 of 2) 


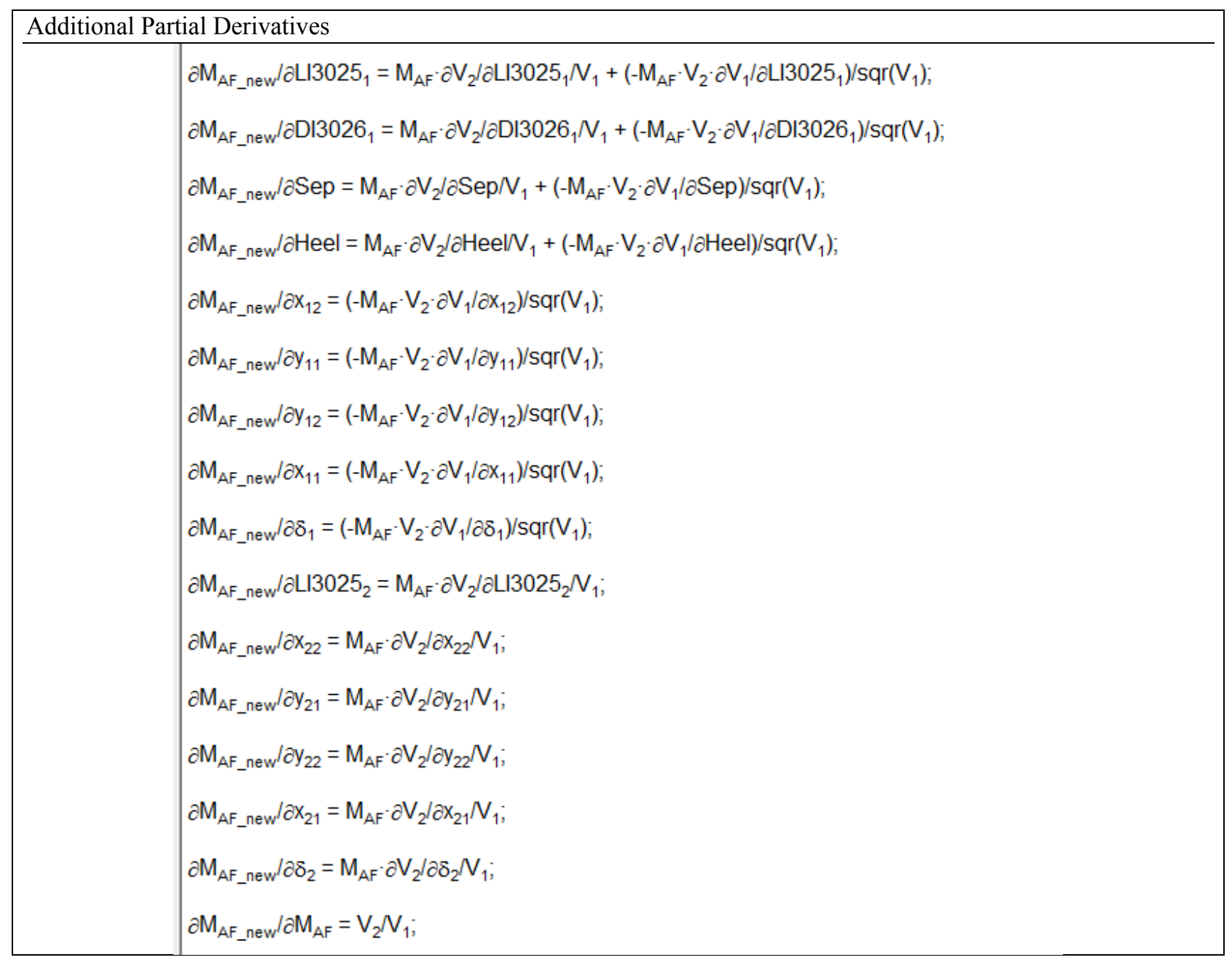

Exhibit 25 Equations for Calculating the Random Uncertainty for the $\mathbf{M}_{\mathrm{AF}}$ Heel in the SRAT (part 2 of 2) 
SRNL-STI-2014-00323

Revision 0

Table 15 Terms and Estimated Random Uncertainties Supporting Equation 34

\begin{tabular}{|c|c|c|}
\hline Term/Instrument & Description & 1-Sigma Random Uncertainty \\
\hline $\mathrm{M}_{\mathrm{AF}}$ & $\begin{array}{l}\text { current AF mass prior to transfer } \\
\qquad(\mathrm{kg})\end{array}$ & Based upon SRAT Status information \\
\hline \multirow[t]{3}{*}{ LI3025 with subscript 1} & level bubbler value (inwc) & $\pm 1 \%$ of 231.6 inwe span [11] \\
\hline & DCS Deviation Limit & \pm 0.1 inwc $[11]$ \\
\hline & & $\begin{array}{l}\text { Using a uniform distribution, 1-sigma random is } \\
{\left[(2.316 / \sqrt{3})^{2}+(0.1 / \sqrt{3})^{2}\right]^{0.5}=1.3384 \text { inwc }}\end{array}$ \\
\hline \multirow[t]{3}{*}{ DI3026 with subscript 1} & density bubbler value (inwc) & $\pm 1 \%$ of 161.0 inwc span $[12]$ \\
\hline & DCS Deviation Limit & \pm 0.05 inwc $[12]$ \\
\hline & & $\begin{array}{l}\text { Using a uniform distribution, 1-sigma random is } \\
{\left[(1.61 / \sqrt{ } 3)^{2}+(0.05 / \sqrt{3})^{2}\right]^{0.5}=0.9300 \text { inwc }}\end{array}$ \\
\hline$\delta_{1}$ & $\begin{array}{l}\text { tank calibration uncertainty } \\
\text { (see footnote for Table } 7 \text { ) }\end{array}$ & 1 -sigma random $=9$ gallons \\
\hline$\delta_{2}$ & $\begin{array}{c}\text { tank calibration uncertainty } \\
\text { (see footnote for Table 7) }\end{array}$ & 1-sigma random $=9$ gallons \\
\hline
\end{tabular}

To complete the evaluation of the $\mathrm{M}_{\mathrm{AF} \text { new }}$ required for Step 4, the bias for $\mathrm{M}_{\mathrm{AF} \text { new }}$ determined by Equation 33 must be estimated. A bound (at 95\% confidence) on the bias of the antifoam mass for the SRAT heel, $\mathrm{M}_{\mathrm{AF}_{\text {_new }}}$, is estimated, as above, by appealing to a Taylor Series expansion of Equation 33 in the fundamental measurements. Once again, note that $\rho, V_{1}$, and $V_{2}$ are intermediary values. Also, the $V_{1}$ and $V_{2}$ values each have a potential bias that is to be included in the evaluation. The Taylor's Series expansion may be expressed in the fundamental measurements and the potential biases of the calculated volumes as given by:

Equation 35

$$
\begin{aligned}
& \left\{\operatorname{bias}\left(M_{A F_{n e w}}\right)\right\}^{2} \approx\left(\frac{\partial M_{A F_{n e w}}}{\partial M_{A F}}\right)^{2} \times\left\{\operatorname{bias}\left(M_{A F}\right)\right\}^{2}+\left(\frac{\partial M_{A F_{\text {new }}}}{\partial L I 3025_{1}}\right)^{2} \times\{\operatorname{bias}(\text { LI3025 } 1)\}^{2} \\
& +\left(\frac{\partial M_{A F_{n e w}}}{\partial D I 3026_{1}}\right)^{2} \times\left\{\operatorname{bias}\left(D I 3026_{1}\right)\right\}^{2}+\left(\frac{\partial M_{A F_{n e w}}}{\partial S e p}\right)^{2} \times\{\operatorname{bias}(\operatorname{Sep})\}^{2} \\
& +\left(\frac{\partial M_{A F_{\text {new }}}}{\partial{ }_{\text {Heel }}}\right)^{2} \times\{\text { bias }(\text { Heel })\}^{2}+\left(\frac{\partial M_{A F_{\text {new }}}}{\partial L I 3025_{2}}\right)^{2} \times\left\{\text { bias }\left(L I 3025_{2}\right)\right\}^{2} \\
& +\left(\frac{\partial M_{A F_{\text {new }}}}{\partial b_{1}}\right)^{2} \times\left\{\operatorname{bias}\left(b_{1}\right)\right\}^{2}+\left(\frac{\partial M_{A F_{n e w}}}{\partial b_{2}}\right)^{2} \times\left\{\operatorname{bias}\left(b_{2}\right)\right\}^{2} \\
& +2 \times 1 \times\left|\frac{\partial M_{A F_{n e w}}}{\partial L I 3025_{1}}\right| \times\left|\frac{\partial M_{A F_{\text {new }}}}{\partial L I 3025_{2}}\right| \times \operatorname{bias}\left(L I 3025_{1}\right) \times \operatorname{bias}\left(L I 3025_{2}\right) \\
& +2 \times 1 \times\left|\frac{\partial M_{A F_{\text {new }}}}{\partial b_{1}}\right| \times\left|\frac{\partial M_{A F_{\text {new }}}}{\partial b_{2}}\right| \times \operatorname{bias}\left(b_{1}\right) \times \operatorname{bias}\left(b_{2}\right)
\end{aligned}
$$


Note that in evaluating Equation 35, two potential correlations among the biases are introduced in a bounding manner. So the approach may be stated as: the $b_{1}$ and $b_{2}$ terms are the estimated biases in the volumes $\mathrm{V}_{1}$ and $\mathrm{V}_{2}$, respectively, which may be correlated. In addition, the biases of the two LI3025 values (LI3025 ${ }_{1}$ and LI30252) may also be correlated. GUM Workbench was used to develop the model equation and associated intermediary values supporting the determination of the bias of $\mathrm{M}_{\mathrm{AF}_{-} \text {new }}$ for Step 4 (see the upper portion of Exhibit 26) and to document the complete set of partial derivatives needed to support the estimation of the bias of the $\mathrm{M}_{\mathrm{AF}_{-} \text {out }}$ value (see the lower portion of Exhibit 26 and Exhibit 27). Once again, the $x_{11}, x_{12}, y_{11}$, and $y_{12}$ values; and the $x_{21}, x_{22}, y_{21}$, and $y_{22}$ values are appropriately selected values (based upon the values of the LI3025 instrument as indicated by LI3025 and LI3025 respectively) for determining volumes as indicated in Exhibit 8. To complete the information necessary to

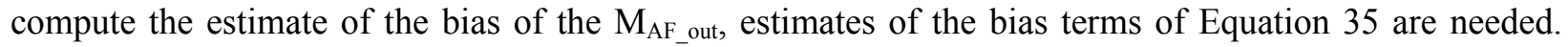
These values along with a description of the terms are provided in Table 16. A sample calculation for this step including the random and bias uncertainties is provided in Exhibit B9 in Appendix B.

Table 16 Terms and Estimated Bias Uncertainties Supporting Equation 35

\begin{tabular}{|c|c|c|}
\hline Term/Instrument & Description & Bias Uncertainty at 95\% Confidence \\
\hline $\mathrm{M}_{\mathrm{AF}}$ & current AF mass prior to transfer (kg) & Based upon SRAT Status information \\
\hline $\begin{array}{c}\mathrm{LI} 3025 \\
\text { with subscripts 1 and 2 }\end{array}$ & level bubbler values (inwc) & $\pm 1 \%$ of 231.6 inwc span [11] \\
\hline DI3026 with subscript 1 & density bubbler value (inwc) & Bias $=2.316$ inwc \\
\hline & $\begin{array}{c}\text { tank calibration uncertainty } \\
\text { (see footnote for Table } 8)\end{array}$ & 12 gallons \\
\hline $\mathrm{b}_{1}$ & $\begin{array}{c}\text { tank calibration uncertainty } \\
\text { (see footnote for Table } 8)\end{array}$ & 12 gallons \\
\hline $\mathrm{b}_{2}$ & $\begin{array}{c}\text { Separation between bubblers } \\
(47 \text { inches) }\end{array}$ & 0.0625 inch [13] \\
\hline Sep & $\begin{array}{c}\text { Tank heel below LI3025 } \\
(6.77 \text { inches })\end{array}$ \\
\hline Heel & $\quad 0.0625$ inch [13] \\
\hline
\end{tabular}


SRNL-STI-2014-00323

Revision 0

Equation:

$\rho=\left(\mathrm{LI} 3025_{1}-\mathrm{Dl} 3026_{1}\right) / \mathrm{Sep}$;

$\mathrm{V}_{1}=\left(\left(\mathrm{L} \mid 3025_{1} / \rho\right)+\text { Heel- } \mathrm{x}_{12}\right)^{*}\left(\mathrm{y}_{11}-\mathrm{y}_{12}\right) /\left(\mathrm{x}_{11}-\mathrm{x}_{12}\right)+\mathrm{y}_{12}+\mathrm{b}_{1}$;

$\mathrm{V}_{2}=\left(\left(\mathrm{L} \mid 3025_{2} / \rho\right)+\text { Heel- } \mathrm{x}_{22}\right)^{*}\left(\mathrm{y}_{21}-\mathrm{y}_{22}\right) /\left(\mathrm{x}_{21}-\mathrm{x}_{22}\right)+\mathrm{y}_{22}+\mathrm{b}_{2}$;

$\mathrm{M}_{\mathrm{AF} \_ \text {new }}=\mathrm{M}_{\mathrm{AF}} \mathrm{V}_{2} \mathrm{~V}_{1} \mathrm{~N}_{1}$

Partial Derivatives:

$\partial \rho / \partial \mathrm{LI} 3025_{1}=1.0 /$ Sep;

$\partial \rho / \partial \mathrm{DI} 3026_{1}=(-1.0) / \mathrm{Sep} ;$

$\partial \rho / \partial$ Sep $=\left(-\left(\right.\right.$ LI $3025_{1}-$ DI3026 1$\left.)\right) /$ sqr $($ Sep $) ;$

$\partial \mathrm{V}_{1} / \partial \mathrm{LI} 3025_{1}=\left(\mathrm{y}_{11}-\mathrm{y}_{12}\right) \cdot\left(1.0 / \rho+\left(-\mathrm{LI} 3025_{1} \cdot \partial \rho / \partial \mathrm{LI} 3025_{1}\right) / \operatorname{sqr}(\rho)\right) /\left(\mathrm{x}_{11}-\mathrm{x}_{12}\right)$

$\partial \mathrm{V}_{1} / \partial \mathrm{DI} 3026_{1}=\left(\mathrm{y}_{11}-\mathrm{y}_{12}\right) \cdot\left(-\mathrm{LI} 3025_{1} \cdot \partial \rho / \partial \mathrm{DI} 3026_{1}\right) / \operatorname{sqr}(\rho) /\left(\mathrm{x}_{11}-\mathrm{x}_{12}\right) ;$

$\partial \mathrm{V}_{1} / \partial \operatorname{Sep}=\left(\mathrm{y}_{11}-\mathrm{y}_{12}\right) \cdot\left(-\mathrm{LI} 3025_{1} \cdot \partial \rho / \partial \operatorname{Sep}\right) / \operatorname{sqr}(\rho) /\left(\mathrm{x}_{11}-\mathrm{x}_{12}\right) ;$

$\partial \mathrm{V}_{1} / \partial$ Heel $=\left(\mathrm{y}_{11}-\mathrm{y}_{12}\right) /\left(\mathrm{x}_{11}-\mathrm{x}_{12}\right) ;$

$\partial \mathrm{V}_{1} / \partial \mathrm{x}_{12}=\left(\mathrm{y}_{11}-\mathrm{y}_{12}\right) \cdot(-1.0) /\left(\mathrm{x}_{11}-\mathrm{x}_{12}\right)+\left(-\left(\right.\right.$ LI3025 $/ \rho+$ Heel $\left.\left.-\mathrm{x}_{12}\right) \cdot\left(\mathrm{y}_{11}-\mathrm{y}_{12}\right) \cdot(-1.0)\right) /$ sqr $\left(\mathrm{x}_{11}-\mathrm{x}_{12}\right)$

$\partial \mathrm{V}_{1} / \partial \mathrm{y}_{11}=\left(\mathrm{LI} 3025_{1} / \rho+\right.$ Heel $\left.-\mathrm{x}_{12}\right) /\left(\mathrm{x}_{11}-\mathrm{x}_{12}\right) ;$

$\partial \mathrm{V}_{1} / \partial \mathrm{y}_{12}=\left(\mathrm{LI} 3025_{1} / \rho+\right.$ Heel $\left.-\mathrm{x}_{12}\right) \cdot(-1.0) /\left(\mathrm{x}_{11}-\mathrm{x}_{12}\right)+1.0$

$\partial \mathrm{V}_{1} / \partial \mathrm{x}_{11}=\left(-\left(\right.\right.$ LI3025 $/ \rho+$ Heel $\left.\left.-\mathrm{x}_{12}\right) \cdot\left(\mathrm{y}_{11}-\mathrm{y}_{12}\right)\right) / \operatorname{sqr}\left(\mathrm{x}_{11}-\mathrm{x}_{12}\right) ;$

$\partial \mathrm{V}_{1} / \partial \mathrm{b}_{1}=1.0$

$\partial \mathrm{V}_{2} / \partial \mathrm{LI} 3025_{1}=\left(\mathrm{y}_{21}-\mathrm{y}_{22}\right) \cdot\left(-\mathrm{LI} 3025_{2} \cdot \partial \rho / \partial \mathrm{LI} 3025_{1}\right) / \operatorname{sqr}(\rho) /\left(\mathrm{x}_{21}-\mathrm{x}_{22}\right) ;$

$\partial \mathrm{V}_{2} / \partial \mathrm{DI} 3026_{1}=\left(\mathrm{y}_{21}-\mathrm{y}_{22}\right) \cdot\left(-\mathrm{LI} 3025_{2} \cdot \partial \rho / \partial \mathrm{DI} 3026_{1}\right) / \operatorname{sqr}(\rho) /\left(\mathrm{x}_{21}-\mathrm{x}_{22}\right)$;

$\partial \mathrm{V}_{2} / \partial \operatorname{Sep}=\left(\mathrm{y}_{21}-\mathrm{y}_{22}\right) \cdot\left(-\mathrm{LI} 3025_{2} \cdot \partial \rho / \partial \operatorname{Sep}\right) / \operatorname{sqr}(\rho) /\left(\mathrm{x}_{21}-\mathrm{x}_{22}\right) ;$

$\partial \mathrm{V}_{2} / \partial$ Heel $=\left(\mathrm{y}_{21}-\mathrm{y}_{22}\right) /\left(\mathrm{x}_{21}-\mathrm{x}_{22}\right) ;$

$\partial \mathrm{V}_{2} / \partial \mathrm{LI} 3025_{2}=\left(\mathrm{y}_{21}-\mathrm{y}_{22}\right) \cdot 1.0 / \rho /\left(\mathrm{x}_{21}-\mathrm{x}_{22}\right) ;$

Exhibit 26 Equations for $M_{A_{-} \text {new }}$ for the SRAT Heel with Bias Uncertainty (part 1 of 2) 


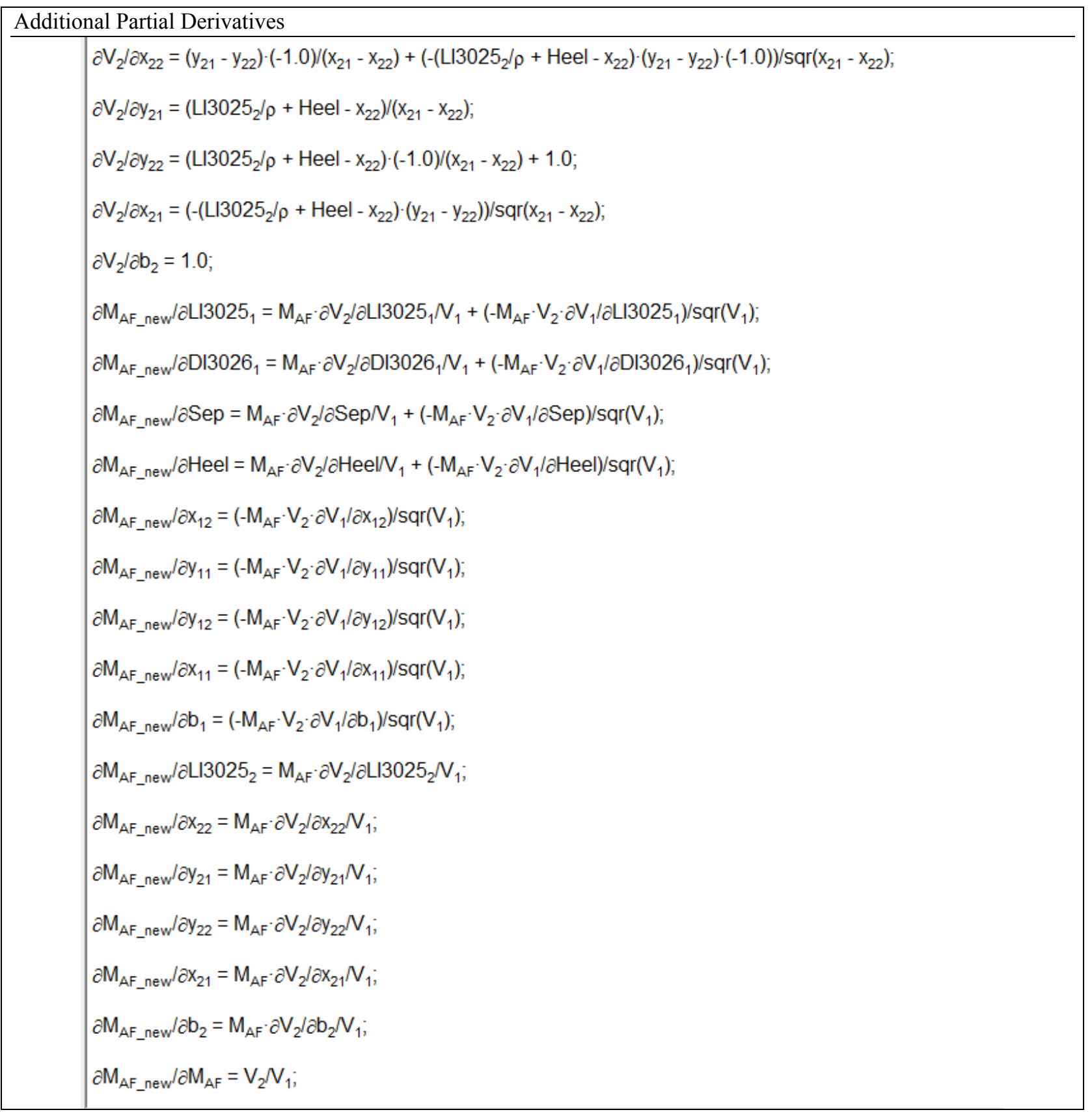

Exhibit 27 Equations for $\mathbf{M}_{\mathrm{AF}_{-} \text {new }}$ for the SRAT Heel with Bias Uncertainty (part 2 of 2) 
SRNL-STI-2014-00323

Revision 0

\subsection{Tracking Antifoam in the SME}

The SME is the hold-point of the antifoam tracking system. It is the contents of the SME that must be shown with high confidence to meet the restrictions imposed in reference [1]. To support the tracking of antifoam for a SME batch, the $\mathrm{M}_{\mathrm{AF}}$ value and its uncertainty (a 1-sigma random uncertainty and limit on bias at $95 \%$ confidence) associated with the SME contents are to be maintained at all times. If these values are not known, the contents of the SME are to be sampled and analyzed to re-baseline the antifoam mass and its uncertainty in this tank. With these values known, the antifoam tracking system must be capable up handling three types of events: (1) an event involving a transfer from the AMFT into the SME, (2) an event involving the transfer of SRAT product to the SME, (3) the event of a determination of acceptability for transfer of the SME material to the Melter Feed Tank (MFT). Handling these events entails updating the status of the $\mathrm{M}_{\mathrm{AF}}$ value and its uncertainty in the SME as well as confirming that the status of the $\mathrm{M}_{\mathrm{AF}}$ and its uncertainty in the SME tank meet are restrictions before transferring the SME product to the MFT

Exhibit 28 provides a flow diagram at the SME level for processing an event involving the SME. For any SME-related event, there is an initial assessment of the current status of the $\mathrm{M}_{\mathrm{AF}}$ value and its uncertainty in the SME. That is represented by the first decision step in the process flow diagram. If the status is unknown, then the "No" branch is taken out of this decision block and the value of the $\mathrm{M}_{\mathrm{AF}}$ and its uncertainty must be re-base lined as indicated in Step 1 of the diagram. If the status is known, the "Yes" branch is taken out of this decision block. With the $\mathrm{M}_{\mathrm{AF}}$ value and its uncertainty known, the next decision block is evaluated to determine the type of event that needs to be addressed by the tracking system. Once again, there are three primary events captured in the flow diagram: a) if there is a transfer of SRAT product to the SME, then the impact of the change in the mass of antifoam in the contents of the SME must be determined (indicated as Step 2 in Exhibit 28), b) if there is a transfer from the AMFT, then an antifoam addition is to be made to the SME and the impact of this addition on the $\mathrm{M}_{\mathrm{AF}}$ value must be determined (indicated as Step 3 in Exhibit 28), and c) if the acceptability of a transfer of SME product to the MFT is to be determined, then the constraints of reference [1] must be met after accounting for appropriate uncertainties (indicated as Step 4 in Exhibit 28) prior to the transfer of material to the MFT. And once acceptability is confirmed and a transfer to the MFT is made there is a need to update the $\mathrm{M}_{\mathrm{AF}}$ status of the SME after the transfer (indicated as Step 5 in Exhibit 28). 


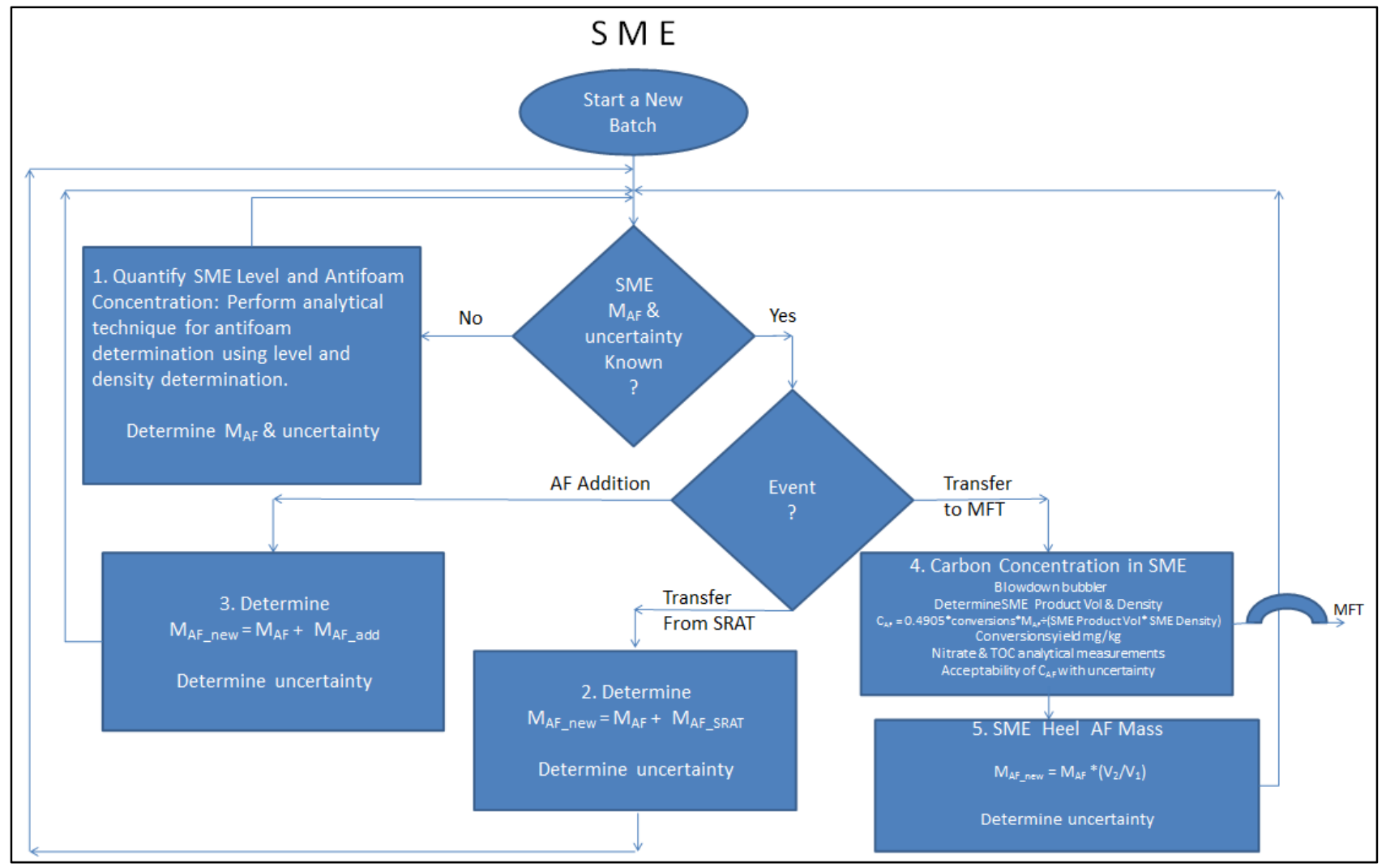

Exhibit 28 Process Flow for Tracking Antifoam Mass in the Slurry Mix Evaporator (SME) Tank

Exhibit 29 and Exhibit 30 provide an overview of the SME calculations supporting the antifoam tracking system. The calculations for Step 1 are executed if the $\mathrm{M}_{\mathrm{AF}}$ value or its uncertainty is unknown for the $\mathrm{SME}$; this results in the re-establishment of a $\mathrm{M}_{\mathrm{AF}}$ value along with its uncertainty.

\subsubsection{SME Step 2 and Step 3 Processing}

For Step 2, the one-sigma uncertainty for the new value of $\mathrm{M}_{\mathrm{AF}}$ (i.e., $\mathrm{M}_{\mathrm{AF} \_ \text {new }}$ in the Step 2 equation) is the square root of the sum of the variances of the two terms on the right-hand side of the Step 2 equation: $\mathrm{M}_{\mathrm{AF}}$ and $\mathrm{M}_{\mathrm{AF} \_\mathrm{Add}}$, while the bias of the new value is simply the sum of the biases of the two terms on the right-hand side of the Step 2 equation. This is also true for Step 3: the one-sigma uncertainty for the new value of $\mathrm{M}_{\mathrm{AF}}$ (i.e., $\mathrm{M}_{\mathrm{AF} \text {-new }}$ in the Step 3 equation) is the square root of the sum of the variances of the two terms on the right-hand side of the Step 3 equation: $\mathrm{M}_{\mathrm{AF}}$ and $\mathrm{M}_{\mathrm{AF}_{-} \mathrm{Add}}$ and the bias of the new value is simply the sum of the biases of the two terms on the right-hand side of the Step 3 equation. Sample calculations for Step 2 and Step 3 including the random and bias uncertainties are provided in Exhibit B10 and Exhibit B11, respectively, in Appendix B.

\subsubsection{Overview of SME Steps 1, 4 and 5 Processing}

Step 4 provides the determination of the acceptability of the SME product for transfer to the MFT. $\mathrm{M}_{\mathrm{AF} \_ \text {out }}$ value associated with the transfer from the SRAT to the SME. Step 5 provides the mass of the antifoam remaining in the SME (i.e., the SME heel) after the transfer out of the SME to the MFT has been completed. The calculations supporting each of steps 1, 3 and 4 of the tracking system for the SME are covered in turn in the following discussion. 
SRNL-STI-2014-00323

Revision 0

\section{SME Calculations}

1. Re-base-lining of the SME

The SME vessel will be re-base-lined using the analytical method for antifoam concentration determination that is currently used. The mass of antifoam at the time of the SME sample can be determined by

$$
M_{A F}=C_{A F} \cdot V_{1} \cdot \rho
$$

where the determination of volume, $V_{1}$, from the source instrumentation, LI3109 and DI3108, is described below and $\rho$ is calculated from these instruments by

$$
\rho=\frac{\left(L I 3109_{1}-D I 3108_{1}\right)}{\operatorname{Sep}}
$$

and Sep stands for the separation between the two instruments. The Sep value is 47 inches.

The volume in the SME can be representedin terms of the value at event, $i=1$ (before a transfer) or $\mathrm{i}=2$ (after a transfer), of its source instrumentation LI3109 as:

$$
\begin{aligned}
\text { For } x_{i 2}<\left(\frac{L I 3109_{i}}{\rho}\right. & + \text { Heel })<x_{i 1}, \\
& \frac{\frac{L I 3109_{i}}{\rho}+\text { Heel }-x_{i 2}}{\left(x_{i 1}-x_{i 2}\right)} \times\left(y_{i 1}-y_{i 2}\right)+y_{i 2}
\end{aligned}
$$

where the Heel is 6.77 inches and there are four sets of $x$ 's and y's corresponding to 4 segments within the SME. These values are (see reference [5]):

\begin{tabular}{|c|c|c|c|c|}
\hline Segment & $\mathrm{x}_{\mathrm{i}:}$ & $\mathrm{x}_{\mathrm{i}}$ & $\mathrm{y}_{\mathrm{it}}$ & $\mathrm{y}_{\mathrm{i} 2}$ \\
\hline 1 (lowest) & 9.8051 & 0 & 500 & 0 \\
\hline 2 & 79.232 & 9.8051 & 5240 & 500 \\
\hline 3 & 125.25 & 79.232 & 8500 & 5240 \\
\hline 4 (highest) & 175.02 & 125.25 & 12000 & 10850 \\
\hline
\end{tabular}

Exhibit 29 SME Calculations Supporting the Antifoam Tracking System (part 1 of 2) 
SRNL-STI-2014-00323

Revision 0

2. Antifoam Mass in the SME after a Transfer from the SRAT

The mass of antifoam in the SME after the SRAT transfer (the amount from the SRAT is as determined in SRAT Step 3) is given by:

$$
\mathrm{M}_{\mathrm{AF}_{-} \mathrm{Sew}}=\mathrm{M}_{\mathrm{AF}}+\mathrm{M}_{\mathrm{AF}_{-} \mathrm{AdS}}
$$

3. Antifoam Mass in the SME after an Addition from the AMFT

The mass of antifoam in the SME after the AMFT addition (the amount from the AMFT is as determined in AMFT Step 3) is given by:

$$
\mathrm{M}_{\mathrm{AF}_{-} \mathrm{DEW}}=\mathrm{M}_{\mathrm{AF}}+\mathrm{M}_{\mathrm{AF}_{-} \mathrm{AdS}}
$$

4. SME Acceptability Decision

The carbon concentration in the SME from antifoam is

$$
C_{A F}=\frac{0.4905 \cdot 1000000 \cdot M_{A F}}{\rho \cdot V_{1} \cdot 3.7854}
$$

where the density $(\mathrm{kg} / \mathrm{L}), \rho$, and the volume $V_{1}$ (gal) are determined as described in Step 1 above. The value of 3.7854 is a conversion factor with units of $\mathrm{L} / \mathrm{gal}$. The value of 0.4905 is a conservative (i.e., bounding on the high side) conversion factor with units of $\mathrm{kg}$ of carbon per $\mathrm{kg}$ of antifoam. The $1,000,000$ value is a conversion factor with units of $\mathrm{mg} / \mathrm{kg}$. The $\mathrm{C}_{\mathrm{AF}}$ value is assessed against the constraints imposed by [1] with all uncertainties appropriately addressed.

5. Amount of Antifoam in the SME Heel Following a Transfer Out to the Melter Feed Tank (MFT) The amount of antifoam remaining in SME after a transfer out to the MFT is

$$
M_{A F_{\text {How }}}=M_{A F} \cdot \frac{V_{2}}{V_{1}}
$$

where $V_{1}$ and $V_{2}$ are volumes in the SME which can be represented in terms of the values for $i=1$ (before the transfer) and 2 (after the transfer) of their source instrumentation, LI3109. These values are determined as described in Step 1 above. Note that the density value, $\rho$, that is used in the determination of $V_{1}$ is also used in the determination of $V_{2}$.

Exhibit 30 SME Calculations Supporting the Antifoam Tracking System (part 2 of 2)

\subsubsection{SME Step 1 Processing}

The equation for Step 1 of Exhibit 29 provides a guide for re-base lining the $\mathrm{M}_{\mathrm{AF} \text { new }}(\mathrm{kg})$ value for the SRAT. Writing the equation out with more detail to include the appropriate unit conversions yields:

\section{Equation 36}

$$
M_{A F_{\text {new }}}=\frac{3.7854 \cdot C_{A F} \cdot V_{1} \cdot \rho}{0.4723 \cdot 1000000}
$$

In this equation, $\mathrm{C}_{\mathrm{AF}}$ represents the carbon concentration $(\mathrm{mg} / \mathrm{kg})$ from $\mathrm{AF}$ determined from the analytical measurements of the SRAT contents with the volume (gal), $\mathrm{V}_{1}$, and density $(\mathrm{kg} / \mathrm{L}), \rho$, determined as indicated in the Step 1 description of Exhibit 29 by measurements from instruments LI3109 and DI3108 along with values for the separation (Sep) between the bubblers and the heel (Heel) for LI3109. The value 
of 3.7854 is a conversion factor with units of L/gal. Once again, the value of 0.4723 is a conservative (i.e., bounding on the low side) conversion factor with units of $\mathrm{kg}$ of carbon per $\mathrm{kg}$ of antifoam. The 1,000,000 value is a conversion factor with units of $\mathrm{mg} / \mathrm{kg}$. Note that $\rho$ and $\mathrm{V}_{1}$ are intermediary values with the $\mathrm{V}_{1}$ value having an additional variability described below. Using the Taylor's Series expansion approach described above, the estimated random variance of $\mathrm{M}_{\mathrm{AF}_{-} \text {new }}$ for Step 1 of Exhibit 29 may be expressed in the fundamental measurements as given by:

\section{Equation 37}

$$
\begin{gathered}
\operatorname{Variance}\left(M_{A F_{n e w}}\right) \approx\left(\frac{\partial M_{A F_{n e w}}}{\partial C_{A F}}\right)^{2} \times \operatorname{variance}\left(C_{A F}\right)+\left(\frac{\partial M_{A F_{\text {new }}}}{\partial L I 3109_{1}}\right)^{2} \times \operatorname{variance}\left(L I 3109_{1}\right) \\
+\left(\frac{\partial M_{A F_{n e w}}}{\partial D I 3108_{1}}\right)^{2} \times \operatorname{variance}\left(D I 3108_{1}\right)+\left(\frac{\partial M_{A F_{n e w}}}{\partial \delta_{1}}\right)^{2} \times \operatorname{variance}\left(\delta_{1}\right)
\end{gathered}
$$

where all of the estimated variances are for the random uncertainties of the indicated measurements. Specifically, the variance for $\mathrm{C}_{\mathrm{AF}}$ is estimated from the analyses of the $\mathrm{SME}$ samples as given by equation 12 and the variance $\left(\delta_{1}\right)$ term represents the variance of the random uncertainty associated with the computed volume, $\mathrm{V}_{1}$. (see the upper portion of Exhibit 31 for the introduction of the $\delta_{1}$ term into the model equation for $\mathrm{M}_{\mathrm{AF}_{-} \text {new }}$ ). GUM Workbench was used to develop the model equation and associated intermediary values supporting the determination of $\mathrm{M}_{\mathrm{AF}_{-} \text {new }}$ for Step 1 (see the upper portion of Exhibit 31 ) and to document the complete set of partial derivatives needed to support the estimation of the variance of the $\mathrm{M}_{\mathrm{AF} \text { _new }}$ value (see the lower portion of Exhibit 31). For example, $\mathrm{x}_{11}, \mathrm{x}_{12}, \mathrm{y}_{11}$, and $\mathrm{y}_{12}$ are appropriately selected values (based upon the value of the LI3109 instrument as indicated by LI3109 ${ }_{1}$ ) for determining volume as indicated in Exhibit 29.To complete the information necessary to compute the estimate of the variance of the $\mathrm{M}_{\mathrm{AF}_{-} \text {new }}$, estimates of the variance terms of Equation 37 are needed. These values along with a description of the terms are provided in Table 17.

\begin{tabular}{|c|c|c|}
\hline Term/Instrument & Description & 1-Sigma Random Uncertainty \\
\hline $\mathrm{C}_{\mathrm{AF}}($ see Equation 11$)$ & antifoam carbon concentration $(\mathrm{mg} / \mathrm{kg})$ & Analytical uncertainty (see Equation 12) \\
\hline \multirow[t]{3}{*}{ LI3109 with subscript 1} & level bubbler value (inwc) & $\pm 1 \%$ of 231.0 inwe span [14] \\
\hline & DCS Deviation Limit & \pm 0.1 inwc $[14]$ \\
\hline & & $\begin{array}{c}\text { Using a uniform distribution, 1-sigma random is } \\
{\left[(2.31 / \sqrt{ } 3)^{2}+(0.1 / \sqrt{ } 3)^{2}\right]^{0.5}=1.3349}\end{array}$ \\
\hline \multirow[t]{3}{*}{ DI3108 with subscript 1} & density bubbler value (inwc) & $\pm 1 \%$ of 160.5 inwc span $[15]$ \\
\hline & DCS Deviation Limit & \pm 0.05 inwc [15] \\
\hline & & $\begin{array}{c}\text { Using a uniform distribution, 1-sigma random is } \\
{\left[(1.605 / \sqrt{ } 3)^{2}+(0.05 / \sqrt{ } 3)^{2}\right]^{0.5}=0.9271}\end{array}$ \\
\hline$\delta_{1}$ & $\begin{array}{l}\text { tank calibration uncertainty } \\
(\text { see WSRC-TR-92-250 [8]*) }\end{array}$ & 1-sigma random $=9$ gallons \\
\hline
\end{tabular}

Table 17 Terms and Estimated Random Uncertainties Supporting Equation 37

\footnotetext{
* The random uncertainty of the tank calibration was estimated in this report for the SRAT and the SME as the total error of the Holledge gauge, $0.25 \mathrm{inch}$, times the slope of the calibration curve. For the SME, the largest slope is $70.847 \mathrm{gal} / \mathrm{inch}$, leading to an estimate of the total (2-sigma) random uncertainty of $70.847 \times 0.25=17.7$ gal, or a 1 -sigma random uncertainty of 9 gal.
} 
SRNL-STI-2014-00323

Revision 0

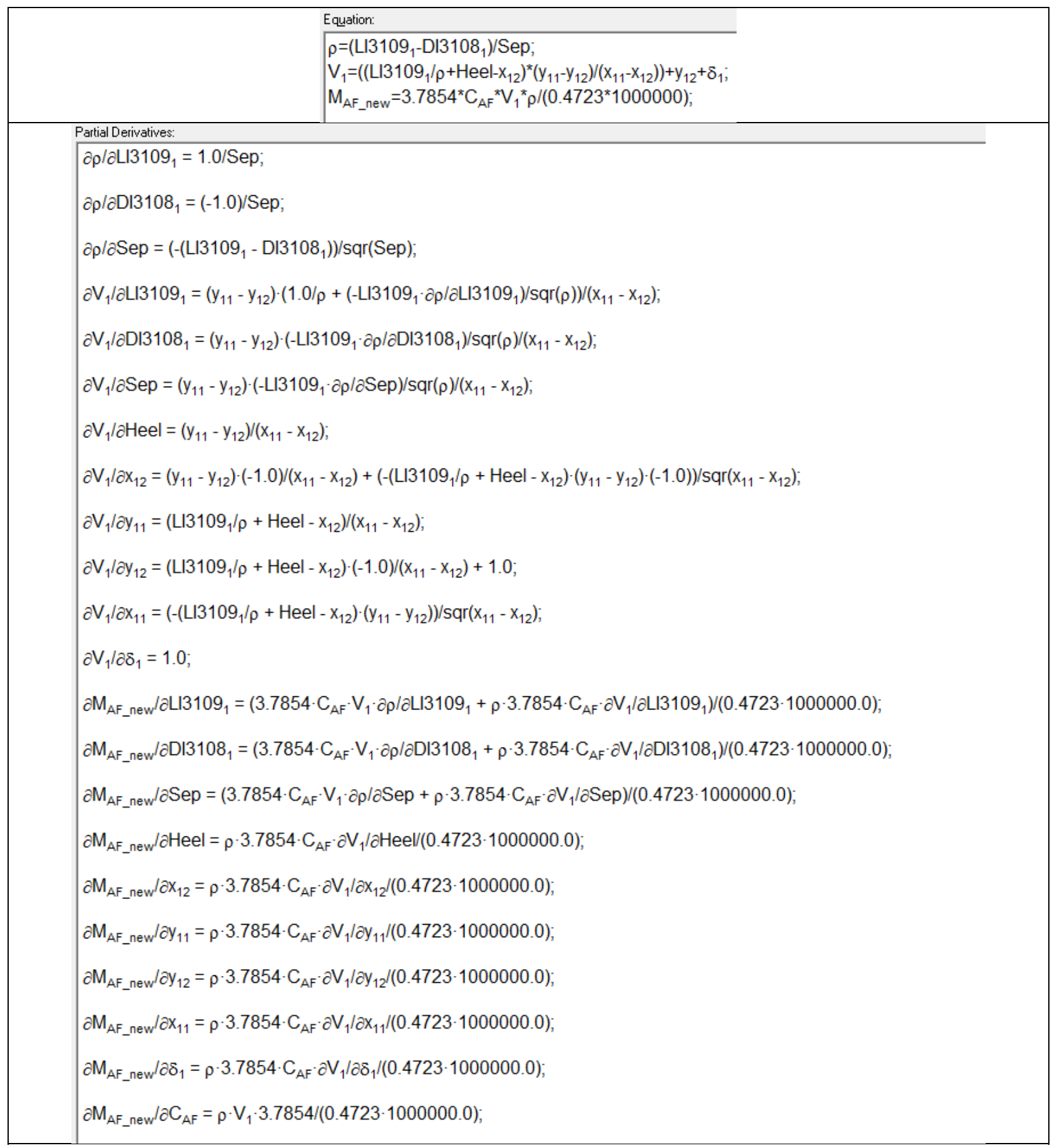

Exhibit 31 Equations for Re-Base-Lining the $\mathbf{M}_{\mathrm{AF}}$ of the SME with Random Uncertainty 
To complete the updating of the $\mathrm{M}_{\mathrm{AF}}$ status required for Step 1, the bias for $\mathrm{M}_{\mathrm{AF} \text { new }}$ determined by Equation 36 must be estimated. A bound (at 95\% confidence) on the bias of the antifoam mass, $\mathrm{M}_{\mathrm{AF}}$, is estimated, as above, by appealing to a Taylor Series expansion of this equation in the fundamental measurements. Once again, note that $\rho$ and $V_{1}$ are intermediary values and that the Taylor's Series expansion may be expressed in the fundamental measurements as given by:

Equation 38

$$
\begin{aligned}
& \left\{\operatorname{bias}\left(M_{A F_{n e w}}\right)\right\}^{2} \approx\left(\frac{\partial M_{A F_{n e w}}}{\partial C_{A F}}\right)^{2} \times\left\{\operatorname{bias}\left(C_{A F}\right)\right\}^{2}+\left(\frac{\partial M_{A F_{n e w}}}{\partial L I 3109_{1}}\right)^{2} \times\{\operatorname{bias}(\text { LI3109 } 1)\}^{2} \\
& +\left(\frac{\partial M_{A F_{n e w}}}{\partial D I 3108_{1}}\right)^{2} \times\left\{\operatorname{bias}\left(D I 3108_{1}\right)\right\}^{2}+\left(\frac{\partial M_{A F_{n e w}}}{\partial \operatorname{Sep}}\right)^{2} \times\{\operatorname{bias}(\operatorname{Sep})\}^{2} \\
& +\left(\frac{\partial M_{A F_{\text {new }}}}{\partial H_{\text {eel }}}\right)^{2} \times\{\text { bias }(\text { Heel })\}^{2}+\left(\frac{\partial M_{A F_{\text {new }}}}{\partial \delta_{1}}\right)^{2} \times\left\{b_{1}\right\}^{2}
\end{aligned}
$$

Note that in evaluating Equation 38, the bias for the $\mathrm{C}_{\mathrm{AF}}$ term, i.e., bias $\left(\mathrm{C}_{\mathrm{AF}}\right)$ term is estimated to be zero and that there are no correlations among the bias terms in this equation. That is, the analytical estimate of the concentration of carbon from AF is unbiased. Also, the $b_{1}$ term is the estimated bias in the volume, $V_{1}$, of Equation 37. GUM Workbench was used to develop the model equation and associated intermediary values supporting the determination of $\mathrm{M}_{\mathrm{AF}_{-} \text {new }}$ for Step 1 (see the upper portion of Exhibit 32) and to document the complete set of partial derivatives needed to support the estimation of the bias of the $\mathrm{M}_{\mathrm{AF}_{-} \text {new }}$ value (see the lower portion of Exhibit 32). Once again, $\mathrm{x}_{11}, \mathrm{x}_{12}, \mathrm{y}_{11}$, and $\mathrm{y}_{12}$ are appropriately selected values (based upon the value of the LI3109 instrument as indicated by LI3109 $)$ for determining volume as indicated in Exhibit 29. To complete the information necessary to compute the estimate of the bias of the $\mathrm{M}_{\mathrm{AF} \_ \text {new }}$, estimates of the bias terms of Equation 38 are needed. Table 18 provides the details of the bias information needed to complete the estimation of the bias for the $\mathrm{M}_{\mathrm{AF}_{-} \text {new }}$ value. A sample calculation for this step including the random and bias uncertainties is provided in Exhibit B12 in Appendix B. 
SRNL-STI-2014-00323

Revision 0

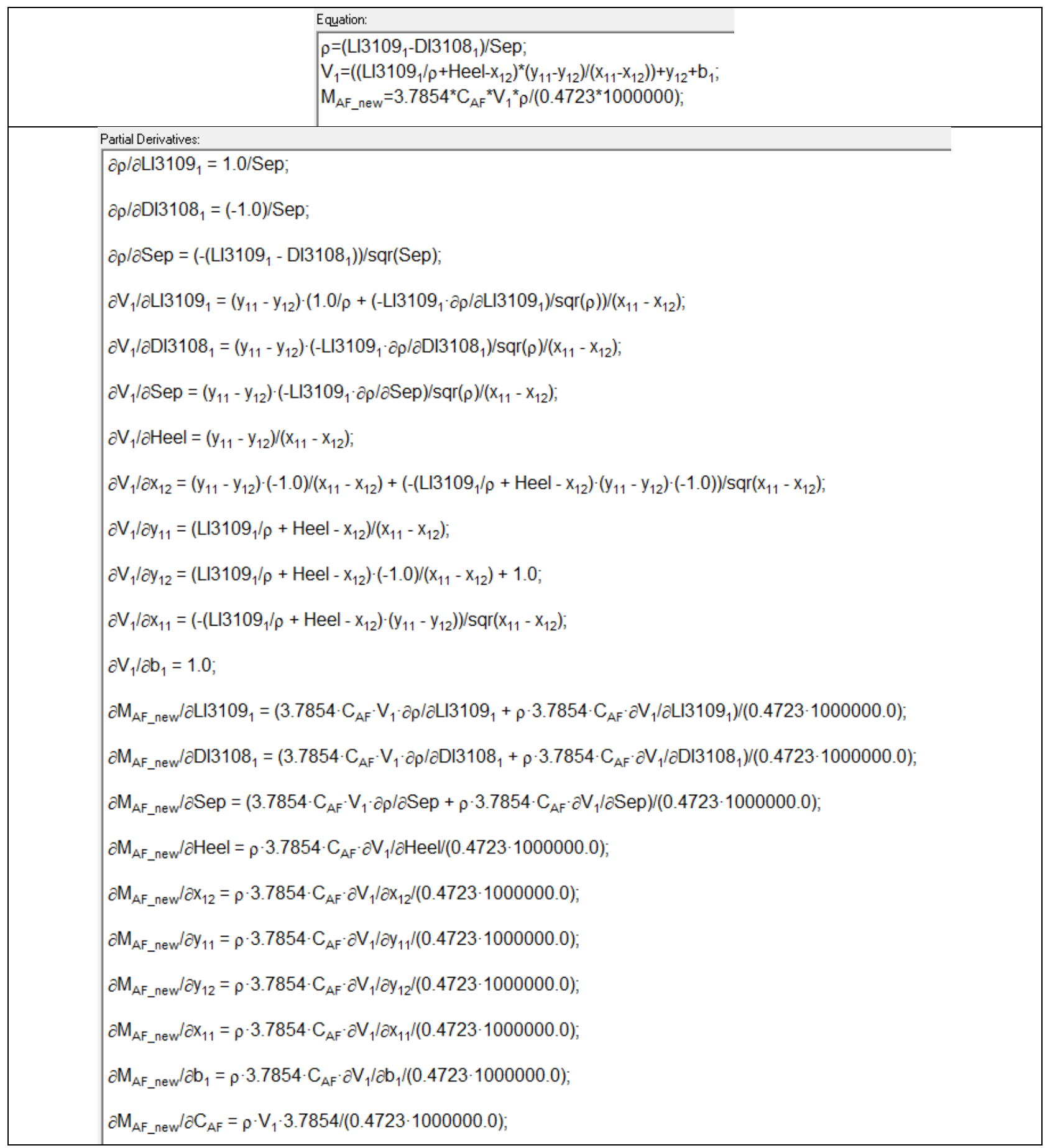

Exhibit 32 Equations for Re-Base-Lining the $\mathbf{M}_{\mathrm{AF}}$ of the SME with Bias Uncertainty 
SRNL-STI-2014-00323

Revision 0

Table 18 Terms and Estimated Bias Uncertainties Supporting Equation 38

\begin{tabular}{|c|c|c|}
\hline Term/Instrument & Description & Bias Uncertainty at 95\% Confidence \\
\hline $\mathrm{C}_{\mathrm{AF}}$ (see Equation 11) & antifoam carbon concentration $(\mathrm{mg} / \mathrm{kg})$ & 0 \\
\hline LI3109 with subscript 1 & level bubbler value (inwc) & $\pm 1 \%$ of 231.0 inwc span [14] \\
\hline DI3108 with subscript 1 & density bubbler value (inwc) & Bias $=2.310$ inwc \\
\hline & $\begin{array}{c}\text { tank calibration uncertainty } \\
\text { (see WSRC-TR-92-250 [8] })\end{array}$ & Bias $=1.605$ inwc \\
\hline $\mathrm{b}_{1}$ & $\begin{array}{c}\text { separation between bubblers } \\
(47 \text { inches })\end{array}$ & 0.0625 inch $[13]$ \\
\hline Sep & $\begin{array}{c}\text { Tank heel below LI3109 } \\
(6.77 \text { inches) }\end{array}$ & 0.0625 inch $[13]$ \\
\hline
\end{tabular}

\subsubsection{SME Step 5 Processing Linked to a Step 1 Event}

If a Step 1 effort is conducted for a SME Product as part of the acceptability decision for a transfer to the MFT, then the analytical work and evaluation must be conducted and the acceptability decision made under the direction of reference [2]. If there is a positive outcome from this process and a transfer to the MFT is made, then the following equation provides an estimate of the mass of antifoam that remains in the SME heel, $\mathrm{M}_{\mathrm{AF}_{-} \text {new }}$, after the transfer has been completed (this corresponds to Step 5 of Exhibit 28):

\section{Equation 39}

$$
M_{A F_{\text {new }}}=\frac{3.7854 \cdot C_{A F} \cdot \rho \cdot V_{2}}{0.4723 \cdot 1000000}
$$

Where the density $(\mathrm{kg} / \mathrm{L}), \rho$, and the volume $\mathrm{V}_{2}$ (gal) are intermediary values which are determined from LI3109 and DI3108 as described in Exhibit 29 and Exhibit 30 with the volume having an additional random variability that is to be incorporated to the random uncertainty of $\mathrm{M}_{\mathrm{AF}_{-} \text {new. }}$. In this equation, $\mathrm{C}_{\mathrm{AF}}$ represents the carbon concentration $(\mathrm{mg} / \mathrm{kg}$ ) from $\mathrm{AF}$ determined from the analytical measurements of the SME contents. The value of 3.7854 is a conversion factor with units of $\mathrm{L} / \mathrm{gal}$. The value of 0.4723 is a conservative (i.e., bounding on the low side) conversion factor with units of $\mathrm{kg}$ of carbon per $\mathrm{kg}$ of antifoam. The 1,000,000 value is a conversion factor with units of $\mathrm{mg} / \mathrm{kg}$.

Following the Taylor's Series expansion approach described above, the estimated variance of $\mathrm{M}_{\mathrm{AF} \_ \text {new }}$ for Step 5 of Exhibit 28 may be written in terms of the fundamental measurements with $\delta_{2}$ representing the random error for $\mathrm{V}_{2}$ as:

\footnotetext{
* The bias in the calibration for the SME is taken as the largest value from Table 1d. Rounding up this value is 6 gallons.
} 
Equation 40

$$
\begin{gathered}
\operatorname{Variance}\left(M_{A F_{n e w}}\right) \approx\left(\frac{\partial M_{A F_{n e w}}}{\partial C_{A F}}\right)^{2} \times \operatorname{variance}\left(C_{A F}\right)+\left(\frac{\partial M_{A F_{n e w}}}{\partial L I 3109_{1}}\right)^{2} \times \operatorname{variance}\left(L I 3109_{1}\right) \\
+\left(\frac{\partial M_{A F_{n e w}}}{\partial D I 3108_{1}}\right)^{2} \times \operatorname{variance}\left(D I 3108_{1}\right)+\left(\frac{\partial M_{A F_{n e w}}}{\partial L I 3109_{2}}\right)^{2} \times \operatorname{variance}\left(L I 3109_{2}\right) \\
+\left(\frac{\partial M_{A F_{n e w}}}{\partial \delta_{2}}\right)^{2} \times \operatorname{variance}\left(\delta_{2}\right)
\end{gathered}
$$

GUM Workbench was used to develop the model equation and associated intermediary values supporting the determination of $\mathrm{M}_{\mathrm{AF}_{-} \text {new }}$ for Step 5 (see the upper portion of Exhibit 33) and to document the complete set of partial derivatives needed to support the estimation of the variance of the $\mathrm{M}_{\mathrm{AF} \_ \text {new }}$ value (see the lower portion of Exhibit 33 and Exhibit 34 ). For example, the $\mathrm{x}_{21}, \mathrm{x}_{22}, \mathrm{y}_{21}$, and $\mathrm{y}_{22}$ values are appropriately selected values (based upon the values of the LI3109 instrument as indicated by LI3109 ${ }_{2}$ for determining the volume remaining the Heel of the SME as indicated in Exhibit 28. To complete the information necessary to compute the estimate of the variance of the $\mathrm{M}_{\mathrm{AF}_{-} \text {out }}$, estimates of the variance terms of Equation 40 are needed. These values along with a description of the terms of the equation are provided in Table 19. 
SRNL-STI-2014-00323

Revision 0

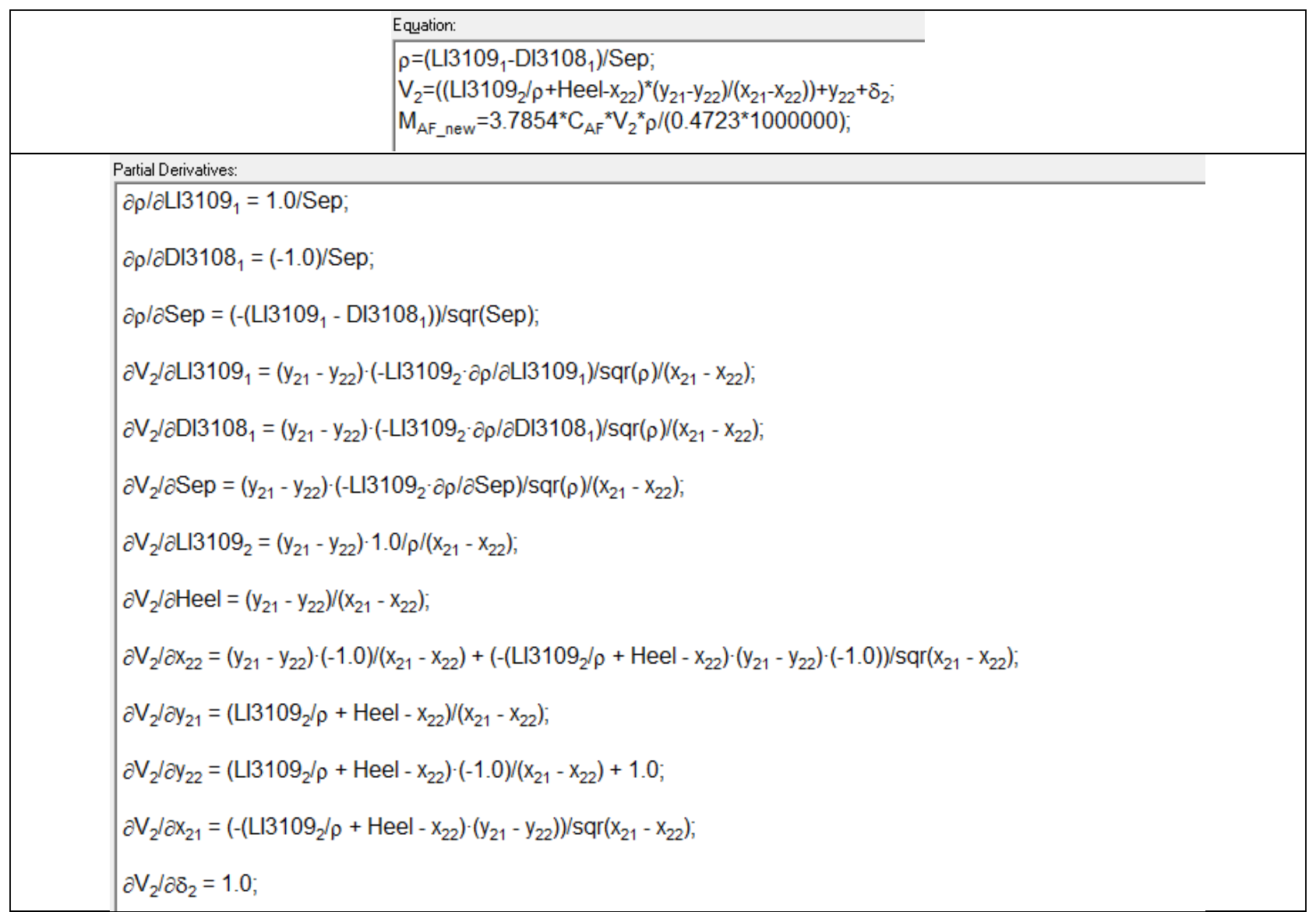

Exhibit 33 Equations for Analytical $\mathrm{M}_{\mathrm{AF}_{-} \text {new }}$ for SME Heel with Random Uncertainty (part 1 of 2) 
SRNL-STI-2014-00323

Revision 0

\begin{tabular}{|c|}
\hline dditional Partial Derivatives \\
\hline 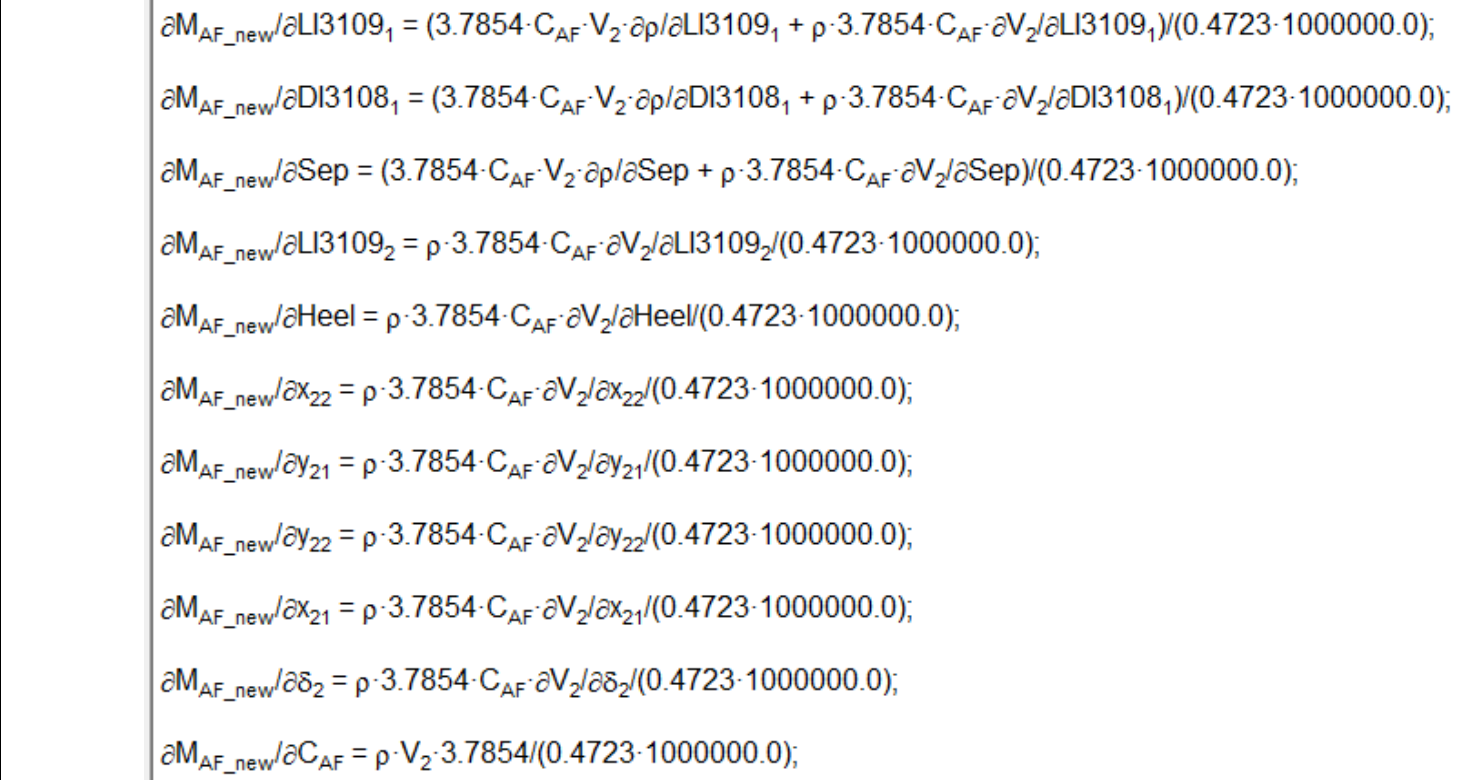 \\
\hline
\end{tabular}

Exhibit 34 Equations for Analytical $\mathrm{M}_{\mathrm{AF}_{-} \text {new }}$ for SME Heel with Random Uncertainty (part 2 of 2)

Table 19 Terms and Estimated Random Uncertainties Supporting Equation 40

\begin{tabular}{|c|c|c|}
\hline Term/Instrument & Description & 1-Sigma Random Uncertainty \\
\hline $\mathrm{C}_{\mathrm{AF}}$ (see Equation 11) & $\begin{array}{l}\text { antifoam carbon concentration } \\
(\mathrm{mg} / \mathrm{kg})\end{array}$ & analytical uncertainty (see Equation 12) \\
\hline \multirow[t]{3}{*}{$\begin{array}{c}\text { LI3109 with } \\
\text { subscripts } 1 \text { and } 2 \\
\end{array}$} & level bubbler values (inwc) & $\pm 1 \%$ of 231.0 inwc span $[14]$ \\
\hline & DCS Deviation Limit & \pm 0.1 inwc $[14]$ \\
\hline & & $\begin{array}{l}\text { Using a uniform distribution, 1-sigma random is } \\
{\left[(2.31 / \sqrt{ } 3)^{2}+(0.1 / \sqrt{ } 3)^{2}\right]^{0.5}=1.3349}\end{array}$ \\
\hline \multirow[t]{3}{*}{ DI3108 with subscript 1} & density bubbler value (inwc) & $\pm 1 \%$ of 160.5 inwc span $[15]$ \\
\hline & DCS Deviation Limit & \pm 0.05 inwc $[15]$ \\
\hline & & $\begin{array}{l}\text { Using a uniform distribution, 1-sigma random is } \\
{\left[(1.605 / \sqrt{ } 3)^{2}+(0.05 / \sqrt{3})^{2}\right]^{0.5}=0.9271}\end{array}$ \\
\hline$\delta_{2}$ & $\begin{array}{l}\text { tank calibration uncertainty } \\
\text { (see footnote for Table 17) }\end{array}$ & 1-sigma random $=9$ gallons \\
\hline
\end{tabular}

To complete the evaluation of the $\mathrm{M}_{\mathrm{AF}_{-} \text {new }}$ required for Step 5, the bias for $\mathrm{M}_{\mathrm{AF} \mathrm{F}_{\text {new }}}$ determined by Equation 39 must be estimated. A bound (at 95\% confidence) on the bias of the antifoam mass remaining in the SME after a transfer out to the MFT, $\mathrm{M}_{\mathrm{AF}_{-} \text {new }}$, is estimated, as above, by appealing to a Taylor Series expansion of Equation 39 in the fundamental measurements. Once again, note that $\rho$ and $V_{2}$ are intermediary values. Also, the $V_{2}$ value has a potential bias that is to be included in the evaluation. The Taylor's Series expansion may be expressed in the fundamental measurements and the potential bias as given by: 
SRNL-STI-2014-00323

Revision 0

\section{Equation 41}

$$
\begin{aligned}
& \left\{\operatorname{bias}\left(M_{A F_{n e w}}\right)\right\}^{2} \approx\left(\frac{\partial M_{A F_{n e w}}}{\partial C_{A F}}\right)^{2} \times\left\{\operatorname{bias}\left(C_{A F}\right)\right\}^{2}+\left(\frac{\partial M_{A F_{n e w}}}{\partial L I 3109_{1}}\right)^{2} \times\{\operatorname{bias}(\text { LI3109 } 1)\}^{2} \\
& +\left(\frac{\partial M_{A F_{n e w}}}{\partial D I 3108_{1}}\right)^{2} \times\left\{\operatorname{bias}\left(D I 3108_{1}\right)\right\}^{2}+\left(\frac{\partial M_{A F_{n e w}}}{\partial S e p}\right)^{2} \times\{\operatorname{bias}(\operatorname{Sep})\}^{2} \\
& +\left(\frac{\partial M_{A F_{\text {new }}}}{\partial H_{\text {eel }}}\right)^{2} \times\{\text { bias }(\text { Heel })\}^{2}+\left(\frac{\partial M_{A F_{\text {new }}}}{\partial L I 3109_{2}}\right)^{2} \times\left\{\text { bias }\left(L I 3109_{2}\right)\right\}^{2} \\
& +\left(\frac{\partial M_{A F_{n e w}}}{\partial b_{2}}\right)^{2} \times\left\{\operatorname{bias}\left(b_{2}\right)\right\}^{2} \\
& +2 \times 1 \times\left|\frac{\partial M_{A F_{n e w}}}{\partial L I 3109_{1}}\right| \times\left|\frac{\partial M_{A F_{\text {new }}}}{\partial L I 3109_{2}}\right| \times \operatorname{bias}\left(L I 3109_{1}\right) \times \operatorname{bias}\left(L I 3109_{2}\right)
\end{aligned}
$$

Note that in evaluating Equation 41, the bias for the $\mathrm{C}_{\mathrm{AF}}$ term, i.e., bias $\left(\mathrm{C}_{\mathrm{AF}}\right)$ term, is estimated to be zero and that a potential correlation among a pair of the biases is introduced in a bounding manner. So the approach may be stated as: The analytical estimate of the concentration of carbon from AF is unbiased, the $b_{2}$ term is the estimated bias in the $V_{2}$ volume, and there is a potential correlation in the biases for the two LI3109 measurements. GUM Workbench was used to develop the model equation and associated intermediary values supporting the determination of the bias of $\mathrm{M}_{\mathrm{AF} \text { nnw }}$ for Step 5 (see the upper portion of Exhibit 35) and to document the complete set of partial derivatives needed to support the estimation of the bias of the $\mathrm{M}_{\mathrm{AF}_{-} \text {new }}$ value (see the lower portion of Exhibit 35 and Exhibit 36). Once again, $\mathrm{x}_{21}, \mathrm{x}_{22}$, $\mathrm{y}_{21}$, and $\mathrm{y}_{22}$ are appropriately selected values (based upon the value of the LI3109 instrument as indicated by LI31092) for determining volume as indicated in Exhibit 29. To complete the information necessary to compute the estimate of the bias of the $\mathrm{M}_{\mathrm{AF} \text { new }}$, estimates of the bias terms of Equation 41 are needed. Table 20 provides the details of the bias information needed to complete the estimation of the bias for the $\mathrm{M}_{\mathrm{AF} \text { new }}$ value. A sample calculation for this step including the random and bias uncertainties is provided in Exhibit B13 in Appendix B. 
SRNL-STI-2014-00323

Revision 0

\begin{tabular}{|c|c|}
\hline & $\begin{array}{l}\text { Equation: } \\
\begin{array}{|l}\rho=\left(\mathrm{LI} 3109_{1}-\mathrm{DI} 3108_{1}\right) / \mathrm{Sep} ; \\
\mathrm{V}_{2}=\left(\left(\mathrm{LI} 3109_{2} / \rho+\mathrm{Heel}_{22} \mathrm{x}_{22}\right)^{*}\left(\mathrm{y}_{21}-\mathrm{y}_{22}\right) /\left(\mathrm{x}_{21} \mathrm{x}_{22}\right)\right)+\mathrm{y}_{22}+\mathrm{b}_{2} ; \\
\mathrm{M}_{\text {AF_new }}=3.7854^{*} \mathrm{C}_{\mathrm{AF}}{ }^{*} \mathrm{~V}_{2}{ }^{*} \rho /\left(0.4723^{*} 1000000\right) ;\end{array}\end{array}$ \\
\hline $\begin{array}{l}\text { Partial Derivatives: } \\
\partial \rho / \partial \mathrm{LI} 3109_{1}= \\
\partial \rho / \partial \mathrm{DI} 3108_{1} \\
\partial \rho / \partial \mathrm{Sep}=(-(\mathrm{L} \\
\partial \mathrm{V}_{2} / \partial \mathrm{LI} 3109_{1} \\
\partial \mathrm{V}_{2} / \partial \mathrm{DI} 3108_{1} \\
\partial \mathrm{V}_{2} / \partial \mathrm{Sep}=(\mathrm{y} \\
\partial \mathrm{V}_{2} / \partial \mathrm{LI} 3109_{2} \\
\partial \mathrm{V}_{2} / \partial \mathrm{Heel}=() \\
\partial \mathrm{V}_{2} / \partial \mathrm{x}_{22}=\left(\mathrm{y}_{2}\right. \\
\partial \mathrm{V}_{2} / \partial \mathrm{Y}_{21}=(\mathrm{LI} / \\
\partial \mathrm{V}_{2} / \partial \mathrm{Y}_{22}=(\mathrm{LI} / \\
\partial \mathrm{V}_{2} / \partial \mathrm{x}_{21}=(-(\mathrm{L} \\
\partial \mathrm{V}_{2} / \partial \mathrm{b}_{2}=1.0\end{array}$ & $\begin{array}{l}\text { (1))/sqr(Sep); } \\
\left.109_{2} \cdot \partial \rho / \partial \mathrm{L} / 3109_{1}\right) / \operatorname{sqr}(\rho) /\left(\mathrm{x}_{21}-\mathrm{x}_{22}\right) ; \\
\left.109_{2} \cdot \partial \rho / \partial \mathrm{DI} 3108_{1}\right) / \mathrm{sqr}(\rho) /\left(\mathrm{x}_{21}-\mathrm{x}_{22}\right) ; \\
2 \cdot \partial \rho / \partial \mathrm{Sep}) / \mathrm{sqr}(\rho) /\left(\mathrm{x}_{21}-\mathrm{x}_{22}\right) ; \\
/\left(\mathrm{x}_{21}-\mathrm{x}_{22}\right) ; \\
\left.-\mathrm{x}_{22}\right)+\left(-\left(\mathrm{LI} 3109_{2} / \rho+\mathrm{Heel}-\mathrm{x}_{22}\right) \cdot\left(\mathrm{y}_{21}-\mathrm{y}_{22}\right) \cdot(-1.0)\right) / \mathrm{sqr}\left(\mathrm{x}_{21}-\mathrm{x}_{22}\right) ; \\
\left.\mathrm{x}_{22}\right) /\left(\mathrm{x}_{21}-\mathrm{x}_{22}\right) ; \\
\left.\mathrm{x}_{22}\right) \cdot(-1.0) /\left(\mathrm{x}_{21}-\mathrm{x}_{22}\right)+1.0 ; \\
\left.\left.-\mathrm{x}_{22}\right) \cdot\left(\mathrm{y}_{21}-\mathrm{y}_{22}\right)\right) / \mathrm{sqr}\left(\mathrm{x}_{21}-\mathrm{x}_{22}\right) ;\end{array}$ \\
\hline
\end{tabular}

Exhibit 35 Equations for Analytical $\mathrm{M}_{\mathrm{AF}_{-} \text {new }}$ for SME Heel with Bias Uncertainty (part 1 of 2) 
SRNL-STI-2014-00323

Revision 0

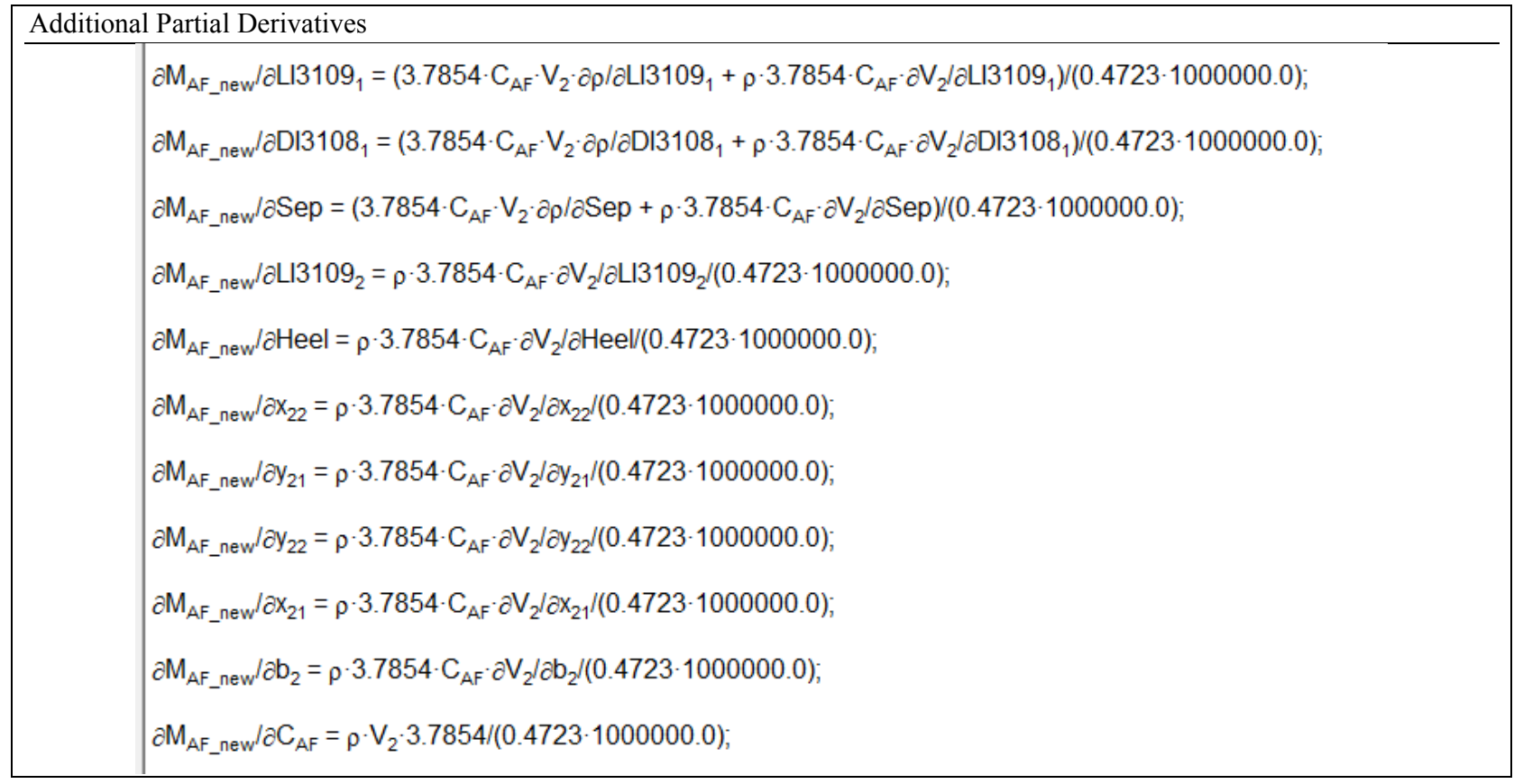

Exhibit 36 Equations for Analytical $\mathrm{M}_{\mathrm{AF}_{-} \text {new }}$ for SME Heel with Bias Uncertainty (part 2 of 2)

Table 20 Terms and Estimated Bias Uncertainties Supporting Equation 41

\begin{tabular}{|c|c|c|}
\hline Term/Instrument & Description & Bias Uncertainty \\
\hline $\mathrm{C}_{\mathrm{AF}}$ (see Equation 11) & antifoam carbon concentration (mg/kg) \\
\hline $\begin{array}{c}\text { LI3109 with } \\
\text { subscripts 1 and 2 }\end{array}$ & level bubbler values (inwc) & $\pm 1 \%$ of 231.0 inwc span [14] \\
\hline DI3108 with subscript 1 & density bubbler (inwc) & Bias $=2.310$ inwc \\
\hline & $\begin{array}{c}\text { Tank Calibration uncertainty } \\
\text { (see footnote for Table 18) }\end{array}$ & Bias = 1.605 inwc \\
\hline $\mathrm{b}_{2}$ & $\begin{array}{c}\text { Separation between bubblers } \\
\text { (47 inches) }\end{array}$ \\
\hline Sep & $\begin{array}{c}\text { Tank heel below LI3109 } \\
(6.77 \text { inches })\end{array}$ \\
\hline Heel & & 0.0625 inch [13] \\
\hline
\end{tabular}

\subsubsection{SME Step 4 Processing}

The primary purpose of the AF tracking system is to provide an additional method beyond the approach provided in [2] of demonstrating that the SME material meets the constraints imposed by [1] for flammability control. Following the process flow diagram (Exhibit 28) and the supporting calculations (Exhibit 29 and Exhibit 30), if the SME $\mathrm{M}_{\mathrm{AF}}$ value is known along with the associated uncertainties, then the concentration of carbon associated with this mass of $\mathrm{AF}, \mathrm{C}_{\mathrm{AF}}$, expressed in $\mathrm{mg} / \mathrm{kg}$, is determined by:

Equation 42

$$
C_{A F}=\frac{0.4905 \cdot 1000000 \cdot M_{A F}}{\rho \cdot V_{1} \cdot 3.7854}
$$


where the density $(\mathrm{kg} / \mathrm{L}), \rho$, and the volume $\mathrm{V}_{1}$ (gal) are intermediary values which are determined from LI3109 and DI3108 as described in Exhibit 29 and Exhibit 30 with the volume having an additional random variability that is to be incorporated into the random uncertainty of $\mathrm{C}_{\mathrm{AF}}$. The value of 3.7854 is a conversion factor with units of $\mathrm{L} / \mathrm{gal}$. The value of 0.4905 is a conservative (i.e., bounding on the high side) conversion factor with units of $\mathrm{kg}$ of carbon per $\mathrm{kg}$ of antifoam ${ }^{f}$. The $1,000,000$ value is a conversion factor with units of $\mathrm{mg} / \mathrm{kg}$.

Following the Taylor's Series expansion approach described above, the estimated variance of $\mathrm{C}_{\mathrm{AF}}$ for Step 4 of Exhibit 28 may be written in terms of the fundamental measurements with $\delta_{1}$ representing the random error for $\mathrm{V}_{1}$ as:

Equation 43

$$
\begin{gathered}
\operatorname{Variance}\left(C_{A F}\right) \approx\left(\frac{\partial C_{A F}}{\partial M_{A F}}\right)^{2} \times \operatorname{variance}\left(C_{A F}\right)+\left(\frac{\partial C_{A F}}{\partial L I 3109_{1}}\right)^{2} \times \operatorname{variance}(\text { LI3109 } 1) \\
+\left(\frac{\partial C_{A F}}{\partial D I 3108_{1}}\right)^{2} \times \operatorname{variance}\left(D I 3108_{1}\right)+\left(\frac{\partial C_{A F}}{\partial \delta_{1}}\right)^{2} \times \operatorname{variance}\left(\delta_{1}\right)
\end{gathered}
$$

GUM Workbench was used to develop the model equation and associated intermediary values supporting the determination of $\mathrm{C}_{\mathrm{AF}}$ for Step 4 (see the upper portion of Exhibit 37) and to document the complete set of partial derivatives needed to support the estimation of the variance of the $\mathrm{C}_{\mathrm{AF}}$ value (see the lower portion of Exhibit 37). For example, the $\mathrm{x}_{11}, \mathrm{x}_{12}, \mathrm{y}_{11}$, and $\mathrm{y}_{12}$ values are appropriately selected values (based upon the values of the LI3109 instrument as indicated by LI3109 ${ }_{1}$ for determining the volume of the SME Product being evaluated for acceptability as indicated in Step 4 of Exhibit 28. To complete the information necessary to compute the estimate of the variance of the $\mathrm{C}_{\mathrm{AF}}$, estimates of the variance terms of Equation 43 are needed. These values along with a description of the terms of the equation are provided in Table 21.

\footnotetext{
${ }^{f}$ See SRNL E-Notebook O7787-00055-09, Antifoam 747 Basic Data and Acceptance Testing, July 29, 2014.
} 
Equation:

$\rho=\left(\mathrm{LI}_{3} 109_{1}-\mathrm{DI} 3108_{1}\right) / \mathrm{Sep}$;

$\mathrm{V}_{1}=\left(\left(\text { LI3109 } 1 / \rho+\text { Heel- } \mathrm{x}_{12}\right)^{\star}\left(\mathrm{y}_{11}-\mathrm{y}_{12}\right) /\left(\mathrm{x}_{11}-\mathrm{X}_{12}\right)\right)+\mathrm{y}_{12}+\delta_{1}$;

$\mathrm{C}_{\mathrm{AF}}=0.4905^{*} 1000000^{*} \mathrm{M}_{\mathrm{AF}} /\left(\mathrm{V}_{1}^{*} \rho^{\star} 3.7854\right)$;

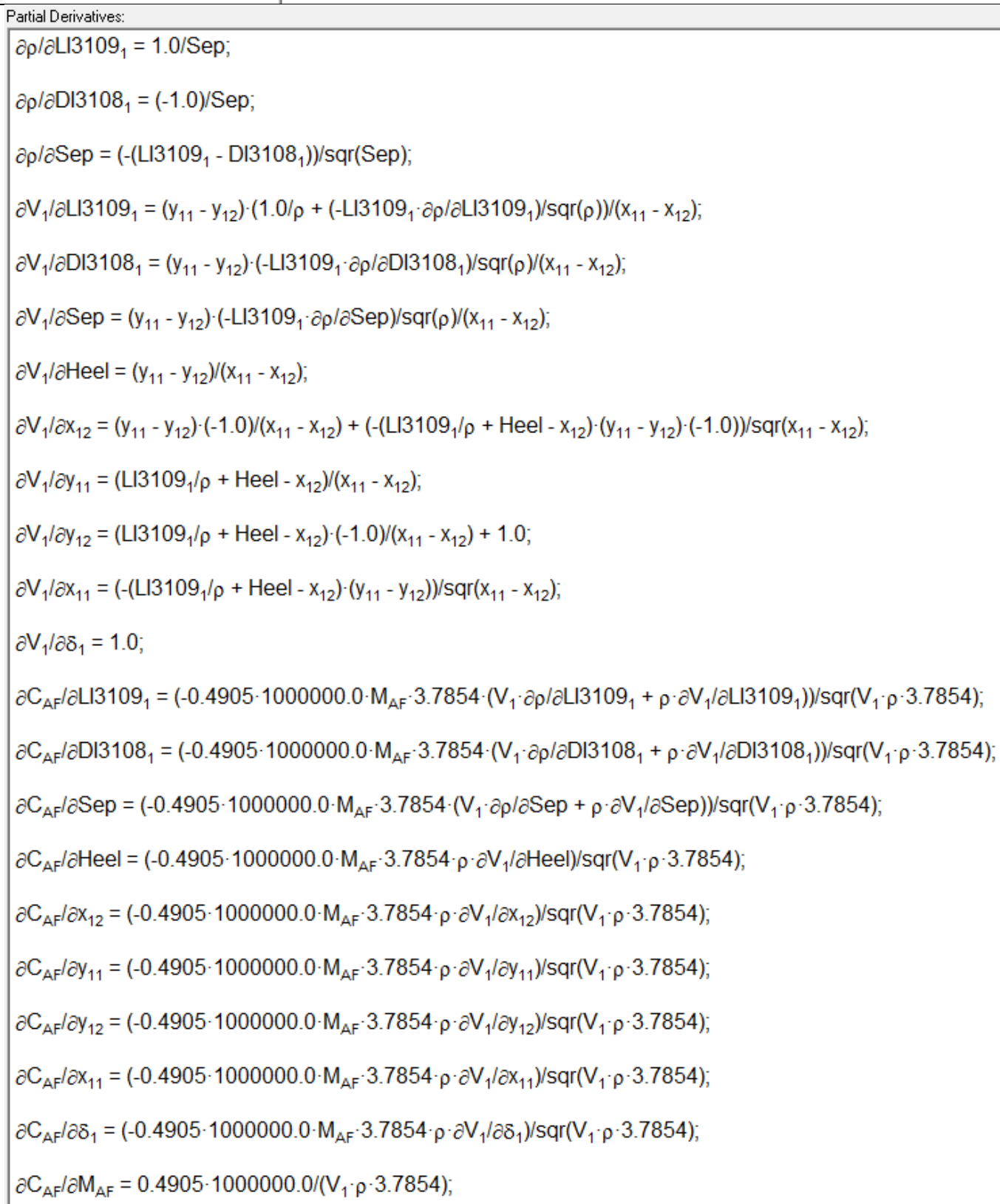

Exhibit 37 Equations for $\mathrm{C}_{\mathrm{AF}}$ for SME Product with Random Uncertainty 
SRNL-STI-2014-00323

Revision 0

Table 21 Terms and Estimated Random Uncertainties Supporting Equation 43

\begin{tabular}{|c|c|c|}
\hline Term/Instrument & Description & 1-Sigma Random Uncertainty \\
\hline $\mathrm{C}_{\mathrm{AF}}$ (see Equation 11) & $\begin{array}{c}\text { antifoam carbon concentration } \\
(\mathrm{mg} / \mathrm{kg})\end{array}$ & Analytical uncertainty (see Equation 12) \\
\hline LI3109 with subscript 1 & level bubbler value (inwc) & $\pm 1 \%$ of 231.0 inwc span [14] \\
\hline & DCS deviation limit & \pm 0.1 inwc $[14]$ \\
\hline & density bubbler value (inwc) & $\begin{array}{c}\text { Using a uniform distribution, } 1 \text {-sigma random is } \\
{\left[(2.31 / \sqrt{3} 3)^{2}+(0.1 / \sqrt{3})^{2}\right]^{0.5}=1.3349}\end{array}$ \\
\hline DI3108 with subscript 1 & DCS deviation limit & $\pm 1 \%$ of 160.5 inwc span $[15]$ \\
\hline & & $\begin{array}{c}\text { Using a uniform distribution, } 1 \text {-sigma random is } \\
{\left[(1.605 / \sqrt{3} 3)^{2}+(0.05 / \sqrt{3})^{2}\right]^{0.5}=0.9271}\end{array}$ \\
\hline & $\begin{array}{c}\text { tank calibration uncertainty } \\
\text { (see footnote for Table } 17)\end{array}$ & $1-\operatorname{sigma}$ random $=9$ gallons \\
\hline
\end{tabular}

To complete the evaluation of the $\mathrm{C}_{\mathrm{AF}}$ required for Step 4, the bias for $\mathrm{C}_{\mathrm{AF}}$ determined by Equation 42 must be estimated. A bound (at 95\% confidence) on the bias of the concentration of carbon from AF in the $\mathrm{SME}$ Product, $\mathrm{C}_{\mathrm{AF}}$, is estimated, as above, by appealing to a Taylor Series expansion of Equation 42 in the fundamental measurements. Once again, note that $\rho$ and $V_{1}$ are intermediary values. Also, the $V_{1}$ value has a potential bias that is to be included in the evaluation. The Taylor's Series expansion may be expressed in the fundamental measurements and the potential bias as given by:

\section{Equation 44}

$$
\begin{gathered}
\left\{\operatorname{bias}\left(C_{A F}\right)\right\}^{2} \approx\left(\frac{\partial C_{A F}}{\partial M_{A F}}\right)^{2} \times\left\{\operatorname{bias}\left(M_{A F}\right)\right\}^{2}+\left(\frac{\partial C_{A F}}{\partial \text { LI3109 }}\right)^{2} \times\left\{\operatorname{bias}\left({\text { LI } 3109_{1}}_{1}\right)\right\}^{2} \\
+\left(\frac{\partial C_{A F}}{\partial D I 3108_{1}}\right)^{2} \times\{\operatorname{bias}(\text { DI3108 } 1)\}^{2}+\left(\frac{\partial C_{A F}}{\partial S e p}\right)^{2} \times\{\text { bias }(\text { Sep })\}^{2} \\
+\left(\frac{\partial C_{A F}}{\partial H e e l}\right)^{2} \times\{\text { bias }(\text { Heel })\}^{2}++\left(\frac{\partial C_{A F}}{\partial b_{1}}\right)^{2} \times\left\{\text { bias }\left(b_{1}\right)\right\}^{2}
\end{gathered}
$$

Note that in evaluating Equation 44 , the bias for the $\mathrm{M}_{\mathrm{AF}}$ term, i.e., bias $\left(\mathrm{M}_{\mathrm{AF}}\right)$, is provided by the status information of the SME at the time of the decision for acceptability of the transfer of the SME Product to the MFT. GUM Workbench was used to develop the model equation and associated intermediary values supporting the determination of the bias of $\mathrm{C}_{\mathrm{AF}}$ for Step 4 (see the upper portion of Exhibit 38) and to document the complete set of partial derivatives needed to support the estimation of the bias of the $\mathrm{C}_{\mathrm{AF}}$ value (see the lower portion of Exhibit 38). Once again, $\mathrm{x}_{11}, \mathrm{x}_{12}, \mathrm{y}_{11}$, and $\mathrm{y}_{12}$ are appropriately selected values (based upon the value of the LI3109 instrument as indicated by LI3109 ) for determining volume as indicated in Exhibit 29. To complete the information necessary to compute the estimate of the bias of the $\mathrm{C}_{\mathrm{AF}}$, estimates of the bias terms of Equation 44 are needed. Table 22 provides the details of the bias information needed to complete the estimation of the bias for the $\mathrm{C}_{\mathrm{AF}}$ value. A sample calculation for this step including the random and bias uncertainties is provided as part of the results in Exhibit B14 in Appendix B. 


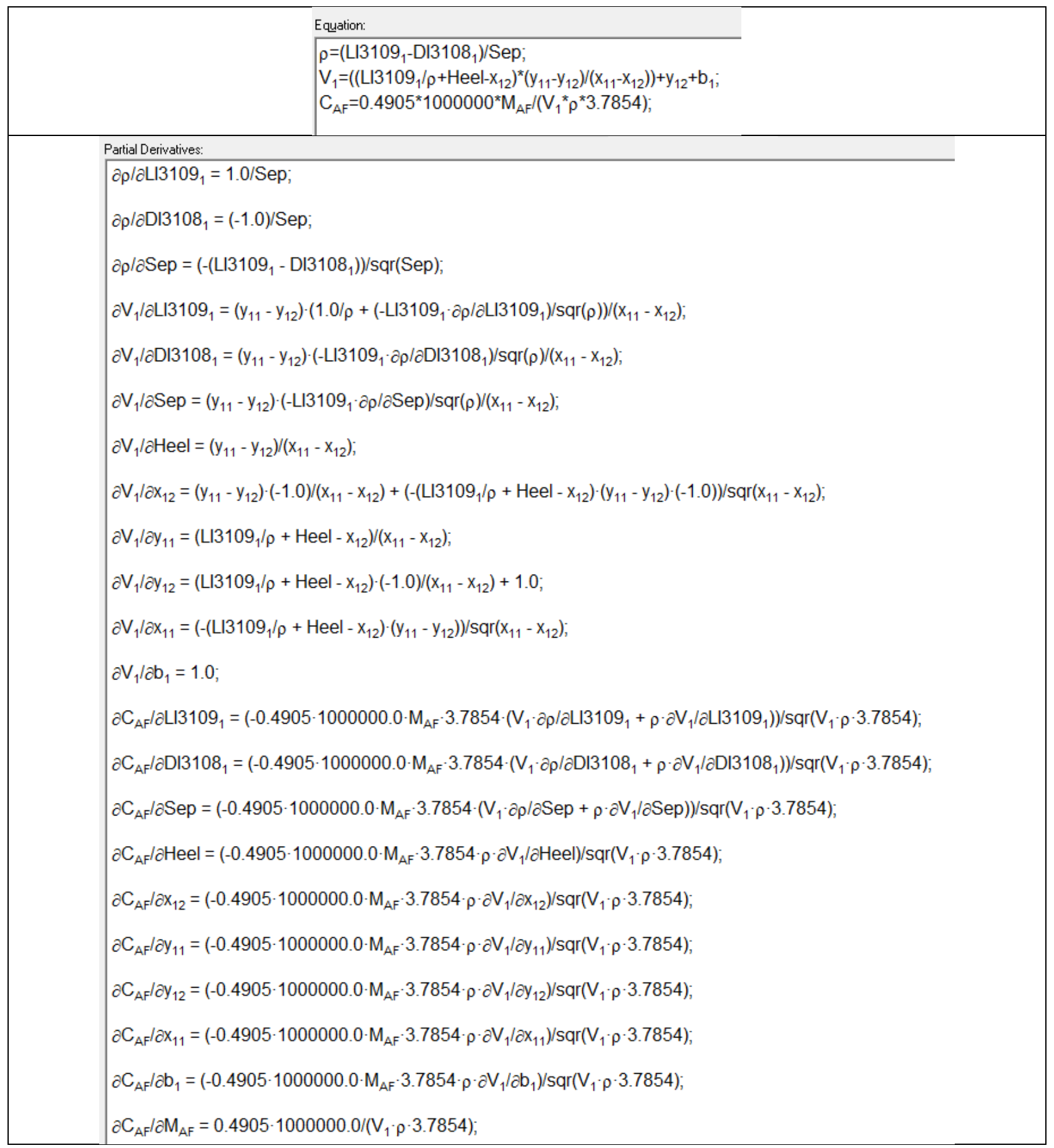

Exhibit 38 Equations for $\mathrm{C}_{\mathrm{AF}}$ for SME Product with Bias Uncertainty 
SRNL-STI-2014-00323

Revision 0

Table 22 Terms and Estimated Bias Uncertainties Supporting Equation 44

\begin{tabular}{|c|c|c|}
\hline Term/Instrument & Description & Bias Uncertainty at 95\% Confidence \\
\hline $\mathrm{C}_{\mathrm{AF}}$ (see Equation 11) & antifoam carbon concentration (mg/kg) & 0 \\
\hline LI3109 with subscript 1 & level bubbler value (inwc) & $\pm 1 \%$ of 231.0 inwc span [14] \\
\hline DI3108 with subscript 1 & density bubbler value (inwc) & Bias 2.310 inwc \\
\hline $\mathrm{b}_{1}$ & $\begin{array}{c}\text { tank calibration uncertainty } \\
\text { (see footnote for Table 18) }\end{array}$ & Bias = 1.605 inwc \\
\hline Sep & $\begin{array}{c}\text { Separation between bubblers } \\
(47 \text { inches) }\end{array}$ \\
\hline Heel & $\begin{array}{c}\text { Tank heel below LI3109 } \\
(6.77 \text { inches) }\end{array}$ & 0.0625 inch [13] \\
\hline
\end{tabular}

The calculations just completed allow for the determination of the $\mathrm{C}_{\mathrm{AF}}$, the concentration of carbon in $\mathrm{mg} / \mathrm{kg}$, attributable to the AF in the SME Product and its uncertainty (both random and bias). The use of the AF tracking system in the AMFT, SRAT, and SME that have led to the completion of these calculations will be applicable beyond just SB8.

To complete the decision as to the acceptability of the $\mathrm{C}_{\mathrm{AF}}$ concentration relative to the flammability controls for SB8 involves analytical measurements of samples of the SME Product. Nitrate and TOC measurements must meet the constraints imposed by reference [1]. For nitrate, see the discussion provided in Section 2.1 above.

With the nitrate concentration successfully meeting its constraint, attention turns to TOC. The allowed amount of TOC for a SME batch is determined from the nitrate as described in [1] and summarized in Section 2.2 above. There are three levels of TOC that have been established with each one having its own acceptable level of carbon from AF [1]. The acceptability of each of these levels of TOC must be determined to assess the lowest level that meets the requirements of [1] as implemented in [2]. Section 2.2 above provides a description of these requirements.

There is an acceptable level of carbon from AF for each level of TOC; see [1], [2] and Section 2.3 above. So, an acceptability decision is the determination that the amount of carbon from AF is less than the amount allowed by [2], after accounting for all of the uncertainties involved. Let $\mathrm{A}_{\mathrm{Ci}}$ represent the allowed carbon for the $i^{\text {th }}$ level of TOC and let $\mathrm{T}_{\mathrm{C}}$ represent the carbon concentration in the SME Product from the tracking system, then before accounting for uncertainties, acceptability may be defined as:

\section{Equation 45}

$$
M_{C_{i}}=A_{C_{i}}-T_{C}>0
$$

where $i=1,2$, or 3 , representing the three levels of TOC developed in [1].

Re-expressing this in terms of the information in Table 2 and the average of the nitrate measurements of the SME Product, $\overline{\mathrm{NO}_{3}}$, yields (for $\mathrm{i}=1,2$, or 3 ): 


\section{Equation 46}

$$
M_{C_{i}}=\sqrt{h_{i}+j_{i} \cdot \overline{N O_{3}}}-T_{C}>0
$$

From the discussion leading up to Equation 10 and the approach used there to address the random uncertainties associated with the terms under the radical and letting $\mathrm{s}_{\mathrm{C}}$ represent the 1-sigma random uncertainties, associated with the $\mathrm{T}_{\mathrm{C}}$ value from the tracking system, the variance of the random errors of $\mathrm{M}_{\mathrm{Ci}}$ is estimated by:

\section{Equation 47}

$$
\begin{gathered}
\operatorname{var}\left(M_{C_{i}}\right)=0.25 \cdot\left(j_{i} \cdot\left(h_{i}+j_{i} \cdot \overline{N O_{3}}\right)^{-0.5}\right)^{2} \cdot\left(s e \overline{N O_{3}}\right)^{2} \\
+0.000186323 \cdot\left(j_{i} \cdot\left(h_{i}+j_{i} \cdot \overline{N O_{3}}\right)^{-0.5}\right)^{2} \cdot\left(\overline{N O_{3}}\right)^{2}+\left(s_{C}\right)^{2}
\end{gathered}
$$

The expanded random uncertainty of the estimated difference, $\mathrm{M}_{\mathrm{Ci}}$, at $95 \%$ confidence is determined by multiplying the square root of the estimated variance of $\mathrm{M}_{\mathrm{Ci}}$ by an appropriate Student's $\mathrm{t}$ statistic. In this case a one-sided confidence statement is needed; so, an upper 5\%-tail of the Student's t distribution will be used. As discussed in Section 2, since the average nitrate value is based upon at least 4 measurements, a conservative 3 degrees of freedom for the estimated variance of $\mathrm{M}_{\mathrm{Ci}}$ will be used. This leads to a $t$ value of 2.353 . Thus, at $95 \%$ confidence the expanded random uncertainty of the difference, $\mathrm{M}_{\mathrm{Ci}}$, is 2.353 times the square root of the estimated variance of $\mathrm{M}_{\mathrm{Ci}}$. To complete the assessment of the impact of uncertainties on the $\mathrm{M}_{\mathrm{Ci}}$ difference, the bias of the $\mathrm{T}_{\mathrm{C}}$ value from the tracking system must be accounted for. Let $b_{C}$ represent that bias. Then, for the antifoam content of the SME to be acceptable (at $95 \%$ confidence), the following constraint must be met:

\section{Equation 48}

$$
\mathrm{M}_{\mathrm{Ci}}-\mathrm{b}_{\mathrm{C}}-2.353 \cdot\left(\operatorname{Var}\left(\mathrm{M}_{\mathrm{Ci}}\right)\right)^{0.5}>0
$$

for $\mathrm{i}=1,2$, or 3 associated with one of the three values:728, 894, or 1,017 gal that is selected to be appropriate for the given SME batch. A sample of these calculations along with the acceptability decision for the SME Product is provided as part of the results in Exhibit B14 in Appendix B. 
SRNL-STI-2014-00323

Revision 0

\subsubsection{SME Step 5 Processing}

Once the SME Product is transferred to the MFT, then the following equation provides an estimate of the mass of antifoam that remains in the $\mathrm{SME}$ heel, $\mathrm{M}_{\mathrm{AF} \text { new }}$, after the transfer has been completed (this corresponds to Step 5 of Exhibit 28):

\section{Equation 49}

$$
M_{A F_{\text {new }}}=\frac{M_{A F} \cdot V_{2}}{V_{1}}
$$

where the volumes $\mathrm{V}_{1}$ and $\mathrm{V}_{2}$ in gallons are intermediary values which are determined from LI3109 and DI3108 as described in Exhibit 29 and Exhibit 30 and with the volumes each having an additional random variability that is to be incorporated to the random uncertainty of $\mathrm{M}_{\mathrm{AF} \text { _new }}$.

Following the Taylor's Series expansion approach described above, the estimated variance of $\mathrm{M}_{\mathrm{AF}}$ new for Step 5 of Exhibit 28 may be written in terms of the fundamental measurements with $\delta_{1}$ and $\delta_{2}$ representing the random errors for $\mathrm{V}_{1}$ and $\mathrm{V}_{2}$, ,respectively, as:

\section{Equation 50}

$$
\begin{gathered}
\operatorname{Variance}\left(M_{A F_{\text {new }}}\right) \approx\left(\frac{\partial M_{A F_{\text {new }}}}{\partial M_{A F}}\right)^{2} \times \operatorname{variance}\left(M_{A F}\right)+\left(\frac{\partial M_{A F_{\text {new }}}}{\partial L I 3109_{1}}\right)^{2} \times \operatorname{variance}\left(L I 3109_{1}\right) \\
+\left(\frac{\partial M_{A F_{n e w}}}{\partial D I 3108_{1}}\right)^{2} \times \operatorname{variance}\left(D I 3108_{1}\right)+\left(\frac{\partial M_{A F_{n e w}}}{\partial L I 3109_{2}}\right)^{2} \times \operatorname{variance}\left(L I 3109_{2}\right) \\
+\left(\frac{\partial M_{A F_{n e w}}}{\partial \delta_{1}}\right)^{2} \times \operatorname{variance}\left(\delta_{1}\right)+\left(\frac{\partial M_{A F_{n e w}}}{\partial \delta_{2}}\right)^{2} \times \operatorname{variance}\left(\delta_{2}\right)
\end{gathered}
$$

GUM Workbench was used to develop the model equation and associated intermediary values supporting the determination of $\mathrm{M}_{\mathrm{AF}_{-} \text {new }}$ for Step 5 (see the upper portion of Exhibit 39) and to document the complete set of partial derivatives needed to support the estimation of the variance of the $\mathrm{M}_{\mathrm{AF}_{-} \text {new }}$ value (see the lower portion of Exhibit 39 and Exhibit 40). For example, the $\mathrm{x}_{11}, \mathrm{x}_{12}, \mathrm{y}_{11}$, and $\mathrm{y}_{12}$ values and $\mathrm{x}_{21}$, $\mathrm{x}_{22}, \mathrm{y}_{21}$, and $\mathrm{y}_{22}$ values are appropriately selected values for determining the volumes $\mathrm{V}_{1}$ and $\mathrm{V}_{2}$, respectively, using instrument LI3109 as indicated in Exhibit 28. To complete the information necessary to compute the estimate of the variance of the $\mathrm{M}_{\mathrm{AF}_{-} \text {new }}$, estimates of the variance terms of Equation 50 are needed. These values along with a description of the terms of the equation are provided in Table 23 . 
SRNL-STI-2014-00323

Revision 0

\begin{tabular}{|c|}
\hline Equation: \\
\hline 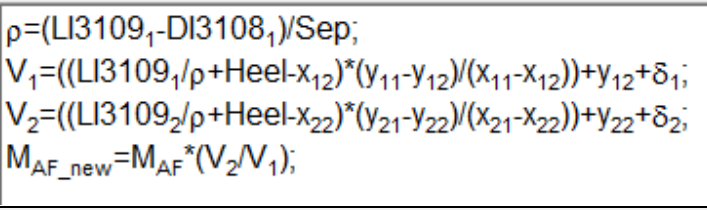 \\
\hline
\end{tabular}

Partial Derivatives:

$\partial \rho / \partial \mathrm{LI} 3109_{1}=1.0 /$ Sep;

$\partial \rho / \partial \mathrm{Dl} 3108_{1}=(-1.0) / \mathrm{Sep}$

$\partial \rho / \partial \operatorname{Sep}=\left(-\left(\mathrm{LI} 3109_{1}-\mathrm{DI} 3108_{1}\right)\right) / \mathrm{sqr}(\mathrm{Sep}) ;$

$\partial \mathrm{V}_{1} / \partial \mathrm{LI} 3109_{1}=\left(\mathrm{y}_{11}-\mathrm{y}_{12}\right) \cdot\left(1.0 / \rho+\left(-\mathrm{LI} 3109_{1} \cdot \partial \rho / \partial \mathrm{LI} 3109_{1}\right) / \operatorname{sqr}(\rho)\right) /\left(\mathrm{x}_{11}-\mathrm{x}_{12}\right) ;$

$\partial \mathrm{V}_{1} / \partial \mathrm{DI} 3108_{1}=\left(\mathrm{y}_{11}-\mathrm{y}_{12}\right) \cdot\left(-\mathrm{LI} 3109_{1} \cdot \partial \rho / \partial \mathrm{DI} 3108_{1}\right) / \operatorname{sqr}(\rho) /\left(\mathrm{x}_{11}-\mathrm{x}_{12}\right) ;$

$\partial \mathrm{V}_{1} / \partial \operatorname{Sep}=\left(\mathrm{y}_{11}-\mathrm{y}_{12}\right) \cdot\left(-\operatorname{LI} 3109_{1} \cdot \partial \rho / \partial \operatorname{Sep}\right) / \operatorname{sqr}(\rho) /\left(\mathrm{x}_{11}-\mathrm{x}_{12}\right) ;$

$\partial \mathrm{V}_{1} / \partial$ Heel $=\left(\mathrm{y}_{11}-\mathrm{y}_{12}\right) /\left(\mathrm{x}_{11}-\mathrm{x}_{12}\right)$;

$\partial \mathrm{V}_{1} / \partial \mathrm{x}_{12}=\left(\mathrm{y}_{11}-\mathrm{y}_{12}\right) \cdot(-1.0) /\left(\mathrm{x}_{11}-\mathrm{x}_{12}\right)+\left(-\left(\mathrm{LI} 3109_{1} / \rho+\right.\right.$ Heel $\left.\left.-\mathrm{x}_{12}\right) \cdot\left(\mathrm{y}_{11}-\mathrm{y}_{12}\right) \cdot(-1.0)\right) / \operatorname{sqr}\left(\mathrm{x}_{11}-\mathrm{x}_{12}\right)$

$\partial \mathrm{V}_{1} / \partial \mathrm{y}_{11}=\left(\mathrm{LI} 3109_{1} / \rho+\right.$ Heel $\left.-\mathrm{x}_{12}\right) /\left(\mathrm{x}_{11}-\mathrm{x}_{12}\right)$

$\partial \mathrm{V}_{1} / \partial \mathrm{y}_{12}=\left(\mathrm{LI} 3109_{1} / \rho+\right.$ Heel $\left.-\mathrm{x}_{12}\right) \cdot(-1.0) /\left(\mathrm{x}_{11}-\mathrm{x}_{12}\right)+1.0$;

$\partial \mathrm{V}_{1} / \partial \mathrm{x}_{11}=\left(-\left(\mathrm{L} \mid 3109_{1} / \rho+\right.\right.$ Heel $\left.\left.-\mathrm{x}_{12}\right) \cdot\left(\mathrm{y}_{11}-\mathrm{y}_{12}\right)\right) / \operatorname{sqr}\left(\mathrm{x}_{11}-\mathrm{x}_{12}\right) ;$

$\partial \mathrm{V}_{1} / \partial \delta_{1}=1.0 ;$

$\partial \mathrm{V}_{2} / \partial \mathrm{LI} 3109_{1}=\left(\mathrm{y}_{21}-\mathrm{y}_{22}\right) \cdot\left(-\mathrm{LI} 3109_{2} \cdot \partial \rho / \partial \mathrm{LI} 3109_{1}\right) / \operatorname{sqr}(\rho) /\left(\mathrm{x}_{21}-\mathrm{x}_{22}\right)$

$\partial \mathrm{V}_{2} / \partial \mathrm{DI} 3108_{1}=\left(\mathrm{y}_{21}-\mathrm{y}_{22}\right) \cdot\left(-\mathrm{LI} 3109_{2} \cdot \partial \rho / \partial \mathrm{DI} 3108_{1}\right) / \mathrm{sqr}(\rho) /\left(\mathrm{x}_{21}-\mathrm{x}_{22}\right) ;$

$\partial \mathrm{V}_{2} / \partial \operatorname{Sep}=\left(\mathrm{y}_{21}-\mathrm{y}_{22}\right) \cdot\left(-\mathrm{L} \mid 3109_{2} \cdot \partial \rho / \partial \operatorname{Sep}\right) / \operatorname{sqr}(\rho) /\left(\mathrm{x}_{21}-\mathrm{x}_{22}\right) ;$

$\partial \mathrm{V}_{2} / \partial$ Heel $=\left(\mathrm{y}_{21}-\mathrm{y}_{22}\right) /\left(\mathrm{x}_{21}-\mathrm{x}_{22}\right) ;$

$\partial \mathrm{V}_{2} / \partial \mathrm{LI} 3109_{2}=\left(\mathrm{y}_{21}-\mathrm{y}_{22}\right) \cdot 1.0 / \rho /\left(\mathrm{x}_{21}-\mathrm{x}_{22}\right) ;$

$\partial \mathrm{V}_{2} / \partial \mathrm{x}_{22}=\left(\mathrm{y}_{21}-\mathrm{y}_{22}\right) \cdot(-1.0) /\left(\mathrm{x}_{21}-\mathrm{X}_{22}\right)+\left(-\left(\mathrm{LI} 310 \mathrm{~g}_{2} / \mathrm{\rho}+\right.\right.$ Heel $\left.\left.-\mathrm{x}_{22}\right) \cdot\left(\mathrm{y}_{21}-\mathrm{y}_{22}\right) \cdot(-1.0)\right) / \operatorname{sqr}\left(\mathrm{x}_{21}-\mathrm{X}_{22}\right)$

$\partial \mathrm{V}_{2} / \partial \mathrm{y}_{21}=\left(\mathrm{L} / 3109_{2} / \rho+\right.$ Heel $\left.-\mathrm{x}_{22}\right) /\left(\mathrm{x}_{21}-\mathrm{x}_{22}\right)$;

$\partial \mathrm{V}_{2} / \partial \mathrm{y}_{22}=\left(\mathrm{LI} 310 \mathrm{~g}_{2} / \rho+\right.$ Heel $\left.-\mathrm{X}_{22}\right) \cdot(-1.0) /\left(\mathrm{x}_{21}-\mathrm{x}_{22}\right)+1.0$;

$\partial \mathrm{V}_{2} / \partial \mathrm{X}_{21}=\left(-\left(\mathrm{LI} 3109_{2} / \rho+\right.\right.$ Heel $\left.\left.-\mathrm{X}_{22}\right) \cdot\left(\mathrm{y}_{21}-\mathrm{y}_{22}\right)\right) / \mathrm{sqr}\left(\mathrm{x}_{21}-\mathrm{x}_{22}\right)$;

$\partial \mathrm{V}_{2} / \partial \delta_{2}=1.0$;

Exhibit 39 Equations for $\mathbf{M}_{\mathrm{AF} \_ \text {new }}$ for SME Heel with Random Uncertainty (part 1 of 2) 


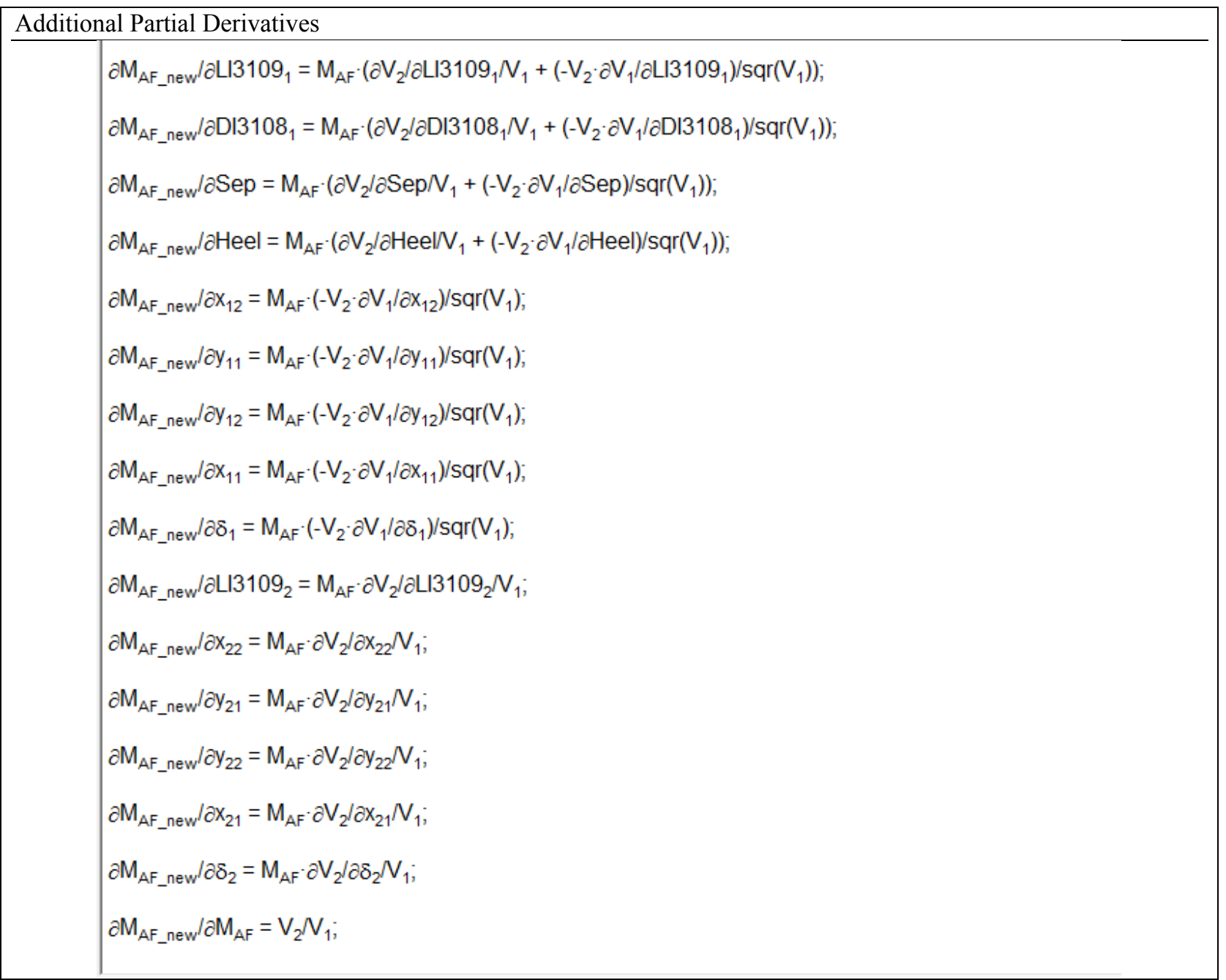

Exhibit 40 Equations for $\mathrm{M}_{\mathrm{AF} \text { _new }}$ for SME Heel with Random Uncertainty (part 2 of 2)

Table 23 Terms and Estimated Random Uncertainties Supporting Equation 50

\begin{tabular}{|c|c|c|}
\hline Term/Instrument & Description & 1-Sigma Random Uncertainty \\
\hline $\mathrm{M}_{\mathrm{AF}}$ & antifoam mass $(\mathrm{kg})$ in SME & Random uncertainty available in status information \\
\hline \multirow[t]{3}{*}{$\begin{array}{c}\text { LI3109 with } \\
\text { subscripts } 1 \text { and } 2\end{array}$} & level bubbler values (inwc) & $\pm 1 \%$ of 231.0 inwc span $[14]$ \\
\hline & DCS deviation limit & \pm 0.1 inwc $[14]$ \\
\hline & & $\begin{array}{l}\text { Using a uniform distribution, 1-sigma random is } \\
{\left[(2.31 / \sqrt{ } 3)^{2}+(0.1 / \sqrt{ } 3)^{2}\right]^{0.5}=1.3349}\end{array}$ \\
\hline \multirow[t]{3}{*}{ DI3108 with subscript 1} & density bubbler value (inwc) & $\pm 1 \%$ of 160.5 inwc span [15] \\
\hline & DCS deviation limit & \pm 0.05 inwc $[15]$ \\
\hline & & $\begin{array}{l}\text { Using a uniform distribution, 1-sigma random is } \\
{\left[(1.605 / \sqrt{3})^{2}+(0.05 / \sqrt{ } 3)^{2}\right]^{0.5}=0.9271}\end{array}$ \\
\hline$\delta_{1}$ & $\begin{array}{l}\text { tank calibration uncertainty } \\
\text { (see footnote for Table 17) }\end{array}$ & 1-sigma random $=9$ gallons \\
\hline$\delta_{2}$ & $\begin{array}{l}\text { Tank Calibration uncertainty } \\
\text { (see footnote for Table 17) }\end{array}$ & 1 -sigma random $=9$ gallons \\
\hline
\end{tabular}


To complete the evaluation of the $\mathrm{M}_{\mathrm{AF} \text { nnw }}$ required for Step 5, the bias for $\mathrm{M}_{\mathrm{AF} \text { nnew }}$ determined by Equation 49 must be estimated. A bound (at 95\% confidence) on the bias of the antifoam mass remaining in the SME after a transfer out to the MFT, $\mathrm{M}_{\mathrm{AF}-\mathrm{n} \text { new }}$, is estimated, as above, by appealing to a Taylor Series expansion of Equation 49 in the fundamental measurements. Once again, note that $V_{1}$ and $V_{2}$ are intermediary values. Also, the each of these volumes has a potential bias that is to be included in the evaluation. The Taylor's Series expansion may be expressed in the fundamental measurements and the potential bias as given by:

\section{Equation 51}

$$
\begin{aligned}
& \left\{\operatorname{bias}\left(M_{A F_{n e w}}\right)\right\}^{2} \approx\left(\frac{\partial M_{A F_{n e w}}}{\partial M_{A F}}\right)^{2} \times\left\{\operatorname{bias}\left(M_{A F}\right)\right\}^{2}+\left(\frac{\partial M_{A F_{\text {new }}}}{\partial L I 3109_{1}}\right)^{2} \times\{\operatorname{bias}(\text { LI3109 } 1)\}^{2} \\
& +\left(\frac{\partial M_{A F_{n e w}}}{\partial D I 3108_{1}}\right)^{2} \times\left\{\operatorname{bias}\left(D I 3108_{1}\right)\right\}^{2}+\left(\frac{\partial M_{A F_{n e w}}}{\partial S e p}\right)^{2} \times\{\text { bias }(\text { Sep })\}^{2} \\
& +\left(\frac{\partial M_{A F_{\text {new }}}}{\partial \text { Heel }^{2}}\right)^{2} \times\{\text { bias }(\text { Heel })\}^{2}+\left(\frac{\partial M_{A F_{\text {new }}}}{\partial L I 3109_{2}}\right)^{2} \times\{\text { bias }(\text { LI3109 } 2)\}^{2} \\
& +\left(\frac{\partial M_{A F_{\text {new }}}}{\partial b_{1}}\right)^{2} \times\left\{\operatorname{bias}\left(b_{1}\right)\right\}^{2}+\left(\frac{\partial M_{A F_{\text {new }}}}{\partial b_{2}}\right)^{2} \times\left\{\operatorname{bias}\left(b_{2}\right)\right\}^{2} \\
& +2 \times 1 \times\left|\frac{\partial M_{A F_{n e w}}}{\partial L I 3109_{1}}\right| \times\left|\frac{\partial M_{A F_{n e w}}}{\partial L I 3109_{2}}\right| \times \operatorname{bias}\left(L I 3109_{1}\right) \times \operatorname{bias}\left(L I 3109_{2}\right) \\
& +2 \times 1 \times\left|\frac{\partial M_{A F_{n e w}}}{\partial b_{1}}\right| \times\left|\frac{\partial M_{A F_{n e w}}}{\partial b_{2}}\right| \times \operatorname{bias}\left(b_{1}\right) \times \operatorname{bias}\left(b_{2}\right)
\end{aligned}
$$

Note that in evaluating Equation 51, the bias for the $\mathrm{M}_{\mathrm{AF}}$ term, i.e., bias $\left(\mathrm{M}_{\mathrm{AF}}\right)$ term, is provided by the status information for the SME prior to the transfer to the MFT and that two potential correlations among the biases are introduced into the equation, both represented in a bounding manner. So the approach may be stated as: the $b_{1}$ and $b_{2}$ terms are the estimated bias in the $V_{1}$ and $V_{2}$ volumes, respectively, and there is a potential correlation in these biases. Also, there is a potential correlation in the biases for the two LI3109 measurements. GUM Workbench was used to develop the model equation and associated intermediary values supporting the determination of the bias of $\mathrm{M}_{\mathrm{AF}_{-} \text {new }}$ for Step 5 (see the upper portion of Exhibit 41) and to document the complete set of partial derivatives needed to support the estimation of the bias of the $\mathrm{M}_{\mathrm{AF}_{-} \text {new }}$ value (see the lower portion of Exhibit 41 and Exhibit 42). Once again, $\mathrm{x}_{21}, \mathrm{x}_{22}$, $\mathrm{y}_{21}$, and $\mathrm{y}_{22}$ are appropriately selected values (based upon the value of the LI3109 instrument as indicated by LI3109 ${ }_{1}$ and LI3109 $)$ for determining volumes as indicated in Exhibit 29. To complete the information necessary to compute the estimate of the bias of the $\mathrm{M}_{\mathrm{AF}_{-} \text {new }}$, estimates of the bias terms of Equation 51 are needed. Table 24 provides the details of the bias information needed to complete the 
SRNL-STI-2014-00323

Revision 0

estimation of the bias for the $\mathrm{M}_{\mathrm{AF} \_ \text {new }}$ value. A sample calculation for this step including the random and bias uncertainties is provided in Exhibit B15 in Appendix B.

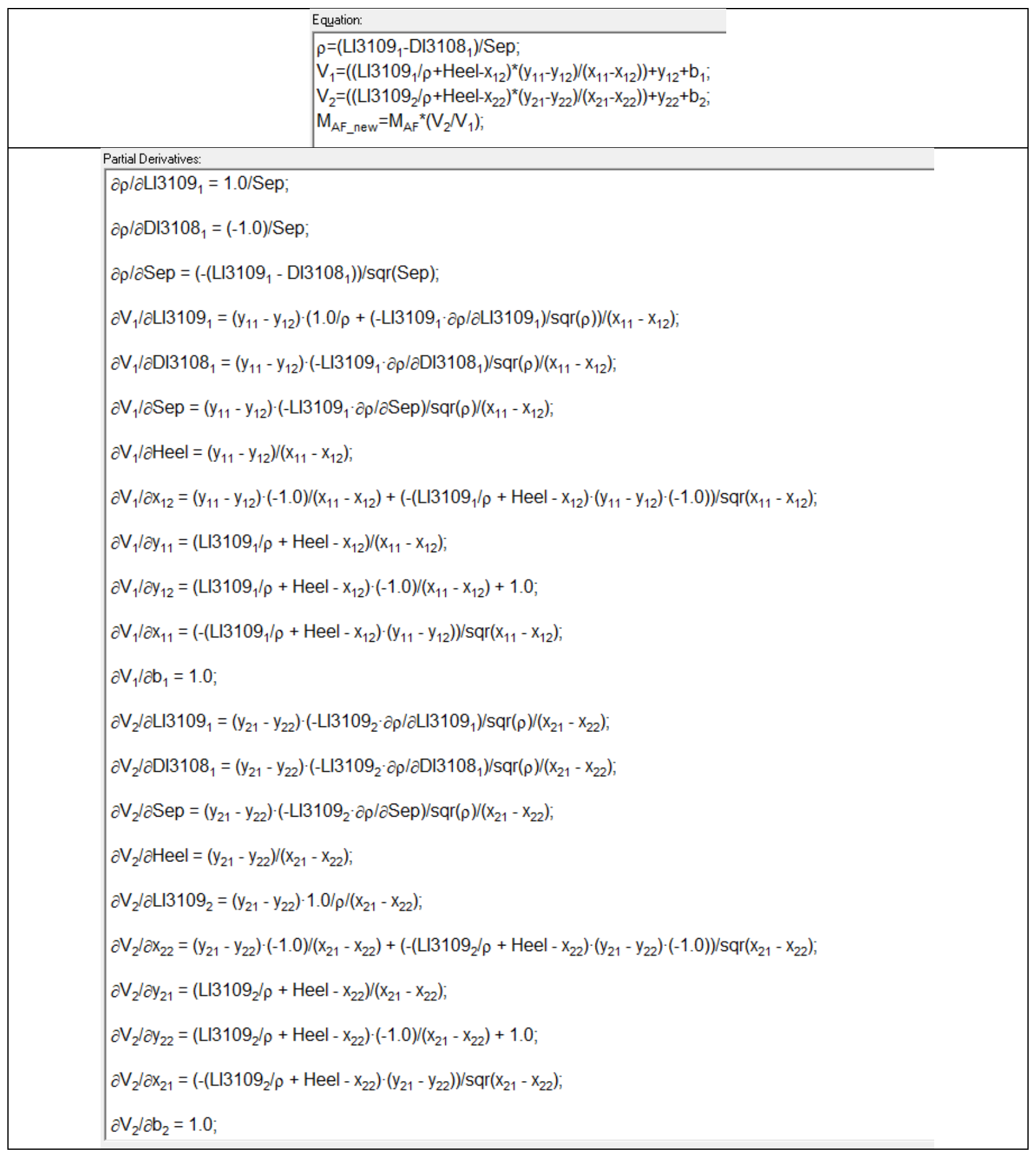

Exhibit 41 Equations for $\mathrm{M}_{\mathrm{AF}_{-} \text {new }}$ for SME Heel with Bias Uncertainty (part 1 of 2) 


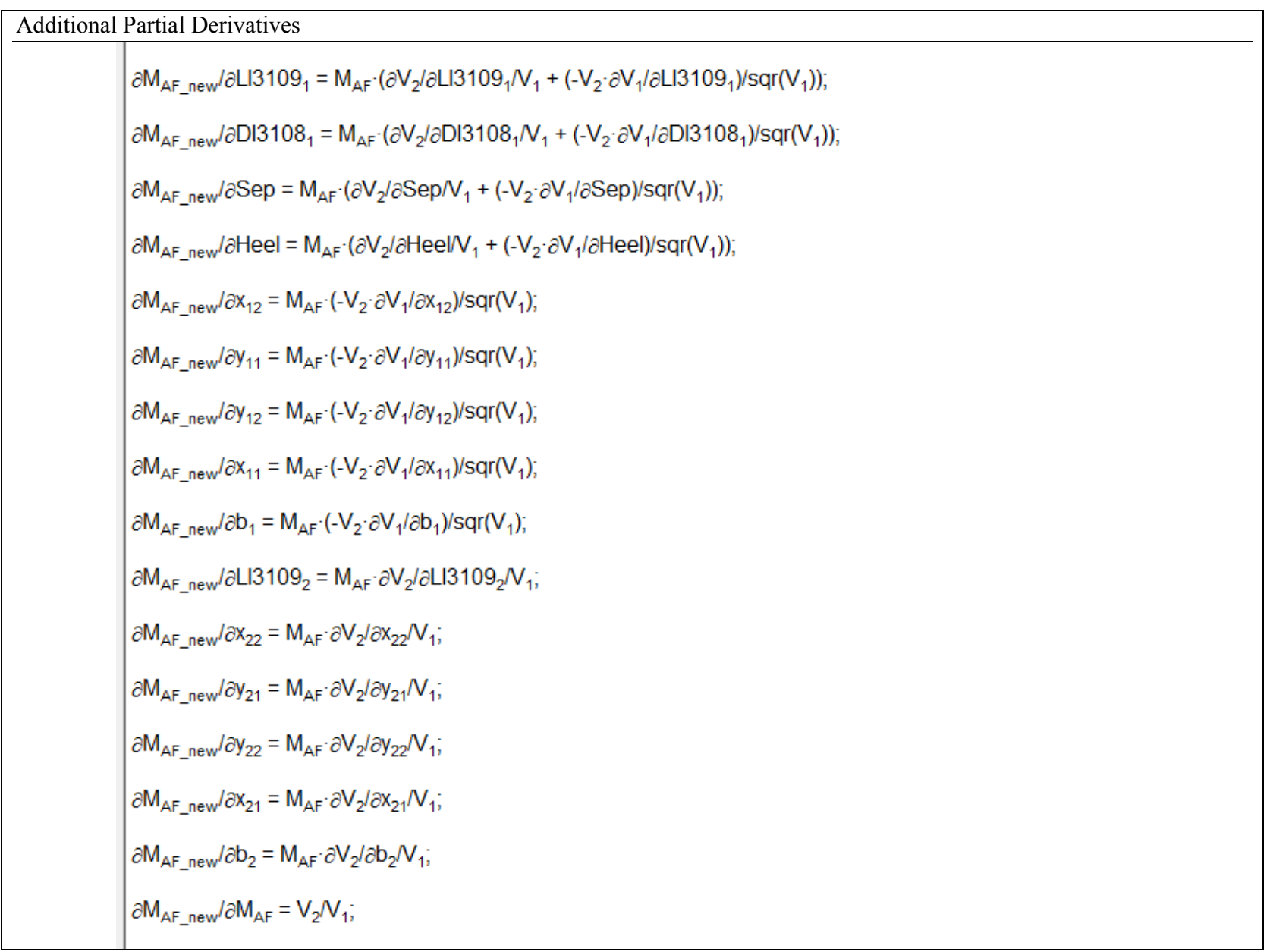

Exhibit 42 Equations for $\mathbf{M}_{\mathrm{AF} \_ \text {new }}$ for SME Heel with Bias Uncertainty (part 2 of 2)

Table 24 Terms and Estimated Bias Uncertainties Supporting Equation 51

\begin{tabular}{|c|c|c|}
\hline Term/Instrument & Description & Bias Uncertainty \\
\hline $\mathrm{M}_{\mathrm{AF}}$ & Antifoam mass $(\mathrm{kg})$ in SME & Bias available in status information \\
\hline \multirow[t]{2}{*}{$\begin{array}{c}\text { LI3109 with } \\
\text { subscripts } 1 \text { and } 2\end{array}$} & level bubbler values (inwc) & $\pm 1 \%$ of 231.0 inwc span $[14]$ \\
\hline & & Bias $=2.310$ inwc \\
\hline \multirow[t]{2}{*}{ DI3108 with subscript 1} & density bubbler value (inwc) & $\pm 1 \%$ of 160.5 inwc span [15] \\
\hline & & Bias $=1.605$ inwc \\
\hline $\mathrm{b}_{1}$ & $\begin{array}{l}\text { tank calibration uncertainty } \\
\text { (see footnote for Table 18) }\end{array}$ & 6 gallons \\
\hline $\mathrm{b}_{2}$ & $\begin{array}{l}\text { tank calibration uncertainty } \\
\text { (see footnote for Table 18) }\end{array}$ & 6 gallons \\
\hline Sep & $\begin{array}{l}\text { Separation between bubblers } \\
\text { (47 inches) }\end{array}$ & 0.0625 inch $[13]$ \\
\hline Heel & $\begin{array}{c}\text { Tank heel below LI3109 } \\
\text { (6.77 inches) }\end{array}$ & 0.0625 inch $[13]$ \\
\hline
\end{tabular}


SRNL-STI-2014-00323

Revision 0

\subsection{Summary}

SRNL has been working with SRR's DWPF in the development and implementation of an additional strategy for confidently satisfying the flammability controls for DWPF's melter operation. An initial strategy for implementing the operational constraints associated with flammability control in DWPF was based upon an analytically determined carbon concentration from antifoam. Due to the conservative error structure associated with the analytical approach, its implementation has significantly reduced the operating window for processing and has led to recurrent SME and MFT remediation.

To address the adverse operating impact of the current implementation strategy, SRR issued a TTR to SRNL requesting the development and documentation of an alternate strategy for evaluating the carbon contribution from antifoam. The proposed strategy presented in this report was developed under the guidance of a TTQAP and involves calculating the carbon concentration from antifoam based upon the actual mass of antifoam added to the process assuming $100 \%$ retention.

The mass of antifoam in the AMFT, in the SRAT, and in the SME is tracked by mass balance as part of this strategy. As these quantities are monitored, the random and bias uncertainties affecting their values are also maintained and accounted for. Thus, this report documents:

1) The development of an alternate implementation strategy and associated equations describing the carbon concentration from antifoam in each SME batch derived from the actual amount of antifoam introduced into the AMFT, SRAT, and SME during the processing of the batch.

2) The equations and error structure for incorporating the proposed strategy into melter off-gas flammability assessments.

Sample calculations of the system are also included in this report. Please note that the system developed and documented in this report is intended as an alternative to the current, analytically-driven system being utilized by DWPF; the proposed system is not intended to eliminate the current system

Also note that the system developed in this report to track antifoam mass in the AMFT, SRAT, and SME will be applicable beyond just SB8. While the model used to determine acceptability of the SME product with respect to melter off-gas flammability controls must be reassessed for each change in sludge batch, the antifoam mass tracking methodology is independent of sludge batch composition and as such will be transferable to future sludge batches. 
SRNL-STI-2014-00323

Revision 0

\subsection{References}

[1] Choi, A.S., "DWPF Melter Off-Gas Flammability Assessment (Sludge Batch 8)," Revision 8, XCLC-S-00164, March 2013.

[2] Edwards, T.B., "Integration of the Uncertainties of Anion and TOC Measurements into the Flammability Control Strategy for Sludge Batch 8 at the DWPF," SRNL-STI-2013-00139, Revision 0, March 2013.

[3] Bricker, J. M., "Development of Alternative Strategy for Evaluating Carbon Contribution from Antifoam,” Technical Task Request, S-TTR-S-00008, Rev. 0; September 11, 2013.

[4] Lambert, D.P. and T.B. "Task Technical and Quality Assurance Plan: Development of Alternate Strategy for Evaluating the Carbon Contribution from Antifoam," SRNL-RP-2013-00762, Revision 0, November 2013.

[5] K.G. Brown, R.L. Postles, and T.B. Edwards, "SME Acceptability Determination for DWPF Process Control,” WSRC-TR-95-00364, Revision 5, September 2006.

[6] Metrodata GmbH, "GUM workbench: User Manual for Version 1.2, 2.3, and 2.4," Weil am Rhein, Germany, 2009.

[7] Coleman, H.W. and W.G. Steele, Experimentation, Validation, and Uncertainty Analysis for Engineers, Third Edition, John Wiley \& Sons, Inc., Hoboken, NJ, 2009.

[8] Weeks, G.E. and K.G. Brown, "Calibration of DWPF Canyon Vessels (U),” WSRC-TR-92-250, May 1992.

[9] JMP Version 11.1.1, SAS Institute, Inc., Cary NC, 1989-2014.

[10] Adondakis, G.E. (preparer), “The Additive Mix Feed Tank Level Scaling Computation,” S329ZZZL-2614, July 1, 2002 (Amended by J-DCF-S-02979 dated July 30, 2014).

[11] Moesta, G. (preparer), "Sludge Receipt Adjustment Tank Level Scaling Computation," S350ZZZL-3025, June 29, 2000 (Amended by J-DCF-S-02980 dated July 31, 2014).

[12] Moesta, G. (preparer), "SRAT Slurry Density Indication Scaling Computation," S350-ZZZL3026, July 13, 2000 (Amended by J-DCF-S-02980 dated July 31, 2014).

[13] "Process Tank Bubbler Jumper", M-M0-S-00140 Revision 0.

[14] Moesta, G. (preparer), "Slurry Mix Evaporator Tank Level Scaling Computation," S350-ZZZL3109, May 8, 1994 (Amended by J-DCF-S-02980 dated July 31, 2014).

[15] "Slurry Mix Evaporator Density Indication Scaling and Setpoint Document," S350-ZZZL-3108, January 30, 2003 (Amended by J-DCF-S-02980 dated July 31, 2014). 
SRNL-STI-2014-00323

Revision 0

\section{Appendix A. Determining a Bounding Mass for Antifoam Additions to the AMFT}

The maximum of mass of antifoam could be added when adding a five gallon pail of antifoam is 18.896 $\mathrm{kg}$ (might call this $18.9 \mathrm{~kg}$ ). This bounding mass was developed by filling up an empty, dry pail of antifoam with water and weighing the water added to the pail $(18.6597 \mathrm{~kg})$. This was adjusted by multiplying the water weight by the quantity equal to the average density of the last 13 valid antifoam density results +3 times the standard deviation of these 13 values (see Table A1):

$18.6597 \times(1.00073+3 \times 0.00360)=18.6597 \times 1.01153=18.875$

This number was adjusted further by dividing by the density of water at 20 Celsius, $0.99835 \mathrm{~g} / \mathrm{mL}$ ).

$$
18.875 \div 0.99823=18.908=18.91
$$

Note that this value, $18.91 \mathrm{~kg}$, was conservatively estimated so there is no need for any additional uncertainty (i.e., the random uncertainty is set to zero and the bias is set to zero).

Table A1. Density Measurements of Antifoam Batches*

\begin{tabular}{|c|c|c|c|c|c|c|}
\hline \multicolumn{7}{|c|}{ Density of Antifoam and 1:20 antifoam mixture in $\mathrm{g} / \mathrm{mL}$ at $20 \times$} \\
\hline Lot & Density & St Dev & Units & 1:20 density & St Dev & Units \\
\hline $0811959-11229$ & 0.997 & & $\mathrm{~g} / \mathrm{mL}$ & 0.99817 & & $\mathrm{~g} / \mathrm{mL}$ \\
\hline 081723-1112 & 0.997 & & $\mathrm{~g} / \mathrm{mL}$ & 0.99817 & & $\mathrm{~g} / \mathrm{mL}$ \\
\hline $090422-324$ & 1.001 & & $\mathrm{~g} / \mathrm{mL}$ & 0.99837 & & $\mathrm{~g} / \mathrm{mL}$ \\
\hline $100106-123$ & 1.00230 & & $\mathrm{~g} / \mathrm{mL}$ & 0.99843 & & $\mathrm{~g} / \mathrm{mL}$ \\
\hline $100120-125$ & 1.00260 & & $\mathrm{~g} / \mathrm{mL}$ & 0.99845 & & $\mathrm{~g} / \mathrm{mL}$ \\
\hline $100653-0420$ & 0.999 & & $\mathrm{~g} / \mathrm{mL}$ & 0.99827 & & $\mathrm{~g} / \mathrm{mL}$ \\
\hline $100897-0525$ & 0.999 & & $\mathrm{~g} / \mathrm{mL}$ & 0.99827 & & $\mathrm{~g} / \mathrm{mL}$ \\
\hline $101115-0707$ & 1.000 & & $\mathrm{~g} / \mathrm{mL}$ & 0.99832 & & $\mathrm{~g} / \mathrm{mL}$ \\
\hline $101480-0915$ & 1.000 & & $\mathrm{~g} / \mathrm{mL}$ & 0.99832 & & $\mathrm{~g} / \mathrm{mL}$ \\
\hline $101820-1110$ & 1.00268 & & $\mathrm{~g} / \mathrm{mL}$ & 0.99845 & & $\mathrm{~g} / \mathrm{mL}$ \\
\hline 101876-1111 & 1.00058 & & $\mathrm{~g} / \mathrm{mL}$ & 0.99835 & & $\mathrm{~g} / \mathrm{mL}$ \\
\hline $110684-0413$ & 1.01075 & & $\mathrm{~g} / \mathrm{mL}$ & 0.99886 & & $\mathrm{~g} / \mathrm{mL}$ \\
\hline $111128-0613$ & 0.99756 & & $\mathrm{~g} / \mathrm{mL}$ & 0.99820 & & $\mathrm{~g} / \mathrm{mL}$ \\
\hline Average & 1.00073 & 0.00360 & $\mathrm{~g} / \mathrm{mL}$ & 0.99835 & 0.00018 & $\mathrm{~g} / \mathrm{mL}$ \\
\hline Density of Pure & Water at 20 & & & & 0.99823 & $g / \mathrm{mL}$ \\
\hline
\end{tabular}

\footnotetext{
* SRNL E-Notebook O7787-00055-09, Antifoam 747 Basic Data and Acceptance Testing, July 29, 2014.
} 
Appendix B. Sample Calculations

\section{Exhibit B1. Example Calculation for AMFT Step 2}

$\mathrm{M}_{\mathrm{AF}_{-} \text {new }}=\mathrm{M}_{\mathrm{AF}}+\mathrm{M}_{\mathrm{AF}_{-} \mathrm{Add}}$

AMFT Status Before Event

\begin{tabular}{|c|c|c|}
\hline AMFT & & \\
\hline & & 1 -sigma \\
\hline MAF & Uncertainty \\
\hline 5 & 0.2 \\
\hline $\mathrm{kg}$ & $\mathrm{kg}$ \\
\hline & 0.5 \\
\hline & bias \\
\hline
\end{tabular}

\begin{tabular}{|c|c|c|c|c|c|c|}
\hline \multicolumn{7}{|l|}{ A } \\
\hline d & & & & & & \\
\hline d & & 1-sigma & & 2 & 1-sigma & \\
\hline i & $M_{A_{F} \text { add }}$ & Uncertainty & bias & $M_{A F_{\text {new }}}$ & Uncertainty & bias \\
\hline$t$ & 18.91 & 0.0 & 0 & 23.91 & 0.2 & 0.5 \\
\hline i & $\mathrm{kg}$ & $\mathrm{kg}$ & $\mathrm{kg}$ & $\mathrm{kg}$ & kg & $\mathrm{kg}$ \\
\hline 0 & & & & & & \\
\hline
\end{tabular}




\section{Exhibit B2. Example Calculation for AMFT Step 3}

$$
M_{A F_{\text {out }}}=\frac{M_{A F} \cdot\left(V_{1}-V_{2}\right)}{V_{1}}
$$

AMFT Status Before Event

\begin{tabular}{|c|c|c|}
\hline AMFT & & \\
\hline & & 1 -sigma \\
\hline & $\mathrm{M}_{\mathrm{AF}}$ & Uncertainty \\
\hline 5 & 0.2 \\
\hline $\mathrm{kg}$ & $\mathrm{kg}$ \\
\hline & & 0.5 \\
\hline & & bias \\
\hline
\end{tabular}

\begin{tabular}{|c|c|c|c|c|c|}
\hline \multirow{2}{*}{$\mathrm{T}$} & \multicolumn{2}{|c|}{ Before Transfer Out } & \multicolumn{2}{|c|}{ After Transfer Out } & \\
\hline & \multicolumn{3}{|c|}{\begin{tabular}{|l|l} 
1-sigma \\
\end{tabular}} & \multirow{2}{*}{$\begin{array}{c}\text { 1-sigma } \\
\text { Uncertainty }\end{array}$} & \\
\hline a & LL2614 & Uncertainty & $\mathrm{L} 12614_{2}$ & & \\
\hline $\mathrm{n}$ & 30 & 0.2372 & 25 & 0.2372 & \\
\hline s & inwc & inwc & inwc & inwc & \\
\hline$f$ & bias & 0.41 & bias & 0.41 & \\
\hline e & & inwc & & inwc & \\
\hline$r$ & & 1-sigma & & & \\
\hline \multirow{4}{*}{$\begin{array}{l}t \\
0 S \\
\text { o } \\
\text { t } E\end{array}$} & Density & Uncertainty & bias & & \\
\hline & 1 & 0.0036 & 0.0108 & & \\
\hline & \multicolumn{3}{|c|}{$\mathrm{g} / \mathrm{mL}$ (used as a specific gravity) } & & \\
\hline & & & & & \\
\hline \multirow{2}{*}{ e } & & \multirow{2}{*}{\multicolumn{2}{|c|}{$\begin{array}{l}\text { Inches in Tank (before) } \\
\text { Inches in Tank (after) }\end{array}$}} & 30.00 & \\
\hline & & & & 25.00 & \\
\hline \multicolumn{6}{|l|}{ S } \\
\hline \multirow{3}{*}{$\begin{array}{l}\mathrm{R} \\
\mathrm{A} \\
\mathrm{T}\end{array}$} & & & & Gallons & \\
\hline & & & Before & After & \\
\hline & & & $V_{1}$ & $V_{2}$ & transfer volume \\
\hline \multirow{7}{*}{$\begin{array}{l}0 \\
r\end{array}$} & & & 89.57 & 74.83 & 14.73 \\
\hline & & & $\delta_{1}$ & $\delta_{2}$ & gal \\
\hline & & 1-sigma & 0.637 & 0.637 & \\
\hline & & & gal & gal & \\
\hline & & & $b_{1}$ & $b_{2}$ & \\
\hline & & bias & 0.232 & 0.232 & \\
\hline & & & gal & gal & \\
\hline
\end{tabular}


Exhibit B2. Example Calculation for AMFT Step 3 (continued)

\begin{tabular}{|c|c|c|c|c|c|c|c|c|c|c|c|c|c|c|}
\hline \multicolumn{15}{|c|}{ Partial Derivatives } \\
\hline 3 & 1-sigma & $\underline{\partial}$ & $\underline{M_{A E_{\text {_nut }}}}$ & $\underline{M_{A E_{\text {_nut }}}}$ & $\underline{M_{A E_{2} \text { out }}}$ & $\underline{M_{A E_{\text {_nit }}}}$ & $\underline{M_{A F_{2} \text { ourt }}}$ & $M_{\text {AE_out }}$ & $\underline{V_{1}}$ & $\underline{V_{2}}$ & $\underline{\mathrm{V}_{1}}$ & $\underline{\mathrm{V}_{2}}$ & $\underline{V_{1}}$ & $\underline{\mathrm{V}_{2}}$ \\
\hline$M_{A_{\text {__out }}}$ & Uncertainty & $\partial$ & $\mathrm{M}_{\mathrm{AF}}$ & LI2614 & LII2614 & $\delta_{1}$ & $\delta_{2}$ & density & LLI2614 & $\mathrm{LI} 2614_{2}$ & $\delta_{1}$ & $\delta_{2}$ & density & density \\
\hline 0.822 & 0.0762 & & 0.1645 & 0.1374 & -0.1645 & 0.0466 & -0.0558 & -0.0107 & 2.947 & 2.947 & 1.000 & 1.000 & -88.398 & -73.665 \\
\hline \multirow[t]{5}{*}{ kg } & $\mathrm{kg}$ & & $18.617 \%$ & $18.273 \%$ & $26.176 \%$ & $15.184 \%$ & $21.751 \%$ & $0.000 \%$ & & & & & & \\
\hline & & \multicolumn{13}{|c|}{ Partial Derivatives } \\
\hline & & $\underline{\partial}$ & $\underline{M_{\text {AE_aurt }}}$ & $\underline{M_{A E_{\text {_nut }}}}$ & $M_{\text {AE_out }}$ & $\underline{M_{A E_{\text {_ant }}}}$ & $\underline{M_{A E_{2} \text { ant }}}$ & $M_{\text {AF_ount }}$ & $\underline{V_{1}}$ & $\underline{\mathrm{V}_{1}}$ & $\underline{\mathrm{V}_{2}}$ & $\underline{\mathrm{V}_{2}}$ & $\underline{\mathrm{V}_{1}}$ & $\underline{\mathrm{V}_{2}}$ \\
\hline & bias & $\partial$ & $\mathrm{M}_{\mathrm{AF}}$ & LII2614 ${ }_{1}$ & LI $2614_{2}$ & density & $b_{1}$ & $b_{2}$ & LII2614 ${ }_{1}$ & density & LII2614 2 & density & $b_{1}$ & $b_{2}$ \\
\hline & 0.151 & & 0.164 & 0.137 & -0.164 & -0.011 & 0.047 & -0.056 & 2.947 & -88.398 & 2.947 & -73.665 & 1.000 & 1.000 \\
\hline
\end{tabular}




\section{Exhibit B3. Example Calculation for AMFT Step 4}

$$
M_{A F_{\text {new }}}=\frac{M_{A F} \cdot V_{2}}{V_{1}}
$$

AMFT Status Before Event

\begin{tabular}{|c|c|c|}
\hline AMFT & & \\
\hline & & 1-sigma \\
\hline & M $_{\text {AF }}$ & Uncertainty \\
\hline 5 & 0.2 \\
\hline & $\mathrm{kg}$ & $\mathrm{kg}$ \\
\hline & 0.5 \\
\hline & & bias \\
\hline
\end{tabular}

\begin{tabular}{|c|c|c|c|c|c|}
\hline \multirow{2}{*}{$T$} & \multicolumn{2}{|c|}{ Before Transfer Out } & \multicolumn{2}{|c|}{ After Transfer Out } & \\
\hline & \multicolumn{2}{|r|}{ 1-sigma } & & 1-sigma & \\
\hline a & LI2614 & Uncertainty & $\mathrm{LL}_{2} 614_{2}$ & Uncertainty & \\
\hline $\mathrm{n}$ & 30 & 0.2372 & 25 & 0.2372 & \\
\hline \multirow{2}{*}{$\begin{array}{l}\text { s } \\
\text { f }\end{array}$} & inwc & inwc & inwc & inwc & \\
\hline & bias & 0.41 & bias & 0.41 & \\
\hline \multirow{2}{*}{$\begin{array}{l}\text { e } \\
r\end{array}$} & & inwc & & inwc & \\
\hline & & 1-sigma & & & \\
\hline $\mathrm{t}$ & Density & Uncertainty & bias & & \\
\hline \multirow{3}{*}{$\begin{array}{r}0 S \\
M \\
t \quad E\end{array}$} & 1 & 0.0036 & 0.0108 & & \\
\hline & \multicolumn{3}{|c|}{$\mathrm{g} / \mathrm{mL}$ (used as a specific gravity) } & & \\
\hline & & & & & \\
\hline \multicolumn{6}{|c|}{$h$} \\
\hline \multirow{2}{*}{ e } & & \multirow{2}{*}{\multicolumn{2}{|c|}{$\begin{array}{l}\text { Inches in Tank (before) } \\
\text { Inches in Tank (after }\end{array}$}} & 30.00 & \\
\hline & & & & 25.00 & \\
\hline \multicolumn{6}{|l|}{$\mathrm{s}$} \\
\hline \multicolumn{6}{|c|}{ Gallons } \\
\hline \multirow{3}{*}{$\begin{array}{c}\text { A } \\
T\end{array}$} & & & Gallons & Gallons & \\
\hline & & & Before & After & \\
\hline & & & $\mathrm{V}_{1}$ & $V_{2}$ & transfer volume \\
\hline \multirow{7}{*}{$\begin{array}{l}0 \\
r\end{array}$} & & & 89.57 & 74.83 & 14.73 \\
\hline & & & $\delta_{1}$ & $\delta_{2}$ & gal \\
\hline & & 1-sigma & 0.637 & 0.637 & \\
\hline & & & gal & gal & \\
\hline & & & $b_{1}$ & $b_{2}$ & \\
\hline & & bias & 0.232 & 0.232 & \\
\hline & & & gal & gal & \\
\hline
\end{tabular}




\section{Exhibit B3. Example Calculation for AMFT Step 4}

(continued)

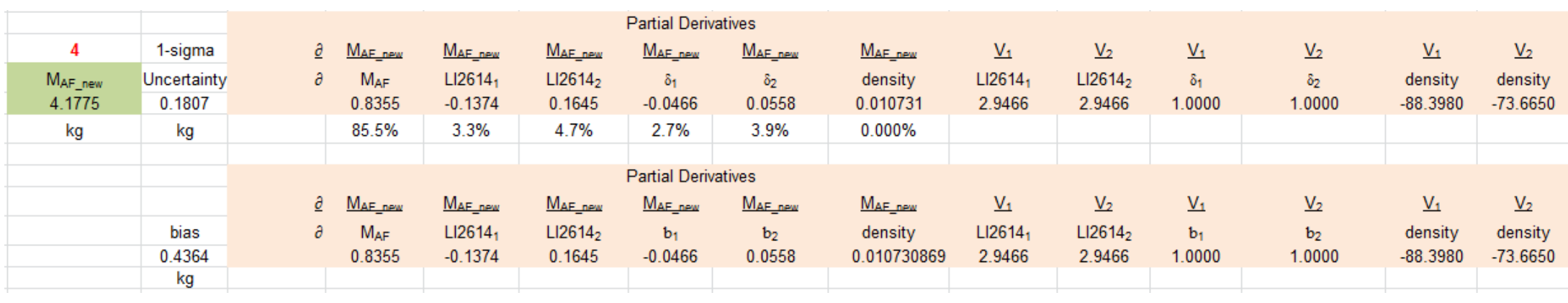




\section{Exhibit B4. Example Calculation for SRAT Step 2}

$\mathrm{M}_{\mathrm{AF}_{-} \text {new }}=\mathrm{M}_{\mathrm{AF}}+\mathrm{M}_{\mathrm{AF}_{-} \text {Add }}$

SRAT Status Before Event

\begin{tabular}{|c|c|c|c|}
\hline SRAT & & & \\
\hline Sep & Heel & M & 1-sigma \\
\hline 47 & 6.77 & 35.210 & Uncertainty \\
\hline 0.0625 & 0.0625 & $\mathrm{~kg}$ & $\mathrm{~kg}$ \\
\hline inches & inches & & bias \\
\hline bias & bias & & 5.25 \\
\hline & & & $\mathrm{kg}$ \\
\hline
\end{tabular}

\begin{tabular}{|c|c|c|c|c|c|c|}
\hline \multicolumn{7}{|l|}{ A } \\
\hline \multicolumn{7}{|l|}{$\mathrm{d}$} \\
\hline d & & 1-sigma & & 2 & 1-sigma & \\
\hline i & $M_{A_{-} \text {add }}$ & Uncertainty & bias & \multirow{2}{*}{$\begin{array}{c}M_{\text {AF_new }} \\
37.010\end{array}$} & Uncertainty & bias \\
\hline $\mathrm{t}$ & 1.800 & 0.200 & 0.5 & & 1.5133 & 5.7500 \\
\hline i & $\mathrm{kg}$ & $\mathrm{kg}$ & $\mathrm{kg}$ & $\mathrm{kg}$ & $\mathrm{kg}$ & $\mathrm{kg}$ \\
\hline 0 & & & & & & \\
\hline $\mathrm{n}$ & & & & & & \\
\hline
\end{tabular}




\section{Exhibit B5. Example Calculation for SRAT Step 1}

$$
M_{A F_{\text {new }}}=\frac{3.7854 \cdot C_{A F} \cdot V_{1} \cdot \rho}{0.4723 \cdot 1000000}
$$

SRAT Status Unknown Before this Event

\begin{tabular}{|l|c|c|c|}
\hline & $\mathrm{mg} / \mathrm{kg}$ & $\mathrm{mg} / \mathrm{kg}$ & $\mathrm{mg} / \mathrm{kg}$ \\
\hline & TOC & Oxalate & Formate \\
\hline & 12852 & 2667 & 41883 \\
& 11670 & 2361 & 41482 \\
& 12818 & 2183 & 42063 \\
\hline & 13129 & 2690 & 42065 \\
\hline Avg & 12617.25 & 2475.25 & 41873.25 \\
\hline Std Dev & 646.68 & 245.86 & 274.44 \\
\hline Std error & 323.34 & 122.93 & 137.22 \\
\hline batch \% rsd $(\delta)$ & $2.72 \%$ & $5.05 \%$ & $2.47 \%$ \\
\hline C factor & 1 & 0.27292 & 0.266806 \\
\hline low bias factor & 1 & 0.9495 & 0.9697 \\
\hline
\end{tabular}

\begin{tabular}{|c|c|c|c|c|c|c|c|}
\hline$\underline{\partial}$ & $\underline{\mathrm{C}_{A E}}$ & $\underline{\mathrm{C}_{A E}}$ & $\underline{\mathrm{C}_{A E}}$ & $\underline{\mathrm{C}_{A E}}$ & $\underline{\mathrm{C}_{A E}}$ & $\underline{\mathrm{C}_{A E}}$ & \\
\hline$\partial$ & TOC & $\delta_{T O C}$ & Oxalate & $\delta_{\text {oxalate }}$ & Formate & $\delta_{\text {formate }}$ & \\
\hline & 1 & 1 & 0.27292 & 0.27292 & 0.266806 & 0.266806 & \\
\hline & $34.61 \%$ & $38.99 \%$ & $0.37 \%$ & $0.39 \%$ & $0.44 \%$ & $25.21 \%$ & $100.000 \%$ \\
\hline
\end{tabular}

\begin{tabular}{|c|c|c|c|c|}
\hline \multicolumn{4}{|c|}{ Volume Determination Before Transfer } & \\
\hline & 1-sigma & & 1-sigma & \\
\hline LI3025 & Uncertainty & DI3026 & Uncertainty & \\
\hline 108.08 & 1.3384 & 55.55 & 0.9300 & \\
\hline \multirow[t]{7}{*}{ bias } & 2.316 & & 1.61 & \\
\hline & $\mathrm{x} 1$ & $\mathrm{x} 2$ & $\mathrm{y} 1$ & $\mathrm{y} 2$ \\
\hline & 17.416 & 0 & 1000 & 0 \\
\hline & 78.513 & 17.416 & 5175 & 1000 \\
\hline & 138.28 & 78.513 & 9400 & 5175 \\
\hline & 158.89 & 138.28 & 10850 & 9400 \\
\hline & 175.91 & 158.89 & 12000 & 10850 \\
\hline Before Info & 138.28 & 78.513 & 9400 & 5175 \\
\hline
\end{tabular}

\begin{tabular}{|c|c|c|c|c|}
\hline & & & \\
\hline & & Uncertainty & bias & \\
\hline $\mathrm{C}_{\mathrm{AF}}$ & 1142 & 549.64 & 0 & $\mathrm{mg} / \mathrm{kg}$ \\
\hline & & 1-sigma, $\delta_{1}$ & bias, $\mathrm{b}_{1}$ & \\
\hline Volume, $\mathrm{V}_{1}$, Before & 6939.4 & 9.00 & 12 & gal \\
\hline & & & & \\
\hline Density, $\rho$ & 1.1177 & $\mathrm{~kg} / \mathrm{L}$ & & \\
\hline
\end{tabular}




\section{Exhibit B5. Example Calculation for SRAT Step 1}

(continued)

\begin{tabular}{|c|c|c|c|c|c|c|c|c|c|c|c|c|c|c|c|c|}
\hline 1 & 1-sigma & $\underline{\partial}$ & $M_{A_{\text {_news }}}$ & $\underline{M_{A E_{\text {nes }}}}$ & $M_{A E_{\text {nex }}}$ & $M_{A E_{\text {nes }}}$ & $\underline{V_{1}}$ & $\underline{V_{1}}$ & $\varrho$ & $\varrho$ & $\underline{V_{1}}$ & & & & & \\
\hline$M_{\text {AF_new }}$ & Uncertainty & $\partial$ & $\mathrm{C}_{\mathrm{AF}}$ & LL13025, & $\mathrm{D} 13026_{1}$ & $\delta_{1}$ & LI3025, & DI3026, & LL3025, & DI3026, & $\delta_{1}$ & & & & & \\
\hline 71.01 & 34.18 & & 0.062 & 0.667 & -0.020 & 0.010233 & -66.886 & 130.135 & 0.021 & -0.021 & 1.000 & & & & & \\
\hline \multirow[t]{6}{*}{$\mathrm{kg}$} & $\mathrm{kg}$ & & $99.93 \%$ & $0.07 \%$ & $0.0000 \%$ & $0.0007 \%$ & & & & & & $100.00 \%$ & & & & \\
\hline & & & & & & & & & & & & & & & & \\
\hline & & $\underline{\partial}$ & $M_{A E_{\text {_ness }}}$ & $M_{A E_{\text {nes }}}$ & $M_{A E_{\text {_nex }}}$ & $M_{A E_{\text {_new }}}$ & $M_{A E_{\text {_nes }}}$ & $M_{A E_{\text {_nes }}}$ & $\underline{V_{1}}$ & $\underline{V_{1}}$ & $\varrho$ & 巳 & $\underline{V_{1}}$ & $\underline{V_{1}}$ & e & $\underline{V_{1}}$ \\
\hline & bias & $\partial$ & $\mathrm{C}_{\mathrm{AF}}$ & LI3025, & DI3026, & Sep & Heel & $\delta_{1}$ & LL13025, & $\mathrm{D}_{3026}$ & LI3025, & DI3026, & Sep & Heel & Sep & $\delta_{1}$ \\
\hline & 1.55 & & 0.0622 & 0.6673 & -0.0201 & -0.0225 & 0.7233 & 0.0102 & -66.8856 & 130.1349 & 0.0213 & -0.0213 & 145.4465 & 70.6912 & -0.0238 & 1.0000 \\
\hline & $\mathrm{kg}$ & & & & & & & & & & & & & & & \\
\hline
\end{tabular}




\section{Exhibit B6. Example Calculation for SRAT Step 3 Linked to Step 1}

$$
M_{A F_{\text {out }}}=\frac{3.7854 \cdot C_{A F} \cdot \rho \cdot\left(V_{1}-V_{2}\right)}{0.4723 \cdot 1000000}
$$

SRAT Status Unknown --- Sampling the SRAT Product Prior to Transfer to the SME

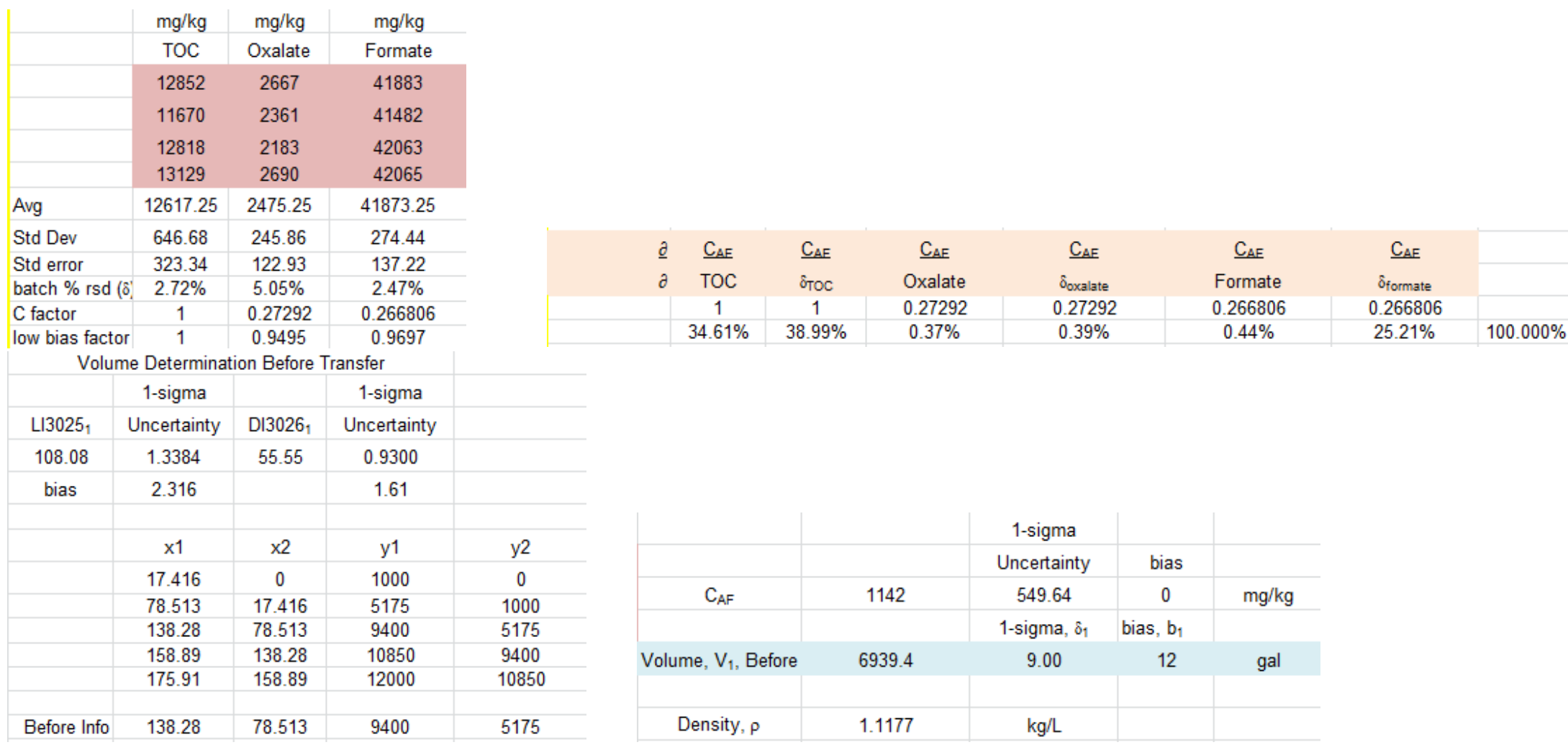




\section{Exhibit B6. Example Calculation for SRAT Step 3 Linked to Step 1}

(continued)

After Transfer Out

\begin{tabular}{|c|c|c|c|c|}
\hline & \multicolumn{4}{|c|}{ After Transfer Out } \\
\hline & & 1-sigma & & \\
\hline & Ll $3025_{2}$ & Uncertainty & bias & \\
\hline & 17.45 & 1.3384 & 2.316 & \\
\hline & & inwc & inwc & \\
\hline & $\mathrm{x} 1$ & $x 2$ & $\mathrm{y} 1$ & $\mathrm{y} 2$ \\
\hline & 17.416 & 0 & 1000 & 0 \\
\hline & 78.513 & 17.416 & 5175 & 1000 \\
\hline & 138.28 & 78.513 & 9400 & 5175 \\
\hline & 158.89 & 138.28 & 10850 & 9400 \\
\hline & 175.91 & 158.89 & 12000 & 10850 \\
\hline After Info & 78.513 & 17.416 & 5175 & 1000 \\
\hline & & & 1-siama & \\
\hline & & & Uncertainty & \\
\hline & & Volume, after, $V_{2}$ & $\delta_{2}$, gal & \\
\hline & & 1339.4 & 9 & \\
\hline & & & bias, $b_{2}$, gal & \\
\hline & & & 12 & \\
\hline
\end{tabular}

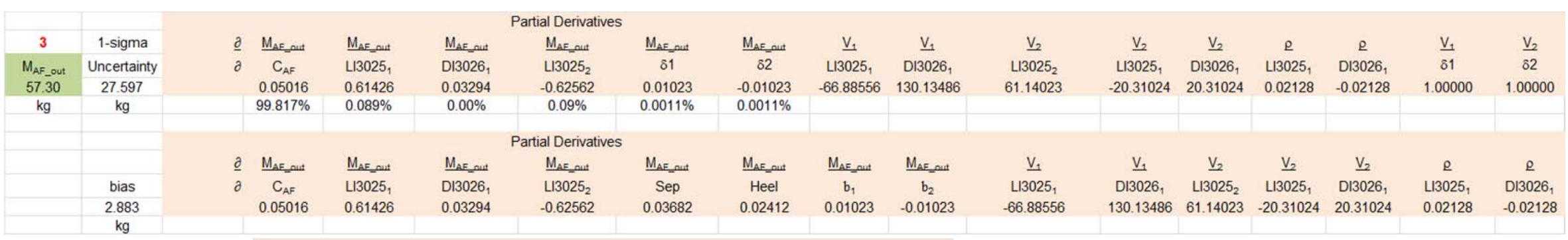

\begin{tabular}{|c|c|c|c|c|c|c|}
\hline$\underline{v_{1}}$ & $\underline{V_{1}}$ & $\underline{V_{2}}$ & $\underline{V_{2}}$ & $\underline{V_{1}}$ & $\underline{V_{2}}$ & $\varrho$ \\
\hline Sep & Heel & Sep & Heel & $b_{1}$ & $b_{2}$ & Sep \\
\hline 145.44647 & 70.69118 & 22.69994 & 68.33396 & 1.00000 & 1.00000 & -0.02378 \\
\hline
\end{tabular}




\section{Exhibit B7. Example Calculation for SRAT Step 4 Linked to Step 1}

$$
M_{A F_{\text {new }}}=\frac{3.7854 \cdot C_{A F} \cdot V_{2} \cdot \rho}{0.4723 \cdot 1000000}
$$

SRAT Status Unknown --- Sampling the SRAT Product Prior to Transfer to the SME

\begin{tabular}{|l|c|c|c|}
\hline & $\mathrm{mg} / \mathrm{kg}$ & $\mathrm{mg} / \mathrm{kg}$ & $\mathrm{mg} / \mathrm{kg}$ \\
\hline & TOC & Oxalate & Formate \\
\hline & 12852 & 2667 & 41883 \\
& 11670 & 2361 & 41482 \\
& 12818 & 2183 & 42063 \\
& 13129 & 2690 & 42065 \\
\hline Avg & 12617.25 & 2475.25 & 41873.25 \\
\hline Std Dev & 646.68 & 245.86 & 274.44 \\
\hline Std error & 323.34 & 122.93 & 137.22 \\
\hline batch \% rsd $(\delta)$ & $2.72 \%$ & $5.05 \%$ & $2.47 \%$ \\
\hline C factor & 1 & 0.27292 & 0.266806 \\
\hline low bias factor & 1 & 0.9495 & 0.9697 \\
\hline
\end{tabular}

\begin{tabular}{|c|c|c|c|c|c|c|c|}
\hline$\underline{\partial}$ & $\underline{\mathrm{C}_{A E}}$ & $\underline{\mathrm{C}_{A E}}$ & $\underline{\mathrm{C}_{A E}}$ & $\underline{\mathrm{C}_{A E}}$ & $\underline{\mathrm{C}_{A E}}$ & $\underline{\mathrm{C}_{A E}}$ & \\
\hline$\partial$ & TOC & $\delta_{\text {TOC }}$ & Oxalate & $\delta_{\text {oxalate }}$ & Formate & $\delta_{\text {formate }}$ & \\
\hline & 1 & 1 & 0.27292 & 0.27292 & 0.266806 & 0.266806 & \\
\hline & $34.61 \%$ & $38.99 \%$ & $0.37 \%$ & $0.39 \%$ & $0.44 \%$ & $25.21 \%$ & $100.000 \%$ \\
\hline
\end{tabular}

bias factor

\begin{tabular}{|c|c|c|c|c|}
\hline & \multicolumn{4}{|c|}{ After Transfer Out } \\
\hline & & 1-sigma & & \\
\hline & LI $3025_{2}$ & Uncertainty & bias & \\
\hline & 17.45 & 1.3384 & 2.316 & \\
\hline & & inwc & inwc & \\
\hline & $\mathrm{x} 1$ & $x 2$ & $\mathrm{y} 1$ & y2 \\
\hline & 17.416 & 0 & 1000 & 0 \\
\hline & 78.513 & 17.416 & 5175 & 1000 \\
\hline & 138.28 & 78.513 & 9400 & 5175 \\
\hline & 158.89 & 138.28 & 10850 & 9400 \\
\hline & 175.91 & 158.89 & 12000 & 10850 \\
\hline After Info & 78.513 & 17.416 & 5175 & 1000 \\
\hline & & & 1-sigma & \\
\hline & & & Uncentanty & \\
\hline & & $\begin{array}{c}\text { Volume, atter, } V_{2} \\
1339.4\end{array}$ & $\begin{array}{c}{ }_{2}^{2} \text {, gal } \\
9\end{array}$ & \\
\hline & & & bias, $b_{2}$, gal & \\
\hline & & & 12 & \\
\hline
\end{tabular}

\begin{tabular}{|c|c|c|c|c|}
\hline \multicolumn{5}{|c|}{ Volume Determination Before Transfer } \\
\hline \\
\hline LI3025 & 1-sigma & & 1-sigma & \\
\hline 108.08 & 1.3384 & 55.55 & 0.9300 & \\
\hline bias & 2.316 & & 1.61 & \\
\hline & & & & \\
\hline & $\mathrm{x} 1$ & $\mathrm{x} 2$ & $\mathrm{y} 1$ & $\mathrm{y} 2$ \\
\hline & 17.416 & 0 & 1000 & 0 \\
\hline & 78.513 & 17.416 & 5175 & 1000 \\
\hline & 138.28 & 78.513 & 9400 & 5175 \\
\hline & 158.89 & 138.28 & 10850 & 9400 \\
\hline & 175.91 & 158.89 & 12000 & 10850 \\
\hline & & & & \\
\hline Before Info & 138.28 & 78.513 & 9400 & 5175 \\
\hline
\end{tabular}

12 


\section{Exhibit B7. Example Calculation for SRAT Step 4 Linked to Step 1}

(continued)

\begin{tabular}{|c|c|c|c|c|}
\hline & & 1-sigma & & \\
\hline & & Uncertainty & bias & \\
\hline C $_{\text {AF }}$ & 1142 & 549.64 & 0 & $\mathrm{mg} / \mathrm{kg}$ \\
\hline Density, $\rho$ & 1.1177 & $\mathrm{~kg} / \mathrm{L}$ & & \\
\hline
\end{tabular}

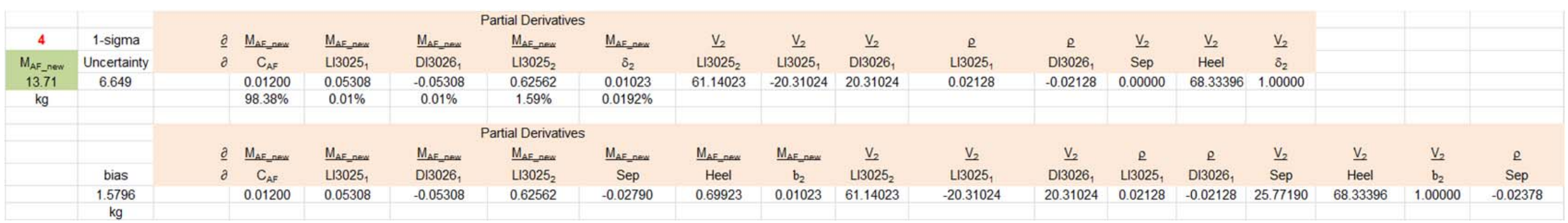




\section{Exhibit B8. Example Calculation for SRAT Step 3}

$$
M_{A F_{\text {out }}}=\frac{M_{A F} \cdot\left(V_{1}-V_{2}\right)}{V_{1}}
$$

SRAT Status Before Event

\begin{tabular}{|c|c|c|c|c|}
\hline SRAT & & & \\
\hline Sep & Heel & M & & 1-sigma \\
\hline 47 & 6.77 & 35.210 & 1.500 \\
\hline 0.0625 & 0.0625 & $\mathrm{~kg}$ & $\mathrm{~kg}$ \\
\hline inches & inches & & bias \\
\hline bias & bias & & 5.25 \\
\hline & & & $\mathrm{kg}$ \\
\hline
\end{tabular}

\begin{tabular}{|c|c|c|c|c|c|c|c|}
\hline \multicolumn{4}{|c|}{ Before Transfer Out } & \multicolumn{2}{|c|}{ After Transfer Out } & & \multirow{2}{*}{$\begin{array}{c}\text { 1-sigma } \\
\text { Uncertainty }\end{array}$} \\
\hline & 1-sigma & & 1-sigma & & 1-sigma & & \\
\hline LI3025 & Uncertainty & DI3026 & Uncertainty & $\mathrm{LI} 3025_{2}$ & Uncertainty & $\mathrm{V}_{1}$ & $\delta 1$ for $V_{1}$ \\
\hline 104.02 & 1.3384 & 53.389 & 0.9300 & 16.975 & 1.3384 & 6929.36 & 9 \\
\hline \multirow[t]{4}{*}{ inwc } & Bias & inwc & Bias & inwc & Bias & gal & gal \\
\hline & 2.316 & & 1.61 & & 2.316 & & bias, $b_{1}$ \\
\hline & inwc & & inwc & & inwc & & 12 \\
\hline & & & & & & & gal \\
\hline
\end{tabular}

\begin{tabular}{|l|c|c|c|c|c|c|}
\hline & $\mathrm{x} 1$ & $\mathrm{x} 2$ & $\mathrm{y} 1$ & $\mathrm{y}$ & & $\begin{array}{c}\text { 1-sigma } \\
\text { Uncertainty }\end{array}$ \\
\hline & 17.416 & 0 & 1000 & 0 & $\mathrm{~V}_{2}$ & $\delta 2$ for $\mathrm{V}_{2}$ \\
\hline & 78.513 & 17.416 & 5175 & 1000 & 1349.30 & 9 \\
\hline & 138.28 & 78.513 & 9400 & 5175 & gal & gal \\
\hline & 158.89 & 138.28 & 10850 & 9400 & & bias, $b_{2}$ \\
\hline & 175.91 & 158.89 & 12000 & 10850 & Density, $P$ & 12 \\
\hline & & & & & 1.0773 & gal \\
\hline Before & 138.28 & 78.513 & 9400 & 5175 & $\mathrm{~kg} / \mathrm{L}$ & \\
\hline After & 78.513 & 17.416 & 5175 & 1000 & & \\
\hline
\end{tabular}




\section{Exhibit B8. Example Calculation for SRAT Step 3}

(continued)

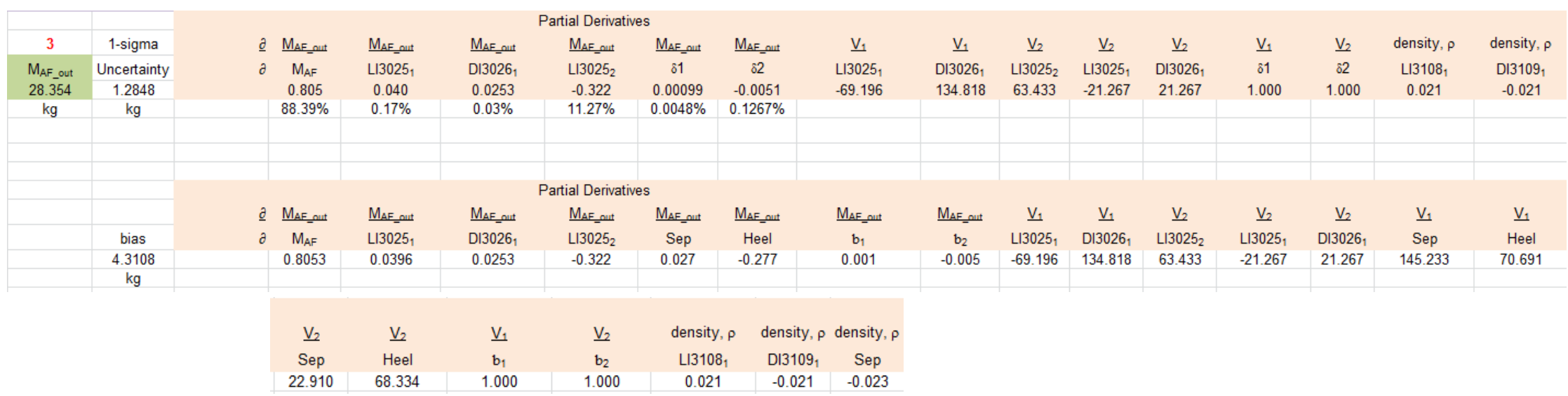




\section{Exhibit B9. Example Calculation for SRAT Step 4}

$$
M_{A F_{\text {new }}}=\frac{M_{A F} \cdot V_{2}}{V_{1}}
$$

SRAT Status Before Event

\begin{tabular}{|c|c|c|c|c|}
\hline SRAT & & & \\
\hline & & & 1-sigma \\
\hline Sep & Heel & M & Uncertainty \\
\hline 47 & 6.77 & 35.210 & 1.500 \\
\hline 0.0625 & 0.0625 & $\mathrm{~kg}$ & $\mathrm{~kg}$ \\
\hline inches & inches & & bias \\
\hline bias & bias & & 5.25 \\
\hline & & & $\mathrm{kg}$ \\
\hline
\end{tabular}

\begin{tabular}{|c|c|c|c|c|c|c|c|}
\hline \multicolumn{4}{|c|}{ Before Transfer Out } & \multicolumn{2}{|c|}{ After Transfer Out } & & \multirow{2}{*}{$\begin{array}{c}\text { 1-sigma } \\
\text { Uncertainty }\end{array}$} \\
\hline & 1-sigma & & 1-sigma & & 1-sigma & & \\
\hline LI3025 & Uncertainty & DI3026 1 & Uncertainty & $\mathrm{LI} 3025_{2}$ & Uncertainty & $V_{1}$ & $\delta 1$ for $V_{1}$ \\
\hline 104.02 & 1.3384 & 53.389 & 0.9300 & 16.975 & 1.3384 & 6929.36 & 9 \\
\hline \multirow[t]{4}{*}{ inwc } & Bias & inwc & Bias & inwc & Bias & gal & gal \\
\hline & 2.316 & & 1.61 & & 2.316 & & bias, $b_{1}$ \\
\hline & inwc & & inwc & & inwc & & 12 \\
\hline & & & & & & & gal \\
\hline
\end{tabular}

\begin{tabular}{|c|c|c|c|c|c|c|}
\hline & $\times 1$ & $\mathrm{x} 2$ & $\mathrm{y} 1$ & y2 & & 1-sigma \\
\hline & 78513 & 17416 & 5175 & 1000 & $V_{2}$ & $\delta 2$ for $V_{2}$ \\
\hline & 138.28 & 78.513 & 9400 & 5175 & 1349.30 & 9 \\
\hline & 158.89 & 138.28 & 10850 & 9400 & gal & gal \\
\hline & 175.91 & 158.89 & 12000 & 10850 & & bias, $b_{2}$ \\
\hline & & & & & Density, $p$ & 12 \\
\hline Before & 138.28 & 78.513 & 9400 & 5175 & 1.0773 & gal \\
\hline After & 78.513 & 17.416 & 5175 & 1000 & $\mathrm{~kg} / \mathrm{L}$ & \\
\hline
\end{tabular}




\section{Exhibit B9. Example Calculation for SRAT Step 4} (continued)

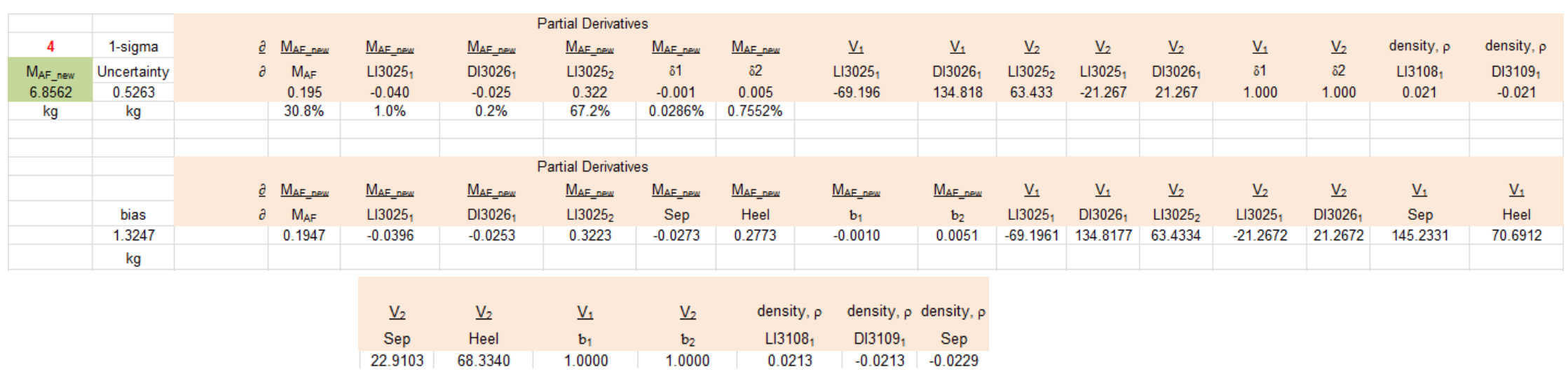




\section{Exhibit B10. Example Calculation for SME Step 2}

$\mathrm{M}_{\mathrm{AF}_{-} \text {new }}=\mathrm{M}_{\mathrm{AF}}+\mathrm{M}_{\mathrm{AF} \_ \text {Add }}$

SME Status Before Event

\begin{tabular}{|c|c|c|c|c|c|c|c|}
\hline \multirow[t]{2}{*}{ SME } & & & & & & & \\
\hline & & & 1-sigma & & & & \\
\hline Sep & Heel & $\mathrm{M}_{\mathrm{AF}}$ & Uncertainty & & & & \\
\hline 47 & 6.77 & 55.02 & 0.75 & & & & \\
\hline \multirow{2}{*}{$\begin{array}{l}0.0625 \\
\text { inches }\end{array}$} & 0.0625 & kg & $\mathrm{kg}$ & & & & \\
\hline & inches & & bias & & & & \\
\hline \multirow[t]{2}{*}{ bias } & bias & & 5.25 & & & & \\
\hline & & & $\mathrm{kg}$ & & & & \\
\hline \multirow{2}{*}{\multicolumn{8}{|c|}{$A_{r}^{f}$}} \\
\hline & & & & & & & \\
\hline \multirow{3}{*}{$A^{d}{ }^{d}$} & & & & & & & \\
\hline & & & & & & & \\
\hline & & & 1-sigma & & 2 & 1-sigma & \\
\hline \multirow{3}{*}{$\begin{array}{ll}\mathrm{t} & \mathrm{S} \\
\mathrm{i} & \mathrm{R} \\
\mathrm{o} & \mathrm{A} \\
\mathrm{n} & \mathrm{T}\end{array}$} & \multicolumn{2}{|c|}{$M_{A_{-} F_{-a d d}}$} & Uncertainty & bias & $M_{A_{F} \text { new }}$ & Uncertainty & bias \\
\hline & \multicolumn{2}{|c|}{28.354} & 1.285 & 4.311 & 83.374 & 1.488 & 9.561 \\
\hline & \multicolumn{2}{|c|}{$\mathrm{kg}$} & $\mathrm{kg}$ & $\mathrm{kg}$ & $\mathrm{kg}$ & kg & $\mathrm{kg}$ \\
\hline
\end{tabular}




\section{Exhibit B11. Example Calculation for SME Step 3}

$\mathrm{M}_{\mathrm{AF}_{-} \text {new }}=\mathrm{M}_{\mathrm{AF}}+\mathrm{M}_{\mathrm{AF} \_ \text {Add }}$

SME Status Before Event

\begin{tabular}{|c|c|c|c|}
\hline SME & & & \\
\hline Sep & Heel & M-sigma \\
\hline 47 & 6.77 & M AF & Uncertainty \\
\hline 0.0625 & 0.0625 & $\mathrm{~kg}$ & 0.75 \\
\hline inches & inches & & $\mathrm{kg}$ \\
\hline bias & bias & & 5.25 \\
\hline & & & $\mathrm{kg}$ \\
\hline
\end{tabular}

\begin{tabular}{|c|c|c|c|c|c|c|}
\hline \\
\hline \\
\hline$d f A$ & & & & & & \\
\hline$A$ i $r N$ & & 1-sigma & & 3 & 1-sigma & \\
\hline$F \quad t \quad F$ & $\mathrm{M}_{\mathrm{AF}_{\text {_add }}}$ & Uncertainty & bias & $M_{A_{F} \text { new }}$ & Uncertainty & bias \\
\hline $\mathrm{i} \mathrm{m} \mathrm{T}$ & 14.0 & 1.2 & 5.00 & 69.020 & 1.396 & 10.250 \\
\hline 0 & $\mathrm{~kg}$ & $\mathrm{~kg}$ & $\mathrm{~kg}$ & $\mathrm{~kg}$ & $\mathrm{~kg}$ & $\mathrm{~kg}$ \\
\hline
\end{tabular}




\section{Exhibit B12. Example Calculation for SME Step 1}

$$
M_{A F_{\text {new }}}=\frac{3.7854 \cdot C_{A F} \cdot V_{1} \cdot \rho}{0.4723 \cdot 1000000}
$$

SME Status Unknown before Event

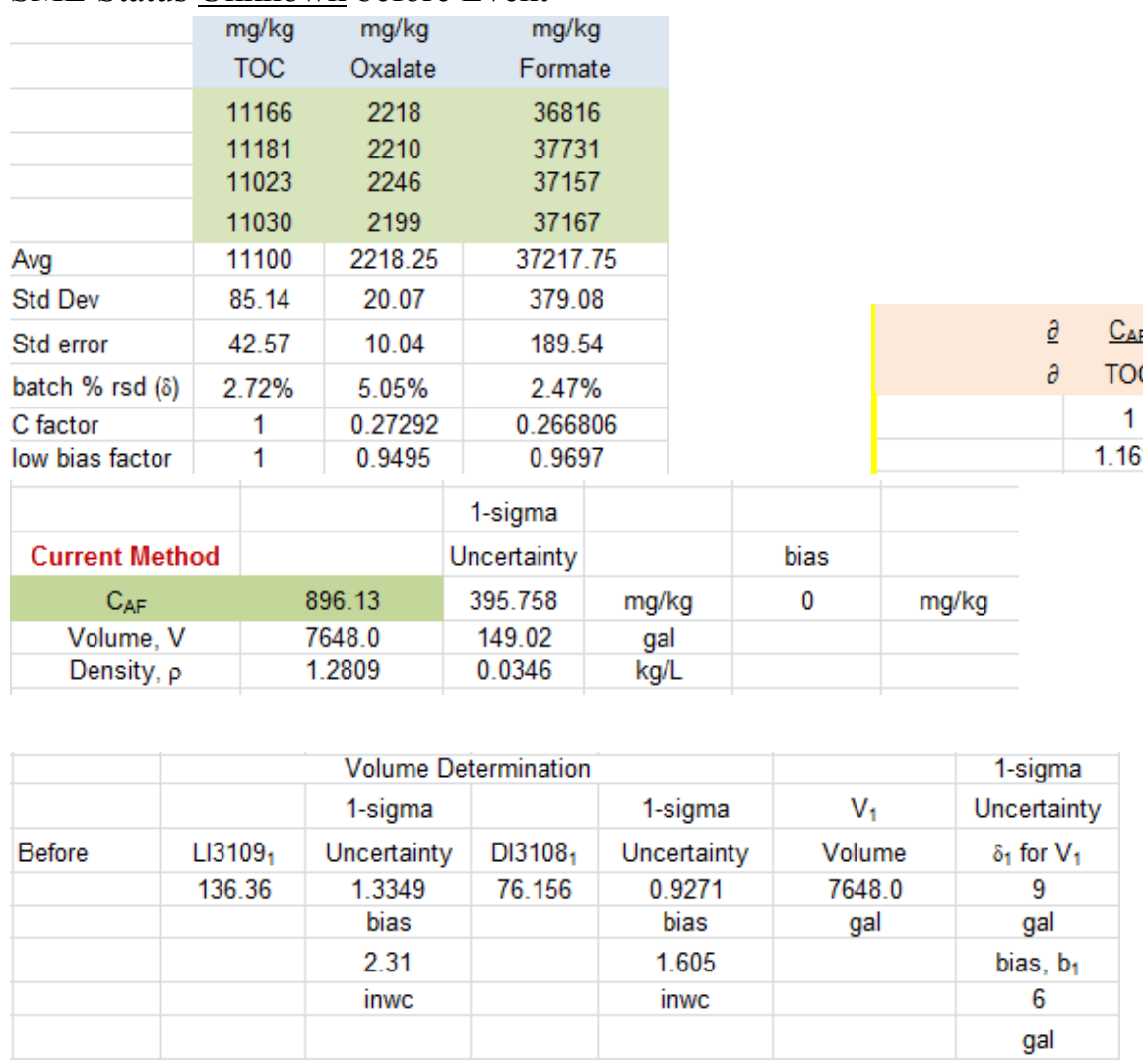

\begin{tabular}{|c|c|c|c|c}
\hline & $\mathrm{x} 1$ & $\mathrm{x} 2$ & $\mathrm{y} 1$ & $\mathrm{y} 2$ \\
\hline & 9.8051 & 0 & 500 & 0 \\
\hline & 79.232 & 9.8051 & 5240 & 500 \\
\hline & 125.25 & 79.232 & 8500 & 5240 \\
\hline & 175.02 & 125.25 & 12000 & 10850 \\
\hline Level Info & 125.25 & 79.232 & 8500 & 5240 \\
\hline
\end{tabular}




\section{Exhibit B12. Example Calculation for SME Step 1}

(continued)

\begin{tabular}{|c|c|c|c|c|c|c|c|c|c|c|c|c|c|c|c|c|}
\hline 1 & 1-sigma & $\underline{\partial}$ & $M_{A E \text { new }}$ & $\underline{M}_{A E \text { _eus }}$ & $\underline{M_{A E \text { new }}}$ & $\underline{M_{A E \text { _enes }}}$ & $\underline{V_{1}}$ & $\underline{\mathrm{V}}_{1}$ & $\varrho$ & $\varrho$ & $\underline{\mathrm{V}_{1}}$ & & & & & \\
\hline$M_{A_{\text {_n new }}}$ & Uncertainty & $\partial$ & $\mathrm{C}_{A F}$ & 니시 & DI3109, & $\delta_{1}$ & LI3108, & DI3109, & LL3108 & DI3109, & $\delta_{1}$ & & & & & \\
\hline 70.36 & 31.082 & & 0.07852 & 0.52511 & -0.01630 & 0.00920 & -69.95861 & 125.26335 & 0.02128 & -0.02128 & 1.00000 & & & & & \\
\hline \multirow[t]{6}{*}{$\mathrm{kg}$} & kg & & $99.948 \%$ & $0.051 \%$ & $0.000 \%$ & $0.0007 \%$ & & & & & & & & & & \\
\hline & & & & & & & & & & & & & & & & \\
\hline & & $\underline{\partial}$ & $\underline{M_{A E_{\text {_nes }}}}$ & $\mathrm{M}_{\mathrm{AE} \text { _nes }}$ & $M_{A E_{\text {_nes }}}$ & $\mathrm{M}_{\mathrm{AE}_{\text {_ness }}}$ & $M_{A E_{\text {new }}}$ & $M_{A E_{\text {ness }}}$ & $\underline{V_{1}}$ & $\underline{V_{1}}$ & $\varrho$ & $\varrho$ & $\underline{\mathrm{V}}_{1}$ & $\underline{V_{1}}$ & $\varrho$ & $\underline{v_{1}}$ \\
\hline & bias & $\partial$ & $\mathrm{C}_{\mathrm{AF}}$ & LL3108 & DI3109, & Sep & Heel & $b_{1}$ & LI3108, & DI3109, & LI3108, & DI3109, & Sep & Heel & Sep & $b_{1}$ \\
\hline & 1.2152 & & 0.07852 & 0.52511 & -0.01630 & -0.02088 & 0.65175 & 0.00920 & -69.95861 & 125.26335 & 0.02128 & -0.02128 & 160.45435 & 70.84184 & -0.02725 & 1.00000 \\
\hline & $\mathrm{kg}$ & & & & & & & & & & & & & & & \\
\hline
\end{tabular}




\section{Exhibit B13. Example Calculation for SME Step 5 Linked to Step 1}

$$
M_{A F_{\text {new }}}=\frac{3.7854 \cdot C_{A F} \cdot V_{2} \cdot \rho}{0.4723 \cdot 1000000}
$$

SME Status Unknown before Event

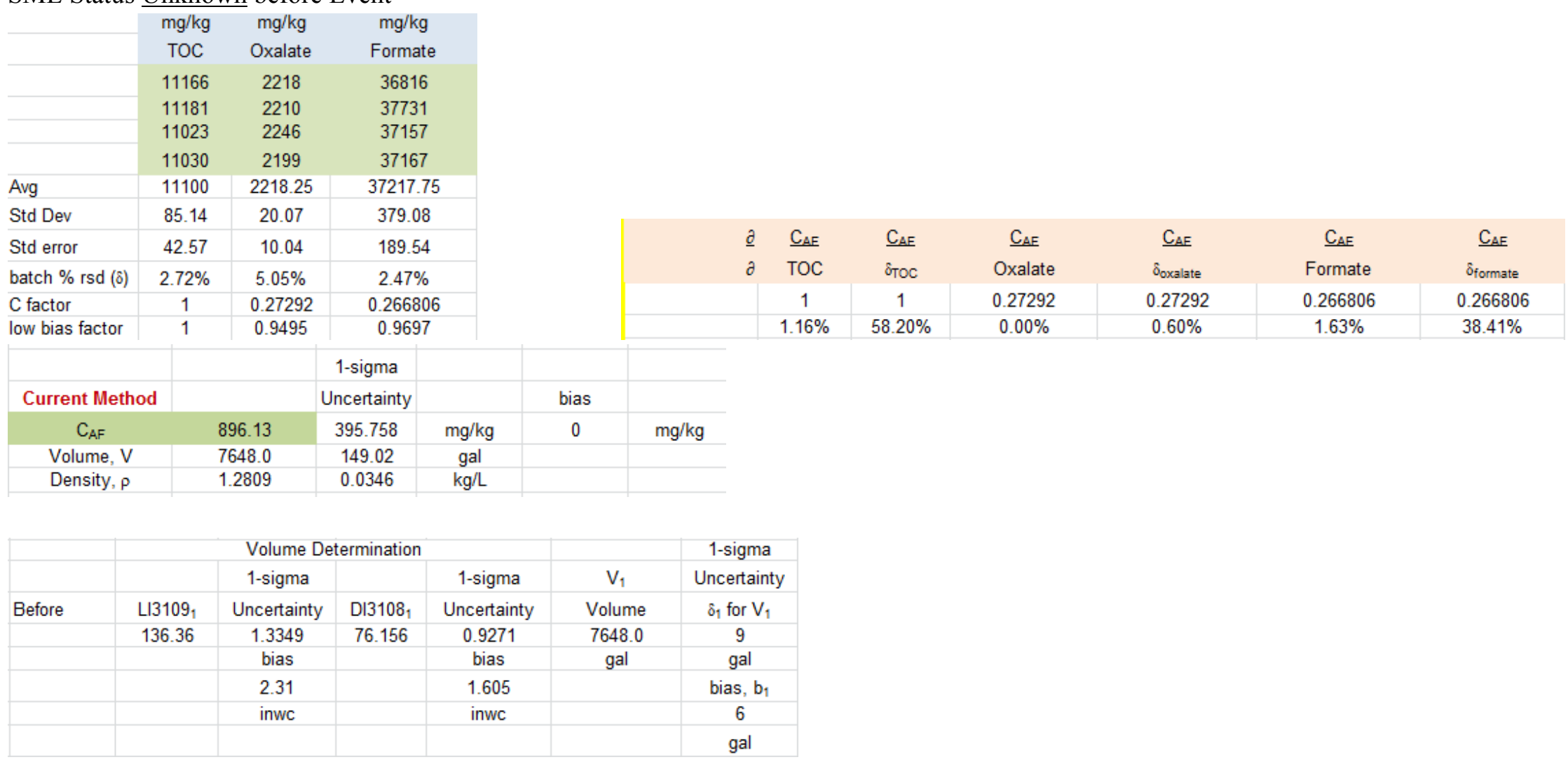




\section{Exhibit B13. Example Calculation for SME Step 5 Linked to Step 1}

(continued)

\begin{tabular}{|c|c|c|c|c|}
\hline & \multicolumn{3}{|c|}{ After Acceptability --- Transfer Out } & 1-sigma \\
\hline & & 1-sigma & After & Uncertainty \\
\hline \multirow[t]{6}{*}{ After } & $\mathrm{LI} 3109_{2}$ & Uncertainty & $V_{2}$ & $\delta_{2}$ for $V_{2}$ \\
\hline & 23.511 & 1.3349 & 1545.9 & 9 \\
\hline & & bias & gal & gal \\
\hline & & 2.31 & & bias, $b_{2}$ \\
\hline & & inwc & & 6 \\
\hline & & & & gal \\
\hline
\end{tabular}

\begin{tabular}{|c|c|c|c|c|}
\hline & $\mathrm{x} 1$ & $\mathrm{x} 2$ & $\mathrm{y} 1$ & $\mathrm{y} 2$ \\
\hline & 9.8051 & 0 & 500 & 0 \\
\hline & 79.232 & 9.8051 & 5240 & 500 \\
\hline & 125.25 & 79.232 & 8500 & 5240 \\
\hline & 175.02 & 125.25 & 12000 & 10850 \\
\hline & & & & \\
\hline Level Info & 125.25 & 79.232 & 8500 & 5240 \\
\hline After & 79.232 & 9.8051 & 5240 & 500 \\
\hline
\end{tabular}

\begin{tabular}{|c|c|c|c|c|c|c|c|c|}
\hline 5 & & \multirow[b]{2}{*}{$\underline{\partial}$} & \multirow[b]{2}{*}{$\underline{M_{A E_{\text {nex }}}}$} & \multicolumn{5}{|c|}{ Partial Derivatives } \\
\hline After & 1-sigma & & & $\underline{M_{A E_{\text {new }}}}$ & $\underline{M_{A E \text { ness }}}$ & $\underline{M}_{A E_{\text {_nes }}}$ & $\underline{M_{A E_{\text {_nes }}}}$ & $\alpha$ \\
\hline$M_{\text {AF_new }}$ & Uncertainty & \multirow[t]{2}{*}{$\partial$} & $\mathrm{C}_{\mathrm{AF}}$ & LI3025, & DI3026, & $\mathrm{LI} 3025_{2}$ & $\delta_{2}$ & LI302 \\
\hline 14.222 & 6.3161 & & 0.01587 & 0.04474 & -0.04474 & 0.49036 & 0.00920 & 53.29 \\
\hline \multirow[t]{8}{*}{$\mathrm{kg}$} & $\mathrm{kg}$ & & $98.895 \%$ & $0.009 \%$ & $0.004 \%$ & $1.074 \%$ & $0.0172 \%$ & \\
\hline & & \multicolumn{3}{|c|}{ Partial Derivatives } & & & & \\
\hline & bias & \multirow{3}{*}{$\frac{\partial}{\partial}$} & $M_{A E_{\text {_nex }}}$ & $M_{A E_{\text {_new }}}$ & $\underline{M}_{A E_{\text {_nex }}}$ & $M_{A_{\text {_ness }}}$ & $\underline{M}_{A E_{\text {_nex }}}$ & $\underline{M_{A}}$ \\
\hline & 1.142 & & $\mathrm{C}_{\mathrm{AF}}$ & LI3025, & DI3026, & $\mathrm{LI} 3025_{2}$ & Sep & $\mathrm{Hee}$ \\
\hline & \multirow[t]{4}{*}{$\mathrm{kg}$} & & 0.01587 & 0.04474 & -0.04474 & 0.49036 & -0.05731 & 0.62 \\
\hline & & & $\varrho$ & $\underline{\mathrm{V}_{2}}$ & $\underline{v}$ & & $\underline{\mathrm{V}_{2}}$ & $\varrho$ \\
\hline & & & DI3109, & Sep & $\mathrm{He}$ & & $\mathrm{b}_{2}$ & Sep \\
\hline & & & -0.02128 & 26.66222 & 68.2 & & 1.00000 & -0.02725 \\
\hline
\end{tabular}




\section{Exhibit B14. Example Calculation for SME Step 4}

$$
C_{A F}=\frac{0.4905 \cdot 1000000 \cdot M_{A F}}{\rho \cdot V_{1} \cdot 3.7854}
$$

SME Status Before Event

\begin{tabular}{|c|c|c|c|}
\hline \multirow{2}{*}{ SME } & & & \\
\hline & & & 1-sigma \\
\hline Sep & Heel & $\mathrm{M}_{\mathrm{AF}}$ & Uncertainty \\
\hline 47 & 6.77 & 55.02 & 0.75 \\
\hline 0.0625 & 0.0625 & $\mathrm{~kg}$ & $\mathrm{~kg}$ \\
\hline inches & inches & & bias \\
\hline \multirow[t]{2}{*}{ bias } & bias & & 5.25 \\
\hline & & & $\mathrm{kg}$ \\
\hline
\end{tabular}

\begin{tabular}{|l|c|c|}
\hline \multicolumn{3}{|c|}{ Before Acceptability Decision } \\
\hline \multicolumn{1}{|c|}{ Coal } & 240 & $\mathrm{mg} / \mathrm{kg}$ \\
\hline & $\mathrm{mg} / \mathrm{kg}$ & $\mathrm{mg} / \mathrm{kg}$ \\
\hline & Before & Before \\
\hline & TOC & Nitrate \\
\hline & 9945 & 20634 \\
& 9958 & 20047 \\
\hline & 9963 & 20028 \\
\hline & 9905 & 20854 \\
\hline Avg & 9942.75 & 20390.75 \\
\hline Std Dev & 26.29 & 417.74 \\
\hline Std error & 13.14 & 208.87 \\
\hline batch \% rsd (8) & $2.72 \%$ & $2.73 \%$ \\
\hline C factor & 1 & 0 \\
\hline low bias factor & 1 & 0.9924 \\
\hline & Low $\mathrm{NO}_{3}$ & Acceptable \\
\hline & High $\mathrm{NO}_{3}$ & Acceptable \\
\hline & & \\
\hline
\end{tabular}

\begin{tabular}{|c|c|c|c|c|}
\hline & \multicolumn{4}{|c|}{ Volume/Density Determinations } \\
\hline & & 1-sigma & & 1-sigma \\
\hline \multirow[t]{6}{*}{ Before } & LI3109 & Uncertainty & DI3108 & Uncertainty \\
\hline & 126.48 & 1.3349 & 65.018 & 0.9271 \\
\hline & & bias & & bias \\
\hline & & 2.31 & & 1.605 \\
\hline & & inwc & & inwc \\
\hline & & 1-sigma & & \\
\hline Before & Before & Uncertainty & & \\
\hline Density. $p$ & Volume, $V_{1}$ & $\delta_{1}$ for $V_{1}$ & & \\
\hline 1.3077 & 6958.4 & 9 & & \\
\hline \multirow[t]{4}{*}{$\mathrm{kg} / \mathrm{L}$} & gal & gal & & \\
\hline & & bias, $b_{1}$ & & \\
\hline & & 6 & & \\
\hline & & gal & & \\
\hline
\end{tabular}




\section{Exhibit B14. Example Calculation for SME Step 4}

(continued)

\begin{tabular}{|c|c|c|c|c|}
\hline & $\mathrm{x} 1$ & $\mathrm{x} 2$ & $\mathrm{y} 1$ & $\mathrm{y} 2$ \\
\hline & 9.8051 & 0 & 500 & 0 \\
\hline & 79.232 & 9.8051 & 5240 & 500 \\
\hline & 125.25 & 79.232 & 8500 & 5240 \\
\hline & 175.02 & 125.25 & 12000 & 10850 \\
\hline & & & & \\
\hline Before & 125.25 & 79.232 & 8500 & 5240 \\
\hline
\end{tabular}

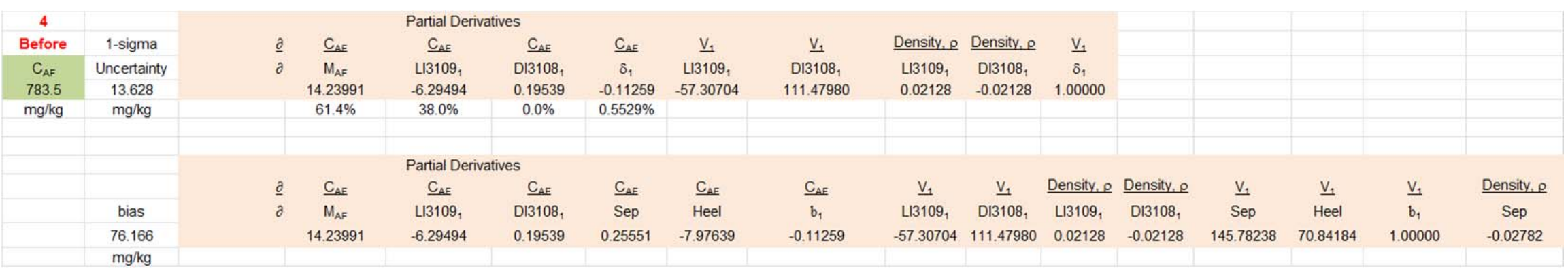

Acceptability Decision for the SME Product

\begin{tabular}{|c|c|c|c|c|c|c|c|c|c|c|}
\hline & & & & Allowed fo & given $\mathrm{NO} 3$ & & & & & \\
\hline & & $\mathrm{C}_{\mathrm{AF}}$ Mode & oefficients & TOC Model & Coefficients & & & & & \\
\hline & Gallons on AF & h & j & f & g & & & & & \\
\hline & 728 & 5117745.1 & -35.869438 & 8140 & 0.37 & & & & & \\
\hline & 894 & 7884790.5 & -55.545316 & 6550 & 0.37 & & & & & \\
\hline & 1017 & 10373798 & -73.602487 & 5300 & 0.37 & & & & & \\
\hline & & $\mathrm{C}_{\mathrm{AF}}$ & 1-sigma & TOC & 1-sigma & AF Tra & Ig Method Ac & tability & & \\
\hline & Gallons on AF & $\mathrm{mg} / \mathrm{kg}$ & Uncertainty & $\mathrm{mg} / \mathrm{kg}$ & Uncertainty & & $\mathrm{C}_{\mathrm{AF}}$ & TOC & Delta $\mathrm{C}_{\mathrm{AF}}$ & Delta TOC \\
\hline & 728 & 2094.36 & 5.09 & 15627.24 & 219.99 & & Acceptable & Acceptable & 1200.2 & 4617.3292 \\
\hline \& TOC & $\begin{array}{c}894 \\
1017\end{array}$ & $\begin{array}{l}2598.50 \\
2978.76\end{array}$ & $\begin{array}{l}6.35 \\
7.35\end{array}$ & $\begin{array}{l}14037.24 \\
12787.24\end{array}$ & $\begin{array}{l}219.99 \\
219.99\end{array}$ & Decision & $\begin{array}{l}\text { Acceptable } \\
\text { Acceptable }\end{array}$ & $\begin{array}{l}\text { Acceptable } \\
\text { Acceptable }\end{array}$ & $\begin{array}{l}1703.2 \\
2082.4\end{array}$ & $\begin{array}{l}3027.3292 \\
1777.3292\end{array}$ \\
\hline
\end{tabular}




\section{Exhibit B15. Example Calculation for SME Step 5}

$$
M_{A F_{\text {new }}}=\frac{M_{A F} \cdot V_{2}}{V_{1}}
$$

SME Status Before Event

\begin{tabular}{|c|c|c|c|}
\hline SME & & & \\
\hline Sep & Heel & M $_{\text {AF }}$ & Uncertainty \\
\hline 47 & 6.77 & 55.02 & 0.75 \\
\hline 0.0625 & 0.0625 & $\mathrm{~kg}$ & $\mathrm{~kg}$ \\
\hline inches & inches & & bias \\
\hline bias & bias & & 5.25 \\
\hline & & & $\mathrm{kg}$ \\
\hline
\end{tabular}

\begin{tabular}{|c|c|c|c|c|}
\hline & \multicolumn{4}{|c|}{ Volume/Density Determinations } \\
\hline & & 1-sigma & & 1-sigma \\
\hline \multirow[t]{7}{*}{ Before } & LII3109 & Uncertainty & DI3108 & Uncertainty \\
\hline & 126.48 & 1.3349 & 65.018 & 0.9271 \\
\hline & & bias & & bias \\
\hline & & 2.31 & & 1.605 \\
\hline & & inwc & & inwc \\
\hline & & & & \\
\hline & & 1-sigma & & \\
\hline Before & Before & Uncertainty & & \\
\hline Density. $\rho$ & Volume, $V_{1}$ & $\delta_{1}$ for $V_{1}$ & & \\
\hline 1.3077 & 6958.4 & 9 & & \\
\hline \multirow[t]{4}{*}{$\mathrm{kg} / \mathrm{L}$} & gal & gal & & \\
\hline & & bias, $b_{1}$ & & \\
\hline & & 6 & & \\
\hline & & gal & & \\
\hline
\end{tabular}

\begin{tabular}{|c|c|c|c|c|}
\hline & \multirow{2}{*}{\multicolumn{2}{|c|}{$\begin{array}{c}\text { After Acceptability -- Transfer Out } \\
1 \text {-sigma }\end{array}$}} & & \multirow{2}{*}{$\begin{array}{c}\text { 1-sigma } \\
\text { Uncertainty }\end{array}$} \\
\hline & & & After & \\
\hline \multirow[t]{6}{*}{ After } & $\mathrm{L} \mid 3109_{2}$ & Uncertainty & $V_{2}$ & $\delta_{2}$ for $V_{2}$ \\
\hline & 20.433 & 1.3349 & 1359.6 & 9 \\
\hline & & bias & gal & gal \\
\hline & & 2.31 & & bias, $b_{2}$ \\
\hline & & inwc & & 6 \\
\hline & & & & gal \\
\hline
\end{tabular}




\section{Exhibit B15. Example Calculation for SME Step 5}

(continued)

\begin{tabular}{|c|c|c|c|c|}
\hline & $\mathrm{x} 1$ & $\mathrm{x} 2$ & $\mathrm{y} 1$ & $\mathrm{y} 2$ \\
\hline & 9.8051 & 0 & 500 & 0 \\
\hline & 79.232 & 9.8051 & 5240 & 500 \\
\hline & 125.25 & 79.232 & 8500 & 5240 \\
\hline & 175.02 & 125.25 & 12000 & 10850 \\
\hline & & & & \\
\hline Before & 125.25 & 79.232 & 8500 & 5240 \\
\hline After & 79.232 & 9.8051 & 5240 & 500 \\
\hline
\end{tabular}

\begin{tabular}{|c|c|c|c|c|c|c|c|c|c|c|c|c|c|c|c|c|c|}
\hline 5 & & \multicolumn{16}{|c|}{ Partial Derivatives } \\
\hline After & 1-sigma & $\underline{\partial}$ & $M_{A E_{\text {_new }}}$ & $\underline{M_{A E_{\text {_new }}}}$ & $\underline{M_{A E_{\text {_new }}}}$ & $\underline{M_{A E_{\text {_nes }}}}$ & $\underline{M_{A E_{\text {_new }}}}$ & $\underline{M_{A E_{\text {new }}}}$ & $\underline{v_{1}}$ & $\underline{V}_{1}$ & $\underline{\mathrm{V}}_{2}$ & $\underline{V_{2}}$ & $\underline{V_{2}}$ & $\underline{v_{1}}$ & $\underline{V_{2}}$ & Density & Density \\
\hline $\begin{array}{l}M_{\text {AE-new }} \\
10.75\end{array}$ & $\begin{array}{c}\text { Uncertainty } \\
0.5794\end{array}$ & $\partial$ & $\begin{array}{c}M_{A F} \\
0.19538\end{array}$ & $\begin{array}{l}\text { LI3025, } \\
-0.04871\end{array}$ & $\begin{array}{r}\text { DI3026, } \\
-0.03499\end{array}$ & $\begin{array}{l}\mathrm{LI} 3025_{2} \\
0.41281\end{array}$ & $\begin{array}{c}\delta_{1} \\
-0.00154\end{array}$ & $\begin{array}{c}\delta_{2} \\
0.00791\end{array}$ & $\begin{array}{l}\text { LI3025, } \\
-57.30704\end{array}$ & $\begin{array}{c}\text { DI3026, } \\
111.47980\end{array}$ & $\begin{array}{c}\mathrm{L} \mid 3025_{2} \\
52.20856\end{array}$ & $\begin{array}{c}\text { LI3025, } \\
-17.35670\end{array}$ & $\begin{array}{c}\text { Dl3026, } \\
17.35670\end{array}$ & $\begin{array}{c}8 \\
1.00000\end{array}$ & $\begin{array}{c}\delta_{2} \\
1.00000\end{array}$ & $\begin{array}{l}\text { LI3108, } \\
0.02128\end{array}$ & $\begin{array}{r}\text { DI3109, } \\
-0.02128\end{array}$ \\
\hline \multirow[t]{10}{*}{$\mathrm{kg}$} & $\mathrm{kg}$ & & $6.4 \%$ & $1.3 \%$ & $0.3 \%$ & $90.5 \%$ & $0.0576 \%$ & $1.5086 \%$ & & & & & & & & & \\
\hline & & & & & & & & & & & & & & & & & \\
\hline & & & & & & & & & \multicolumn{2}{|c|}{ Partial Derivatives } & & & & & & & \\
\hline & & $\underline{\partial}$ & $M_{A E \text { ness }}$ & $M_{A E_{\text {nes }}}$ & $M_{A E_{\text {nes }}}$ & $M_{A E \text { nes }}$ & $M_{A E \text { ness }}$ & $M_{A E \text { nes }}$ & $\underline{M}_{A E_{\text {_nes }}}$ & $\mathrm{M}_{\mathrm{AE} \text { _new }}$ & $\underline{V_{1}}$ & $\underline{\mathrm{V}_{1}}$ & $\underline{V_{2}}$ & $\underline{V_{2}}$ & $\underline{V_{2}}$ & $\underline{V_{1}}$ & $\underline{\mathrm{V}_{1}}$ \\
\hline & bias & $\partial$ & $M_{A F}$ & LI3025, & DI3026, & $\mathrm{LI}_{3} \mathrm{O}_{2} \mathrm{~F}_{2}$ & Sep & Heel & $b_{1}$ & $b_{2}$ & Lᄂ3025, & DI3026, & $\mathrm{L} 3025_{2}$ & LI3025, & DI3026, & Sep & Heel \\
\hline & 1.482 & & 0.19538 & -0.04871 & -0.03499 & 0.41281 & -0.04575 & 0.43039 & -0.00154 & 0.00791 & -57.30704 & 111.47980 & 52.20856 & -17.35670 & 17.35670 & 145.78238 & 70.84184 \\
\hline & $\mathrm{kg}$ & . & & & & & & & & & & & & & & & \\
\hline & & & & $\underline{V_{2}}$ & $\underline{V_{2}}$ & $\underline{V_{1}}$ & $\underline{V_{2}}$ & Density & Density & Density & & & & & & & \\
\hline & & & & Sep & Heel & $b_{1}$ & $b_{2}$ & LI3108, & DI3109, & Sep & & & & & & & \\
\hline & & & & 22.69739 & 68.27325 & 1.00000 & 1.00000 & 0.02128 & -0.02128 & -0.02782 & & & & & & & \\
\hline
\end{tabular}


SRNL-STI-2014-00323

Revision 0

\section{Appendix C. Volume versus Pressure Correlation for the AMFT}

The volume versus pressure correlation for the AMFT is developed in this appendix. Exhibit C1 provides an overview of how the data were taken and the how the analyses of the data were conducted [10]. Table $\mathrm{C} 1$ shows the data and Exhibit $\mathrm{C} 2$ provides the regression statistics from fitting the pressure values to the volume numbers using JMP 11.1.1 [9]. Included in the JMP output are confidence intervals at 95\% confidence for inverse predictions (i.e., predictions of volume from pressure values): predictions of mean volumes and predictions of individual volumes.

Table C2 summaries these confidence intervals, which were used to provide insight into possible bias and random uncertainties in the use of the correlation between volume and pressure. The bias is estimated by maximum of the upper limit of the confidence interval for mean predictions minus the mean prediction itself and the mean prediction minus the lower limit of the confidence interval. A column showing these estimated biases is included in Table C2. Over the interval of pressures studied, the largest of these values is $0.232 \mathrm{gal}$, which is to be used as a bound on the bias of the correlation at $95 \%$ confidence.

The random uncertainty is estimated by the maximum of the upper limit of the confidence interval for an individual prediction minus the upper limit of the confidence interval for the mean and of the lower limit of the confidence interval for the mean minus the lower limit of the confidence interval for an individual. These estimated random uncertainties are at $95 \%$ confidence, so they are taken to be 2 -sigma estimates. A column showing these values at 1-sigma level is provided in Table $\mathrm{C} 1$. Over the interval of pressures studied, the largest of these 1-sigma values is 0.637 gal, which is to be used as the 1-sigma random uncertainty of the volume versus pressure correlation for the AMFT. 
SRNL-STI-2014-00323

Revision 0

\section{Exhibit C1. DWPF Procedure Utilized to Generate the Data and to Establish Correlation}

\section{Additive Mix Feed Tank (AMFT) Volume-to-Pressure Correlation}

A fill and drain experiment was conducted on the AMFT to determine the pressure difference between the level instrumentation outlet and the vapor space of the tank as a function of liquid volume within the tank. The specific gravity of the material was set to a value of unity. The volume in the tank was the controlled quantity in the experiment and was incrementally increased by 3 gallons. The measurement and test equipment (M\&TE) used in the determination of the pressure difference had a range of $0-100$ inwc with an uncertainty of $0.06 \%$ of span. This device was used in parallel with the LI2614 instrumentation, i.e. the mechanical characteristics of the instrument from which the M\&TE and the LI2614 received information was identical.

Three experimental runs were conducted. The tank and downstream piping were drained before each run to ensure that the experiment was based on an initially empty system. A calibrated container was filled with water to the 3 gallon mark and then subsequently evacuated to the AMFT. After each 3 gallon addition, the pressure was recorded from the M\&TE. After every sixth addition, i.e. 18 gallons, the pressure from the LI2614 was recorded.

The experimental data are plotted in Figure 1 along with the derived correlation. It is important to notice that the derived correlation is only valid for the linear portion of the data. This is appropriate given that the working level in the AMFT will be restricted to the linear portion of the tank. One notices in Figure 1 that the level instrumentation in the tank was not encountered by the liquid level until the volume in the tank was between 3 and 6 gallons. This is inferred from the increase in pressure occurring in this volume range. This information represented the first indication that there may exist some discrepancy between the vendor print for the AMFT, i.e. Drawing Number D-86-241 Rev. 6, and the physical tank. Theoretically, based upon the vendor print tank dimensions, the level instrumentation should not be encountered until the volume of the tank was approximately 10 gallons. A second indication that the tank may have a different geometry is given at the other end of the data range. In this case, one notices that a plateau in the data is encountered which is consistent with an overflow condition. This overflow condition occurs at approximately 168 gallons. The theoretical overflow volume, i.e. that based upon the vendor supplied dimensions, was calculated to occur at 178.5 gallons.

To derive the pressure difference to volume correlation, the data for the three runs were averaged, i.e.

$\langle\Delta P\rangle_{j}=\frac{1}{3} \sum_{i=1}^{3} \Delta P_{i j}$ 
SRNL-STI-2014-00323

Revision 0

Exhibit C1. DWPF Procedure Utilized to Generate the Data and to Establish Correlation (continued)

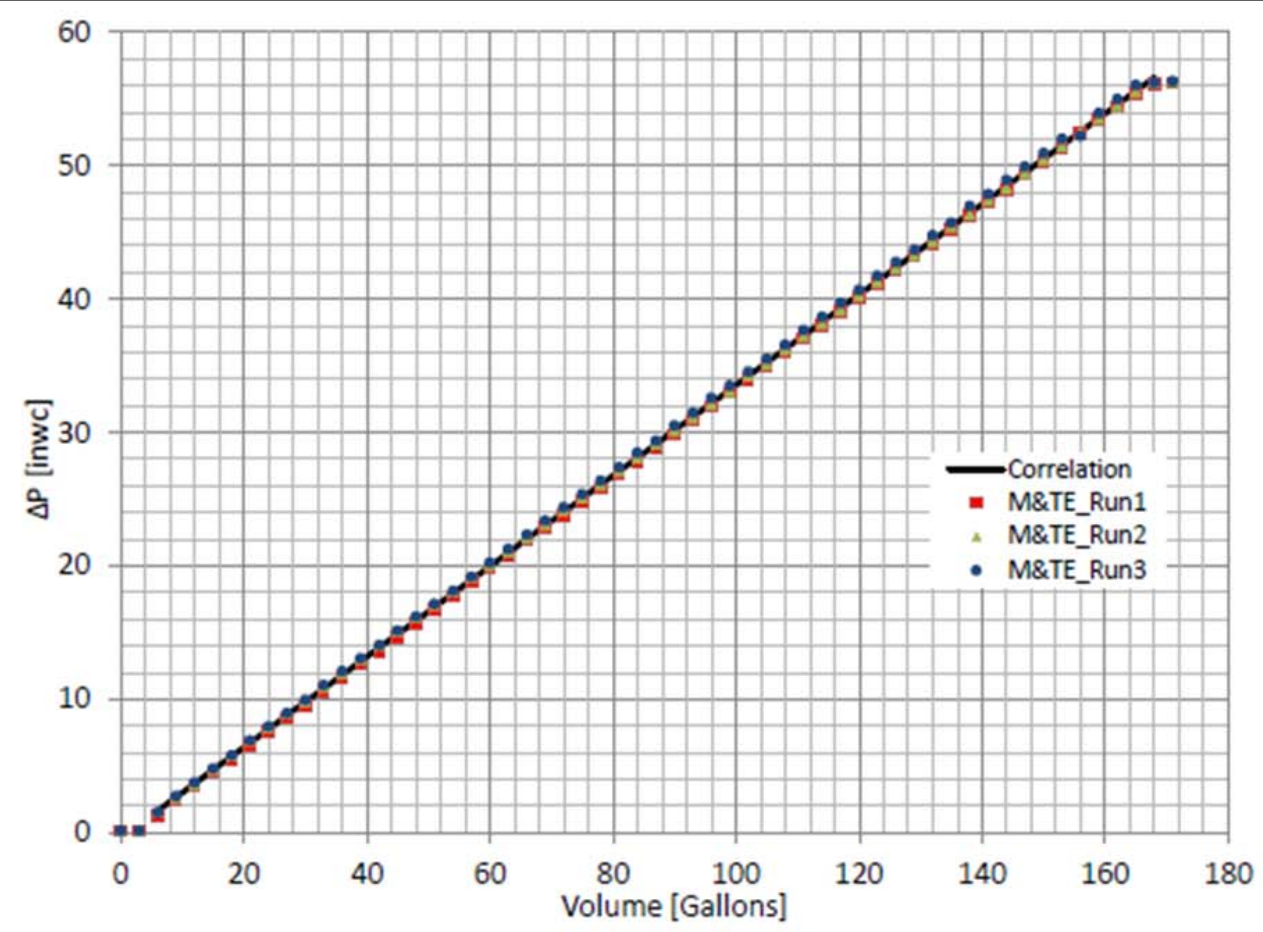

Figure 1. Experimental Determination of Pressure Difference as a Function of Volume and Derived Correlation.

The averaged set, $\langle\Delta P\rangle_{j}$, was used to establish a correlation between the volume of liquid in the tank and the pressure difference as shown in Figure 2. This exercise results in an affine correlation, i.e.

$\Delta P(V)=\left(0.3394 \frac{\text { inwc }}{\text { Gallon }}\right) V-0.3966$ inwc

In practice, one will be using the level instrumentation to determine the volume in the tank. As a result, Equation 2 must be inverted to arrive at such a relationship.

$V(\Delta P)=\frac{\Delta P+0.3966 \text { inwc }}{0.3394 \frac{\text { inwc }}{\text { Gallon }}}$ 
SRNL-STI-2014-00323

Revision 0

Exhibit C1. DWPF Procedure Utilized to Generate the Data and to Establish Correlation (continued)

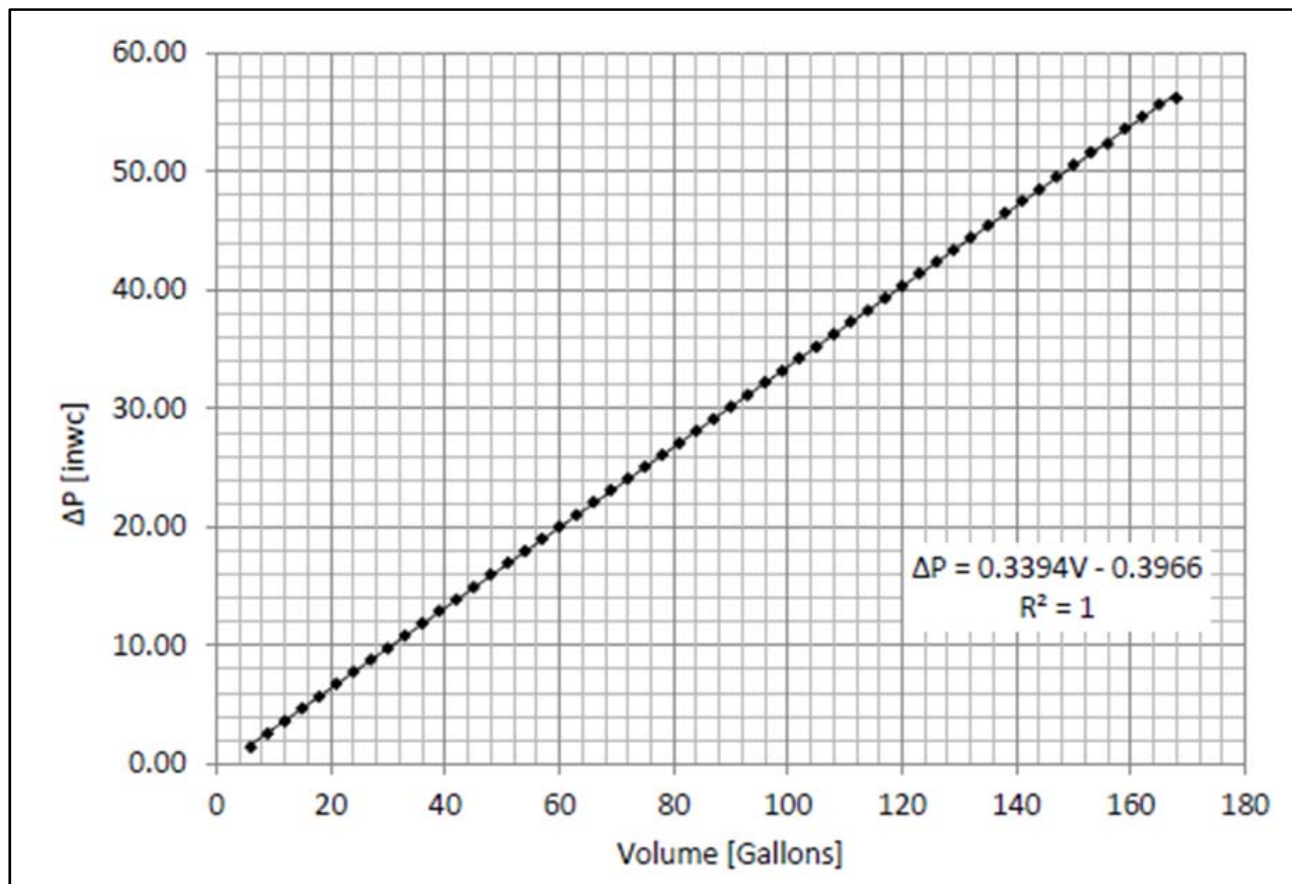

Figure 2. Pressure Difference as a Function of the Volume of the AMFT.

This correlation will be programmed into the DCS to provide an experimentally driven AMFT volume. 
SRNL-STI-2014-00323

Revision 0

\section{Exhibit C2. Regression Analysis with Inverse Prediction}

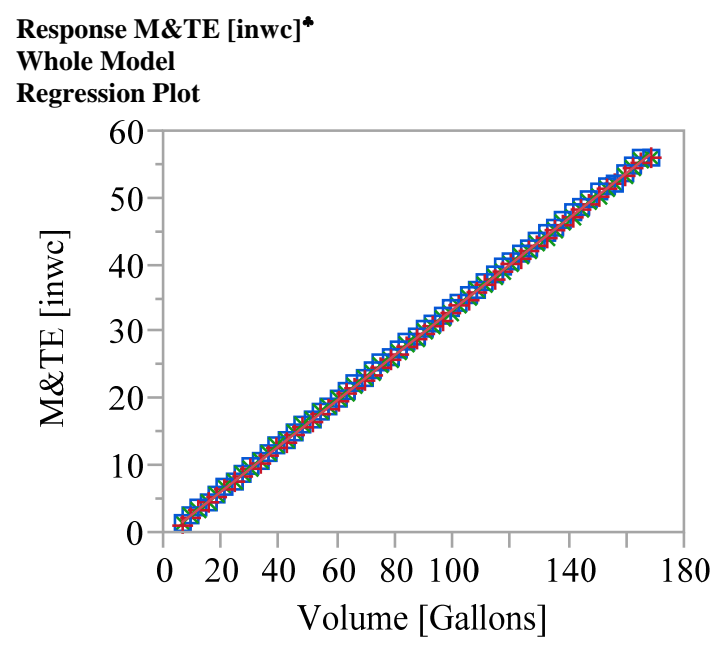

Summary of Fit

$\begin{array}{lr}\text { RSquare } & 0.999788 \\ \text { RSquare Adj } & 0.999787 \\ \text { Root Mean Square Error } & 0.236708 \\ \text { Mean of Response } & 29.12909 \\ \text { Observations (or Sum Wgts) } & 165\end{array}$

Analysis of Variance

Source DF Sum of Squares Mean Square F Ratio

$\begin{array}{llllll}\text { Model } & 1 & 43101.143 & 43101.1 & 769244.6\end{array}$

$\begin{array}{llrr}\text { Error } & 163 & 9.133 & 0.05603 \text { Prob }>\text { F }\end{array}$

C. Total $164 \quad 43110.276<.0001 *$

Lack Of Fit

Source DF Sum of Squares Mean Square F Ratio

$\begin{array}{lllll}\text { Lack Of Fit } \quad 53 & 1.1311681 & 0.021343 & 0.2934\end{array}$

$\begin{array}{lllll}\text { Pure Error } 110 & 8.0018000 & 0.072744 & \text { Prob }>\text { F }\end{array}$

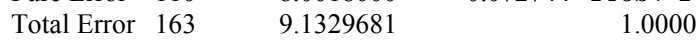

Max RSq

Parameter Estimates

Term Estimate Std Error t Ratio Prob $>|\mathbf{t}|$

$\begin{array}{llllll}\text { Intercept } & -0.396606 & 0.038378 & -10.33<.0001 *\end{array}$

Volume [Gallons] $\quad 0.3393758 \quad 0.000387 \quad 877.07<.0001 *$

* This statistical analysis was conducted using JMP 11.1.1 [7] 
SRNL-STI-2014-00323

Revision 0

Exhibit C2. Regression Analysis with Inverse Prediction (continued)

Inverse Prediction

Specified M\&TE [inwc] Predicted Volume [Gallons] Lower 95\% Upper 95\%

$\begin{array}{rrrr}0.00000 & 1.1686 & 0.9472 & 1.3892 \\ 5.00000 & 15.9016 & 15.7085 & 16.0939 \\ 10.00000 & 30.6345 & 30.4681 & 30.8003 \\ 15.00000 & 45.3674 & 45.2248 & 45.5096 \\ 20.00000 & 60.1003 & 59.9771 & 60.2234 \\ 25.00000 & 74.8333 & 74.7226 & 74.9439 \\ 30.00000 & 89.5662 & 89.4588 & 89.6736 \\ 35.00000 & 104.2991 & 104.1852 & 104.4133\end{array}$

Confidence Interval with respect to an expected response

Inverse Prediction

Specified M\&TE [inwc] Predicted Volume [Gallons] Lower 95\% Upper 95\%

$\begin{array}{rrrr}25.00000 & 74.8333 & 74.7226 & 74.9439 \\ 30.00000 & 89.5662 & 89.4588 & 89.6736 \\ 35.00000 & 104.2991 & 104.1852 & 104.4133 \\ 40.00000 & 119.0321 & 118.9030 & 119.1614 \\ 45.00000 & 133.7650 & 133.6150 & 133.9155 \\ 50.00000 & 148.4979 & 148.3231 & 148.6734 \\ 55.00000 & 163.2309 & 163.0289 & 163.4336 \\ 60.00000 & 177.9638 & 177.7331 & 178.1954\end{array}$

Confidence Interval with respect to an expected response

Inverse Prediction

Specified M\&TE [inwc] Predicted Volume [Gallons] Lower 95\% Upper 95\%

$\begin{array}{rrrr}0.00000 & 1.1686 & -0.227 & 2.5631 \\ 5.00000 & 15.9016 & 14.511 & 17.2919 \\ 10.00000 & 30.6345 & 29.247 & 32.0215 \\ 15.00000 & 45.3674 & 43.983 & 46.7518 \\ 20.00000 & 60.1003 & 58.717 & 61.4830 \\ 25.00000 & 74.8333 & 73.452 & 76.2149 \\ 30.00000 & 89.5662 & 88.185 & 90.9477 \\ 35.00000 & 104.2991 & 102.917 & 105.6812\end{array}$

Confidence Interval with respect to an individual response

Inverse Prediction

Specified M\&TE [inwc] Predicted Volume [Gallons] Lower 95\% Upper 95\%

$\begin{array}{rrrr}25.00000 & 74.8333 & 73.4515 & 76.2149 \\ 30.00000 & 89.5662 & 88.1848 & 90.9477 \\ 35.00000 & 104.2991 & 102.9172 & 105.6812 \\ 40.00000 & 119.0321 & 117.6489 & 120.4155 \\ 45.00000 & 133.7650 & 132.3798 & 135.1507 \\ 50.00000 & 148.4979 & 147.1099 & 149.8866 \\ 55.00000 & 163.2309 & 161.8392 & 164.6233 \\ 60.00000 & 177.9638 & 176.5677 & 179.3608\end{array}$

Confidence Interval with respect to an individual response 
SRNL-STI-2014-00323

Revision 0

Table C1. Measurements of Gallons versus Inches of Water Column

\begin{tabular}{|c|c|c|c|}
\hline run & Additions & Volume [Gallons] & M\&TE [inwc] \\
\hline 1 & 0 & 0 & 0.09 \\
\hline 1 & 1 & 3 & 0.09 \\
\hline 1 & 2 & 6 & 1.2 \\
\hline 1 & 3 & 9 & 2.37 \\
\hline 1 & 4 & 12 & 3.46 \\
\hline 1 & 5 & 15 & 4.46 \\
\hline 1 & 6 & 18 & 5.46 \\
\hline 1 & 7 & 21 & 6.47 \\
\hline 1 & 8 & 24 & 7.57 \\
\hline 1 & 9 & 27 & 8.55 \\
\hline 1 & 10 & 30 & 9.54 \\
\hline 1 & 11 & 33 & 10.56 \\
\hline 1 & 12 & 36 & 11.6 \\
\hline 1 & 13 & 39 & 12.64 \\
\hline 1 & 14 & 42 & 13.6 \\
\hline 1 & 15 & 45 & 14.64 \\
\hline 1 & 16 & 48 & 15.7 \\
\hline 1 & 17 & 51 & 16.7 \\
\hline 1 & 18 & 54 & 17.71 \\
\hline 1 & 19 & 57 & 18.77 \\
\hline 1 & 20 & 60 & 19.81 \\
\hline 1 & 21 & 63 & 20.8 \\
\hline 1 & 22 & 66 & 21.87 \\
\hline 1 & 23 & 69 & 22.85 \\
\hline 1 & 24 & 72 & 23.76 \\
\hline 1 & 25 & 75 & 24.78 \\
\hline 1 & 26 & 78 & 25.8 \\
\hline 1 & 27 & 81 & 26.79 \\
\hline 1 & 28 & 84 & 27.8 \\
\hline 1 & 29 & 87 & 28.85 \\
\hline 1 & 30 & 90 & 29.82 \\
\hline 1 & 31 & 93 & 30.87 \\
\hline 1 & 32 & 96 & 31.93 \\
\hline 1 & 33 & 99 & 32.95 \\
\hline 1 & 34 & 102 & 33.94 \\
\hline 1 & 35 & 105 & 35 \\
\hline 1 & 36 & 108 & 36 \\
\hline 1 & 37 & 111 & 37.04 \\
\hline 1 & 38 & 114 & 38.03 \\
\hline 1 & 39 & 117 & 39.06 \\
\hline 1 & 40 & 120 & 40.11 \\
\hline 1 & 41 & 123 & 41.19 \\
\hline 1 & 42 & 126 & 42.15 \\
\hline 1 & 43 & 129 & 43.16 \\
\hline 1 & 44 & 132 & 44.15 \\
\hline 1 & 45 & 135 & 45.21 \\
\hline 1 & 46 & 138 & 46.25 \\
\hline 1 & 47 & 141 & 47.25 \\
\hline 1 & 48 & 144 & 48.21 \\
\hline 1 & 49 & 147 & 49.33 \\
\hline 1 & 50 & 150 & 50.35 \\
\hline 1 & 51 & 153 & 51.37 \\
\hline 1 & 52 & 156 & 52.37 \\
\hline 1 & 53 & 159 & 53.41 \\
\hline 1 & 54 & 162 & 54.43 \\
\hline 1 & 55 & 165 & 55.45 \\
\hline 1 & 56 & 168 & 56.16 \\
\hline 1 & 57 & 171 & 56.21 \\
\hline 2 & 0 & 0 & 0.12 \\
\hline 2 & 1 & 3 & 0.11 \\
\hline 2 & 2 & 6 & 1.51 \\
\hline
\end{tabular}


SRNL-STI-2014-00323

Revision 0

Table C1. Measurements of Gallons versus Inches of Water Column

\begin{tabular}{|c|c|c|c|}
\hline run & Additions & Volume [Gallons] & M\&TE [inwc] \\
\hline 2 & 3 & $\begin{array}{r}9 \\
\end{array}$ & 2.59 \\
\hline 2 & 4 & 12 & 3.58 \\
\hline 2 & 5 & 15 & 4.71 \\
\hline 2 & 6 & 18 & 5.72 \\
\hline 2 & 7 & 21 & 6.89 \\
\hline 2 & 8 & 24 & 7.81 \\
\hline 2 & 9 & 27 & 8.87 \\
\hline 2 & 10 & 30 & 9.79 \\
\hline 2 & 11 & 33 & 10.9 \\
\hline 2 & 12 & 36 & 11.9 \\
\hline 2 & 13 & 39 & 12.99 \\
\hline 2 & 14 & 42 & 14 \\
\hline 2 & 15 & 45 & 15 \\
\hline 2 & 16 & 48 & 16.07 \\
\hline 2 & 17 & 51 & 17.06 \\
\hline 2 & 18 & 54 & 18.03 \\
\hline 2 & 19 & 57 & 19.09 \\
\hline 2 & 20 & 60 & 20.03 \\
\hline 2 & 21 & 63 & 21 \\
\hline 2 & 22 & 66 & 22.1 \\
\hline 2 & 23 & 69 & 23.06 \\
\hline 2 & 24 & 72 & 24.12 \\
\hline 2 & 25 & 75 & 25.07 \\
\hline 2 & 26 & 78 & 26.05 \\
\hline 2 & 27 & 81 & 27.09 \\
\hline 2 & 28 & 84 & 28.1 \\
\hline 2 & 29 & 87 & 29.08 \\
\hline 2 & 30 & 90 & 30.11 \\
\hline 2 & 31 & 93 & 31.09 \\
\hline 2 & 32 & 96 & 32.09 \\
\hline 2 & 33 & 99 & 33.04 \\
\hline 2 & 34 & 102 & 34.2 \\
\hline 2 & 35 & 105 & 35.1 \\
\hline 2 & 36 & 108 & 36.21 \\
\hline 2 & 37 & 111 & 37.2 \\
\hline 2 & 38 & 114 & 38.15 \\
\hline 2 & 39 & 117 & 39.17 \\
\hline 2 & 40 & 120 & 40.22 \\
\hline 2 & 41 & 123 & 41.28 \\
\hline 2 & 42 & 126 & 42.25 \\
\hline 2 & 43 & 129 & 43.24 \\
\hline 2 & 44 & 132 & 44.3 \\
\hline 2 & 45 & 135 & 45.37 \\
\hline 2 & 46 & 138 & 46.3 \\
\hline 2 & 47 & 141 & 47.41 \\
\hline 2 & 48 & 144 & 48.3 \\
\hline 2 & 49 & 147 & 49.4 \\
\hline 2 & 50 & 150 & 50.44 \\
\hline 2 & 51 & 153 & 51.43 \\
\hline 2 & 52 & 156 & 52.45 \\
\hline 2 & 53 & 159 & 53.49 \\
\hline 2 & 54 & 162 & 54.49 \\
\hline 2 & 55 & 165 & 55.55 \\
\hline 2 & 56 & 168 & 56.25 \\
\hline 2 & 57 & 171 & 56.27 \\
\hline 3 & 0 & 0 & 0.12 \\
\hline 3 & 1 & 3 & 0.11 \\
\hline 3 & 2 & 6 & 1.49 \\
\hline 3 & 3 & 9 & 2.72 \\
\hline 3 & 4 & 12 & 3.75 \\
\hline 3 & 5 & 15 & 4.8 \\
\hline
\end{tabular}


SRNL-STI-2014-00323

Revision 0

Table C1. Measurements of Gallons versus Inches of Water Column

\begin{tabular}{|c|c|c|c|}
\hline run & Additions & Volume [Gallons] & M\&TE [inwc] \\
\hline 3 & 6 & 18 & 5.76 \\
\hline 3 & 7 & 21 & 6.88 \\
\hline 3 & 8 & 24 & 7.93 \\
\hline 3 & 9 & 27 & 8.93 \\
\hline 3 & 10 & 30 & 9.94 \\
\hline 3 & 11 & 33 & 11.02 \\
\hline 3 & 12 & 36 & 12.07 \\
\hline 3 & 13 & 39 & 13.06 \\
\hline 3 & 14 & 42 & 14.03 \\
\hline 3 & 15 & 45 & 15.12 \\
\hline 3 & 16 & 48 & 16.17 \\
\hline 3 & 17 & 51 & 17.13 \\
\hline 3 & 18 & 54 & 18.1 \\
\hline 3 & 19 & 57 & 19.15 \\
\hline 3 & 20 & 60 & 20.22 \\
\hline 3 & 21 & 63 & 21.23 \\
\hline 3 & 22 & 66 & 22.32 \\
\hline 3 & 23 & 69 & 23.37 \\
\hline 3 & 24 & 72 & 24.37 \\
\hline 3 & 25 & 75 & 25.37 \\
\hline 3 & 26 & 78 & 26.35 \\
\hline 3 & 27 & 81 & 27.36 \\
\hline 3 & 28 & 84 & 28.46 \\
\hline 3 & 29 & 87 & 29.36 \\
\hline 3 & 30 & 90 & 30.5 \\
\hline 3 & 31 & 93 & 31.45 \\
\hline 3 & 32 & 96 & 32.58 \\
\hline 3 & 33 & 99 & 33.5 \\
\hline 3 & 34 & 102 & 34.54 \\
\hline 3 & 35 & 105 & 35.5 \\
\hline 3 & 36 & 108 & 36.56 \\
\hline 3 & 37 & 111 & 37.66 \\
\hline 3 & 38 & 114 & 38.64 \\
\hline 3 & 39 & 117 & 39.69 \\
\hline 3 & 40 & 120 & 40.66 \\
\hline 3 & 41 & 123 & 41.74 \\
\hline 3 & 42 & 126 & 42.77 \\
\hline 3 & 43 & 129 & 43.69 \\
\hline 3 & 44 & 132 & 44.77 \\
\hline 3 & 45 & 135 & 45.71 \\
\hline 3 & 46 & 138 & 46.95 \\
\hline 3 & 47 & 141 & 47.85 \\
\hline 3 & 48 & 144 & 48.9 \\
\hline 3 & 49 & 147 & 49.9 \\
\hline 3 & 50 & 150 & 50.94 \\
\hline 3 & 51 & 153 & 52 \\
\hline 3 & 52 & 156 & 52.19 \\
\hline 3 & 53 & 159 & 53.92 \\
\hline 3 & 54 & 162 & 54.97 \\
\hline 3 & 55 & 165 & 56.02 \\
\hline 3 & 56 & 168 & 56.2 \\
\hline 3 & 57 & 171 & 56.33 \\
\hline
\end{tabular}


Table C2. Bias and 1-Sigma Random Uncertainty for Volume versus Pressure Correlation for the AMFT

\begin{tabular}{|c|c|c|c|c|c|c|c|}
\hline Y & $\begin{array}{c}\text { Specified } \\
\text { M\&TE [inwc] }\end{array}$ & $\begin{array}{c}\text { Predicted Volume } \\
\text { [Gallons] }\end{array}$ & $\begin{array}{c}\text { Lower 95\% } \\
\text { for the Line }\end{array}$ & $\begin{array}{c}\text { Upper 95\% } \\
\text { for the Line }\end{array}$ & $\begin{array}{c}\text { Lower 95\% for } \\
\text { an Individual }\end{array}$ & $\begin{array}{c}\text { Upper 95\% for } \\
\text { an Individual }\end{array}$ & $\begin{array}{c}\text { 1-sigma } \\
\text { bias (gal) }\end{array}$ \\
random (gal)
\end{tabular}




\section{Appendix D. Determining Random and Bias Uncertainties for AMFT Density Values}

Volume determinations made in the AMFT are based on readings provided by LI2614 and utilize the relationship described in Appendix C. As indicated in Exhibit 2, the value from the LI2614 is adjusted for the density (actually the specific gravity) of the AMFT contents. The values from Table A1 in Appendix A indicate that the density of the $1: 20$ mix of antifoam and water is about $0.99835 \mathrm{~g} / \mathrm{mL}$ - a value very near 1 . The average density of the undiluted antifoam from this same table is $1.00073 \mathrm{~g} / \mathrm{mL}$.

In determining the AMFT volume, a specific gravity of 1 will be used in the calculations. The 1-sigma random uncertainty for this value will be taken from the standard deviation of the density measurements for the undiluted antifoam; the random standard deviation associated with the use a value of 1 for the specific gravity is 0.0036 . The bounding bias for the specific gravity of the AMFT material is taken to be 3 sigma, which leads to a bias of $3 \times 0.0036=0.0108$. 


\section{Distribution}

\begin{tabular}{|c|c|c|c|}
\hline \multicolumn{2}{|c|}{ SRR } & \multicolumn{2}{|c|}{ SRNL } \\
\hline Name: & Location: & Name: & Location: \\
\hline I.T. Bodey & $704-25 S$ & S.L. Marra & 773-A \\
\hline J.D. Ledbetter & $704-27 \mathrm{~S}$ & C.C. Herman & 773-A \\
\hline R.P. Farrow & $704-26 S$ & C.J. Coleman & 773-A \\
\hline J.R. Coleman & $706-S$ & C.M. Gregory & 773-A \\
\hline P.J. Ryan & $704-S$ & M.J. Barnes & 773-A \\
\hline E.J. Freed & 704-S & E.P. Shine & $703-41 \mathrm{~A}$ \\
\hline J.M. Bricker & $704-30 S$ & M.A. Jones & 773-A \\
\hline J.F. Iaukea & $704-27 S$ & M.E. Stone & 999-W \\
\hline R.T. McNew & $704-S$ & D.K. Peeler & 999-W \\
\hline J.W. Ray & $704-27 \mathrm{~S}$ & T.B. Edwards & 999-W \\
\hline R.N. Hinds & 704-S & D.P. Lambert & 999-W \\
\hline R.N. Mahannah & $704-28 S$ & D.R. Best & 999-W \\
\hline M.T. Feller & $704-28 S$ & A.S. Choi & $773-42 A$ \\
\hline H.P. Boyd & $704-27 S$ & W.E. Daniel & 999-W \\
\hline H.H. Elder & $704-27 S$ & D.H. McGuire & 999-W \\
\hline D.C. Sherburne & $704-S$ & M.K. Harris & $703-41 \mathrm{~A}$ \\
\hline T.L. Fellinger & 766-H & & \\
\hline R.E. Edwards & 766-H & & \\
\hline & & & \\
\hline & & & \\
\hline & & & \\
\hline & & & \\
\hline & & & \\
\hline & & & \\
\hline & & & \\
\hline & & & \\
\hline & & & \\
\hline & & & \\
\hline & & & \\
\hline & & & \\
\hline
\end{tabular}

